ANL-6101

Chemistry - Separation Processes

for Plutonium and Uranium

(TID-4500, 15th Ed.)

$A E C$ Research and

Development Report

\author{
ARGONNE NATIONAL LABORATORY \\ 9700 South Cass Avenue \\ Argonne, Illinois
}

\title{
CHEMICAL ENGINEERING DIVISION SUMMARY REPORT
}

October, November, December, 1959

Stephen Lawroski, Division Director W. A. Rodger, Associate Division Director

R. C. Vogel, Associate Division Director V. H. Munnecke, Assistant Division Director

Eebruary, 1960

\footnotetext{
Preceding Quarterly Reports:

ANL-6068 July, August, September, 1959

ANL-6029 April, May, June, 1959

ANL-5996 January, February, March, 1959
}

Operated by The University of Chicago

under

Contract $W-31-109-e n g-38$ 


\section{DISCLAIMER}

This report was prepared as an account of work sponsored by an agency of the United States Government. Neither the United States Government nor any agency Thereof, nor any of their employees, makes any warranty, express or implied, or assumes any legal liability or responsibility for the accuracy, completeness, or usefulness of any information, apparatus, product, or process disclosed, or represents that its use would not infringe privately owned rights. Reference herein to any specific commercial product, process, or service by trade name, trademark, manufacturer, or otherwise does not necessarily constitute or imply its endorsement, recommendation, or favoring by the United States Government or any agency thereof. The views and opinions of authors expressed herein do not necessarily state or reflect those of the United States Government or any agency thereof. 


\section{DISCLAIMER}

Portions of this document may be illegible in electronic image products. Images are produced from the best available original document. 
TABLE OF CONTENTS

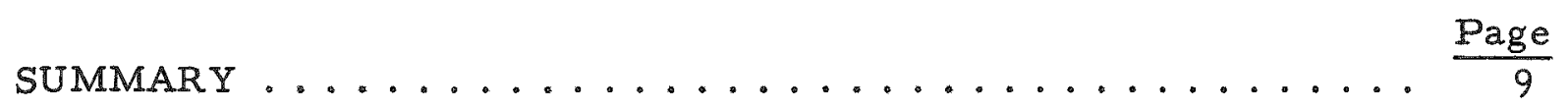

I. CHEMICAL-METALLURGICAL PROCESSING ........ 17

A. Fuel-processing Facilities for EBR-II ......... 19

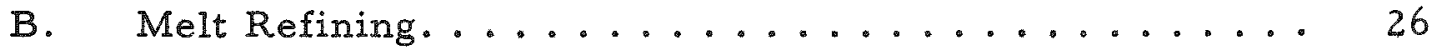

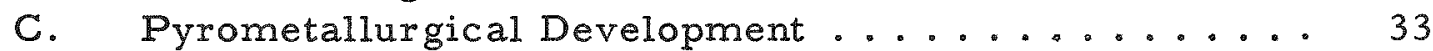

D. Pyrometallurgical Research.............. 62

II. FUEL CYCLE APPLICATIONS OF VOLATILITY AND

FLUIDIZATION TECHNIQUES . . . . . . . . . . . 78

A. Fluorine Chemistry and Fluoride Separation Processes.

B. ADF Process Development for Enriched Uranium-

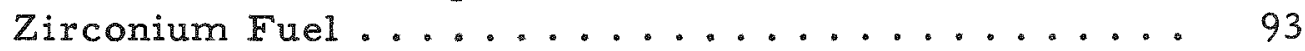

C. Zirconium-Fused Salt Process Development....... 104

D. Direct Fluorination of Uranium Dioxide Fuel. ...... 115

E. Calcination of Reactor Fuel-processing Wastes..... I21

F. Conversion of Uranium Hexafluoride to Uranium

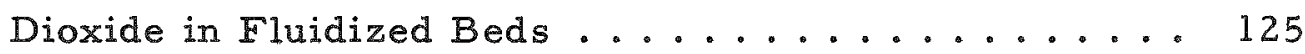

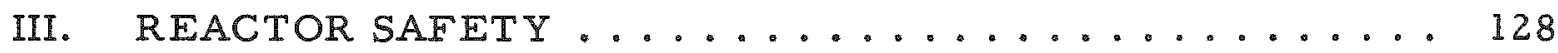

A. Metal Oxidation-Ignition Studies .......... 128

B. Metal-Water Reactions ................ 139

IV. REACTOR CHEMISTRY................. 152

A. Determination of Nuclear Constants........... 152

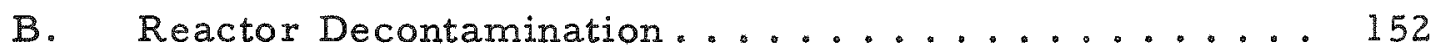

C. Slurrex Chemical Supporting Program .......... 160

V. ANALYTICAL RESEARCH AND DEVELOPMENT....... 165

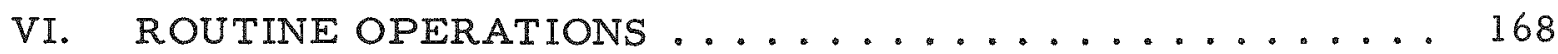

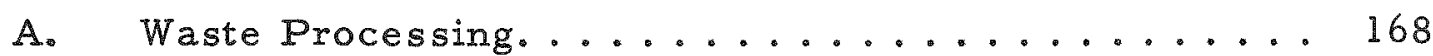

B. High-level Gamma-irradiation Facility ........ 168 


\section{LIST OF TABLES}

No.

Title

Page

1. Power and Thermal Insulation Test Runs .......... 30

2. Summary of Melt-refining Skull Oxidations.......... 37

3. Reduction of Uranium Oxide Added in the Form of

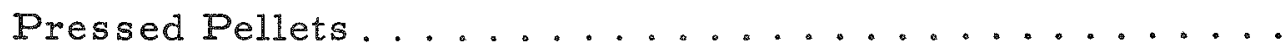

4. Leaching of Nickel From 304 Stainless Steel

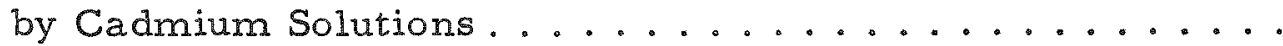

5. Cerium Entrainment during Cadmium-Magnesium

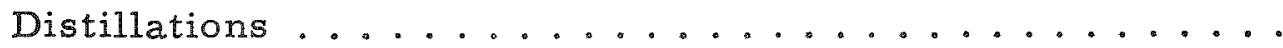

6. Analyses of Uranium Product Retorted in

a Boron Nitride Crucible.................

7. Distribution of Uranium between Liquid Aluminum and Liquid Cadmium ...................... 72

8. Equilibrium Constant for the Reaction $P u F_{4}+F_{2} \rightleftharpoons P u F_{6}$.

9. Decomposition of Plutonium Hexafluoride at

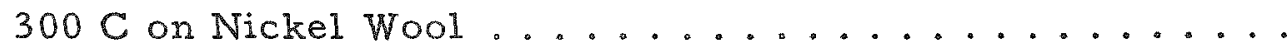

10. Fluorination of 1 Weight Per Cent Plutonium

Tetrafluoride-Uranium Tetrafluoride Mixtures........

11. Complete Fluorination of Plutonium TetrafluorideUranium Tetrafluoride Mixtures ...............

12. Location of the Radionickel Portion of Fluoride Films by Proportional Counting ..............

13. Summary of Bench-scale Static-bed Fluorination

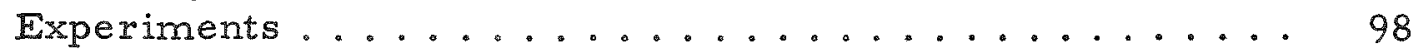

14. Summary of Laboratory Fluorination Experiments ...... 98

15. Pilot-plant Fixed-Bed Fluorination Results ......... 100

16. Effect of Pyrohydrolysis on Uranium Removal ....... 103

17. Effect of Temperature on Uranium Removal from Calcined Dresden and APPR-type Fuels ............ 104

18. Consumption of Hydrogen Fluoride during

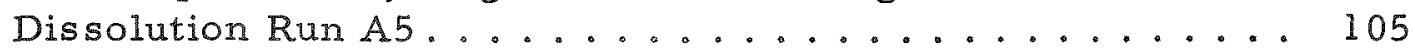

19. Variation of Dissolution Rate during Run A5 ....... 106 20. Comparison of Dissolution Rates ............. 106 


\section{LIST OF TABLES}

No.

Title

Page

21. Variation of Diameter of One-inch Section Graphite

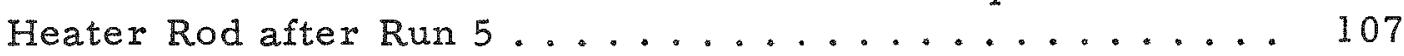

22. Efficiency of Condenser and Bubbler............ 110

23. Heat Balance and Sparge Rates for Fused Salt Runs ..... 114

24. Properties of Salt Wall ................... 114

25. Summary of Results of Uranium Dioxide Pellet

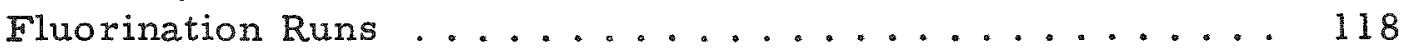

26. Material Balance in Run UOF $-4 \ldots \ldots \ldots$

27. Nominal Operating Conditions for Active Runs for Calcination of Hanford Low-acid Purex Wastes ........

28. Ruthenium Distribution and Condensate Analysis for Active Purex Low-acid Calcination Runs at $500 \mathrm{C} \ldots . . . . .$.

29. Summary of Runs on Fluid-bed Conversion of Uranium Hexafluoride to Uranium Dioxide ............ 126

30. Compositions of Uranium Wires and Foil Samples ...... 130

31. Effect of Uranium Sample Size on Ignition Temperature

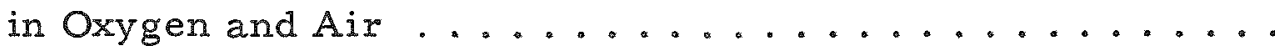

32. Measurements of the Extent of Reaction and Identification of Oxide Produced by Burning Uranium Foil Strips in Air . . . 136

33. Effect of Gas Contaminants on Burning-propagation

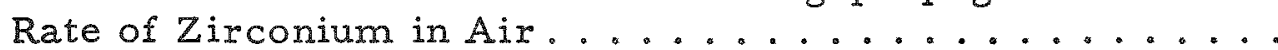

34. Preliminary Results for Zirconium-Water Reaction at $20 \mathrm{~mm}$ Hg by the Pressure-pulse Method ......... 146

35. Summary of Data on Metal-Water Transients in TREAT . . 149

36. Deposition of Activity on Stainless Steel Type $304 \ldots 155$

37. Operating Conditions and Results of Loop Runs

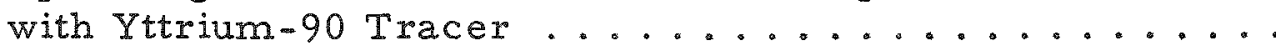

38. Summary of Liquid Radioactive Wastes Processed

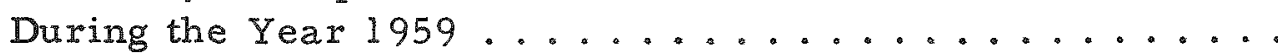

39. Summary of Irradiations Performed in Rack M-1 of the Argonne High-level Gamma-irradiation Facility During 1959. 


\section{LIST OF FIGURES}

No. Title

1 Reduction of $\mathrm{U}_{3} \mathrm{O}_{8}$ By 3 Weight Per Cent Magnesium-

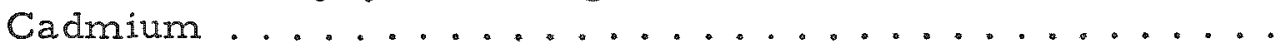

2 Uranium Oxide Reductions in Cadmium-2 Per Cent Magnesium Solutions .................. 40

3 Skull Oxide Reductions in the Presence of Molten Salt Fluxes.

4 Equipment for the Reduction of Uranium Oxide ........

5 Effect of Nickel on the Solubility of Uranium in Cadmium..

6 Stability of Uranium-Cadmium Solutions in

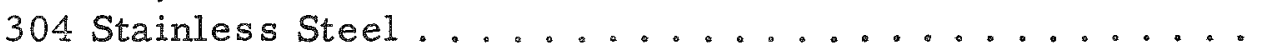

7 Sequence Views on Uranium-retorting Experiment

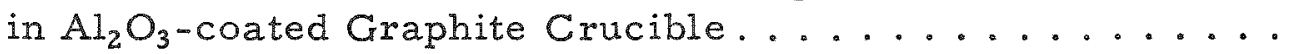

Freeze Valve

Marman Conoseal Pipe Joint

Autoresistively Heated Transfer Lines

Power Characteristics of Flat-blade Impellers in Mercury . .

Photomicrographs of Thermal Convection Loop No. 2....

16 Solubility of Uranium in Zinc-Magnesium Alloys at $680 \mathrm{C}$. .

17 Solubility of Uranium in Zinc-Magnesium ..........

18 Cadmium-rich Portion of Cadmium-Uranium Phase Diagram Showing Data Taken on Retrograde Solubility

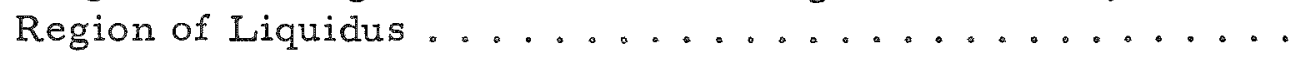
70

19 Free Energy of Formation of $\mathrm{UPb}_{3} \ldots \ldots \ldots$

20 Relation Between Equilibrium Constant and Temperature for the Reaction $\mathrm{PuF}_{4}+\mathrm{F}_{2} \rightleftharpoons \mathrm{PuF}_{6} \ldots \ldots$

21 Fluorination of 1 Weight Per Cent Plutonium TetrafluorideUranium Tetrafluoride with Fluoride at $200 \mathrm{C} \ldots . . . .$.

22 Autoradiograph of Cross Section of Nickel-63-plated

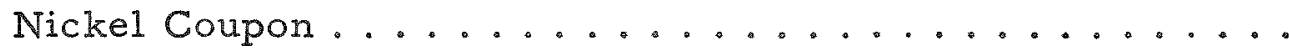

23 Autoradiograph Made on Cross Section of Nickel Coupon and Fluoride Film Showing Radionickel Layer........ 


\section{LIST OF FIGURES}

No.

Title

Page

24 Microphotograph of Cross Section of Fluorinated Nickel Coupon Showing Intergranular Attack............ 92

25 Fixed-bed 6-Inch Diameter Monel Fluorinator ........ 99

26 Hydrogen Fluoride Condenser and Scrubber System ..... 109

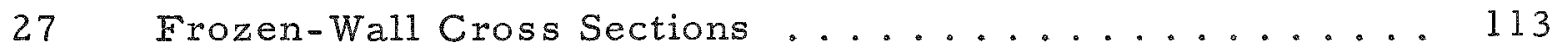

28 Overall Mean Wall Thickness at Various Wall Heat Fluxes . . 113

29 Comparison of Fluidized-bed Expansion in Annuli

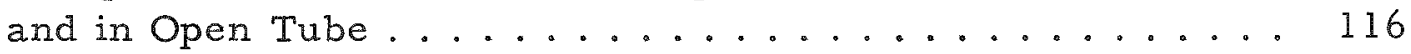

30 Comparison of Fluidized-bed Expansion in an Open Tube with Packed Bed ................. 116

31 Comparison of Bed Pressure Drop for Fluidization in Open Tube and in Packed Bed.................... 117

32 Relationship between Sample Specific Area and Uranium Ignition Temperature in Air and in Oxygen .......... 132

33 Temperature Trace for $620 \mathrm{C}$ Oxidation in Air of

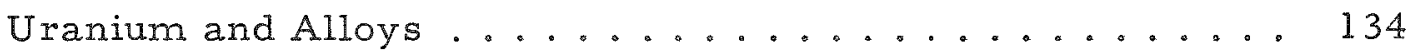

34 Temperature Trace of $500 \mathrm{C}$ Oxidation in Air of

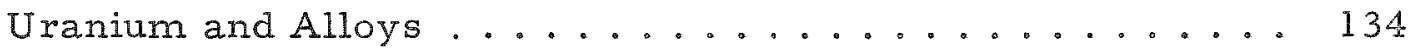

35 Oxidation of ANL-base Metal Uranium at

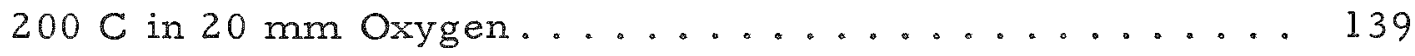

36 Micrographs of Surface Oxidation of Uranium at $200 \mathrm{C}$ in $200 \mathrm{~mm}$ Oxygen for Designated Times........ 140

37 Summary of Experimental Results for Zirconium-Water

Reaction by Condenser-discharge Method........... 142

38 Film Sequences of Condenser-discharge Runs with 30-mil Specimens (4000 Frames/Sec) ............ 143

39 Calibration of Two-color Photoelectric Pyrometer ..... 145

40 Autoclave for Metal-Water Reaction Tests ......... 147

41 Oscillograph Record of Transient CEN-3 ......... 148

42 Transient Oscillograph Record, Run CEN-4 ........ 150

43 Photographs of Pins before and after TREAT

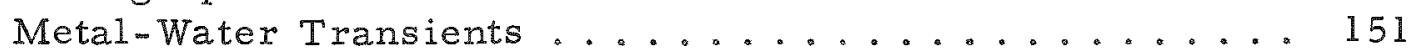

44 Unused Pin and Melted Pin from Transient CEN-8..... 151 


\section{LIST OF FIGURES}

No.

Title

Page

45 Beta Activities Deposited on Stainless Steel 304 Sample

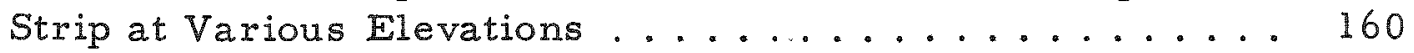

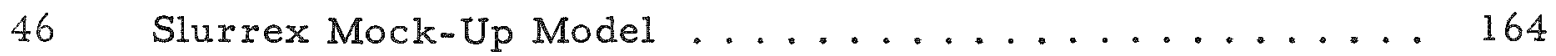

47 Low-energy Characteristic $X$ Rays of Thorium in

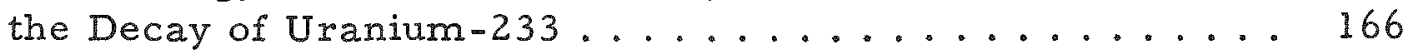

48 Low-energy Characteristic $X$ Rays of Silver in

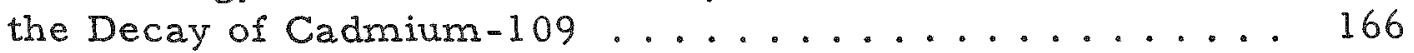

49 Resolution of $\mathbf{K}$-Characteristic $\mathrm{X}$ Rays of Low $\mathrm{Z}, \mathrm{Z}+1$ Elements with the Proportional Gas Spectrometer...... 167

50 Resolution of X-Ray Proportional Counter as a

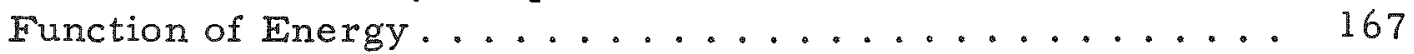


-

- 


\section{CHEMICAL ENGINEERING DIVISION SUMMARY REPORT}

October, November, December, 1959

SUMMARY

I. Chemical-Metallurgical Processing (pages 17 to 77)

A direct-cycle pyrometallurgical fuel-processing plant is being constructed in conjunction with EBR-II. Although the plant will contain decladding, melt refining, and fuel-refabrication equipment initially, the facility is believed to believed to be sufficiently versatile that it will be able to accommodate other pyrometallurgical processes currently in the development stage. Provisions have been made for completely remote operation of all steps, and the entire process cell is filled with a continuously purified argon atmosphere.

Excavation for the EBR-II Fuel Cycle Facility was completed on October 14, 1959; all footings and some walls below grade have been poured. Field construction has been discontinued until March 1960 because of the weather. Construction of the Laboratory and Service Building is very nearly completed, and all the equipment items for the Junior Caves and the Waste Solidification Cell of this building are delivered or are on order. Components for the fuel reprocessing facility, such as cranes, manipulators, shielding windows, and lighting, are in various stages of procurement. A contract was awarded to AMF Atomics for the design and fabrication of the Fuel Cycle Facility transfer-cell equipment.

Various components for the Fuel Cycle Facility are being designed and tested. The gamma-irradiation testing of the 175-watt white fluorescent mercury vapor lamp was continued to an integrated exposure of $2 \times 10^{9} \mathrm{rad}$. Light output was 82 per cent of that from an unirradiated lamp. Irradiation tests of Shell APL grease have been completed, and the estimated useful life of this grease in the Air and Argon Cells is 2 and 3 years, respectively. Tests of the three types of dc motors used in the operating manipulator of the Argon Cell have indicated an expected useful cell operating life of 2 to 3 years. The design of the manipulator permits remote replacement of these motors. Continued irradiation tests of mineral-insulated (MI) cable have shown no catastrophic breakdown of the electric insulation even after an accumulated gamma dose of $8.4 \times 10^{9} \mathrm{rad}$.

Eighteen enriched (approximately 50 per cent) "fissium" alloy ingots for the initial EBR-II fuel loading were produced in the Mark-V prototype melt-refining processing unit during the period October-December, 1959. 
At the conclusion of a melt-refining operation, approximately 10 per cent of the fuel remains behind in the zirconia crucible in the form of a "skull," which ordinarily consists of 70 to 90 per cent metal, the remainder being oxide. Oxidation of the melt-refining skull produces a powdered oxide which can be readily poured from the crucible into another vessel for further processing.

The scheme currently under consideration for processing meltrefining residues involves a reduction of the skull oxides by a solution of magnesium in liquid cadmium. Oxide reductions of around 95 per cent were achieved in 40 hours. Oxide reductions have also been carried out with pure magnesium in the presence of magnesium chloride with promising results. Good reduction was also realized in a "bomb-type" procedure using a blend of solid $\mathrm{U}_{3} \mathrm{O}_{8}$, magnesium, and magnesium chloride powders.

Molten salt fluxes have had variable effects on the rate of oxide reduction in dilute magnesium systems. With some salt compositions, reduction rates were slightly better than those achieved without flux. Salt fluxes serve the very useful purpose of suspending the magnesium oxide reaction product, thus providing an opportunity for its removal in a liquid phase. As appeared from microscopic examination, separation of magnesium oxide from the metal phase appeared to be complete.

Work was continued on development of processes for EBR-II blanket material. Preparations are being made for demonstrations of some of the process steps, including final isolation of plutonium metal on a $100-\mathrm{gram}$ scale. Some distillations performed in the past quarter, using cerium as stand-in for plutonium, disclosed the need for baffles in the vapor space above the still pot to reduce entrainment.

A large-scale metal-distillation unit to demonstrate metal (cadmium) distillation at rates up to $100 \mathrm{~kg} /$ hour is under construction. Other associated operations of metal transfer, liquid-level detection, and freezevalve operation are under study, and the performances of some components have been tested. Steel is unsatisfactory as a crucible material because some alloying with uranium occurs even at temperatures below $600 \mathrm{C}$.

Satisfactory uranium compacts weighing up to $350 \mathrm{grams}$ were produced in boron nitride and alumina-coated graphite. The porous compacts were subsequently arc and induction melted to solid metal buttons, with recoveries of about 95 per cent.

Two medium carbon steel thexmal-convection loops were built and operated to ascertain the extent of corrosion under adverse thermal conditions. The circulation of 15 and 30 per cent magnesium-cadmium alloys under thermal gradients of 575 to $675 \mathrm{C}$ and 630 to $725 \mathrm{C}$, respectively, resulted in mass transfer amounting to a maximum thickness change of only 6 mils 
in 1000 hours. A second forced-circulation loop in which a uranium-fission product-cadmium solution is being circulated at $550 \mathrm{C}$ was started up and has been in trouble-free operation for about 1000 hours.

Since physicochemical and thermodynamic data are lacking for many of the liquid metal systems and materials of construction under consideration, a more general research effort is also essential to the overall program.

Solubilities of a number of elements in liquid metal systems have been determined. Data have been obtained for the solubilities of vanadium, iron, and nickel in liquid cadmium at temperatures from 400 to $650 \mathrm{C}$. Vanadium is virtually insoluble $(<0.2 \mathrm{ppm}$ at $650 \mathrm{C})$; ir on solubility ranges from $0.5 \mathrm{ppm}$ at $400 \mathrm{C}$ to $7 \mathrm{ppm}$ at $610 \mathrm{C}$, and nickel solubility ranges from 1.4 per cent at $410 \mathrm{C}$ to 5 per cent at $540 \mathrm{C}$.

Corrections were made to data on the solubility of thorium in liquid zinc. Solubilities of uranium in silicon-free zinc-magnesium solutions were found to be significantly higher than when silicon was present. A method, based on the solubility of the solute in the two pure components of the binary solvent, the free energy of formation of the solid phase in equilibrium with the pure solvent components, and an estimate of the excess free energy of the binary solvent system, has been developed for the calculation of the solubility of the solute in a binary liquid metal solvent.

The peritectic temperature $\left(\mathrm{UCd}_{11}\right.$ incongruent melting point) in the uranium-cadmium system was found to be $474 \pm 1 \mathrm{C}$.

The activity coefficient of uranium in aluminum at 4.8 per cent uranium and $686 \mathrm{C}$ is estimated to be $1.25 \times 10^{-3}$, based on a distribution coefficient of uranium between cadmium and aluminum and the activity coefficient of uranium in pure cadmium.

The free energy of formation of $\mathrm{UPb}_{3}$, determined by galvanic cell measurements, varied between -14.8 to $-10.0 \mathrm{kcal} / \mathrm{mole}$ at temperatures of 400 to $800 \mathrm{C}$.

A thermochemistry program, directed toward obtaining basic information on systems of interest to high-temperature chemistry, is in progress. Oxygen and fluorine bomb calorimetry are being used to obtain heats of combustion and heats of formation for sulfur and fluorine compounds of such elements as molybdenum, tungsten, boron and zirconium. 
II. Fuel Cycle Applications of Volatility and Fluidization Techniques (pages 78 to 127 )

Several schemes involving the volatility of uranium hexafluoride have been proposed for processing irradiated fuels. These include a direct fluorination process, the Aqueous Dissolution Fluorination (ADF) Process, and the Fused Fluoride Volatility Process. Many steps of these schemes involve the use of fluidization techniques. Fluidization techniques are also being applied to calcination of radioactive liquid wastes and preparation of uranium compounds.

The Direct Fluorination Process now under study involves direct fluorination of oxide-matrix fuels with fluorine or other fluorination agents to produce volatile uranium hexafluoride and plutonium hexafluoride. Allied reactions of intermediate compounds are being studied. Equilibrium constants for the reaction $\mathrm{PuF}_{4}+\mathrm{F}_{2}=\mathrm{PuF}_{6}$ have been determined in the temperature range from 150 to $400 \mathrm{C}$. The results may be represented by the equation

$\log K=(-1331 / T)-0.275$

Additional work was performed on the ADF Process being developed for the recovery of uranium from low uranium-Zircaloy-2 fuel alloys. Studies of the drying step have included use of high zirconium feed solution (3.6 M zirconium) and dilute zixconium feed solution ( $1.5 \mathrm{M}$ zirconium) at feed rates up to $150 \mathrm{ml} / \mathrm{min}$ for concentrated feed and $210 \mathrm{ml} / \mathrm{min}$ for dilute feed. Some particle growth was evident at feed rates of 100 and $150 \mathrm{ml} / \mathrm{min}$ for concentrated and dilute feed, respectively. An internal autoresistance-type Inconel strip heater has been introduced into the fluid bed to provide additional capacity to the dryer.

To provide feed materials with low residual water and oxygen contents, investigation of the fluorination step included study of the hydrofluorination of dryer product at $300 \mathrm{C}$ with equal mixtures of hydrogen fluoride and nitrogen. Static-bed fluorination studies of the uraniumzirconium fluoride dryer products have been carried out in bench and pilot-scale fluorination reactors. Uranium removals greater than 99 per cent have been achieved in 1 to 3 -hour runs at $700 \mathrm{C}$.

Laboratory studies of uranium removal from calcined solutions of uranium-zirconium alloys have shown that vacuum sublimation may be used to remove zirconium tetrafluoride from the dried solids. The addition of sodium fluoride to the calcined solid does not substantially aid in uranium 
removal. Experimental data indicate that the ADF volatility process at moderate fluorination temperatures could be used to recover uranium from Dresden reactor fuel, but that higher temperatures would be required for quantitative recovery from APPR fuel.

Additional studies have been made in the Fused Salt Fluoride Volatility Process for the recovery of uranium from uranium-zirconium-matrix fuels. The development of process equipment has been directed at either avoiding corrosive salt-metal contact or using corrosion-resistant materials, such as graphite. A graphite pilot-plant dissolver is being tested for the dissolution step. A synthetic 10-plate zirconium-uranium fuel element was dissolved in molten sodium fluoride-zirconium tetrafluoride in 6 hours at $700 \mathrm{C}$ at $60 \mathrm{lb} / \mathrm{hr}$ hydrogen fluoride sparge rate. The dissolution rate was $2.2 \mathrm{mg} /$ $(\mathrm{sq} \mathrm{cm})(\mathrm{min})$.

The use of an electrolytically heated frozen-wall fluorinator has been proposed for the fluorination step as a means of minimizing corrosion. Operation of a 17-inch diameter frozen-wall fluorinator has been successfully demonstrated in tests in which thin, uniform frozen walls were maintained. Some problems due to crust formation on the surface of the melt were encountered.

Volume reduction of radioactive liquid wastes to free-flowing granular solids may be achieved by means of calcination in a heated fluidized bed. Recent runs with radioactive wastes have demonstrated the feasibility of extending this process from aluminum nitrate-bearing wastes to Purex-type wastes.

Additional studies of a one-step fluid-bed process for the conversion of uranium hexafluoride to uranium dioxide were made in the newly installed 3-inch Monel reactor.

\section{Reactor Safety (pages 128 to 15l)}

The program to clarify the factors governing the pyrophoric characteristics of the metals uranium, zirconium, thorium, and plutonium has continued with studies of ignition phenomena and the combustion process. Techniques reported in ANL-5974 have been used to extend the study to determine the effects of specific area and contaminants on the ignition of uranium metal in the form of wires and powders. The linear relationship between specific area and the reciprocal of the ignition temperature is obeyed by the wires as well as cubes and foils, and covers the range of specific areas of uranium fuel assemblies in use in enriched reactors (from 3/8-inch rod through 1 -mil foil). Measurements of particle size distribution and surface areas are under way in the continuing study of powder ignitions. Burning-curve experiments have demonstrated that 
the presence of 10 per cent ferric oxide or zirconium dioxide does not decrease the ignition temperature of uranium powder but does increase the burning temperature, as might be expected from a thermite-type reaction.

The effects of aluminum and copper additives on the ignition temperature of uranium in oxygen are masked in burning-curve experiments in air by the complexity of the thermocycling behavior. Weight gain and sample temperature measurements have been used to demonstrate that, when the alloys are heated in helium to $700 \mathrm{C}$ and exposed to air, the oxidation rates are in accord with the order of ignition temperature in oxygen.

One of the most common pyrophoricity hazards involves the ignition and burning of chips from machining operations. Because chips usually have irregular cross sections and are not uniform along their length, a more careful study of the burning process can be performed on foil strips or wires. Studies of the propagation of burning along foil strips have provided a method for appraising the effects of many variables on the combustion process.

Studies with uranium during this period have shown (1) that the extent of combustion is strongly dependent on the thickness of the foil and (2) that the product oxide is a mixture of $\mathrm{UO}_{2}$ and $\mathrm{U}_{3} \mathrm{O}_{8-\mathrm{x}}$. Studies with zirconium and several gas contaminants (ozone, carbon dioxide, and water vapor) have shown a limited effect of these gases on the burning propagation rates of foils in air.

Microscopic observation of the surfaces of uranium samples during oxidation at 150 and $200 \mathrm{C}$ have indicated by time-lapse photography that change in the rate of onset and growth of nucleation on the oxide surface occurs at the same time as the transition of the kinetics to the second-stage oxidation rate.

The experimental program to determine rates of reaction of molten reactor fuel and cladding metals with water is continuing. The principal laboratory-scale method involves the rapid melting and dispersion of metal wires in a water or steam environment by a surge current from a bank of condensers. Further runs with 30 -mil zirconium wires showed that the apparently critical "ignition temperature" of $2600 \mathrm{C}$ is independent of initial wire diameter.

A series of runs with aluminum showed that very irregular heating occurred. The bulk of the specimen wire was heated only slightly by the discharge, while several points along the wire were heated to vaporization. The energy of the discharge was thus dissipated as arcs. 
A second laboratory-scale method involves the rapid contact of steam with molten metal. In this method the molten metal receives a "pressure pulse" of water vapor. A series of preliminary runs with molten zirconium and water vapor at $20 \mathrm{~mm}$ was completed.

A series of eight experiments has been conducted in the TREAT reactor. In each experiment, a stainless steel autoclave containing a fuel pin, gold foils, helium, and water was subjected to a short burst of neutrons. In these experiments, 20 per cent enriched uranium pins were heated to a maximum of $1560 \mathrm{C}$ and completely melted. A maximum of 3.2 per cent of the uranium reacted with water in the most energetic run to date. The uranium was not effectively dispersed throughout the water.

IV. Reactor Chemistry (pages 152 to 164)

Current work being carried out on the determination of nuclear constants includes the determination of cross sections of uranium-236 with neutrons from the Van de Graaff.

Studies are being made in the Boiling Water Reactor Decontamination Program for determination of contamination resulting from a fuel defect and investigation of methods of activity removal.

A two-step alkaline-permanganate procedure has been developed for room-temperature decontamination of stainless steel surfaces.

Transportation of decontamination reagents using foaming techniques is being investigated. Ethylene oxide-base and alkyl-aryl sulfonate-base foaming agents have been selected for initial studies. A decontamination factor of 15 was obtained with the alkaline-permanganate procedure at room temperature in conjunction with Makon 10 (ethylene oxide-base) foaming agent; a factor of 50 was obtained with ammonium persulfate-hydrofluoric acid.

Qualitative studies of foam characteristics revealed that both types of foaming agents (in 0.2 per cent solution) had no foaming ability above $75 \mathrm{C}$, moderate ability at $75 \mathrm{C}$, and considerable ability at room temperature. Measured foam ratios (foam volume generated to the original volume of liquid) of 20 to 30 were obtained at room temperature.

Chemical stability tests with 0.1 per cent potassium permanganate indicated incompatibility with ethylene oxide-base foaming agents, and reasonable stability with alkyl-aryl sulfonate base. 
Several additional runs with yttrium-90 tracer activity were made at 600 psi and a steam rate of 0.36 feet per second in a loop simulating the action of a boiling water reactor. Deposition of yttrium-90 in the steam phase in all runs reached a minimum value at 25 to 35 inches about the steamwater interface. Disengaging factors were obtained up to a maximum of $8.1 \times 10^{3}$, depending on activity level.

Work has begun on development of a Boiling Slurry Reactor (Slurrex) Concept, which consists basically of a vessel in which the boiling slurry circulates by natural convection. Steam is withdrawn directly from the vessel into the primary heat exchanger, making this an indirect-cycle boiling reactor. This concept retains many of the advantages of both the pressurized homogeneous and the boiling hetergeneous reactors. These advantages include promise of high power density, a potentially attractive fuel cycle, excellent safety characteristics, simplicity of reactor control and operation, and significant reduction in the external system, simplifying the problem of remote maintenance.

Several chemical problems relating to development of the Slurrex reactor are being examined. They include determination of physical properties of uranium trioxide-thorium dioxide slurries and slurry ingredients, methods for determination of particle sizes and surface areas of thorium and uranium oxide powders, and the effect of in-pile radiation up to 10 per cent burnup.

A program has been initiated on the preparation of slurry from spherical colloid gel particles.

V. Analytical Research and Development (pages 165 to 167)

Studies are being made of the use of proportional gas spectrometers in conjunction with the multichannel analyzing equipment used with the scintillation detectors. They are best applied in the low energy range ( 1 to 50 kev).

VI. Routine Operations (pages 168 to 170 )

The operation of the radioactive waste-processing facility and the gamma-irradiation facility continued without incident. 


\section{CHEMICAL-METALLURGICAL PROCESSING}

Pyrometallurgical methods have been chosen for chemical reproces sing of the EBR-II core and blanket. The first process to be incorporated into the fuel cycle is melt refining, in which the discharged fuel pins are melted in a zirconium oxide crucible and the melt is maintained at a mini = mum temperature of $1300 \mathrm{C}$ for a period of several hours. In this procedure fission products are removed from the metal by vaporization and selective oxidation reactions. The metal is then poured into a mold, new pins are prepared by injection casting, and, after cladding, are returned to the reactor core.

A direct-cycle pyrometallurgical fuel processing plant is being constructed in conjunction with EBR-II. Although the plant will contain decladding, melt refining, and fuel-refabrication equipment initially, the facility is believed to be sufficiently versatile that it will be able to accommodate other pyrometallurgical processes currently in the development stage. Provisions have been made for completely remote operation of all steps, and the entire process cell is filled with a continuously purified argon atmosphere.

At the conclusion of the melt-refining operation, approximately 10 per cent of the fuel remains behind in the zirconia crucible in the form of a "skull," which ordinarily consists of 70 to 90 per cent metal, the remainder being oxide. Oxidation of the melt-refining skull produces a powdered oxide which can be readily poured from the crucible into another vessel for fur ther processing. This oxide contains practically all of the reactive fission product elements and about 10 per cent of the noble metal fission products (about 10 per cent of the metal from the melt-refining charge appears in the skull). Consequently, the fission product removal achieved by processing this "dragout" stream influences the fission product concentrations in the whole fuel cycle. An equilibrium fuel composition containing about 5 per cent noble metal fission products, i.e., ruthenium, molybdenum, niobium, and palladium, has been shown to possess desirable metallurgical properties for use in the reactor.

The scheme currently under consideration for dragout processing involves a reduction of the skull oxides by a solution of magnesium in liquid cadmium. Some of the noble metal fission products are sufficiently insoluble at this point so that they can be removed by a phase separation. Cadmium is then removed from the solution by distillation, producing a high magnesium concentration which causes the uranium to precipitate. Another phase sepa ration recovers the solid uranium, leaving the remaining fission products in the liquid metal solution. The uranium is retorted to remove traces of magnesium and cadmium and to consolidate it into an ingot. The various steps of this scheme are under study, and it is possible that alternate techniques may prove advantageous in some cases. 
It appears that a similar process would be applicable to blanket processing. The liquid metal solution in this case would be obtained by direct dissolution of the blanket fuel elements instead of oxide reduction. The primary objective in the blanket process is to recover uranium and plutonium separately, fission product removal being of only minor importance. This separation is based on the high solubility of plutonium and low solubility of uranium in liquid magnesium.

The design of suitable equipment and adaptation of techniques for use in liquid metal systems at high temperatures require considerable engineering development work. Corrosion testing, studies of unit operations and investigation of scale-up effects are necessary.

Since physicochemical and thermodynamic data are lacking for many of the liquid metal systems and materials of construction under consideration, a more general research effort is also essential to the overall program.

Solubilities of a number of elements in liquid metal systems have been determined. New data were obtained for the solubilities of vanadium, iron, and nickel in liquid cadmium at temperatures from 400 to $650 \mathrm{C}$. Vanadium is virtually insoluble $(<0.2 \mathrm{ppm}$ at $650 \mathrm{C})$; iron solubility ranges from $0.5 \mathrm{ppm}$ at $400 \mathrm{C}$ to $7 \mathrm{ppm}$ at $610 \mathrm{C}$, and nickel solubility ranges from 1.4 per cent at $410 \mathrm{C}$ to 5 per cent at $540 \mathrm{C}$.

Corrections were made to the data on the solubility of thorium in liquid zinc. Solubilities of uranium in silicon-free zinc-magnesium solutions were found to be significantly higher than when silicon was present. A method, based on the solubility of the solute in the two pure components of the binary solvent, the free energy of formation of the solid phase in equilibrium with the pure solvent components and an estimate of the excess free energy of the binary solvent system, has been developed for the calculation of the solubility of the solute in a binary liquid metal solvent. A check of earlier data with this calculation prompted the experimental reinvestigations discussed earlier.

The peritectic temperature ( $U C_{11}$ incongruent melting point) in the uranium-cadmium system was found to be $474 \pm 1 \mathrm{C}$.

The activity coefficient of uranium in aluminum at 4.8 per cent uranium and $686 \mathrm{C}$ is estimated to be $1.25 \times 10^{-3}$, based on a distribution coefficient of uranium between cadmium and aluminum and the activity coefficient of uranium in pure cadmium.

The free energy of formation of $\mathrm{UPb}_{3}$, determined by galvanic cell measurements, varied between -14.8 to $-10.0 \mathrm{kcal} / \mathrm{mole}$ at temperatures of 400 to $800 \mathrm{C}$. 
A thermochemistry program, directed toward obtaining basic infor mation on systems of interest to high-temperature chemistry, is in progress. Oxygen and fluorine bomb calorimetry are being used to obtain heats of combustion and heats of formation for sulfur and fluorine compounds of such elements as molybdenum, tungsten, boron and zirconium.

A. Fuel-processing Facilities for EBR-II

(J.H. Schraidt, M. Levenson)

A direct-cycle fuel-reprocessing plant using pyrometallurgical prow cedures is being designed as part of the Experimental Breeder Reactor No. II (EBR-II) project. Melt refining and processes involving fractional crystallization from liquid metal systems are methods being examined for the recovery and purification of EBR-II fuels. Process equipment is being designed and tested.

Excavation for the EBR-II Fuel Cycle Facility was completed on October 14, 1959; all footings and some walls below grade have been poured. Field construction has been discontinued until March 1960 because of the weather. Construction of the Laboratory and Service Building is very nearly completed, and all the equipment items for the Junior Caves and the Waste Solidification Cell of this building are delivered or are on order. Components for the fuel reprocessing facility, such as cranes, manipulators, shielding windows, and lighting, are in various stages of procurement. A contract was awarded to AMF Atomics for the design and fabrication of the Fuel Cycle Facility transfer-cell equipment.

The gamma-irradiation testing of the 175-watt white fluorescent mercury vapor lamp was continued to an integrated exposure of $2 \times 10^{9} \mathrm{rad}$. Light output was 82 per cent of that from an unirradiated lamp. Irradiation tests of Shell APL grease have been completed, and the estimated useful life of this grease in the Air and Argon Cells is 2 and 3 years, respectively. Tests of the three types of dc motors used in the operating manipulator of the Argon Cell have indicated an expected useful cell operating life of 2 to 3 years. The design of the manipulator permits remote replacement of these motors. Continued irradiation tests of mineral insulated (MI) cable have shown no catastrophic breakdown of the electric insulation even after an accumulated gamma dose of $8.4 \times 10^{9} \mathrm{rad}$.

Eighteen enriched (approximately 50 per cent) "fissium" alloy ingots for the initial EBR-II fuel loading were produced in the Mark-V prototype melt-refining processing unit during the period October-December, 1959 .

1. Design, Development and Construction of Buildings and Equipment

The Fuel Cycle Facility and the Laboratory and Service Building were described in previous quarterly reports (ANL-5789 and ANL-5820). 
The former is for the processing of EBR-II fuel and the latter will provide radiochemical analytical and related facilities for the entire Idaho Division of Argonne National Laboratory. The architect-engineer is the $\mathrm{H}$. K. Ferguson Company, Cleveland, Ohio.

a. Status of Laboratory and Service Building Construction and Equipment

(G.J.Bernstein, A. A. Chilenskas, T.W. Eckels)

Building construction is 92 per cent complete. The contractor has promised completion except for laboratory furniture and ventilation balancing by December 31, 1959, but late January 1960 is believed to be a more realistic date.

All equipment items for the Junior Caves and the Waste Solidification Cell are delivered or are on ordex. Installation instructions and bills of material are being prepared to facilitate final installation. AMF Atomics reported that the first test unit of the new Model 8 manipulator will be ready for inspection early in January 1960. The completed Junior Cave windows will be inspected January 11, 1960, and will be shipped to Idaho shortly thereafter. On the same date, joint light transmittance tests will be made on one Junior Cave window for comparison of Argonne and Pittsburgh Plate Glass Company light-measuring equipment and techniques.

A comprehensive study of the disposal of radioactive wastes for the EBR-II site is being made. A report on the procedures and the equipment to be used in the handling and disposal of radioactive wastes at the site is in preparation.

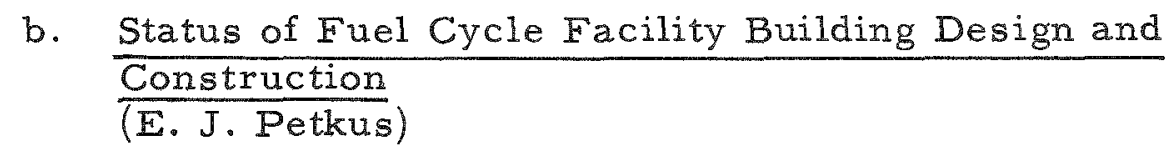

Excavation for the Fuel Cycle Facility was begun on July 30, 1959, and completed on October 14, 1959. The facility was 8 per cent complete as of December 15, 1959. All the footings and some of the walls below the first floor level have been poured. The contractor has scheduled no further field construction until March 1960. During the period of construction inactivity the contractor plans to concentrate on getting shop drawings submitted, procurement of material, and shop fabrication of components.

c. Cranes and Manipulators

All parts for the five-ton cranes for the Argon and Air Cells have been fabricated and assembly is now underway. Testing under load is scheduled for January or February 1960, pending delivery of special MI cable terminations. 
Final bid specifications and drawings for the eight operating manipulators are now ready to be sent out to vendors for firm bids. Three standard General Mills articulated mechanical arms (exclusive of telescoping tubes, carriages, bridges and control equipment) are being purchased. These arms will be adapted for use on operating manipulators and will be attached in the same manner that hands and dual hooks now are attached. Electric power and control will be through a special carriage-mounted adaptor which has been mocked-up and tested on the prototype manipulators.

Control equipment for the manipulators, cranes and blister hoist has been ordered.

\section{d. Process Cell Windows (T.W. Eckels)}

At the Idaho installation the two innermost ("hot" side) slabs of glass in the shielding windows may require replacement, because of radiation darkening, during the active lifetime of the facility. It is therefore necessary that these two slabs be replaceable by remotely controlled operations with the in-cell cranes, assisted by the electromechanical manipulators. In mid-November, Argonne and vendor personnel attended a demonstration in Detroit of the installation procedure for the components of the windows. The demonstration as a whole was deemed a success and work is proceeding to correct a few shortcomings observed.

$$
\text { e. } \frac{\text { Cell Lighting }}{\text { (T.W.Eckels, L. F. Coleman })}
$$

The contract for fabricating the wall mounts and luminaires for the 1000-watt mercury vapor lighting system of the Argon and Air Cells was awarded to All Metal Manufacturing Company of Chicago on November 30. The 101 wall mounts and four luminaires are scheduled for delivery January 1, 1960, with the balance to be delivered on or before May 1, 1960.

Irradiation tests of the 175-watt white fluorescent mercury vapor lamp " $B$ " continued. While lighted, the lamp has received an integrated exposure of $2 \times 10^{9} \mathrm{rad}$ * There was no noticeable change in light output from that recorded at $1 \times 10^{9} \mathrm{rad}$. The intensity observed was still 82 per cent of that before gamma irradiation commenced.

It is estimated that the 1000-watt lamps will have a useful life of one year for the proposed applications. During this period the expow sure will be approximately $1 \times 10^{9} \mathrm{rad}$.

* All exposure doses and exposure rates as reported are in terms of rads (water), since the dosimetry method at the facility employs a water solution. 
f. Material Testing

(G.J.Bernstein, L.F. Coleman, A. A. Chilenskas, M. A. Slawecki)

The effect of irradiation upon the lubricity of Shell APL grease has been studied both in the presence and in the absence of air. The grease samples, weighing about one gram each, were loaded in glass vials and placed in either open or closed brass plugs. Some samples were open to the air in the radiation urn, while others were sealed with a cap and copper gasket. The grease was evaluated by comparing the flow and the spreadability of the irradiated specimens with the corresponding characteristics of the unirradiated grease. Based upon these tests and upon an exposure level of $1 \times 10^{5} \mathrm{rad} / \mathrm{hr}$ in both the Air Cell and Argon Cell, the useful lifetime of this grease is estimated to be about 2 years in the Air Cell and about 3 years in the Argon Cell. It is assumed that the grease will not be affected by the argon -5 per cent nitrogen atmosphere in the Argon Cell.

Tests to determine the effects of irradiation upon a grease designated as California Research 159 have begun. The tests, like those for Shell APL grease, are being conducted both in the presence and absence of air. Since this grease is considerably less viscous than Shell APL grease, the former would be a superior lubricant for certain applications. Radiation studies reported in the literature indicate that this grease could have a useful lifetime of about 4 years under Fuel Cycle Facility conditions.

The use of Loctite (a product of American Sealants Company, Hartford, Connecticut) in the Fuel Cycle Facility has been proposed as a means of locking nuts to bolts and bearings to shafts. The effect of radiation upon the locking property of this sealant has been evaluated at radiation levels up to $1.5 \times 10^{9} \mathrm{rad}$. Specimens were prepared using Loctite $A$ to seal a steel nut to a steel bolt having a $\frac{1}{2}-28$ thread. The torque required to turn the nut slowly was measured on unirradiated and irradiated specimens. The results are tabulated below.

\begin{tabular}{cc}
$\begin{array}{c}\text { Radiation Dose } \\
\text { (Rad) }\end{array}$ & $\begin{array}{c}\text { Average Torque } \\
\text { (inch-1b) }\end{array}$ \\
\hline 0 & $\begin{array}{c}30 \pm 5 \mathrm{a} \\
4.9 \times 10^{8}\end{array}$ \\
$1.04 \pm 10^{9}$ & $15 \pm 5 \mathrm{~b}$ \\
$1.51 \times 10^{9}$ & $9 \pm 1^{\mathrm{b}}$ \\
\hline $\begin{array}{l}\mathrm{a} \text { Two samples } \\
\mathrm{b} \text { Three samples }\end{array}$ &
\end{tabular}


The torque required to turn the nut on the bolt without being sealed with Loctite was less than one inch-pound. The results show that prolonged radiation exposure decreases the bonding strength of this sealant. However, the strength exhibited might be sufficient for some applications.

Tests on three types of dc motors to be used in the operating manipulators have been completed. Tests were intermittent $[20 \mathrm{~min}$ utes on, 20 minutes off (20/20) for Howard motors, 30/60 for Eemco motors, and 60/60 for Masters motors] with reversal of direction between cycles. Results with the Howard Industries $\frac{1}{10}-\mathrm{hp}$ motor, SPN 73660 , and the Eemco $\frac{1}{4}$-hp motor, Model C743-C, were less satisfactory than results with the $\frac{1}{4}$-hp Master motor, Gr-2730. This difference in behavior is attributed largely to the fact that the Master motor has a large frame allowing field interpoles; the other two motors are much smaller, having been selected because of space limitation, and do not have interpoles. An Eemco motor is to be used on the manipulator grip drive and five Howard motors will be used in the General Mills articulated arm attachment.

Because of excessive arcing in the argon atmosphere at nor mal operating voltage, the Howard and Eemco motors have been tested under reduced armature voltage. Armature voltage on the Eemco motor was limited to 80 volts and on the Howard motor to 70 volts. Using high-altitudetype brushes in the dry (10 to $20 \mathrm{ppm}$ water) argon, brush life of about 250 hours is predicted, which is equivalent to two or three years of operating life in the Fuel Cycle Facility. These motors were tested under the intermittent conditions described above. The Master motor will be used in the bridge, manipulator and shoulder-rotation drives. Operating at 105 volts (maximum attainable with the test stand), the maximum rate of brush wear was $\frac{1}{10} \mathrm{mil} / \mathrm{hour}$. At this rate, cell operating life will be greater than three years.

The MI cable with ceramic end seals has been irradiated to $8.4 \times 10^{9} \mathrm{rad}$. The insulation resistance of these samples was 200 megohms or greater. A small length of the 54-conductor manipulator power cable is being irradiated preliminary to the more extensive irradiation tests that will be performed when test equipment is fabricated. To date the cable has received an accumulated dose of $2.5 \times 10^{8} \mathrm{rad}$. The insulation resistances of a few adjacent conductors picked at random are still greater than 200 megohms each. The sheath and insulation are stiffer than originally, but are still workable. The color coding on the conductors has completely disappeared.

Asbestos-covered alloy wire has been irradiated to a total dose of $4.4 \times 10^{9} \mathrm{rad}$. The insulation resistances of the samples are still greater than 200 megohms each, but the insulation is beginning to powder and break apart. At a dose of $2.9 \times 10^{9}$ rad the samples were checked with a 500 -volt, 0 to 1000 -megohm Megger; all samples read infinity. 
Samples of aluminum paint have received an irradiation dose of $4.4 \times 10^{9} \mathrm{rad}$ to date, with only slight discoloration of the samples. Steelkote samples were removed after $2.9 \times 10^{\circ}$ rad because of extreme discoloration and blistering. These samples started to discolor after about $5 \times 10^{8} \mathrm{rad}$. Other miscellaneous paint samples have been irradiated to $1.4 \times 10^{9} \mathrm{rad}$ with only slight darkening.

Sauereisen \#31 compound was tested as a sealant for MI cable. The material did not produce a satisfactory seal. A sealant of this type is desired for sealing nonpermanent electrical leads into the Argon and Air Cells, such as those at the service slots. The ceramic terminations or end seals which are used exclusively on all cable runs through the shielding walls are satisfactory for this purpose, but are expensive and difficult to install properly. Other sealants of this type are on order and will be tested as they are received.

$$
\begin{aligned}
& \text { g. Transfer-cell Equipment } \\
& \text { (G. J.Bernstein, J.Graae) }
\end{aligned}
$$

A purchase contract has been awarded to AMF Atomics for design and fabrication of transfer-cell equipment. This equipment will be used in conjunction with the transfer lock for movement of materials into and out of the Argon Cell. The principal components consist of a base plate which can be sealed to the lock, a transfer cart to move the base plate between the Argon Cell and Air Cell openings, and two hydraulic rams beneath these openings for elevating the base plate. Controls, drives and safety in= terlocks are also provided. Preliminary layouts and drawings have been examined and returned to AMF Atomics with comments.

\section{EBR-II Fuel-processing Mock-up}

a. Manipulator and Manipulator Removal Blister

A number of Timken roller bearings have been either Electrolized or coated with molybdenum disulfide, or both, and will be returned to Timken for assembly. These bearings will be tested by placing some of them on the operating manipulator and by running some under a dry inert atmosphere. In addition, a number of small test-blocks have been surfacetreated in the same manner as the bearings and will be tested for wear by Timken.

The APL grease has not proved entirely satisfactory in the prototype manipulator. For the grip drive mechanism, where a relatively large number of gears and bearings are involved, the high viscosity of this grease caused the drive to slow down. These have therefore been cleaned and relubricated temporarily with a conventional lubricant. In the meantime efforts will be made to find a more fluid, radiation-resistant lubricant. 
b. Melt-refining Furnaces

(D. C. Hampson, W.E.Miller, H.L. Stethers)

Past experience has shown that occasionally the standard Norton crucibles used for melt-refining cracked so severely that handling in a processing plant would be difficult. For this reason practical methods are being sought to minimize crucible cracking. The Mark $V$ furnace and its associated auxiliary equipment was used to test Leco thin-wall, stabilized zirconia crucibles. The twelve thin wall crucibles tested were the same ID and height as the standard Norton crucibles, but had inch wall and $\frac{1}{2}$ inch bottom (vs $\frac{5}{6}$ inch and 1 inch, respectively, for the Norton crucible). Eleven were made by the pressing technique using the same mix (Norton RZ 300) as used in the Norton crucibles; the other one was made of a finer - grained zirconia mix, using a joggling technique.

These crucibles stand up very well when empty or when melting a copper charge, even at heating rates up to $40 \mathrm{C} / \mathrm{min}$. However, when used for melting uranium, "fissium, "or "fissium" containing cerium, they did not stand up as well as the thicker walled crucibles, even when the heat up rate was reduced to $8 \mathrm{c} / \mathrm{min}$. Two of the elght used with uranium alloy broke on removal from the furnace, and all of the other six were badly cracked.

Three of the melts made in the Leco crucibles failed to pour because of a tough skin (dross) on the top of the melt. The skin could be broken through and pouring completed by shaking the crucible when it was in the tilted position. However, this procedure resulted in spilling a consid erable amount (estimated to be $6 \mathrm{~kg}$ ) of uranium onto the furnace base. This afforded an opportunity to test methods of remotely removing spilled, sol idified uranium from the furnace. In about 8 hours the uranium was completely removed with the aid of only the manipulator and manipulator tools operated from behind the shielding window.

The failure of these crucibles and the excessive dross formation under standard liquation conditions ( $1400 \mathrm{C}$ for 3 hours) indicates that some reaction having an appreciable rate is occurring. Additional crucibles have been ordered and tests will be run under less severe conditions of time and/or temperature. The effect of degassing before charging will also be investigated, although studies with standard Norton crucibles indicated that degassing was unnecessary.

The Mark $V$ furnace was returned to the production of enriched fuel (approximately 50 per cent enriched "fissium" alloy) ingots for EBR-II fuel manufacture on December 4, 1959. Eighteen ingots were produced, bringing the total production to thirty four. The analyses of samples from these last ingots have not been completed. (Results of analyses of 
the first sixteen ingots were reported in the April-June quarterly report, ANL-6029.) This prototype processing unit, made up of furnace and associated equipment, has performed satisfactorily for alloy preparation.

The Mark IV furnace and its auxiliaries were moved to a new location and put into operation to investigate the compatability of materials of construction used in the furnace components. Component life in the pres * ence of sodium vapor is one of the questions to be answered. Four sodium vaporization runs were made in a furnace assembly made up of a graphite susceptor, zirconia grain insulation and rigid Fiberfrax outer shell and insulator. About one hundred grams of sodium were vaporized from a zir * conia crucible contained in the susceptor during each run. The fourth run was terminated by a coil burnout, apparently due to an arc formation, since it was cut through cleanly. Preliminary tests showed that the electrical conductivities of the furnace insulating materials had increased markedly. A more thorough study is being made of the residue to determine if the sodium contributed to the coil failure.

B. Melting Refining

(L. Burris, Jr., R. K. Steunenberg)

A pyrometallurgical plant is being built adjacent to the EBR-II reactor in Idaho to enable undelaved processing, refabrica ion and recycle of the discharged fuel material. The initial processing method to be employed involves simple melting in an oxide crucible for fission product removal by volatilization and selective oxidation (called melt refining). The plant, how ever, is believed to be constructed in a manner sufficiently versatile to handle other processes which are currently in the development stage. These generally involve the use of liquid metals as processing media. Principal attention is now being given to a process for recorering fiss:onable material left behind as a skull in the crucible of the meltwrefining operation. A process is also under development for separating the bred plutonium from the fertile uranium in the blanket.

Equipment has been installed and is being checked out in the Senior Cave Facility for small-scale, high-activity level demonstration runs of the melt refining process. Ir radiation of material is now in progress in the ANL CP-5 reactor: some material is also to be 1 rradiated in the MTR.

Equipment has been built and tested to enable handling and charging of sodium-coated pins for subsequent melting without exposure to air. This will make possible a realistic evaluation of any problems connected with the melting of such pins.

In the study of alternate materials for the melt refining furnace, powdered boron carbide and powdered graphite, both of which are compatible with a graphite susceptor, proved to be efficient thermal insulators, the graphite being superior from the standpoint of sintering. Graphite powder 
would be an effective replacement for the presently used zirconia insulating grain. Alternatively, the use of a tungsten susceptor which would be compatible with the zirconium oxide insulating grain was successfully demonstrated, but the power efficiencywas less than that of a graphite susceptor.

Rhenium-tungsten thermocouples are being investigated for use in the temperature region of melt refining (1200 to $1600 \mathrm{C}$ ). Preliminary results are encouraging.

\section{Melt-refining Irradiated "Fissium" Pins \\ (V.G. Trice, W. H. Spicer, N.R. Chellew)}

Plans have been made to conduct small-scale melt-refining demonstration runs, using highly irradiated uranium-"fissium" pins of a composition characteristic of the first core loading of EBR-II. The purpose of this program is to determine if laboratory results previously obtained from inactive and low-level runs are valid under realistic conditions of burnup.

Irradiations. The first EBR - II core is expected to consist of enriched uranium alloyed with 5 per cent "fissium." For the melturefining demonstration runs, a $2.9-\mathrm{kg}$ batch of 10 per cent enriched uranium pins of this composition has been prepared.* The nominal composition of this alloy is as follows:

\begin{tabular}{lc} 
Element & Weight per cent \\
\cline { 1 - 1 } $\mathrm{U}^{235}$ & 10.05 \\
$\mathrm{U}^{238}$ & 84.94 \\
Mo & 2.46 \\
$\mathrm{Ru}$ & 1.96 \\
$\mathrm{Rh}$ & 0.28 \\
$\mathrm{Pd}$ & 0.19 \\
$\mathrm{Zr}$ & $0.10(30$ per cent excess added $)$ \\
$\mathrm{Nb}$ & 0.01
\end{tabular}

Ir radiation of approximately 800 grams of this material is now in progress in CP-5. If the reactor operates at the expected power levels, these fuel pins will attain the desired burnup of one atom per cent in April, 1960. A proposal to irradiate additional 400-gram batches of fuel pins in the Materials Testing Reactor has been approved by the Atomic Energy Commission, and a suitable capsule for this purpose has been designed.

* Alloy prepared by G. A. Bennett 
Furnace Testing. A small induction-heated melting and casting furnace has been installed in the Senior Cave Facility of the Chemical En gineering Division. This equipment is designed to handle 350 to $400-$ gram batches of the alloy irradiated to one atom per cent burnup.

Preliminary testing of the furnace has been completed with a satisfactory demonstration of the operability of all components required for remotely controlled melting and casting. The present plans are to process the ir radiated fuel for 3 hours at $1400 \mathrm{C}$ under an argon atmosphere of $800 \mathrm{~mm} \mathrm{Hg}$. The durability and reliability of the equipment are being established by an endurance test of twenty runs currently in progress.

Three runs have been completed in the endurance test program. Unir radiated charges of uranium 5 per cent "fissium" pins weighing about 400 grams were processed in lime-stabilized zirconia crucibles for 3 hours at $1400 \mathrm{C}$. Metallic cerium had been added to each charge to a concentration of 0.6 weight per cent. The cast ingots of purified metal were of good quality with no blow holes and with bright surfaces, which was indicative of a clean atmosphere in the furnace. All the operations incident to the remote control of melting and casting were conducted without difficulty.

Argon, due to its much lower thermal conductivity, appears to be superior to helium as a furnace atmosphere. The substitution of argon for helium, which was used in the earlier tests, afforded a 50 per cent reduction in power requirements: this result should have a beneficial effect upon the lifetime of furnace components. The use of argon also permitted the surface of the melt to reach a temperature closer to that of the bulk of the charge: thereby the tendency for unmelted pins to float on the surface of the molten metal was reduced.

Fission Gas Release. In addition to the study of fission product separation during melt refining, a separate program has been planned to investigate the behavior of 9.4 -year krypton-85 and 5.3 -day xenon-133 during the heating and melting of highly ir radiated "fissium" pins. Attempts will be made to establish whether these gases are released on heating prior to the melting of the alloy, what physical changes of the alloy occur on heating, what are the effects on the coalescence of pins, and whether spattering occurs when the pins are melted.

\section{Melt refining of Sodium-coated Pins}

(G.A. Bennett, W.A. Pehl)

Difficulties have been encountered in the melting of sodiumcoated fuel pins of the EBR-II type which have been exposed briefly to air. Apparently an oxide film forms on the pin surface. Equipment for the handling and charging of such pins without exposure to air has been built. This will make possible a better assessment of problems connected with the melting of sodium-coated pins under plant conditions. 
The possibility of using calcium to reduce oxide films is also being considered. Since molten calcium attacks zirconia crucibles severely, calcium zirconate $\left(\mathrm{CaO} \cdot \mathrm{ZrO}_{2}\right.$ ) crucibles were procured for testing. A British report ${ }^{1}$ has indicated that such crucibles have been used successfully for the reduction of vanadium oxide and thorium tetrachloride with calcium. Two calcium zirconate crucibles have been employed at 1300 and $1400 \mathrm{C}$ in which 15 grams of calcium was added to 300-gram batches of sodium-coated pins. No pin shells were evident in the $1400 \mathrm{C}$ run; a very few were present in the $1300 \mathrm{C}$ run. Chemical attack on the crucible did not appear to have taken place. The thermal shock resistance of the crucibles also appeared to be satisfactory.

3. Study of Alternate Materials and Designs for EBR-II MeltRefining Furnace (J.Wolkof, R.Peterson,* C.A. Bayens**

Various materials and designs for use in a melt-refining furnace are being tested to determine possible improvements. The most fruitful areas of work appeared to be the following:

a. Testing of alternate insulating materials. The zirconia grain now used in contact with a graphite susceptor tends to be partially reduced at operating temperature; carbon monoxide is produced simultane ously. Insulating grains compatible with graphite, e.g., boron carbide, are being tested as possible replacements for the zirconia. An alternate approach is the use of other susceptor materials compatible with zirconia, e.g., tungsten.

b. Reduction of the operating temperature of the solid copper inductor coil. This now operates in the range from 650 to $750 \mathrm{C}$ and a lower temperature is desired. Improved thermal insulation can lower the coil temperature significantly. Further improvement is possible through coil space factor and geometry modifications.

c. Crucible integrity. Crucible cracking and occasional breakage is experienced. However, metal leakage into the susceptor chamber has been rare. Occasionally a bottom breaks off within the susceptor and is dif ficult to remove by remotely operated manipulators. Minimization of the breakage by dimensional modifications of the crucible and by modifications in the fabrication of the crucible (with the cooperation of the manufacturer) is being investigated.

1 Best, P., and Proudfoot, E. Investigation of Refractories for Use in the Extraction of High Melting Point Metals, R + DB(C)TN=110 (January 24, 1955).

* Student Aide from Northwestern University

* Student Aide from University of Detroit 
Three different types of insulating grains were tested: boron carbide ( $800 \mathrm{mesh}$ ), graphite powder ( $-200 \mathrm{mesh}$ ) each at two densities, and zirconia grain at two particle size distributions. A summary of data from six runs is shown in Table 1.

Table 1

POWER AND THERMAL INSULATION TEST RUNS

(All runs at steady state with $\mathrm{ZrO}_{2}$ crucible cover; rigid Fiberfrax used as grain retainer)

\begin{tabular}{|c|c|c|c|c|c|c|c|c|}
\hline $\begin{array}{l}\text { Run } \\
\text { No. }\end{array}$ & $\begin{array}{l}\text { Insulating } \\
\text { Grain }\end{array}$ & Pressure & $\begin{array}{l}\text { Susceptor } \\
\text { Material }\end{array}$ & $\begin{array}{c}\text { Power } \\
(\mathrm{kw})\end{array}$ & $\begin{array}{l}\text { Temp } \\
\text { Crucible } \\
\text { Wall } \\
\text { (C) }\end{array}$ & $\begin{array}{c}\text { Temp } \\
\text { Outer } \\
\text { Grain } \\
\text { Retainer } \\
\text { (c) }\end{array}$ & $\begin{array}{l}\text { Temp } \\
\text { Copper } \\
\text { Coil } \\
\text { (max) } \\
\text { (c) }\end{array}$ & $\begin{array}{c}\text { Slope } \\
\text { of } \\
\text { Cooling } \\
\text { Curve } 2 \\
\left(\min ^{-1} x-10^{-3}\right)\end{array}$ \\
\hline 10 & $\begin{array}{l}\text { Boron carbide, } \\
800 \text { mesh } \\
\text { (Density: } 0.50 \mathrm{~g} / \mathrm{ml} \text { ) }\end{array}$ & atmos & Graphite & 3.0 & 1065 & 312 & 326 & 2.2 \\
\hline $11 \mathrm{a}$ & $\begin{array}{l}\text { Boron carbide, } \\
800 \text { mesh } \\
\text { (Density: } 0.66 \mathrm{~g} / \mathrm{ml} \text { ) }\end{array}$ & atmos & Graphite & 3.0 & 1022 & 336 & 343 & 2.3 \\
\hline $11 \mathrm{~b}$ & $"$ & atmos & Graphite & 5.7 & $1400^{b}$ & 485 & 466 & 2.7 \\
\hline $13 a$ & $\begin{array}{l}\text { Graphite, } \\
95 \%-200 \text { mesh } \\
\text { (Density: } 1.08 \mathrm{~g} / \mathrm{ml} \text { ) }\end{array}$ & $1 \mu$ & Graphite & 1.5 & $810^{b}$ & 219 & 236 & - \\
\hline $13 \mathrm{~b}$ & $"$ & atmos & Graphite & 1.5 & 681 & 241 & 222 & 2.1 \\
\hline $13 c$ & $"$ & atmos & Graphite & 6.3 & $1435^{b}$ & 539 & 485 & 2.6 \\
\hline $16 a$ & $\begin{array}{l}\text { Graphite, } \\
95 \%-200 \text { mesh } \\
\text { (Density: } 0.71 \mathrm{~g} / \mathrm{ml} \text { ) }\end{array}$ & $0.1 \mu$ & Graphite & 1.5 & 932 & 217 & 232 & $0.87 / 0.97^{c}$ \\
\hline $16 \mathrm{~b}$ & $" n$ & atmos & Graphite & 1.5 & 772 & 239 & 208 & 1.9 \\
\hline $16 c$ & $"$ & atmos & Graphite & 4.8 & 1431 & 473 & 412 & 2.0 \\
\hline $15 a$ & $\begin{array}{l}\text { Zirconia, Type } \mathrm{I} \\
25 / 40 \text { mesh } \\
\text { (Density: } 2.08 \mathrm{~g} / \mathrm{ml} \text { ) }\end{array}$ & $08 \mu$ & Graphite & 1.5 & 945 & 268 & 249 & $0.96 / 1.1^{\mathrm{c}}$ \\
\hline $15 b$ & $n$ & atmos & Graphite & 1.5 & 762 & 283 & 232 & 2.1 \\
\hline $15 c$ & $n$ & atmos & Graphite & 5.7 & 1405 & 574 & 473 & - 2.0 \\
\hline $14 a$ & $\begin{array}{l}\text { Zirconia, Type } \mathrm{I} \\
325 \mathrm{~F} \text { mesh } \\
\text { (Density: } 2.74 \mathrm{~g} / \mathrm{ml} \text { ) }\end{array}$ & $0.5 \mu$ & $\begin{array}{l}\text { Sintered } \\
\text { Tungsten }\end{array}$ & 1.5 & 650 & 177 & 259 & 0.9 \\
\hline $14 \mathrm{~b}$ & $n$ & atmos & $\begin{array}{l}\text { Sintered } \\
\text { Tungsten }\end{array}$ & 1.5 & 515 & 209 & 233 & 2.3 \\
\hline $14 c$ & $"$ & atmos & $\begin{array}{l}\text { Sintered } \\
\text { Tungsten }\end{array}$ & 11.1 & 1395 & 659 & 706 & 2.3 \\
\hline
\end{tabular}

a Slope of cooling curve on $\log \theta \mathrm{vs} T$ plot after linearity is reached, $d(\log \theta) / d \tau ; \theta=$ temp above ambient, $T=$ time in minutes.

${ }^{b}$ Corrected wall temperature based on gas immersion temperature within empty crucible.

c Low value after 12 hours cooling; high value after 4 hours. 
The runs consist of several parts for each assembly. In the first part of the run, a steady-state temperature for a constant low-power input is determined, after which the power is turned off and the temperatures recorded during cooling. This generally is done first under vacuum and then under normal argon pressure. The subsequent part of the run is a determination of the power required to maintain the crucible wall temperature at $1400 \mathrm{C}$ at steady state. Steady-state temperatures (or power for the latter part of the run) are indicative of the efficiency of the thermal insulation of an assembly, while the transient cooling temperatures are indicative of the system capacity lag, which depends on the overall thermal diffusivity.

An untamped and tamped boron carbide insulating grain was tested in Runs 10 and 11 , respectively. The grain was closely sized at 800 mesh. After the run, the grain was caked and contained a number of cracks through which heat loss by radiation to the grain retained could occur. Although thermal conductivity is adequately low, the sintering tendency of the grain precludes its use in this mesh size.

In Runs 13 and 16, a -200 mesh graphite powder was tested, both tamped and untamped. The loosely packed powder was superior as thermal insulation. Both densities showed little or no sintering tendency. Although these materials are relatively good electrical conductors, there was no noticeable power loss from the induction field to the grain.

Run 15 was a similar assembly using $25 / 40$ mesh untamped zirconia grain. The insulating effectiveness of this grain is intermediate to the dense and loose graphite powders. This size of zirconia grain is currently used in the melt-refining mock-up furnaces.

The -200 mesh loosely packed graphite powder is therefore an effective substitute for the zirconia grain now in use. The use of the graph ite powder could eliminate the problem of compatibility of oxide refractory grains with the graphite susceptor.

A -325 mesh zirconia grain was tested in Run 14. It was extensively cracked and caked hard after the run and was not reusable. With this size of zirconia grain, considerable sintering occured.

Calculation of the thermal diffusivity of $25 / 40$ mesh zirconium dioxide insulating grain was attempted from the data of some of the runs reported in the previous quarterly (ANL-6068). Some of the values of ther mal diffusivity (sq in./min) obtained were as follows:

Based on physical properties at $900 \mathrm{C} \quad 0.060$

Calculated from difference approx. to Fick's Equation 0.060

Calculated from periodic cycling (Run 7)* $\quad 0.056$

* Max Jakob "Heat Transfer," Vol. I (1949), p. 294. 
The temperatures and power needs shown in Table 1 for Run 14 are not directly comparable with preceding runs since a porous sintered tungsten susceptor (53 per cent porosity) was used instead of graphite. The tungsten was used for high-temperature compatibility with zirconia grain. The power transfer efficiency between the copper induction coil and the tung = sten susceptor was lower than with a graphite susceptor: about $11 \mathrm{kw}$ of input power were required to maintain the crucible at $1400 \mathrm{C}$ as compared to about $6 \mathrm{kw}$ required with a graphite susceptor. The copper coil temperature was correspondingly higher.

Electrical efficiency of the power transfer from the inductor coil to the susceptor depends on the resistivity of the susceptor material. Analogous to the primary and secondary of a loosely coupled transformer, the electrical efficiency of the power transfer from primary to secondary is given by

$$
\eta=\frac{r_{s}}{r_{p}+r_{s}}
$$

where $r_{\mathrm{S}}$ is the resistance of the secondary or susceptor circuit and $r_{p}$ the resistance of the primary or coil circuit. The efficiency therefore increases with a large secondary resistance relative to the primary. Since the electrical resistivity of tungsten'islower than graphite by an order of magnitude, more power for a given design will be required to maintain operating temperatures with a tungsten susceptor than with graphite. Porous tungsten was tested because of its higher volume resistivity and its relative ease of fabrim cation compared with massive metal.

Rigid Fiberfrax has been used as a grain retainer (ANL-6068, page 43 ) in these runs. It is an effective heat insulation but replacements were made after about three runs because of cracking and general weaken ing. These retainers have been subjected to inner surface temperatures of about $1225 \mathrm{C}$. The use of a thicker annulus of insulating grain (now $\frac{3}{4}$ in.) and/or a thinner retainer wall (now in.) will prolong the retainer life.

As a result of a discussion with the representative of the manufacturer of the present zirconia crucibles, the fabrication procedure for the present crucibles was revised and a modified crucible with thinner walls and bottom was ordered. The revised fabrication procedure has been successful in decreasing the incidence and severity of cracking in the meltarefining mock-up furnaces.

4. Testing of High-temperature Thermocouples

(G. A. Bennett, W.A. Pehl)

Throughout the development work on melt refining, platinum/ platinum-10 per cent rhodium thermocouples have been used for temperature measurements. This thermocouple has provided satisfactory temperature 
measurement, but its lifetime has been fairly short. Thermocouple failures have often occurred during melt-refining runs. Consequently, a thermocouple with longer life and greater dependability is desirable.

The present work extends that begun by $R$. Mesler, in which it was concluded that "platinum -30 " (platinum-6 per cent rhodium/platinum-30 per cent rhodium) and rhenium/wolfram showed the greatest promise. In the past quarter, these two thermocouples were compared with a standard platinum-platinum-10 per cent rhodium thermocouple at temperatures ranging up to $1600 \mathrm{C}$.

A summary of the observations follows:

1. Both platinum-containing thermocouples fail at temperatures of around $1500 \mathrm{C}$. Just before failure, a decrease in the measured emf at constant temperature occurs.

2. No failures with the rhenium/wolfram thermocouple have yet occurred at temperatures up to $1600 \mathrm{C}$; the thermocouple appears to be unaffected: however, the brittleness of the tungsten (wolfram) makes it extremely susceptible to mechanical shock.

3. During the initial heating period, a change in the calibration of the rhenium/wolfram wire occurs. Consistent values are obtained after this induction period.

These experiments will be continued to establish further the stability of rhenium/wolfram thermocouples at 1600 C. Details will be made available in a separate report at the conclusion of the experiments.

C. Pyrometallurigical Development

(L. Burris, Jr., R. K. Steunenberg)

When a melt-refining operation is completed by pouring the molten charge from the zirconium oxide crucible, a shell composed of oxides and unpoured metal remains on the inside surfaces of the crucible. This "skull" represents approximately ten per cent of the total charge. Since the solidified mixture of metal and oxides adheres rather strongly to the crucible, a method of removing it efficiently for subsequent processing is necessary. The requirements for a technique of skull removal depend in part upon the type of recovery process to be used.

Further work has indicated that mechanical removal of the skull material is not practical. Either complete or partial oxidation by oxygen diluted with argon enables essentially complete recovery of the material, and appears readily adaptable to remote operation. A careful study of the behavior of ruthenium and molybdenum under various oxidation conditions is in progress. 
The uranium and fission product oxides resulting from a skull oxidation are reduced by magnesium, either in elemental form or in a cadmium solution. Oxide reductions of around 95 per cent were achieved in 40 hours. A number of variables, e.g., magnesium concentration, use of salt fluxes, and temperature, are being investigated to effect an increase in reduction rate.

Oxide reductions have also been carried out with pure magnesium in the presence of magnesium chloride with promising results. Good reduction was also realized in a "bomb-type" procedure using a blend of solid $\mathrm{U}_{3} \mathrm{O}_{8}$, magnesium, and magnesium chloride powders.

Molten salt fluxes have had variable effects on the rate of oxide reduction in dilute magnesium systems. With some salt compositions reduction rates were slightly better than those achieved without flux. Salt fluxes serve the very useful purpose of suspending the magnesium oxide reaction product, thus providing an opportunity for its removal in a liquid phase. Microscopic examination revealed that separation of magnesium oxide from the metal phase appeared to be complete.

Nickel has been found to precipitate uranium from cadmium solution. Although the rate of leaching of nickel from the 300 series stainless steel was shown to be low, the use of this material in many applications has been discontinued.

Work was continued on development of processes for the EBR-II blanket material. Preparations are being made for demonstration of some of the process steps, including the final isolation of plutonium metal on a 100 -gram scale. The results of distillations with cerium serving as a stand-in for plutonium disclosed the need for baffles in the vapor space above the still pot in order to reduce entrainment.

A large-scale metal-distillation unit to demonstrate (cadmium) metal distillation at rates up to $100 \mathrm{~kg} / \mathrm{hour}$ is under construction. Other associated operations of metal transfer, liquid-level detection, and freeze-valve operation are under study, and the performance of some components has been tested. Conditions and materials for uranium retorting to remove residual cadmium, magnesium or zinc are being studied. Steel is unsatisfactory as a crucible material because some alloying with uranium occurs, even at temperatures below $600 \mathrm{C}$. Satisfactory uranium compacts weighing up to 350 grams were produced in boron nitride and alumina-coated graphite. The porous compacts were subsequently arc and induction melted to solid metal buttons, recoveries being about 95 per cent.

Two medium carbon steel thermal convection loops were built and operated to ascertain the extent of corrosion under adverse thermal conditions. The circulation of 15 and 30 per cent magnesium-cadmium alloys 
under thermal gradients of 575 to $675 \mathrm{C}$ and 630 to $725 \mathrm{C}$, respectively, resulted in mass transfer amounting to a maximum thickness change of only 6 mils in 1000 hours. A second forced circulation loop in which a uraniumfission product-cadmium solution is being circulated at $550 \mathrm{C}$ was started up and has been in trouble-free operation for about 1000 hours.

\section{Processing of Melt-refining Skulls}

a. Preliminary Treatment for Skull Removal (R.D. Pierce, L. F. Dorsey)

Three approaches to the removal of crucible skulls are under consideration: (1) complete oxidation of the skull to a fine powder which can be dumped from the crucible, (2) partial oxidation of the skull, just sufficient to permit it to be dumped from the crucible, and (3) physical recovery of shell pieces after breaking the crucible away.

Complete oxidation of "fissium" skulls has been success fully accomplished many times with a mixture of 25 per cent oxygen in argon at $800 \mathrm{~mm}$ pressure and temperatures between 575 and $950 \mathrm{C}$. The uranium is converted to $\mathrm{U}_{3} \mathrm{O}_{8}$. No difficulty has been encountered in maintaining iso thermal conditions and the product has always been easily poured out with a recovery of over 99 per cent. Material is prepared for skull oxide reduction runs by burning skulls at $800 \mathrm{C}$ with this oxygen-argon mixture. All of the uranium in a nitrided skull was readily converted to the oxide under these same conditions. This was of interest since skulls have an opportunity to undergo nitridation during storage in the cell atmosphere which is argon containing up to 5 per cent nitrogen.

Two preliminary runs in which skulls from meltorefining runs were separated from the crucibles by partial oxidation were made. The crucibles were upside-down during oxidation in order to permit material to fall as soon as it became free. One skull fell completely free after $20 \mathrm{~min}$ utes of exposure to 25 per cent oxygen in argon at $800 \mathrm{~mm}$ and $700 \mathrm{C}$. The second skull fell free in four minutes at $750 \mathrm{C}$ in the same atmosphere. Complete oxidation under these conditions would have required about four hours. The crucibles broke in several places during both of these runs: however, it is believed that if they had been supported on the outside by a secondary con tainer the crucible pieces would have stayed together. Runs to check this point are planned.

Ten melt-refining crucibles were broken to attempt to recover the adhering skulls physically. The skulls ranged in size from 350 to 1000 grams. Two of the skulls were completely recovered, but the presence of a large fraction of very fine skull material indicated that they had been partially oxidized earlier. One other skull was essentially all recovered, but each of the other seven had about 100 grams of skull which adhered tenaciously to the crucible fragments. Since there is also doubt that small 
pieces of skull can be separated from crucible fragments, the present belief is that physical removal is not as attractive as one of the oxidation techniques.

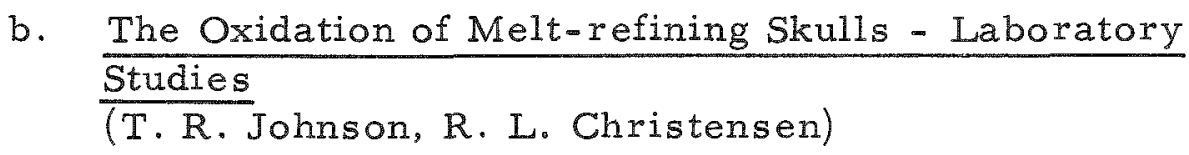

Previous work (ANL-6068, page 49) has indicated that oxidation of the skull in oxygen produces a free-flowing powder which can be poured easily from the crucible. This oxidized material, consisting primarily of $\mathrm{U}_{3} \mathrm{O}_{8}$, is a suitable feed material for the dragout process. The objectives of the current program are to determine the optimum conditions for the oxidation of skulls and to determine the fate of fission product ruthenium, molybdenum, technetium and tellurium during the oxidation. These elements are known to form volatile oxides and it is anticipated that they may be volatilized during oxidation. Some consideration is also being given to methods of skull removal other than direct oxidation.

The skulls used in this work were prepared in the same manner as those used for the nitridation experiments described in the previous quarterly report (ANL-6068, page 46). The skull oxidation was performed in much the same way as the nitridation. The zirconium oxide crucible containing the skull was held at the proper temperature in a furnace and the rate of oxygen uptake was measured volumetrically.

The nominal composition of the "fissium" alloy from which the skulls were prepared was as follows:

\begin{tabular}{cc} 
Element & Conc (weight per cent) \\
\cline { 3 - 3 } Zr & 0.6 \\
Mo & 2.9 \\
Ru & 2.5 \\
Pd & 0.6 \\
Ce & 0.6 \\
U & balance
\end{tabular}

Four oxidation runs were made with undiluted oxygen and five with oxygen diluted with argon. The experimental conditions and some of the results are given in Table 2. When undiluted oxygen is used, the initial reaction rate is very rapid, causing in some cases large temperature increases and breakage of the zirconia crucible due to the thermal shock. It is desirable to minimize the amount of crucible disintegration, since the zirconium oxide fragments are carried into the dragout process with the uranium oxide 
powder. This places an addtional burden on the dragout process in the removal of excessive zirconium from the system. A certain amount of crucible cracking resulting from the melt-refining process must be tolerated, however.

Table 2

SUMMARY OF MELT-REFINING SKULL OXIDATIONS

Initial

\begin{tabular}{|c|c|c|c|c|c|}
\hline \multirow{2}{*}{$\begin{array}{l}\text { Furnace } \\
\text { Temperature } \\
\text { (C) }\end{array}$} & \multicolumn{2}{|c|}{ Pressure } & \multirow[b]{2}{*}{$\begin{array}{r}\text { Time } \\
\text { (min) }\end{array}$} & \multirow{2}{*}{$\begin{array}{l}\text { Amount of } \\
\text { Skull Burned a } \\
\text { (per cent) }\end{array}$} & \multirow[b]{2}{*}{ Comments } \\
\hline & $\begin{array}{c}\text { Oxygen } \\
\text { (mm) }\end{array}$ & $\begin{array}{c}\text { Argon } \\
\text { (mm) }\end{array}$ & & & \\
\hline 500 & 75 & 0 & - & - & $\begin{array}{l}\text { Skull ignited, melting } \\
\text { thermocouple well and } \\
\text { admitting air. }\end{array}$ \\
\hline 700 & 75 & 0 & 125 & $\sim 100$ & $\begin{array}{l}\text { Oxygen pressure } \\
\text { raised to } 500 \mathrm{~mm} \\
\text { after } 70 \text { minutes. }\end{array}$ \\
\hline $800^{b}$ & 75 & 0 & 160 & $\sim 50$ & \\
\hline 800 & 75 & 0 & 90 & 95 & \\
\hline 500 & 200 & 400 & 100 & $\sim 5$ & \\
\hline 700 & 200 & 400 & 270 & 100 & \\
\hline 850 & 100 & 400 & 120 & 56 & \\
\hline 850 & 30 & 400 & 170 & 50 & $\begin{array}{l}\text { Oxygen pressure } \\
\text { raised to } 200 \mathrm{~mm} \\
\text { after } 110 \text { minutes. }\end{array}$ \\
\hline 850 & 30 & 600 & 115 & 46 & $\begin{array}{l}\text { Oxygen pressure } \\
\text { raised to } 200 \mathrm{~mm} \\
\text { after } 50 \text { minutes }\end{array}$ \\
\hline
\end{tabular}

a Based on the conversion of all uranium to $\mathrm{U}_{3} \mathrm{O}_{8}$ and "fissium" elements. to zirconium dioxide, molybdenum trioxide, ruthenium dioxide, palladium oxide and cerium dioxide, respectively.

${ }^{b}$ Ruthenium and molybdenum behavior examined during this run.

Dilution of the oxygen with argon decreases the initial reaction rate, apparently due to the diffusion barrier offered by the argon and the improved transfer of heat from the oxidizing skull. A substantial reduction in the degree of crucible damage was observed when diluted oxygen was used. 
Chemical analyses of the oxidized skulls show that some of the ruthenium and molybdenum are lost during the oxidation. Analyses made on the sodium hydroxide and hydrochloric acid washes revealed that negligible amounts of molybdenum and no ruthenium were adherent to the stainless steel furnace tube. It is known, however, that ruthenium is very difficult to dissolve under certain circumstances. Since ordinary chemical analyses are not adequate for definitive results under these conditions, radioactive tracers of the individual fission elements which are expected to form volatile oxides will be used.

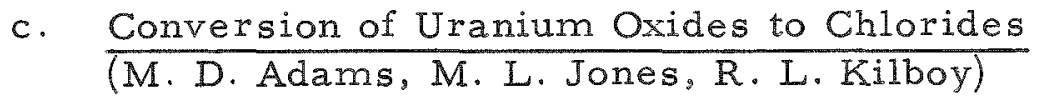

As a possible alternative to reduction of uranium oxides, it was considered worthwhile to investigate conversion of uranium oxide to the chloride prior to reduction in cadmium-magnesium solutions. In order to avoid the handling of volatile uranium chlorides, methods which produce the tri- and tetrachlorides were considered.

Of the methods studied, two show particular promise. The simplest consisted of adding solid $\mathrm{U}_{3} \mathrm{O}_{8}$ in small increments to liquid hexachloropropene refluxing at about $170 \mathrm{C}$. The conversion occurs rapidly with the evolution of considerable heat. The product received no purification other than removal of the excess hexachloropropene by vaporization. Chemical analyses for uranium and chloride gave values of 62.9 and 37.2 per cent, respectively. Corresponding values for pure uranium tetrachloride are 62.7 and 37.3 per cent. Polarographic analysis for uranium (VI) in the product showed less than 0.5 per cent. Although this method of conversion is efficient and convenient, it is questionable whether hexachloropropene would be sufficiently stable in a high radiation field to be a practical reagent.

Uranium tetrachloride was prepared by the reaction of $\mathrm{U}_{3} \mathrm{O}_{8}$ with ammonium chloride at $450 \mathrm{C}$. A preliminary experiment in an open Vycor tube with less than five grams of oxide resulted in a conversion some what in excess of fifty per cent.

\section{d. Reduction of Oxides in Liquid Metal Solution}

The $\mathrm{U}_{3} \mathrm{O}_{8}$ and fission product oxides formed by oxidation treatment of the skull may be reduced to the elemental state and dissolved in a liquid metal. The reduction and dissolution can be accomplished in a combined step, or they can be done separately. Cadmium has been investigated as a liquid metal solvent with magnesium as the reducing agent. The pur poses of the following studies were to explore various methods of reduction and dissolution and to examine the factors controlling the rates and extent of the reactions. 
(1) Oxide Reductions in Cadmium-Magnesium Solutions

Laboratory-scale Reductions

(A.Schneider, J.D.Schilb, J.W.Walsh, C.R. Williams)

Several uranium oxide (10-gram scale) reduction experiments were performed in alumina crucibles, using tantalum stirrers and thermocouple tubes in which $\mathrm{U}_{3} \mathrm{O}_{8}$ was contacted with cadmium-3 weight per cent magnesium at $650 \mathrm{C}$. The results of these reduction runs are shown in Figure 1. Although the reduction rate decreases progressively with time, over 93 per cent of the original $\mathrm{U}_{3} \mathrm{O}_{8}$ charged was reduced after 39 hours in one experiment. The results imply that the particle size of the $\mathrm{U}_{3} \mathrm{O}_{8}$ charged initially is not a significant factor within the size range used in the experiments. Additional work is underway in which an attempt is being made to identify the factors controlling the reduction rate.

FIGURE I

REDUCTION OF $U_{3} \mathrm{O}_{8}$ BY THREE WEIGHT PER CENT MAGNESIUM-CADMIUM

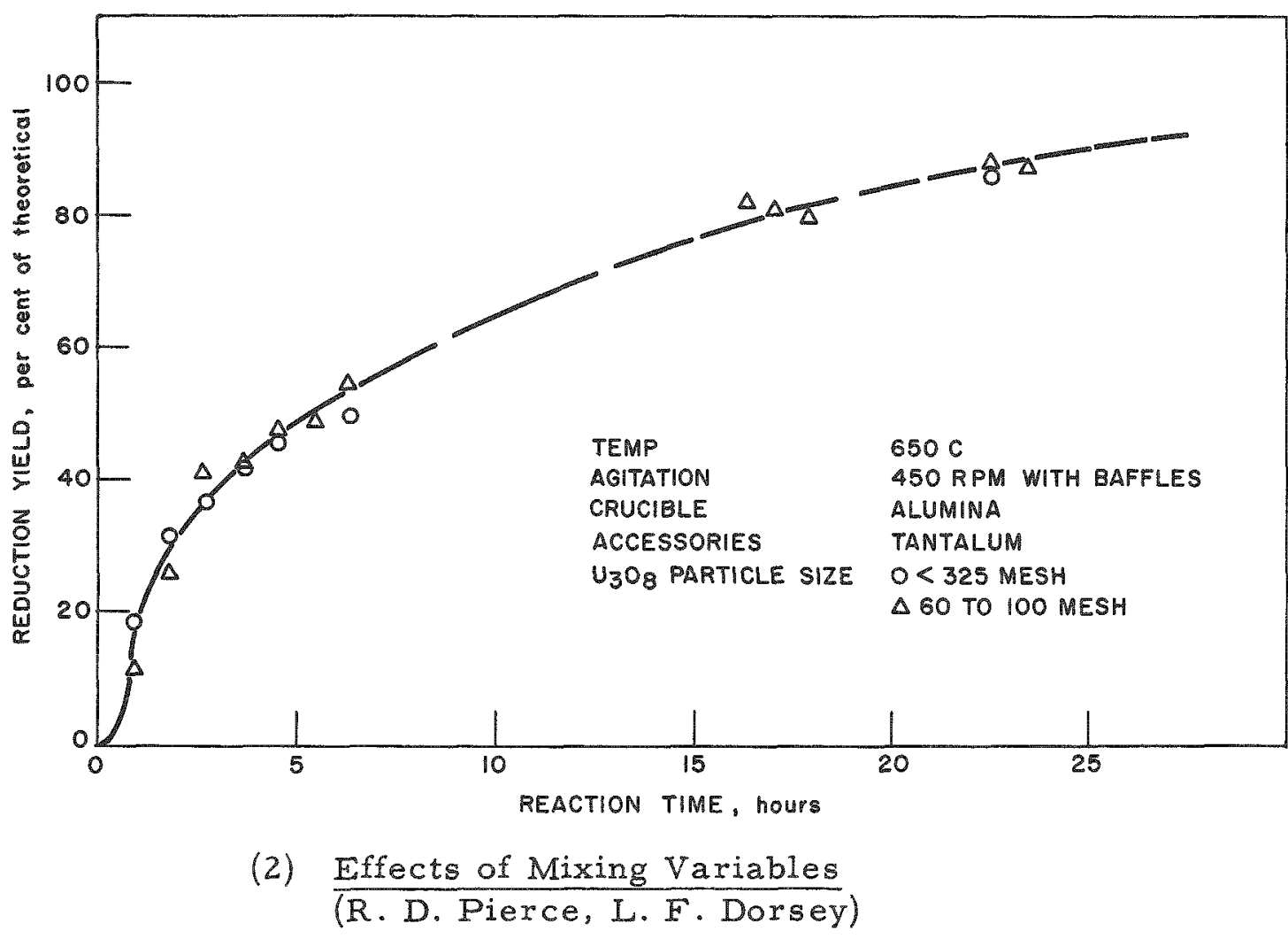

A number of reduction runs using about 100 grams of oxidized skull material were made in 5-inch, baffled crucibles of 304 stainless steel. Although 304 stainless steel is not an ideal container material, these runs have aided in the understanding of some of the process variables. The effect of temperature determined in this equipment has been reported (ANL-6068, page 54). 

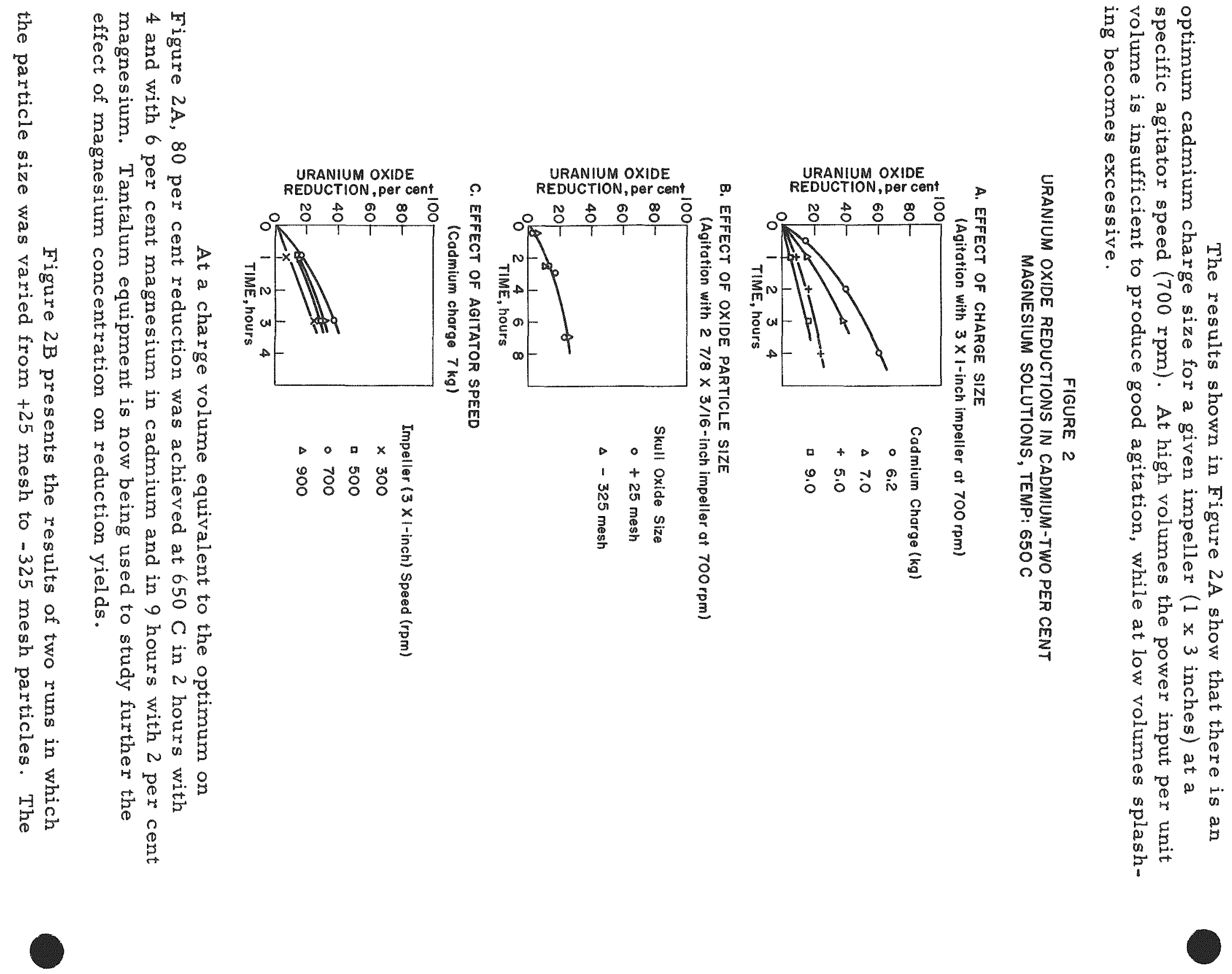
The surprisingly small influence of particle size noted previously was also observed in this equipment.

The effect of agitator speed was studied for one impeller (Figure 2C). At $900 \mathrm{rpm}$ impeller shaft whip or excessive splashing reduced the efficiency. Comparison has been made between $3 \times 1$-inch and $2 \frac{3}{8} \times \frac{7}{16}$-inch impellers in reduction runs. At the same agitator power the larger paddle has been more efficient. The power required for the $300-\mathrm{rpm}$ run on Figure $2 \mathrm{C}$ was comparable to that for the runs in Figure $2 \mathrm{~B}$.

(3) Influence of Salt Fluxes on the Reduction of Skull

Oxides with Cadmium-Magnesium

(M. D. Adams, R. D. Pierce, L. F. Dorsey, M. L. Jones, R. L. Kilboy)

The use of molten salt fluxes during the reduction of uranium oxides by cadmium-magnesium solution may prove desirable for two reasons. Such a flux aids materially by acting as a vehicle for the removal of magnesium oxide formed during the reduction. This finely divided

FIGURE 3

SKULL OXIDE REDUCTIONS IN THE PRESENCE OF MOLTEN SALT FLUXES

CHARGE: $8.8 \mathrm{~kg}$ OF CADMIUM,ITO 2 PER CENT IN MAGNESIUM

TEMP: $700 \mathrm{C}$

AGITATION: $3 \times 1$ - INCH IMPELLER AT 455 RPM IN 5-INCH 410 SS CRUCIBLE

SALT FLUX CONSTITUENTS, GRAMS

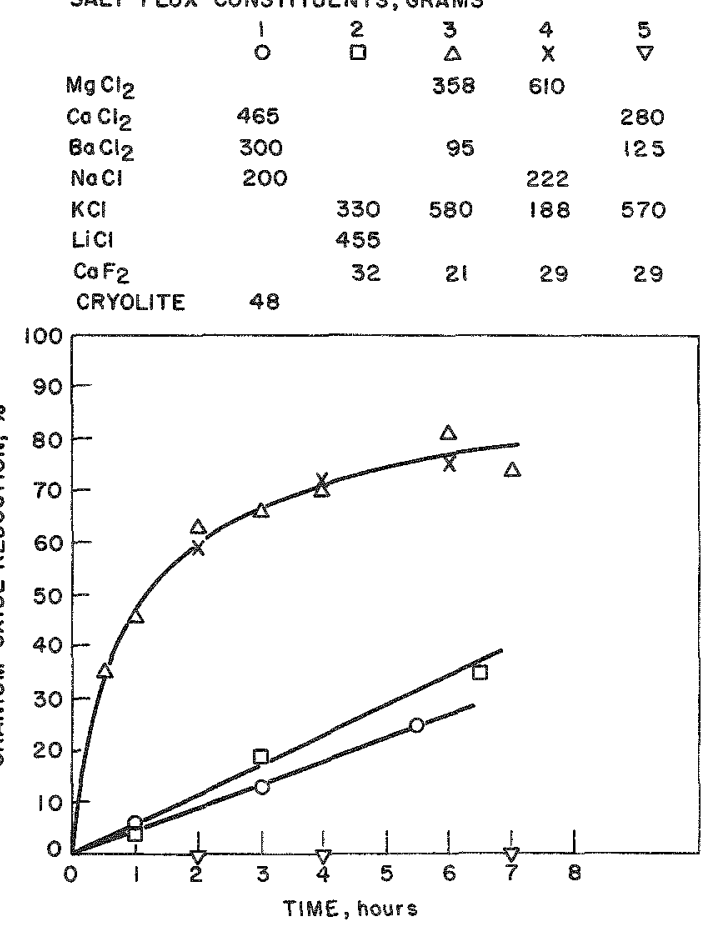
material, if not retained in one place, tends to disperse throughout the reduction equipment. There is a possibility that it also tends to inhibit the reduction reaction by forming a protective layer on particles of unreduced uranium oxide. A second potential advantage of a molten salt flux is that it would provide a liquid-liquid, rather than a solid-liquid, interface for the uranium oxide-liquid metal reaction, provided the uranium oxide were soluble in the flux to at least a small extent.

Several salt fluxes were used in conjunction with cadmium-2 per cent magnesium in oxide reduction runs. Figure 3 presents the results with five different fluxes at otherwise identical conditions. Oxide reduction was slow with fluxes 1 and 2 and was essentially nil with flux number 5 . However, the results with the two fluxes containing magnesium chloride (numbers 3 and 4 on Figure 3) were much better than have been achieved at these conditions without flux. 
All of the salt fluxes wetted the skull oxide. At the termination of the runs, any untreated oxide settled to the bottom of the salt phase but remained above the cadmium phase. Efficient wetting of the oxide by a salt coupled with a low uranium oxide solubility in the salt might inhibit reduction, as was the case with the number 5 flux.

Preliminary laboratory studies have been made on three types of molten salt systems in which uranium oxides are soluble. Mixtures of aluminum chloride and alkali metal chlorides melt in the range from 200 to $400 \mathrm{C}$ and form complexes which cause the aluminum chloride to remain relatively nonvolatile. The dissolution of $\mathrm{U}_{3} \mathrm{O}_{8}$ in molten sodium chloride potassium chloride-aluminum chloride appears to result in the for mation of uranyl chloride in solution and the precipitation of aluminum oxide. In one set of experiments with salts of this type, a maximum uranium solubility of 2.8 weight per cent (as uranium) was observed at $750 \mathrm{C}$ and an aluminum chloride concentration of 9.2 mole per cent. If an attempt is made to reduce this type of solution with cadmium-5 weight per cent magnesium, a black solid phase, probably uranium dioxide, appears in the interface. It is possible that this reaction could be avoided by converting the uranium first to uranium (IV) chloride in the salt solution. A qualitative experiment indicated that the uranyl ion can be converted to uranium (IV) by the addition of carbon to the molten salt. The aluminum chloride systems, however, still proved to be impractical because significant amounts of aluminum (e.g., 1.2 weight per cent in one experiment) are introduced into the cadmiummagnesium solution during the reduction.

Molten sodium borate dissolves uranium oxides, appare ently without reaction. However, the very high viscosity of the molten salt, even at temperatures as high as $900 \mathrm{C}$, rules out its use as a practical flux.

Uranium oxides can also be dissolved in sodium metaphos phate. The pure salt is rather viscous up to $900 \mathrm{C}$, but considerably less so than the borate. An equimolar mixture of sodium metaphosphate, sodium chloride and potassium chloride had a relatively low viscosity and a melting point of about $650 \mathrm{C}$. The solubility of $\mathrm{U}_{3} \mathrm{O}_{8}$ in the mixture was reasonably high - at least 1.5 per cent. Reduction of $\mathrm{U}_{3} \mathrm{O}_{8}$ from such mix tures is to be tried.

(4) Reductions with Other Flux-metal Combinations

(A. Schneider, J. D. Schilb, J.W.Walsh,

C. R. Williams)

Use of Oxide flux Pellets. One possible factor affecting the rate in a heterogeneous reaction involving solid oxide particles and a liquid metal solution is the efficiency with which the solid is dispersed in the liquid. In one experiment a special technique in which the uranium oxide was released gradually into the solution, in an effort to achieve more effective dispersion, was employed. Pellets were prepared by pressing a thoroughly blended mixture of $\mathrm{U}_{3} \mathrm{O}_{8}$ and anhydrous magnesium chloride ( $1: 2$ weight ratio). 
The pellets were then heated to $650 \mathrm{C}$ in an agitated cadmium-3 weight per cent magnesium solution blanketed with a potassium chloride-magnesium chloride flux having a melting point of $640 \mathrm{C}$. Since the temperature of the system was held below the melting point $(708 \mathrm{C}$ ) of the magnesium chloride binder in the pellets, the uranium oxide was dispersed gradually as the dissolution of the pellet binder in the fused salt mixture progressed. However, the reduction rates obtained by this method, based on uranium analyses of filtered samples, were only slightly higher than rates taken from Figure 3 (see Table 3 ).

Table 3

\section{REDUCTION OF URANIUM OXIDE ADDED IN THE FORM OF PRESSED PELLETS}

\begin{tabular}{|c|c|c|c|}
\hline \multirow[b]{2}{*}{$\begin{array}{c}\text { Reaction Time } \\
\text { (hours) }\end{array}$} & \multirow{2}{*}{$\begin{array}{c}\text { Uranium Content } \\
\text { of Liquid Metal } \\
\text { (w/o) }\end{array}$} & \multicolumn{2}{|c|}{ Reduction Yield (\%) } \\
\hline & & $\begin{array}{c}\text { Flux-dispersion } \\
\text { Technique }\end{array}$ & $\begin{array}{c}\text { Conventional } \\
\text { Agitation }\end{array}$ \\
\hline $1^{a}$ & 0.12 & 15 & 18 \\
\hline 2 & 0.35 & 44 & 31 \\
\hline 3 & 0.39 & 50 & 39 \\
\hline 4.5 & 0.45 & 57 & 46 \\
\hline
\end{tabular}

a Temperature below melting point during the first hour.

Reduction of $\mathrm{U}_{3} \mathrm{O}_{3}$ in Magnesium-Magnesium Chloride

Systems. This method consists of contacting uranium oxide with vigorously agitated molten magnesium in the presence of magnesium chloride. Since uranium is only sparsely soluble in liquid magnesium, it is not possible to follow the progress of the reaction from the uranium contents of periodically withdrawn samples of the liquid metal. Instead, the extent of oxide reduction may be determined by dissolving the resulting ingot in liquid cadmium.

In the first exploratory experiment, 7.4 grams of $\mathrm{U}_{3} \mathrm{O}_{8}$, 200 grams of magnesium and 10.4 grams of magnesium chloride were stirred for three hours at $920 \mathrm{C}$ in an argon atmosphere, using an alumina crucible with tantalum accessories. The resulting ingot was sectioned and surveyed with a $G-M$ counter, and the activity was found to be evenly dis tributed. Part of this ingot was then dissolved in 1100 grams of cadmium and filtered samples were withdrawn periodically. The uranium content increased rapidy and remained fairly constant after two hours at a concentration level corresponding to a reduction yield of about 80 per cent. Comparison with previous reduction runs in cadmium-3 weight per cent magnesium solution indicated that the uranium oxide had been reduced more rapidly in this experiment. 
In the second experiment, 156 grams of $\mathrm{U}_{3} \mathrm{O}_{8}, 202$ grams of magnesium and 201 grams of magnesium chloride were stirred for four hours at 870 to $898 \mathrm{C}$ in an argon atmosphere, using an alumina crucible and tantalum accessories. The resulting ingot was treated with 10 kilograms of cadmium. Mechanical and heating difficulties during the second part of the experiment made a complete material balance impossible. The uranium contents of filtered samples taken from the cadmium melt, however, showed that at least 75 per cent of the original uranium had been reduced during the experiment.

Further work on this approach may lead to a scheme for the dragout process. Considerable corrosion of the tantalum accessories was encountered in these runs. A separate experiment showed that tantalum is not suitable for use with molten magnesium chloride at temperatures above $800 \mathrm{C}$.

"Bomb"-type Reductions of Uranium Oxide. In this method, pulverized uranium oxide, magnesium and magnesium chloride are blended thoroughly and heated in an inert atmosphere to a temperature at which the reduction proceeds spontaneously with considerable energyrelease.

After an investigation of graphite, magnesia and alumina containers, resistance and induction heaters, and partially or fully enclosed "bombs," the assembly shown schematically in Figure 4 was found to perform satisfactorily.

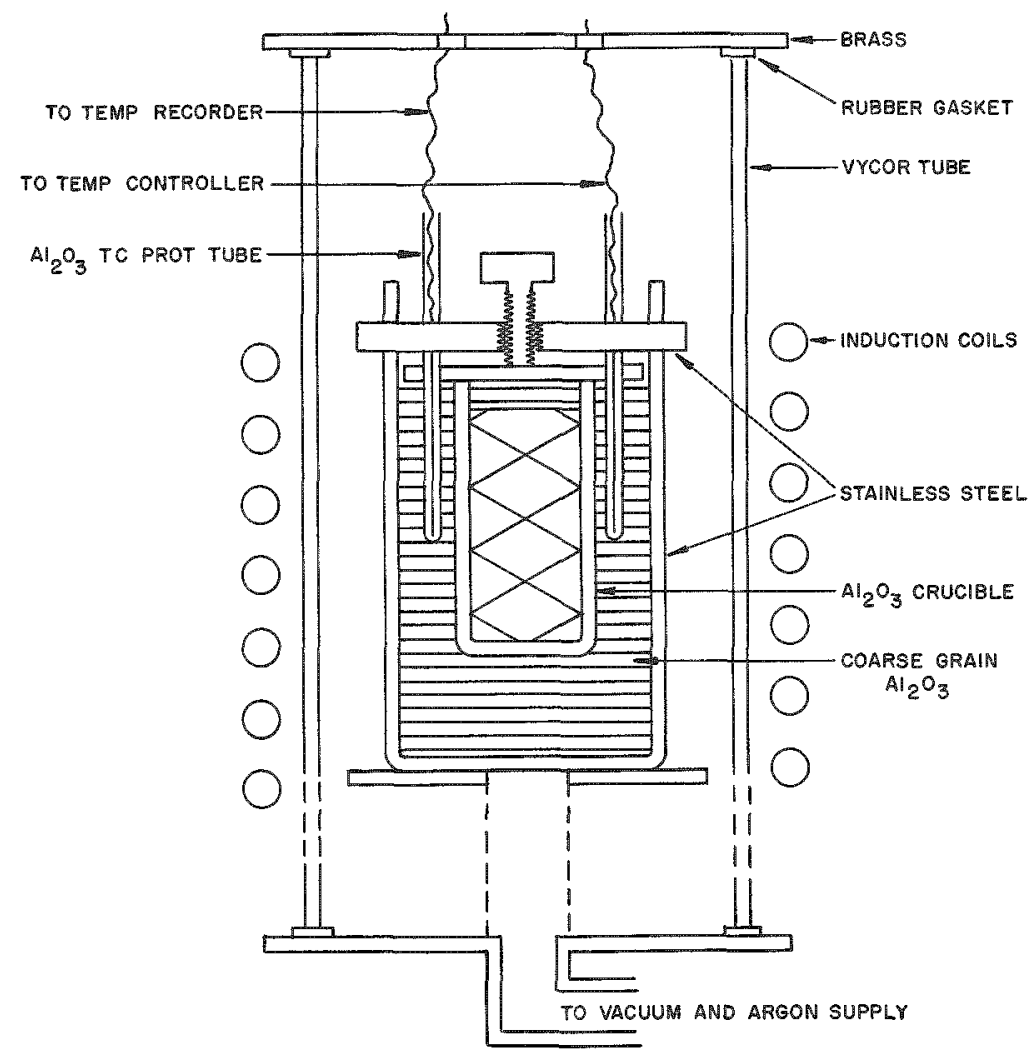

Figure 4 EQUIPMENT FOR THE REDUCTION OF URANIUM OXIDE 
Firing is indicated by a sudden temperature rise, and is about $780 \mathrm{C}$ for uranium dioxide and $550 \mathrm{C}$ for $\mathrm{U}_{3} \mathrm{O}_{8}$. The reaction product is a soft, nonpyrophoric cake which can be recovered easily from the alumina crucible. The uranium metal obtained from the reduction consisted of spherical particles, each about 8 microns in diameter. Two procedures were employed to determine the reduction yields: (1) dissolution of the reduction cake in cadmium and determination of the dissolved uranium content, and (2) chemical separation of the uranium and uranium oxides from all other compounds present in the reaction cake, followed by an analytical determination of the fraction of metallic uranium. Preliminary results indicated that at least 70 per cent of the uranium oxide charged had been reduced to metallic uranium.

e. Effects of Stainless Steel Constituents on Uranium Behavior
$\frac{\text { in Liquid Cadmium }}{\text { (M. D. Adams, R. D. Pierce, A. Schneider, L. F. Dorsey, }}$
M. L. Jones, J. W. Walsh)

(1) Effect of Nickel on the Solubility of Uranium in Liquid

As work has progressed on the development of processes involving liquid metal systems, it has become increasingly apparent that cer tain constituents of alloys and other materials of construction can have pro* found effects upon solubility relationships in the liquid metal media. Although a certain rate of corrosion may be tolerable from the standpoint of strength or expected life of equipment, it may not be satisfactory with regard to contamination of the liquid metal solutions. A particular example is the use of nickel-containing alloys, such as certain stainless steels, for handling solutions of uranium in liquid cadmium. It is well-known that nickel is readily soluble in liquid cadmium, so a few specific laboratory experiments were conducted to determine its effect upon dissolved uranium.

A cadmium solution containing 5.8 weight per cent nickel was added in small increments to a 2.1 weight per cent solution of uranium in cadmium. After each addition, the solution was stirred for several minutes and a filtered sample was taken for uranium analysis. When the overall atomic ratio of nickel to uranium in the system had reached a value of 1.0 , the concentration of uranium in the cadmium had dropped to 0.4 weight per cent. At higher nickel-to-uranium ratios, the uranium concentration appeared to level off at about 0.1 weight per cent. These results are shown in Figure 5 .

Addition of three moles of nickel per mole of uranium to a uranium solution in cadmium in a subsequent experiment reduced the ura. nium concentration to les than 0.001 weight per cent.

In another similar experiment, magnesium was dissolved in the original cadmium-uranium solution to the extent of about two per cent. The added magnesium had no effect upon the removal of uranium from the solution by the nickel. 
FIGURE 5

EFFECT OF NICKEL ON THE SOLUBILITY OF

URANIUM IN CADMIUM

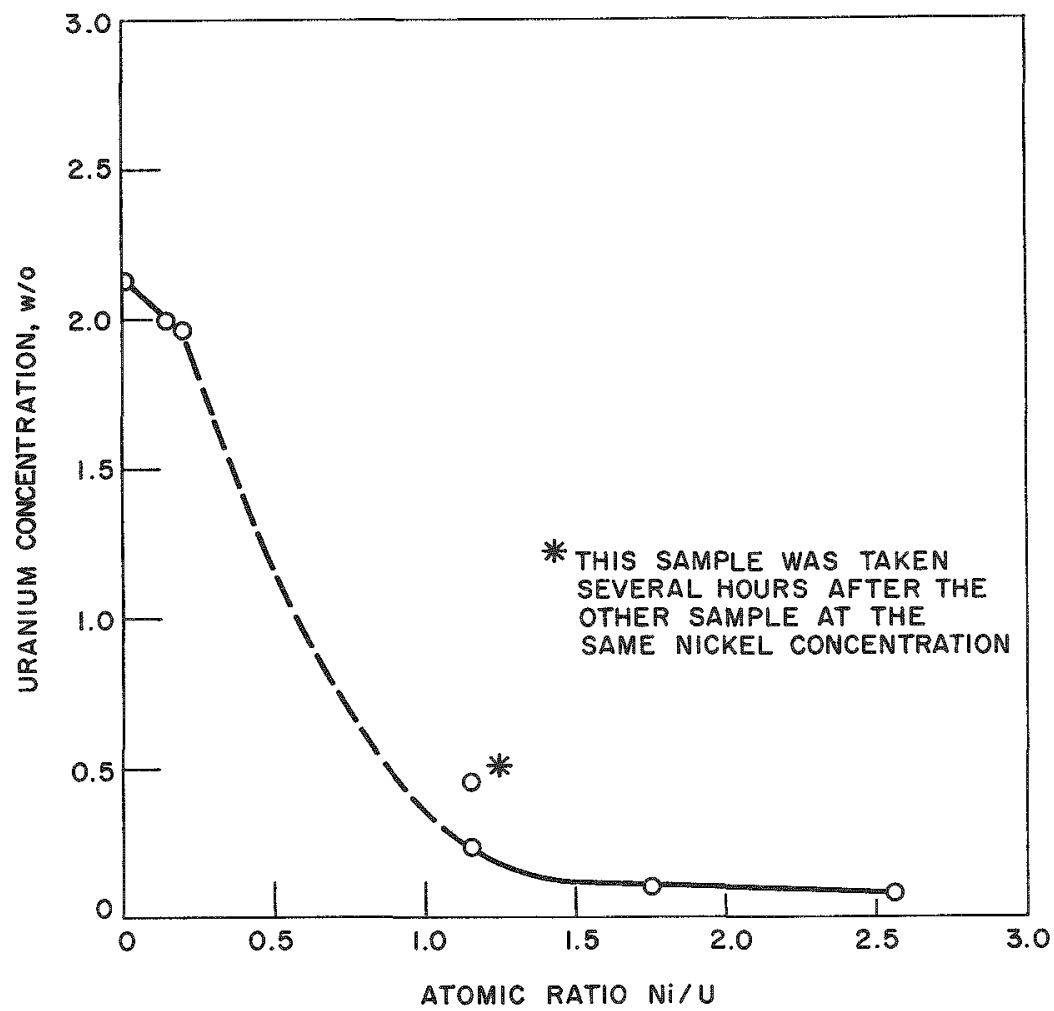

Dissolution of the cadmium in the solidified ingot by saturated ammonium nitrate solution resulted in the isolation of a uraniumnickel intermetallic compound. An X-ray diffraction powder pattern from the material was complex, suggesting that more than one compound might have been present It is suspected that at least part of the material was $\mathrm{U}_{2} \mathrm{Ni}_{7}$, a previously reported, but poorly characterized, compound. No oxide, uranium metal nor nickel metal was present. Microscopic examination indicated a metallic-appearing microcyrstalline structure which was very hard and was stable in air Chemical analyses for uranium and nickel gave values of 56 and 43 per cent, respectively, which correspond to a nickelto-uranium ratio of 312 , rather than of 35 from the formula $\mathrm{U}_{2} \mathrm{Ni}_{7}$. It was concluded that at least a part of the material was $U_{2} \mathrm{Ni}_{7}$ and that further work would be needed to identify the system satisfactorily

In view of the above-described effect of nickel in precipitating uranium from cadmium solution, it became of interest to determine the rate of leaching of nickel from 304 stainless steel equipment. Accordingly, two relatively large-scale holding runs, in which about $8 \mathrm{~kg}$ of cadmium-2 weight per cent magnesium solution were stirred in new and used 5-inch diameter, baffled steel vessels, were made at $650 \mathrm{C}$. The 
results, shown in Table 4, show a relatively low rate of nickel pickup from a new crucible (about 20 ppm in 6 hours with a possible error in analysis amounting to a factor of two) and a somewhat lower rate from a used crucible.

Table 4

LEACHING OF NICKEL FROM 304 STAINLESS STEEL BY CADMIUM SOLUTIONS

Solution: $\quad 8 \mathrm{~kg}$ of cadmium $=2$ per cent magnesiuma

Temperature: $650 \mathrm{C}$

Crucible: $\quad$ Baffled 5-inch ID, 304 SS Crucible

Stirring Speed: $300 \mathrm{rpm}$ with $3 \times 1$-inch paddle

Time $(\mathrm{hr})$

1

3

7
Nickel Concentration (ppm) b

\begin{tabular}{cc}
\hline New Crucible & Used Crucible \\
5 & $<5$ \\
20 & $<5$ \\
20 & $\sim 10$
\end{tabular}

a Initial magnesium and cadmium contained less than 5 ppm of nickel.

${ }^{b}$ By spectrographic analysis, having a factor of 2 accuracy.

In order to investigate further the possible incompatibility of uranium =cadmium solutions with nickel-bearing stainless steel, changes in uranium concentration were measured in uranium-cadmium solutions held in stainless steel equipment. In one experiment uranium was dis solved in cadmium and held at $650 \mathrm{C}$ for $13 \frac{1}{2}$ hours in a 5 -inch 304 stainless steel vessel. A plot of concentration versus time in Figure 6 shows a final uranium concentration of about 0.96 per cent as compared to a theoretical concentration of 1.06 per cent. The total loss from the theoretical 1.06 per cent is only about ten per cent; accordingly this vessel has been used for a number of short reduction runs. This low loss is still surprisingly high in view of the rates of leaching of nickel reported in the previous section, which are also qualitatively confirmed by corrosion data. The possibility of interaction between dissolved uranium and a steel constituent, probably iron, at the vessel wall is also under consideration.

After the $13 \frac{1}{2}$ hour holding run above, the equivalent of 0.1 per cent nickel was added to the solution. The uranium concentration dropped abruptly to about 0.75 per cent and the nickel concentration to 0.033 per cent, confirming the precipitating effect of nickel. 
FIGURE 6

STABILITY OF URANIUM-CADMIUM SOLUTIONS IN 304 STAINLESS STEEL

CHARGE: $10 \mathrm{~kg}$ OF $2 \mathrm{w} / \mathrm{Mg}$ - CADMIUM ALLOY

TEMP: $650 \mathrm{C}$

AGITATION: $3-X 1-$ INCH IMPELLER AT 500 RPM IN 5MINCH, BAFFLED 304 SS CRUCIBLE

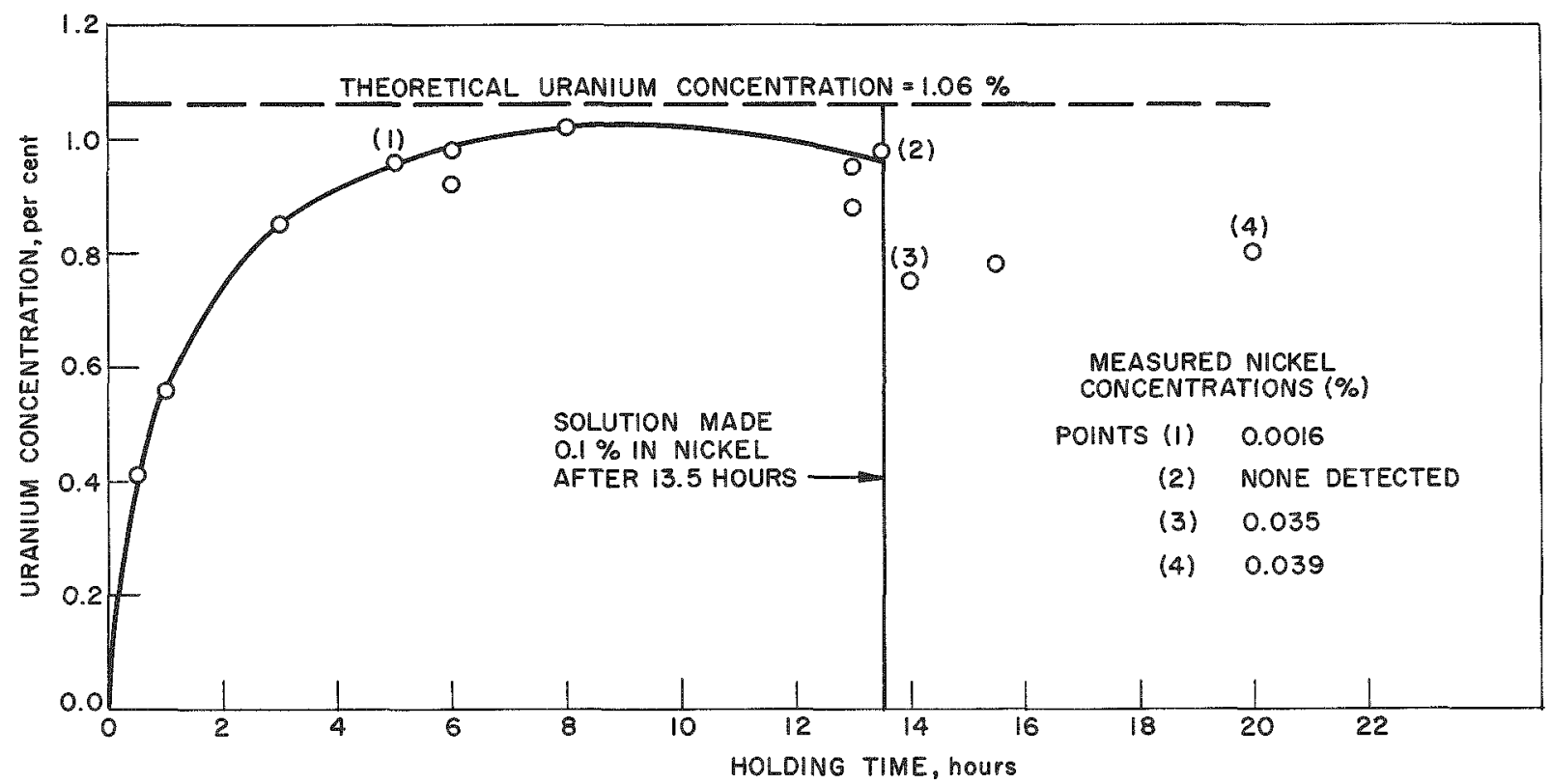

The effect of stainless steel was even more pronounced in a smaller crucible ( -2 inches ID) in which the surface-to-volume ratio was larger than in the experiments described above. In one experiment at $660 \mathrm{C}$, the uranium concentration dropped from 0.5 to $0.42,0.15$, and 0.01 per cent after 2,8 and 31 hours, respectively. That uranium was present in an insoluble form was confirmed by an unfiltered 31-hour sample which was found to contain 0.29 per cent uranium. In a parallel experiment in highpurity aluminum oxide using tantalum accessories, no significant change in uranium concentration occurred in a 30-hour holding experiment.

Although the rate of nickel pickup can account for very little uranium precipitation, it is, nevertheless, considered unwise to have potentially damaging elements present in experimental equipment. Therefore, the use of $300-$ series stainless steel equipment for containing uranium solutions of cadmium has been discontinued.

2. Development of Processes for Recovery of Plutonium from EBR-II Blanket Material

(I. O. Winsch, T.F.Cannon)

Work has continued on the development of pyrometallurgical process for isolation from EBR-II blanket material of plutonium with 
sufficient purity for reconstitution of core material. Fission product removal is not particularly important because of the small amount of fission in blanket material relative to core material.

As pointed out in previous quarterlies, separation of uranium and plutonium may be achieved through their large difference in solubilities in magnesium-rich solutions, plutonium being fairly soluble, uranium only slightly soluble. In a cadmium-based process, such a condition may be produced after dissolution of blanket material in cadmium by addition of magnesium, or by distillation of the cadmium in the presence of magnesium. The latter procedure has been emphasized because of the smaller solution volumes involved. After separation of the phases, plutonium would be recovered by distilling off the magnesium and residual cadmium.

At the present time, preparatory work is in progress for demonstration of this process with 50 to 100 grams of plutonium. The magnesium= distillation unit has been placed in a hood and is essentially ready for operation with plutonium. A number of runs have been made in the cadmiumdistillation unit described in the previous quarterly (ANL-6068, page 58) to check its performance, to demonstrate metal solution transfer operations, and to study entrainment with cerium as a stand-in for plutonium.

Cadmium may be distilled smoothly and reasonably rapidly in the present equipment. Two runs involving about $14 \mathrm{~kg}$ of cadmium, in which the cadmium distillation rates were $9 \mathrm{~kg}$ per hour for both. were conducted at $660 \mathrm{C}$ and a pressure of $200 \mathrm{~mm}$ of mercury. The cadmium vapors were condensed to solid on the condenser wall. The solid distillate was subse quently melted down and transferred by means of pressure to a receiver.

Distillations of cadmium-magnesium-cerium alloys have shown appreciable entrainment of cerium from an open distillation vessel (see Runs 1 and 2, Table 5).

\section{Table 5}

\section{CERIUM ENTRAINMENT DURING CADMIUM- MAGNESIUM DISTILLATIONS}

\begin{tabular}{|c|c|c|c|c|}
\hline \multicolumn{2}{|c|}{ Charge: } & \multicolumn{3}{|c|}{$\begin{array}{l}6 \text { to } 8 \mathrm{~kg} \text { of cadmium alloy containing } \\
1 \text { per cent cerium and } 6 \text { to } 20 \text { per cent } \\
\text { magnesium }\end{array}$} \\
\hline \multicolumn{2}{|c|}{ Conditions: } & \multicolumn{2}{|c|}{ Distillation at $700 \mathrm{C}$} & \\
\hline Run No. & Distil & $\begin{array}{l}\text { lation Rate } \\
\mathrm{kg} / \mathrm{hr} r)\end{array}$ & $\begin{array}{l}\text { Baffles } \\
\text { Present }\end{array}$ & $\begin{array}{c}\% \text { of Cerium Charged } \\
\text { in Distillate }\end{array}$ \\
\hline 1 & & 2.75 & No & 5.3 \\
\hline 2 & & 2.65 & No & 37.5 \\
\hline 3 & & 7.20 & Yes & 1.5 \\
\hline 4 & & 6.43 & Yes & 0.033 \\
\hline
\end{tabular}


By use of baffles in the vapor space, entrainment was reduced considerably (Runs 3 and 4 ). Since the cadmium would be recycled, entrainment would not represent plutonium loss, but low entrainment is nevertheless preferred. At the distillation rates employed, the baffles had no adverse effect on the oper = ation: in fact, the baffles were beneficial in reducing pressure fluctuations.

Some further equipment modifications and additional check runs are required before work with plutonium can commence, probably near the end of the next quarter.

3. Engineering Development for Liquid Metal Solvents (L. Burris, Jro)

Development of engineering techniques and equipment for liquid metal solvent processes are in progress on distillation and retorting, solidliquid phase separations, and materials handling.

$$
\text { a. } \frac{\text { Distillation }}{(P \cdot A \cdot \text { Nelson, J.F. Lenc, R. Zeman })}
$$

Distillation of metals such as zinc, cadmium, and magnesium is an important operation in liquid metal processes under consideration. Distillation is employed for solution concentration, for reclaiming metal sol vents for recycle, and for recovering the final product metals: uranium and plutonium. Because of the importance of distillation, a full-scale distillation station is being constructed to demonstrate metal distillation at plant-scale rates of 50 to $100 \mathrm{~kg}$ of cadmium per hour. Other associated operations of uranium retorting, metal transfer, liquid-level detection and freeze-valve operation will be demonstrated also. The main components of the distillation station are a 100-liter feed tank, a 7-liter continuously fed, inductively heated distillation unit, a 100 aliter condensate receiver, and a 25-liter vessel for receiving molten metal transferred from the distillation unit. The metal vapor will be condensed in a finned-tube, forced-air cooled condenser.

Most of the larger items have been ordered or received, including the following items: the vessels and condenser described above, a $100 \mathrm{kw}, 960-\mathrm{cycle} / \mathrm{sec}$ motor-generator for induction heating of the distilla. tion unit, a $40 \mathrm{kw}$ furnace for maintaining the vessels and transfer lines at $500 \mathrm{C}$, and the instruments required to control the pressures and temperatures of the vessels and condenser.

\section{b. Retorting of Uranium Concentrates \\ (J. Lenc, P.A. Nelson, R. Zeman, M. Bowden)}

In a liquid metals process, recovery of the uranium is achieved by retorting isolated uranium concentrates to remove residual cadmium, magnesium, or zinc solvent metals. The final uranium product 
must be in a form suitable for remote removal and handling. Consequently, several experiments to find suitable retorting crucible materials for this purpose have been performed.

In an attempt to produce an easily removable powder or compact using conventional steel materials, two low-temperature retorting runs were conducted in 304 stainless steel crucibles. Temperatures were maintained below $600 \mathrm{C}$ to final absolute pressures of $20 \mathrm{microns}$. In both cases the uranium product (about 100 grams) was highly pyrophoric and was not readily removable from the crucible. Iron concentrations ranged from 0.19 to 1.90 per cent, indicating that some alloying had occurred. Steel crucibles would therefore prabably be unsatisfactory.

Subsequent retorting experiments were therefore performed in ceramic and flame-sprayed ceramic-coated graphite crucibles. In order to increase the uranium concentration of the charge used in these runs, hy drided and dehydrided uranium was reacted with molten cadmium at $460 \mathrm{C}$ to form the intermetallic compound $\mathrm{UCd}_{11}$.

An alloy charge weighing about 5000 grams and having a nominal composition of cadmium-2 per cent magnesium-10 per cent uranium was prepared in this manner in a boron nitride crucible. After preparation, the cadmium and magnesium were retorted from the uranium. The initial retorting temperature was $650 \mathrm{C}$ at 160 millimeters absolute pressure and the final temperature was $850 \mathrm{C}$ at 30 microns absolute pressure. A com pacted uranium product weighing about 350 grams resulted. It was easily removed from the boron nitride crucible. Analysis of the product is shown in Table 6. Coalescence of an 80 -gram sample of this uranium product was better than 99 per cent complete by means of arc melting, and about 95 per cent complete on a separate 65-gram sample induction heated to $1400 \mathrm{C}$.

Table 6

ANALYSES OF URANIUM PRODUCT RETORTED IN A BORON NITRIDE CRUCIBLE

\begin{tabular}{|c|c|c|}
\hline Constituent & Concentration $(\%)$ & Analytical Procedure \\
\hline Magnesium & 0.1 & Spectrographic \\
\hline Boron & 0.007 & Spectrographic \\
\hline Iron & 0.08 & Spectrographic \\
\hline Oxygen & 0.14 & Gasometric \\
\hline Nitrogen & 0.1 & Kjeldahl \\
\hline
\end{tabular}

Figure 7 shows the $\mathrm{UCd}_{11}$ ingot charge, the uranium product after retorting, and a coalesced arc-melted button of the uranium product 
from anothex experiment in which a graphite crucible, flame sprayed with aluminum oxide, was employed. Arc melting was employed only to demonstrate that the compact was metallic.

FIGURE 7

SEQUENCE VIEWS OF URANIUM RETORTING EXPERIMENT

IN $\mathrm{Al}_{2} \mathrm{O}_{3}$-COATED GRAPHITE CRUCIBLE

UCd INGOT CHARGE

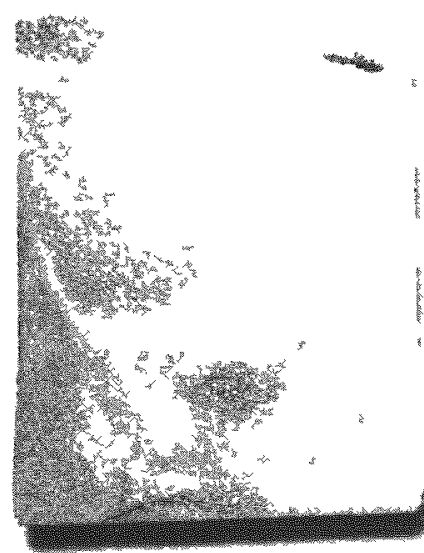

URANUUM PRODUCT AFTER RETORTING

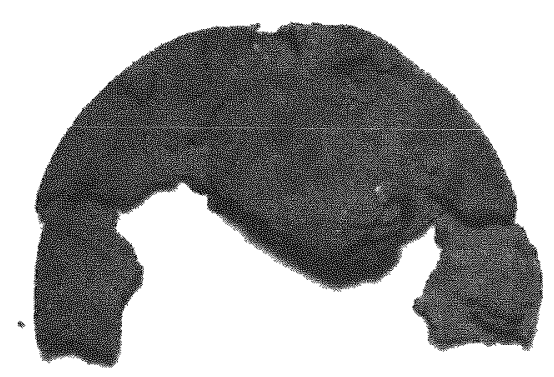

ARC MELTED URANIUM PRODUCT
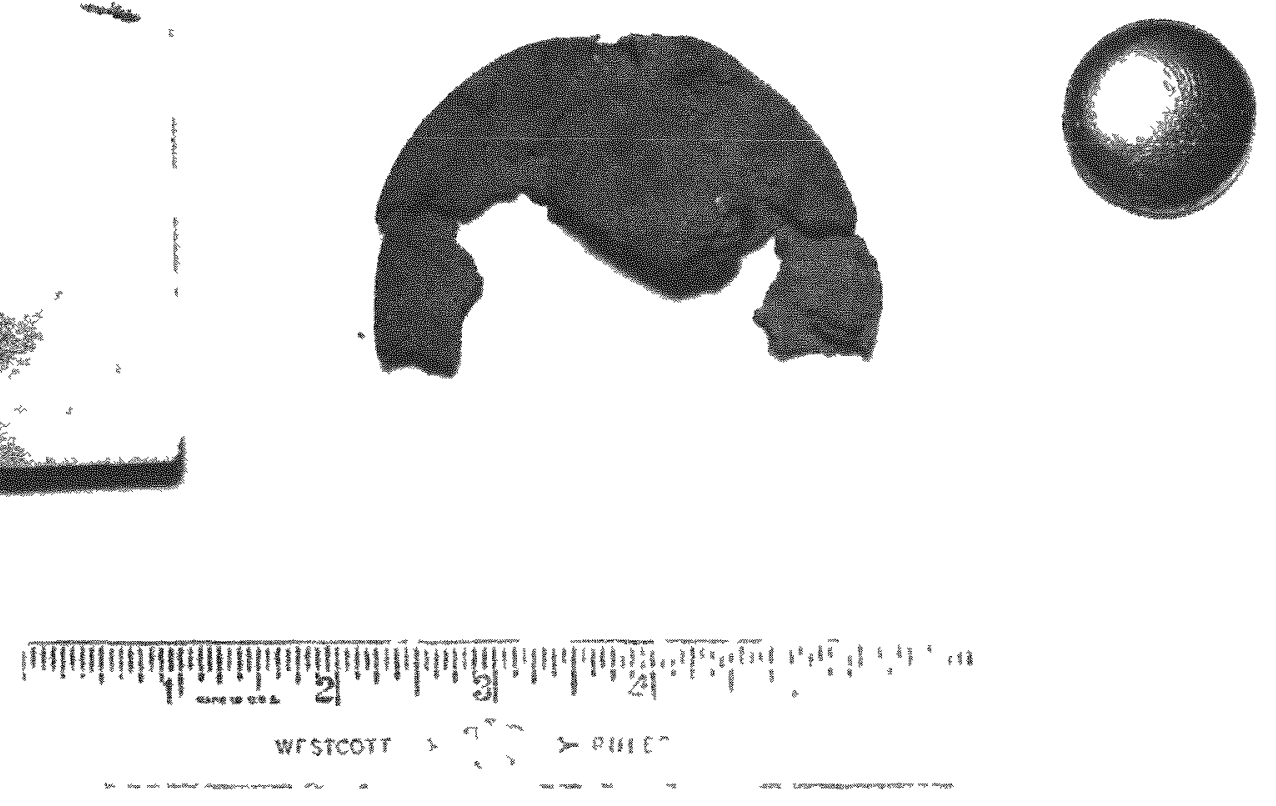

Preparation of the charge for this latter run was done in a recrystallized aluminum oxide crucible by reacting hydrided and dehydrided uranium with molten cadmum to form $\mathrm{UCd}_{11}$. After cropping off the major portion of the cadmium-magnesium phase from the resulting ingot, about 2700 grams of the $\mathrm{UCd}_{11}-$ rich portion of the ingot was charged into the aluminum oxide-coated graphite crucible for retorting. The thickness of the aluminum oxide coating was approximately $20 \mathrm{mils}$. Retorting of the cadmium and magnesium began at $650 \mathrm{C}$ and 138 millumeters absolute pressure. Completion of the retorting occurred at $850 \mathrm{C}$ and $35 \mathrm{microns}$ absolute pressure. The resulting uranium product welghing about 350 grams was easily removed from the crucible. A 100 -gram sample of this material was arc melted into a button (see Figure 7) with less than a 0.5 per cent weight loss. Future experimentation will ascertain whether the graphite crucible can be successfully reused without requiring a new aluminum oxide coating. 
Other ceramic coatings under consideration are of zirconium oxide, magnesium oxide, magnesium zirconate, beryllium oxide, cerium oxide, or thorium oxide. These coatings are to be evaluated on base materials such as graphite, mild steel, series 400 stainless steel, and tantalum.

\section{c. Phase-separation Studies \\ (J.C.Hesson, K. Tobias)}

As discussed in the previous quarterly report (ANL-6068, page 60), the separation of insoluble oxides, such as magnesium and uranium oxides, from metal suspensions by filtration promises to be difficult. An alternative procedure, which was investigated in the past quarter, is to sus. pend the oxide in a molten salt flux to enable a separation from the metal phase.

A qualitative study was made of the effects of adding mag nesium oxide and uranium oxide to a molten Dow 230 flux at 550 to $650 \mathrm{C}$. Magnesium oxide was readily wet by the flux, and did not settle out when stirring was stopped. The mixture thickened as more and more oxide was added, being fairly fluid and transferrable up to 25 per cent oxide, but approaching the consistency of wet plaster at 33 per cent oxide. The magnesi= um oxide could not be successfully filtered through porous graphite filters, either plugging fine (\#40 $\mathrm{C}$ and $\# 60 \mathrm{C}$ ) filters or passing through coarse (\#20 C) filters.

Uranium oxide added at 600 and $675 \mathrm{C}$ was also wet but did not remain suspended when stirring was stopped, settling out rather rapidly. The mixtures resembled slurries and could be easily stirred at up to 43 per cent oxide, the highest concentration investigated. In contrast to the behavior of magnesium oxide, uranium oxide could be filtered quite readily through porous graphite filter frits fitted into $4 \mathrm{mmm}$ ID glass tubes. Analyses of uranium in the filtered material shown below indicated incomplete filtra tion by grade $20 \mathrm{C}$ frits, but essentially complete filtration by $\# 40$ and $\# 60$ frits:

Filter Type

$$
\begin{aligned}
& \text { No Filter } \\
& \text { \#20 Graphite (140-micron pores) } \\
& \text { \#40 Graphite (69-micron pores) } \\
& \text { \#60 Graphite (33-micron pores) }
\end{aligned}
$$

$$
\begin{aligned}
& \text { Uranium Concentration (\%) } \\
& 11.59,10.5,12.23,12.19 \\
& 1.86 \\
& 0.228,0.265 \\
& 0.213,0.267
\end{aligned}
$$

Since the analyses of material filtered through the 40 and 60 grade frits are in good agreement, these may be solubility values of the oxide in the flux.

In the presence of either liquid zinc or liquid cadmium at 600 and $800 \mathrm{C}$, the uranium oxide was distributed predominantly into the flux 
phase, about 95 per cent in the case of cadmium and 90 per cent in the case of zinc. On cessation of stirring, the oxide settled in the flux phase to the flux-metal interface. Oxide reductions in the presence of a molten flux would, accordingly, require good mixing of the two immiscible phases.

d. Development of Equipment for Molten Cadmium Service (J.C.Hesson, K.R. Tobias)

Various equipment components are being tested and developed for incorporation into liquid metal equipment systems. These include freeze valves, pipe joints, autoresistively-heated transfer piping, check valves, and liquid-level indication devices.

Several of these were tested during the past quarter in a line connecting two crucibles located in bottom-loaded pressure vessels in a resistance furnace. The crucibles could be raised and lowered to permit transferring molten cadmium or salt fluxes back and forth.

Freeze Valve. The freeze valve shown schematically in Figure 8 was tested with liquid cadmium and liquid salt flux. Two features of this valve are the symmetry with respect to flow direction and the design of the dividing wall for the trap. The design is such that any leakage through welds would be to the outside rather than through the frozen valve. This latter feature makes testing for weld leaks relatively simple.

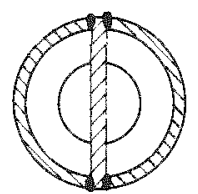

SECTION B.B

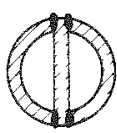

SECTION A-A
FIGURE 8

FREEZE VALVE

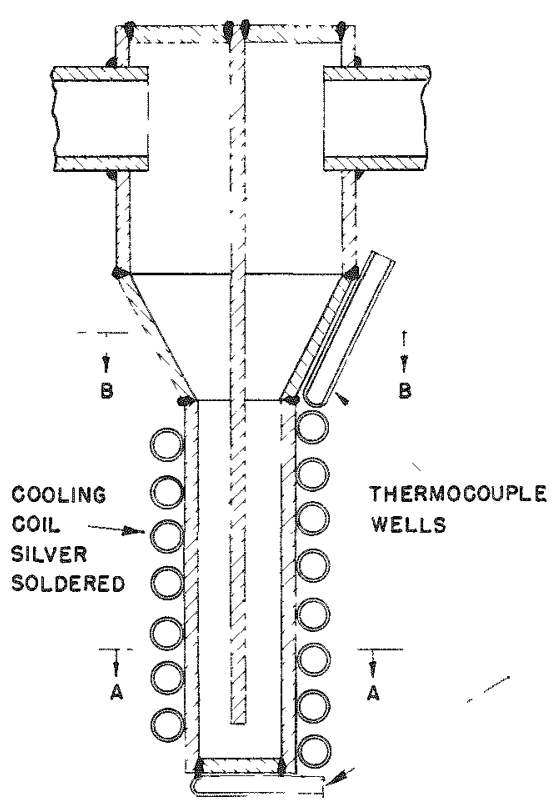


The freeze valve was tested with liquid cadmium at about 450,500 , and $650 \mathrm{C}$, and with Dow-230 flux at about $550 \mathrm{C}$. When wet with cadmium and when flux was used, the valve was vacuum tight when frozen. In normal transfers where only sufficient argon pressure was used to make the transfer, the valve retained enough cadmium or flux after the argon bubbled through at the end of the transfer to provide a freeze seal. The freeze valve was insulated by Fiberfrax and was cooled by compressed air. It could be frozen in about two minutes, while about five minutes were required to thaw or open the valve. The valve could be kept frozen by using about $1 \mathrm{cfm}$ of air.

Pipe Union. The two-bolt pipe flange union shown schematically in Figure 9 was tested with liquid cadmium at about $450 \mathrm{C}$. No leakage of cadmium or argon occurred. The union lends itself to remote

FIGURE 9

TWO-BOLT PIPE FLANGE UNION
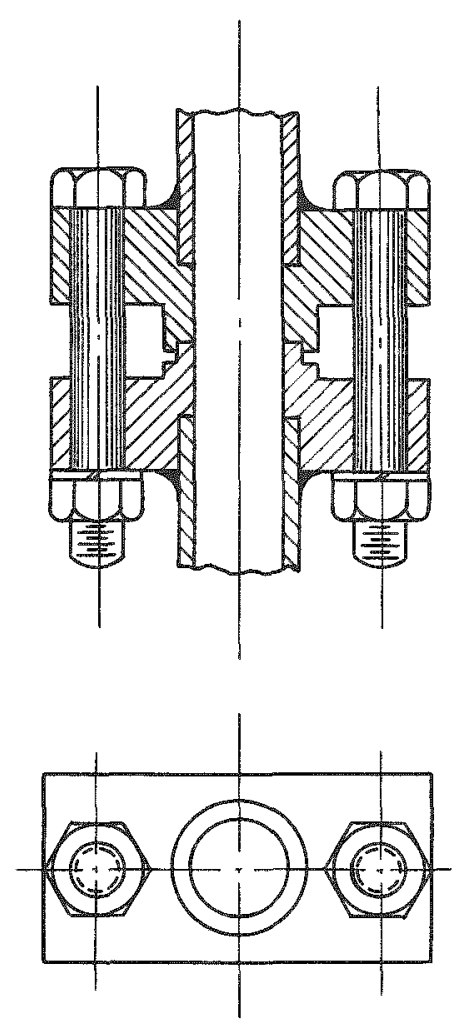
assembly because only two points of force application are required and assembly can be made without a gasket. The union was removed from the furnace and assembled and disassembled several times. When assembled and the piping evacuated, a slight amount of air leakage was noticed, as made evident by a slight pressure increase after several hours. This leakage could be tolerated in most operations, perhaps all except highvacuum distillation. The faces of the union were not honed or polished. The addition of a slight amount of hightemperature lubricant for stainless steel (Silver Goop) to the faces of the union rendered it tight. It was held eight days at full vacuum without noticeable increase in pressure.

Marman Conoseal Pipe Joint. The Marman Conoseal Pipe Joint shown schematically in Figure 10 was tested with liquid cadmium, once with a mild steel gasket at about $600 \mathrm{C}$, and twice

with stainless steel gaskets at about $650 \mathrm{C}$. In these tests the joint was vacuum tight before and after the tests. The tests revealed two disadvantages of this joint. The molten cadmium can fill the spaces between the disc washer and the female flange, and between the inner ends of the flanges. When the joint is cold and the cadmium is frozen, it is difficult to disassemble and reassemble the joint, depending upon the extent to which the cadmium has wet the surfaces. Remote operation would be quite difficult. 
Also, the outer coupling must be lubricated where it slides on the flanges to prevent sticking when it is reused. This disadvantage is not serious.

FIGURE 10

MARMAN CONOSEAL PIPE JOINT

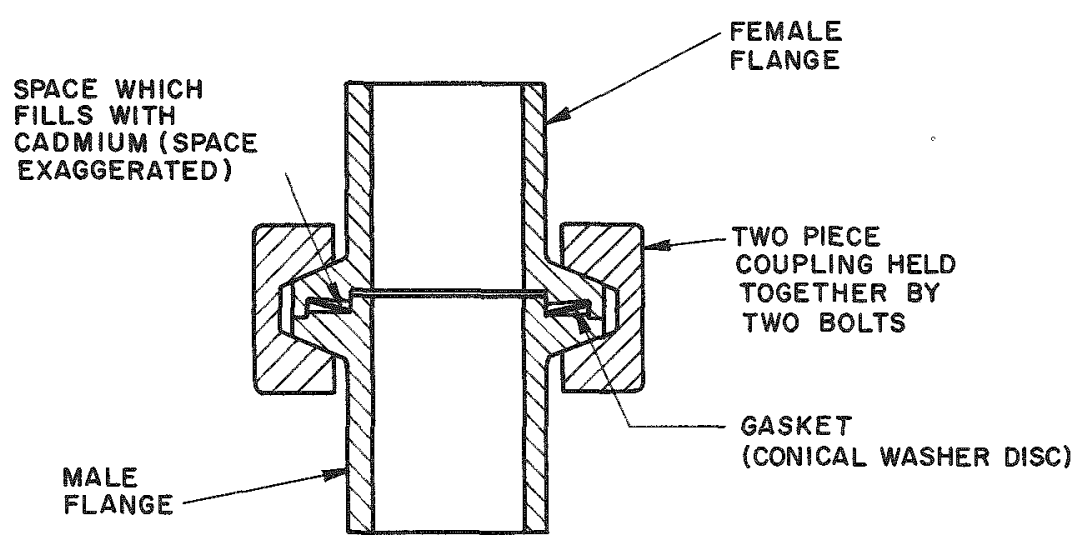

This principle of a cone gasket sealing at its inner and outer edges might be used as a back-up seal for a union similar to that shown in Figure 9. In this case the inner face seal would prevent liquid cadmium from flowing into the disc space.

\section{Autoresistive Heating of Liquid Metal Transfer Lines} (I. O. Winsch, T.F.Cannon)

In processing EBR-II blanket material with cadmium and magnesium, a magnesium-cadmium-plutonium phase rich in magnesium and a solid uranium phase would remain in the still pot after distillation of the bulk of the cadmium. To enable a separation of the magnesium phase from the uranium phase, it has been planned for experimental purposes to introduce a heated down line with a filter into the still pot and transfer the magnesium-plutonium phase by pressure into another vessel.

After some experimentation, the design shown in Figure 11 was evolved, and a model successfully demonstrated the transference of cadmium at $550 \mathrm{C}$. The mild steel line is heated autoresistively. Excessive heat losses in the condenser area are prevented by installation in a well in which the annulus is packed with thermal insulation (Fiberfrax) which also acts as electrical insulation. This also eliminates the need for electrical insulation at the wall. 
FIGURE II

AUTORESISTIVELY HEATED TRANSFER LINES

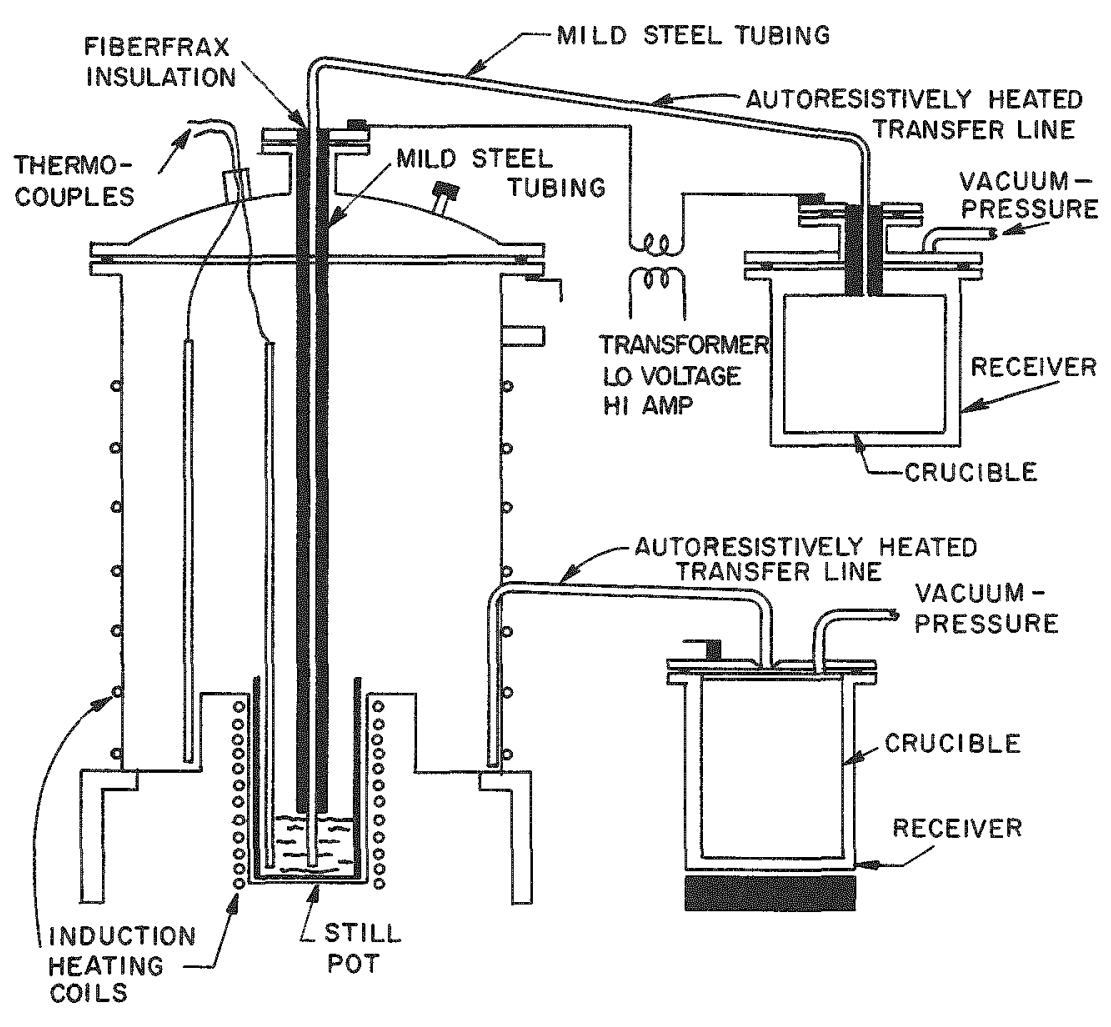

e. Power Requirements for Mechanical Mixing of Liquid Metals (R. D. Pierce, L.F. Dorsey)

The power required to agitate mercury with flat-blade impellers was measured calorimetrically in a 5-inch diameter, flat-bottom vessel which had four $\frac{1}{2}$-inch baffles and contained 15.8 kilograms of mercury. The liquid level was 4.0 inches, and the agitators were located 0.25 inch, off the vessel bottom. Six impeller sizes were tested. As expected, the power input varied approximately with the cube of the agitator speed, as shown in Figure 12.

\section{f. Liquid Metal Corrosion Studies \\ (J.De Kany, J.C.Hesson, H. Lavendel, J. Pavlik)}

\section{(1) Dynamic Tests}

Two medium carbon steel thermal convection loops were built and operated in the past quarter to ascertain the extent of corrosion under adverse thermal conditions. The design of the loops (see Figure 13) is similar to the type operated by Brookhaven National Laboratory. A high-temperature protective paint was applied to the exterior surfaces of the steel to prevent air oxidation. 

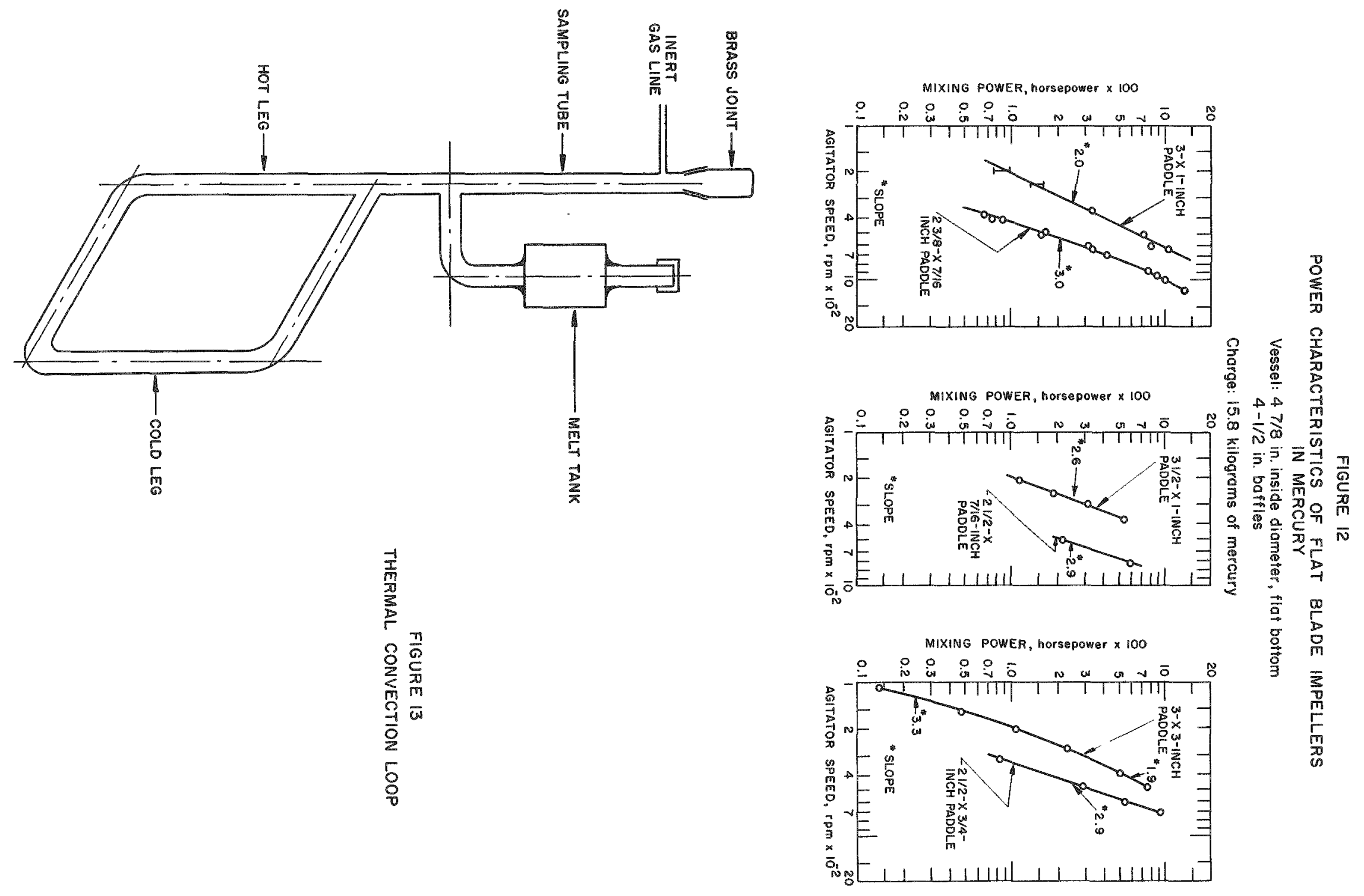

产 
The conditions of operation may be summarized as

follows:

\begin{tabular}{llll}
\multicolumn{1}{c}{ Condition } & \multicolumn{1}{c}{ loop 1} & & loop 2 \\
nominal composition: & $\begin{array}{l}30 \text { weight per cent } \\
\text { magnesium-cadmium }\end{array}$ & $\begin{array}{l}15 \text { weight per cent } \\
\text { magnesium-cadmium }\end{array}$ \\
temperature range: & 575 to $675 \mathrm{C}$ & & 630 to $725 \mathrm{C}$ \\
estimated flow rate: & 0.02 to $0.04 \mathrm{ft} / \mathrm{sec}$ & & 0.02 to $0.04 \mathrm{ft} / \mathrm{sec}$ \\
duration of test: & 144 hours & & $1004 \mathrm{hours}$.
\end{tabular}

It was intended that both loop tests operate for

1000 hours, but a Vycor sampling tube broke and remained in loop 1, neces sitating shut down after 144 hours.

Both loops were sectioned and the sections examined with an optical microscope. It was readily apparent that mass transfer of iron had occurred in both of the loops. The cold leg of loop 1 had a deposition layer of iron averaging about $2.5 \mathrm{mils}$ in thickness. The surface of the hot region was pitted and void of grain structure, indicating attack by solid solution of iron. The total weight transfer of iron to the cold leg was estio mated at $0.9 \mathrm{gram}$. This represents a maximum iron concentration difference between the cold and hot legs of $2.7 \mathrm{ppm}$.

The deposition layer of iron in the cold leg of loop 2 had an average thickness of 6 mils. The total weight of iron transferred was calculated to be approximately 6.4 grams. The concentration difference between the hot and cold legs amounted to $2.8 \mathrm{ppm}$.

Because solubility data for iron in magnesium-cadmium alloys are not available, the efficiency of iron mass transfer could not be determined. However, qualitative calculations and the considerations of the solubility of iron in pure magnesium and cadmium at the test temperatures seem to indicate efficiences of mass transfer of less than 10 per cent. Thus, even relatively large thermal gradients could be tolerated in processing equipment without excessive corrosion.

Figure 14 illustrates the natures of the iron deposition layer and the corrosion areas in the thermal convection loops.

A second forced-circulation (electromagnetically pumped) corrosion loop was placed in operation at $550 \mathrm{C}$ during the past quarter and has now been in trouble-free operation for about 1000 hours. The details of construction, design, and operation are identical to those practiced on the previous loops (ANL-6029, pages 43 to 46 ). The cadmium alloy being circulated has the following nominal composition, representative of one of the streams in a dragout flowsheet: 
FIGURE 14

PHOTOMICROGRAPHS OF THERMAL CONVECTION LOOP NO. 2 A. COLD LEG

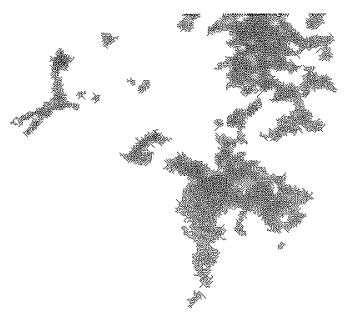

Carbon

Steel

$15 \mathrm{w} / \mathrm{o} \mathrm{Mg}-\mathrm{Cd}$

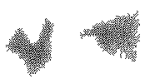

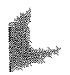

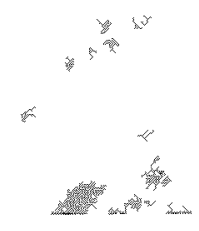

Magnification: $100 \mathrm{X}$

Etchant: $2 \%$ Nital

Photomicrograph 25 Showing Deposition of Iron Upon Cold Leg of Thermal Convection Loop
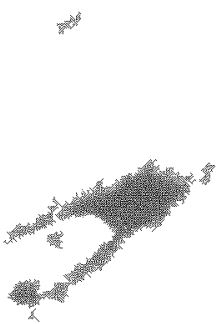

$15 \mathrm{w} / 0 \mathrm{Mg}-\mathrm{Cd}$
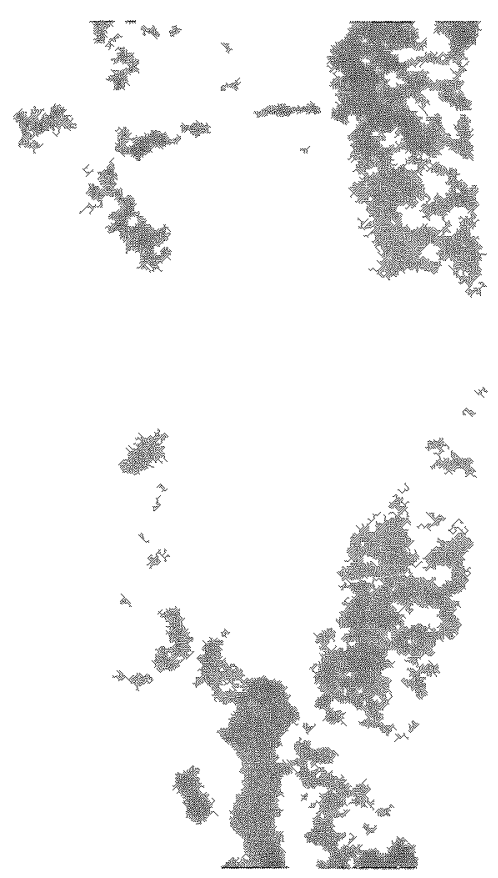

Magnification: $250 \mathrm{X}$

Photomicrograph 26
Etchant: $2 \% \mathrm{~N} 1 \mathrm{tal}$

Showing Deposition Layer of Iron in Cold Leg of Thermal Convection Loop
Carbon Steel. 
FIGURE 14

PHOTOMICROGRAPHS OF THERMAL CONVECTION LOOP NO. 2

B. HOT LEG

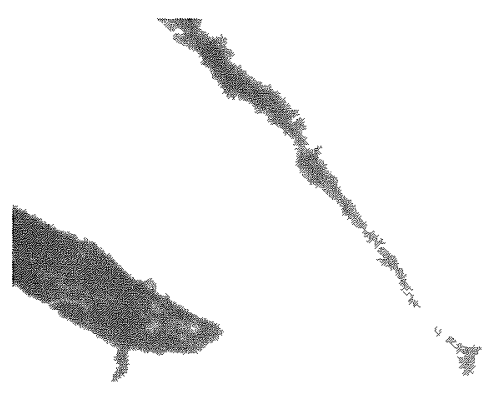

$15 \mathrm{w} / \mathrm{OMg}-\mathrm{Cd}$

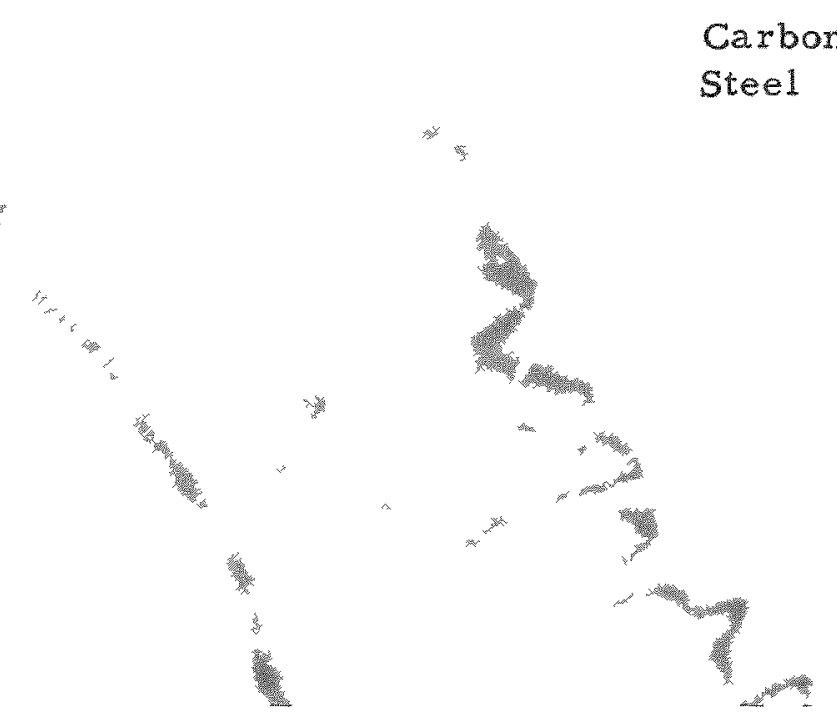

Etchant: $2 \%$ Nital

Magnification: $100 \mathrm{X}$

Photomicrograph 27 Showing Corrosion of Steel in Hot Leg of Thermal Convection Loop

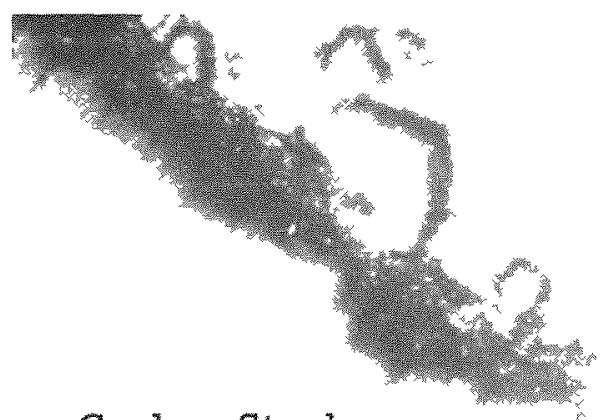

Carbon Steel

Magnification: $250 X$

$15 \mathrm{w} / \mathrm{OMg}-\mathrm{Cd}$

굥

笔

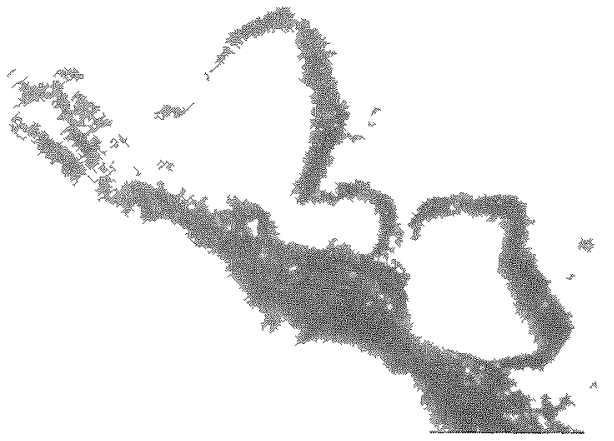

Etchant: $2 \%$ Nital

Photomicrograph 28 Illustrating Corrosion in Hot Leg of Thermal Convection Loop 


\begin{tabular}{|c|c|c|c|}
\hline Element & $\operatorname{Conc}(w / 0)$ & Element & $\operatorname{Conc}(w / 0)$ \\
\hline Uranium & 1.0 & Ruthenium & 0.002 \\
\hline Magnesium & 2.0 & Rhodium & 0.003 \\
\hline Strontium & 0.007 & Palladium & 0.002 \\
\hline Yttrium & 0.004 & Tellurium & 0.002 \\
\hline Zirconium & 0.02 & Barium & 0.009 \\
\hline Niobium & 0.001 & Rare Earths & 0.065 \\
\hline Molybdenum & 0.002 & & \\
\hline
\end{tabular}

thousand hours.

Operation of this loop will be continued for several

D. Pyrometallurgical Research

(H. M. Feder)

Preliminary values of the solubilities of vanadium, iron and nickel in liquid cadmium have been obtained. Vanadium is virtually insoluble (less then $0.2 \mathrm{ppm}$ at $650 \mathrm{C}$ ). Iron solubility ranges from $0.5 \mathrm{ppm}$ at $400 \mathrm{C}$ to $7 \mathrm{ppm}$ at $610 \mathrm{C}$. Nickel solubility increases from 1.4 per cent at 410 to approximately 5 per cent at $540 \mathrm{C}$.

A systematic error was found in the solubilities previously reported (ANL-5959, page 119) for thorium in liquid zinc. When corrected, the values fit the equation

$\log ($ atom per cent $T h)=8.025-\frac{10,391}{T}+\frac{1.799 \times 10^{6}}{T^{2}}$

with a standard deviation of 4.8 per cent.

A reinvestigation of the solubility of uranium in zinc-magnesium liquid solutions showed that the previous data were inaccurate due to the in. troduction of silicon (presumably formed by the reduction of silica by magnesium) into the system. New data, which show a significantly higher solubility in the magnesium-rich solutions, are presented.

The principles for the theoretical calculation of the solubility of a solute in a binary liquid metal solvent are presented. The method requires knowledge of the solubility of the solute in the two pure components of the binary solvent, the free energy of formation of the solid phase in equilibrium with the pure solvent components, and an estimate of the excess free energy of formation of the binary solvent system. This method was used to predict correctly the solubility of uranium in zinc-magnesium solutions. The dis a agreement of this theoretical computation with the earlier measurement was one of the factors which prompted the experimental reinvestigation. 
The peritectic temperature (incongruent melting point of $\mathrm{UCd}_{\Perp}$ ) in the uranium-cadmium system has been determined by the intersection of the solubility curves, direct thermal analysis, and by a galvanic cell method. The weighted average of these determinations is $474 \pm 1 \mathrm{C}$.

The distribution coefficient $\left(\mathrm{x}_{\mathrm{Cd}} / \mathrm{x}_{\mathrm{Al}}\right)$ of uranium between the immiscible liquids cadmium and aluminum has been found to be $2.3 \times 10^{-5}$ at $686 \mathrm{C}$. This distribution coefficient. when combined with the previously reported data on the activity coefficients of uranium in pure cadmium (ANL-5996), allows the estimation of the activity coefficient of uranium in aluminum. At 4.8 per cent uranium and $686 \mathrm{C}$ the activity coefficient of ura* nium in aluminum is $1.25 \times 10^{-3}$.

Preliminary measurements have been made of the thermodynamic quantities for the lead-rich portion of the lead-uranium system using an appropriate galvanic cell. The free energy of formation of $\mathrm{UPb}_{3}$ was found to vary between -14.8 and $-10.0 \mathrm{kcal} / \mathrm{mole}$ over the temperature range 400 to $800 \mathrm{C}$.

A thermochemistry program to obtain basic thermochemical infor mation on inorganic systems, with particular emphasis on high-temperature thermodynamic data, is being carried out. Oxygen bomb and fluorine bomb calorimetry is being studied. Preliminary noncalorimetric combustions of tungsten disulfide in oxygen have been carried out in the glass trial bomb. Studies of the combustion of molybdenum in fluorine have continued. Heats of formation of borontrifluoride and zirconium tetrafluoride are being determined.

\section{Chemistry of Liquid Metal Solvents (I. Johnson)}

The chemistry of liquid metal systems is being studied to per mit the logical design of pyrometallurgical separations and to furnish data for the evaluation of concurrent theoretical studies. The general separation process under consideration consists of dissolution of the spent reactor fuel in an appropriate volatile liquid metal, separation of the fission products or other extraneous elements by recrystallizations and/or extractions into immiscible liquids (either fused salts or other liquid metals), and final recovery of the fissile metal(s) by evaporation of the solvent.

\section{a. Solubilities in Liquid Metals}

The solubilities of the elements whose separations are being attempted, and of construction metals, are of prime importance in the design of fuel reprocessing schemes. The influences of temperature and solvent composition on solubilities need to be known. In the characterization of new systems it is very useful to determine the nature of the solid phase whose solubility is being studied. 
Solubility of First Transition Series Metals in Liquid

Cadmium

(M. S. Chasanov, C. Wade)

This study was undertaken because the first transition series metals include most of the useful materials of construction and be cause the systematization is expected to furnish data for theoretical cor relations. The investigation of these solubilities was carried out by the usual filtered sample methods. Preliminary results obtained are as follows:

(1) Vanadium appears to be virtually insoluble in cadmium and cadmium-0.1 weight per cent magnesium melts; the solubility has been estimated at less than $0.2 \mathrm{ppm}$ at $650 \mathrm{C}$.

(2) The solubility of iron in liquid cadmium ranges from less than $0.5 \mathrm{ppm}$ at $400 \mathrm{C}$ to approximately $7 \mathrm{ppm}$ at $610 \mathrm{C}$.

(3) The solubility of nickel in liquid cadmium increases from 1.43 weight per cent at $410 \mathrm{C}$ to 4.9 weight per cent at $541 \mathrm{C}$. These values are about 25 per cent lower than those obtained by Swarz and Phillips 2 by thermal analysis. Our investigations indicate a peritectic transformation at about $505 \mathrm{C}$. Swarz and Phillips reported a peritectic at $490 \mathrm{C}$; Voss ${ }^{3}$ reported the peritectic at $502 \mathrm{C}$.

These results are tentative and may be altered after more extensive studies.

The Solubility of Thorium in Liquid Zinc

(A. E. Martin and R. Uhle)

A systematic error was found in the solubilities previously reported in ANL-5959, page 119. The corrected data are given in Figure 15 along with other data reported 4,5 in the literature. The data were fitted by least squares to the following three-constant equation:

$$
\log (\text { atom per cent } T h)=8.025-\frac{10,391}{T}+\frac{1.779 \times 10^{6}}{T^{2}} \text {. }
$$

${ }^{2}$ Swarz, C. E., and Phillips, A. J., Trans. AIME, 111, 333 (1934).

3 Voss, G., Z. anorg. Chem., 57, 34 (1908).

${ }^{4}$ Smirnov, M. G., Ilyushchenko, N. G., Detkov, S. P., and Ivanovskii, L. E., Zhur. Fiz. Khim. 31, 1013 (1957).

5 Iowa State College Newsletter, July 1958. 
FIGURE 15

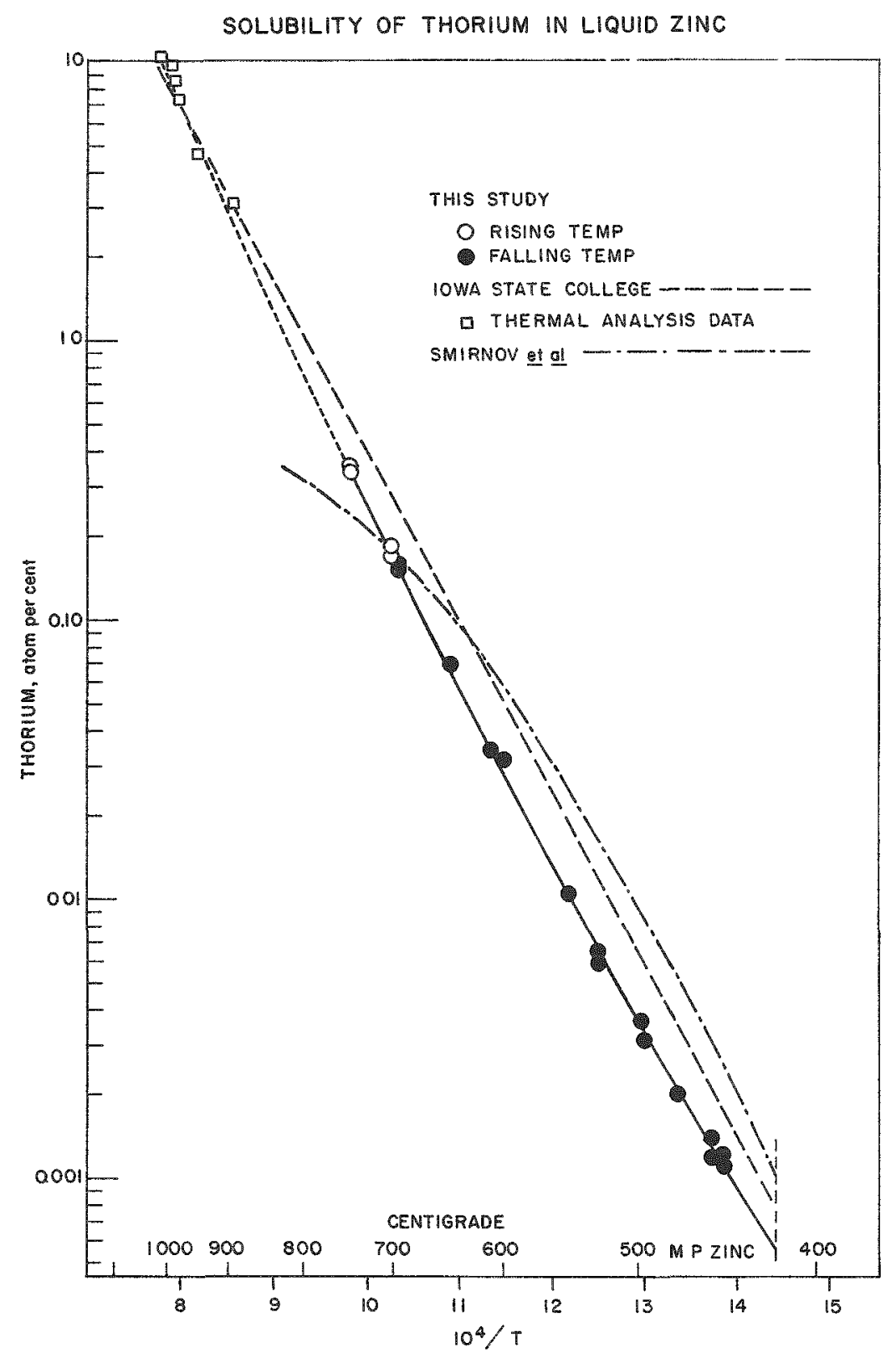

The standard deviation of the data from this equation is 4.8 per cent. A statistically highly significant improvement over the best linear equation,

$$
\log (\text { atom per cent } T h)=5.557-(6171 / \mathrm{T}) \text {, }
$$

was obtained. The standard deviation for the latter is 8.2 per cent. The slightly curved line through our data in Figure 15 corresponds to the threeconstant equation. This line has been extended (dashed) to higher temperatures. The extrapolation agrees very well with the high-temperature thermal analysis data obtained at Iowa State College. Note that their solubility line at lower temperatures is based on unfiltered samples for which the individual points have not been shown. 
Solubility Equations for Zinc Solvent Systems

(A. E. Martin, C. Wach and R. Uhle)

Solubility data for three systems which had been previously reported have now been fitted to equations of the form log (atom per cent $M$ ) $=$ $\mathrm{A}+(\mathrm{B} / \mathrm{T})$ by least squares. The results are tabulated below.

Temperature

Range

\begin{tabular}{|c|c|c|c|}
\hline Solute & (C) & A & $B$ \\
\hline \multirow[t]{2}{*}{ Zirconium } & $431-545$ & $8.982 \pm 0.090$ & $-7525 \pm 67$ \\
\hline & $545-732$ & $4.255 \pm 0.106$ & $-3609 \pm 98$ \\
\hline Palladium & $439-750$ & $4.034 \pm 0.052$ & $-3212 \pm 43$ \\
\hline Molybdenum & $422-550$ & $2.527 \pm 0.390$ & $-3587 \pm 296$ \\
\hline
\end{tabular}

Average deviation of the data from the equation (\%)

2.1

5.3

5.5

11.4

Metallographic and X-ray examinations of a number of magnesium-rich ingots obtained in the course of investigations of the zincmagnesium-uranium and cadmium-magnesium-uranium systems revealed the presence of magnesium silicide. Since silicon was not deliberately added to the original charges nor was it present as a significant impurity in the charge constituents, it became apparent that it had originated from the Vycor tubes used for sampling melts and for thermocouple protection. Presumably, silica is reduced by magnesium at high concentrations. These observations suggested that the reported measurements of uranium solubility may have been adversely affected by the presence of silicon (cf. the next section). Accordingly, an isothermal solubility run was made in the zincmagnesium-uranium system to check the results of a prior run (ANL-5996, page 110$)$. The addition of silicon to the melt was avoided by the substitution of tantalum thermocouple protection tubes and high-purity alumina sampling tubes. The procedure was otherwise similax to that used before. A zinc melt was first saturated with uranium at $680 \mathrm{C}$ and magnesium was then added incrementally. Each addition was followed by intervals of equilibration and sampling. The result of this run is compared with the prior run in Figure 16. It is apparent that the solubilities measured earlier were invalidated by the presence of silicon, especially at the high magnesium levels. Until a further check is made, the initial portion of the first run at a low magnesium level is assumed to be correct. The portion of the curve shown by long dashes is still undefined. The solubility curve as drawn is composed of two arcs which intersect at a cusp marking a point on the binary eutectic between $\mathrm{U}_{2} \mathrm{Zn}_{17}$ and uranium. The exact location of this join requires additional data. 
FIGURE 16

SOLUBILITY OF URANIUM IN ZINC-MAGNESIUM ALLOYS AT $680 \mathrm{C}$

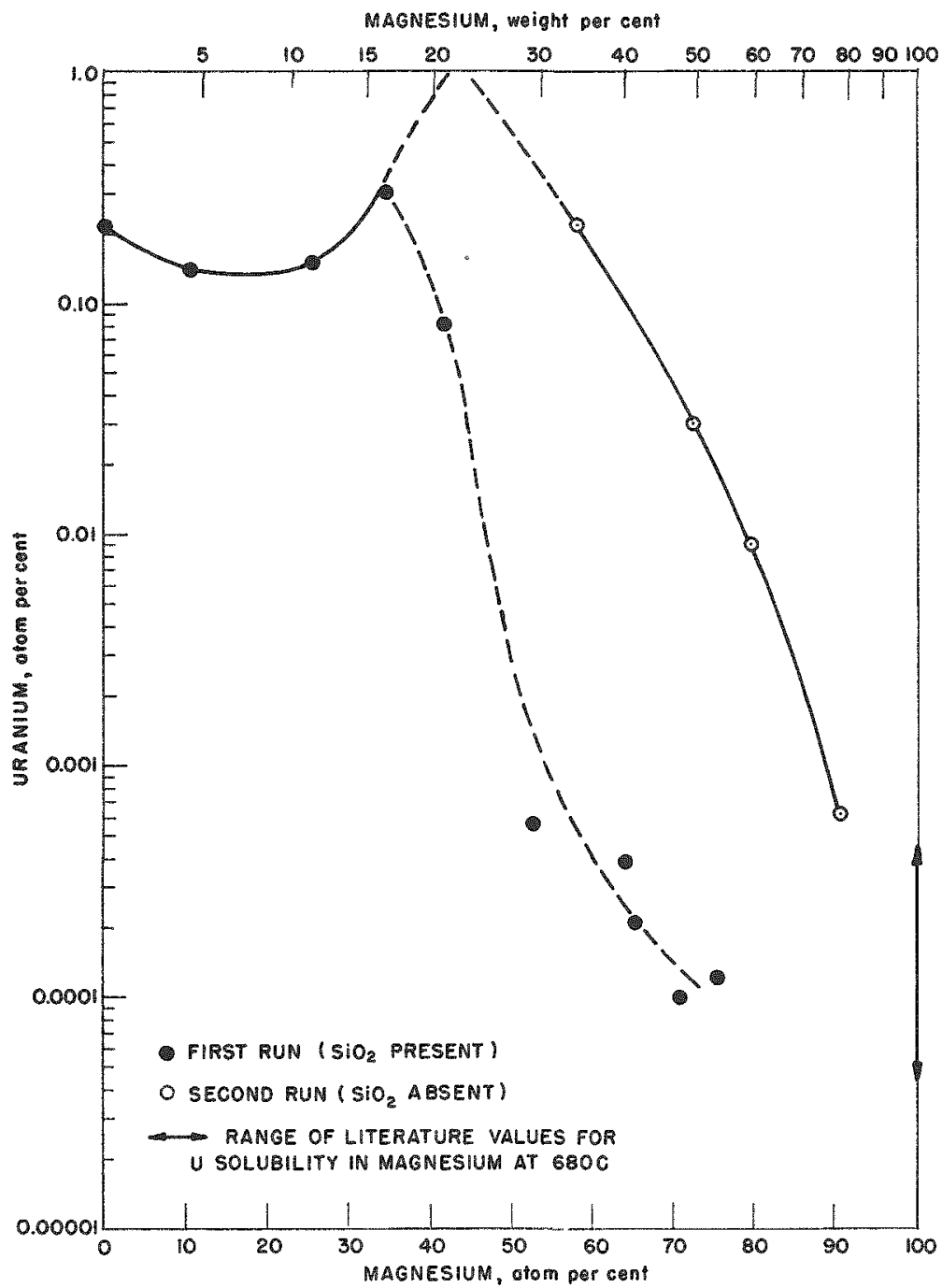

This solubility study extended only to 90.4 atom per cent (77.8 weight per cent) magnesium, but it is apparent that the extension of the curve to pure magnesium gives a result within the range of the somewhat discordant values reported in the literature. An effort to refine the data for the solubility of uranium in pure magnesium is underway.

Theoretical Solubilities in Binary Liquid Metal Solvents (I. Johnson)

In general, the solubility of a metal, such as uranium, in a liquid metal solvent is governed by an equilibrium of the form

$$
U M_{X}(s) \rightleftharpoons U(\operatorname{soln})+x M(\operatorname{soln})
$$


where $M$ represents a constituent of the solvent and $\mathrm{x}$ may be finite or zero, depending upon whether the solid phase is an intermetallic phase or pure uranium. This equilibrium leads directly to the relation

$$
0=-\Delta F_{U M_{X}}^{o}+R T \ln a_{U} a_{M}^{\mathrm{x}},
$$

where $\triangle F_{U}^{\circ} M_{\mathrm{X}}$ is the standard free energy of formation of the solid phase, $a_{U}$ and $a_{M}$ are the activities of uranium and metal $M$ in the liquid solution, respectively, and the standard states are the pure metals at the temperature of the system. When the solid phase in equilibrium with the saturated solution is pure uranium, its activity in solution is unity. Equation (2) may be rewritten in the form

$$
\log \mathrm{x}_{U}=\left(\Delta F \mathrm{UM}_{\mathrm{X}} / 2.3 \mathrm{RT}\right)-\mathrm{x} \log \mathrm{a}_{\mathrm{M}}=\log \gamma_{\mathrm{U}}
$$

where $x_{U}$ and $\gamma_{U}$ are the atom fraction and activity coefficient of uranium in the saturated solution. This equation formally permits prediction of the solubility provided the free energy of formation of the (known) intermetallic phase has been obtained from galvanic cell or decomposition pressure studies or the like. In a mixed solvent, say of metals $M$ and $N$, whose activities are known, the addition of a solute in very low concentrations may be assumed to have negligible effect on the activity coefficients. Hence, equation (2) may be used to calculate solubilities in a mixed solvent system provided that the variation of the activity coefficient of the solute as a function of solvent composition is known or can be estimated. Such an estimation is provided by the equation of Alcock and Richardson, 6 which for this case may be written as

$$
\log \gamma_{U}=x_{M} \log \gamma_{U}^{M}+x_{N} \log \gamma_{U}^{N}-\left(\Delta F_{M-N}^{x s} / 2.3 R T\right)
$$

In equation (4), the quantities $x_{M}$ and $x_{N}$ are the atom fractions of the solvent metals in the mixed solvent, $\gamma_{U}^{M}$ and $\gamma_{U}^{N}$ are the activity coefficients of uranium in the pure solvents, and $\Delta F_{M-N}^{\mathrm{XS}}$ is the excess free energy of formation of the solvent solution. The latter term will be zero if the solvent system is Raoultian.

Equations (3) and (4) have been used to predict the approximate solubility of uranium in zinc-magnesium solutions at $680 \mathrm{C}$. The activity coefficients of zinc and magnesium in their solutions and the excess free energy of mixing have been estimated by H. M. Feder from boiling point data and some scattered heat of solution data. The activity coefficient of uranium in pure zinc and the free energy of formation of $\mathrm{U}_{2} \mathrm{Zn}_{17}$ have been obtained from cell measurements (ANL-5924). The activity coefficient of uranium in pure magnesium is the reciprocal of its atom fraction solubility, since the solid phase is pure uranium. The solubility value reported by Chiotti was used.

${ }^{6}$ Alcock, C. B., and Richardson, F. D., Acta. Met.. 6, 385 (1958). 
FIGURE 17

SOLUBILITY OF URANIUM IN ZINC-MAGNESIUM

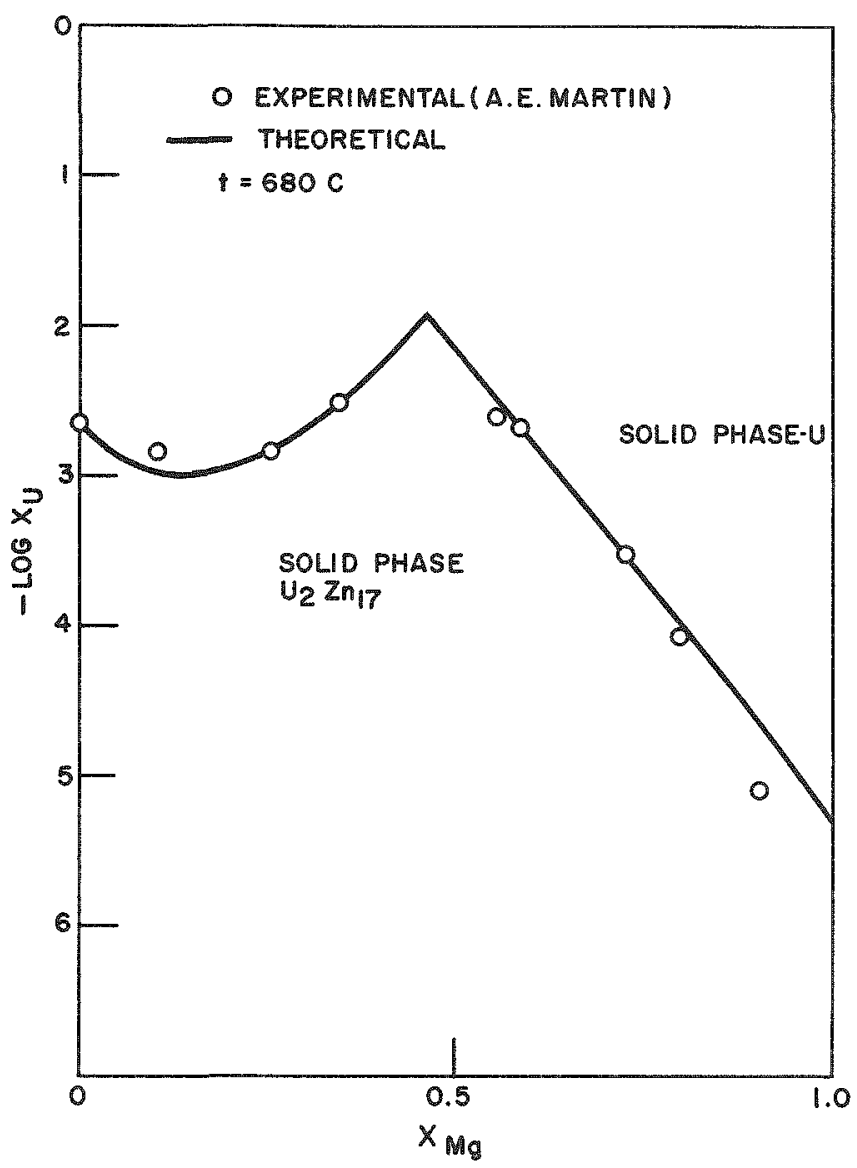

The results of this calculation are compared in Figure 17 with the recent experimental results reported by Martin (page 66). The thermodynamic calculation satisfactorily reproduces the complex solubility relation observed. Note that the predicted solubility is in disagreement with the shape of the curve obtained in the earlier work. This disagreement was one of the factors which prompted the experimental reinvestigation.

Physically, the observed solubility behavior arises as follows: As magnesium is added to the zinc solution, the activity of zinc is reduced. This tends to increase the solubility of uranium, i.e., shifts the equilibrium of equation (1) to the right. However, the addition of magnesium also increases the activity coefficient of uranium in solution. This tends to decrease the solubility of uranium. These two

factors together cause the solubility to decrease, pass through a minimum, and then increase as the magnesium is added. At about 46 a/o magnesium the zinc activity has decreased to such an extent that an activity of unity for uranium is required if the equilibrium of equation ( 1 ) is to be satisfied. Such a solution must also be in equilibrium with solid uranium. Beyond $46 \mathrm{a} / \mathrm{o}$ magnesium, the compound $U_{2} Z_{n_{1}}$ is unstable because its formation requires a uranium activity greater than unity, which is impossible. Hence, the solution remains saturated only with respect to solid uranium. In this region the solubility is simply equal to the reciprocal of the activity coefficient computed from equation (4).

Further calculations of such ternary system relations will be presented as new and improved data become available.

The Solubility of Uranium in Liquid Cadmium (A. E. Martin, C. Wach)

The slow rate of solution of uranium in liquid cadmium makes the determination of its solubility relatively difficult. In 
experimental procedures, this has been compensated by the use of unusually long holding periods. The solubility of uranium above the peritectic temperature in this system, which was indicated as retrograde by preliminary measurements, has now been determined to be retrograde beyond any reasonable doubt. The data are shown on Figure 18, along with previously established features of the cadmium-uranium system. The data show that the solubility is most retrograde at the peritectic temperature; from $580 \mathrm{C}$ to the highest temperature of this study, $654 \mathrm{C}$, there is very little further change in uranium solubility with temperature.

FIGURE 18

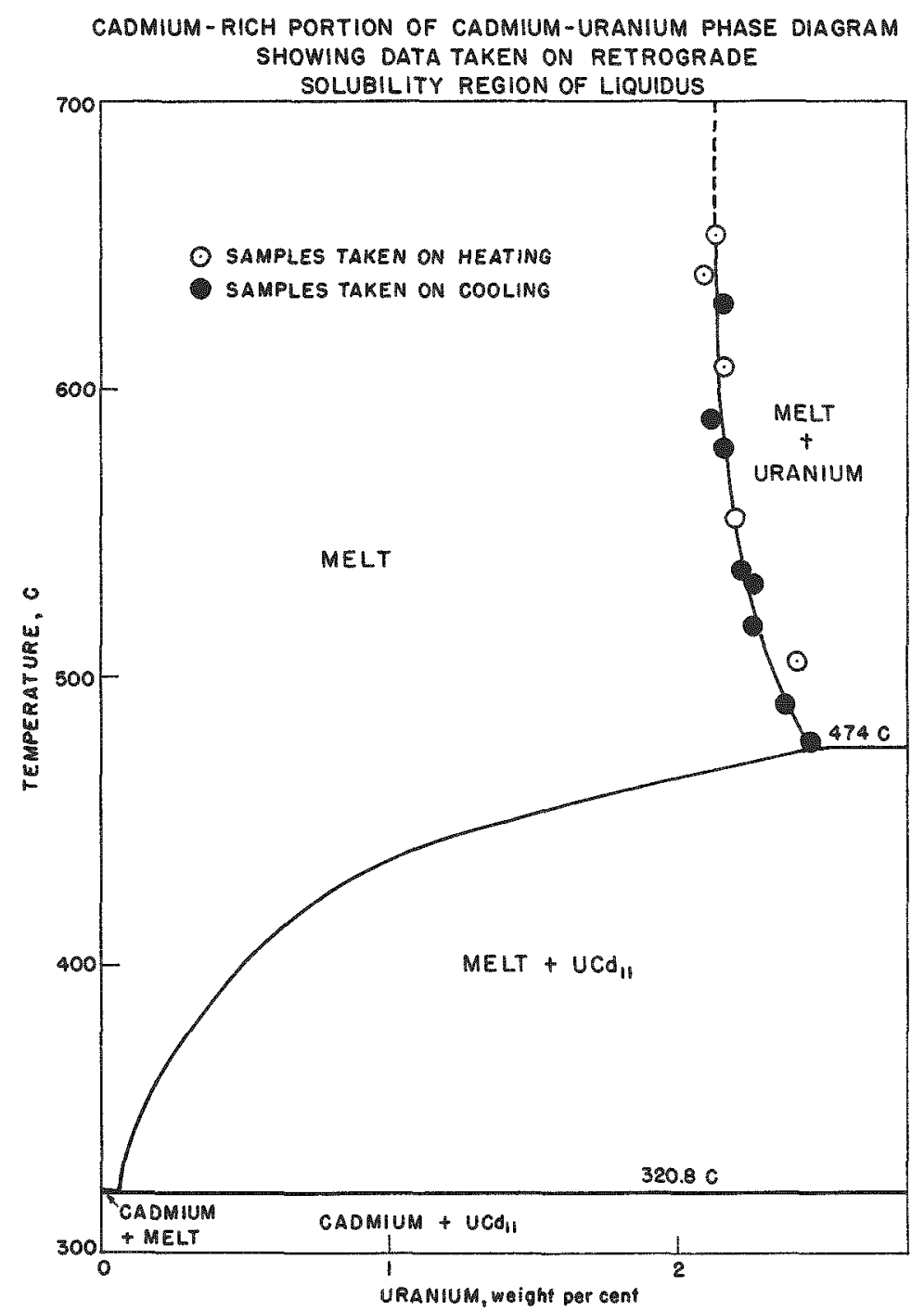

The Peritectic Temperature in the Cadmium-Uranium

System

(A. E. Martin, I. Johnson)

The peritectic temperature in the cadmium-uranium sys tem has been determined by three distinctly different methods: 
(a) The intersection of the solubility line of uranium in liquid cadmium above the peritectic with the least-squares line for the solubility below this temperature, viz., log (atom per cent $U$ ) $=5.993$. $(4457 / \mathrm{T})$, yields a peritectic temperature of $476.5 \mathrm{C}$.

(b) The peritectic temperature was also determined by thermal analysis of melts containing nominally 9 to 10 weight per cent uranium in the form of 20 -mesh particles, roughly spherical in shape. The average of six plateaus obtained on heating was $473.9 \mathrm{C}$, with a standard deviation of $0.8 \mathrm{C}$. (A relatively weak thermal arrest obtained on cooling is not believed to be of any significance other than indicating that the peritectic reaction approached from the high-temperature side is very sluggish.)

(c) The galvanic cell studies made on the uranium-cadmium system (ANL-5996, page 119) offer an additional method for determining the peritectic temperature, since above this temperature the cell emf must vanish, provided that solubility of cadmium in solid uranium is negligible. By means of this method, two cells gave temperatures of 475.4 and $471.8 \mathrm{C}$. The average of these deter minations has been taken to be $474+1 \mathrm{C}$.

\section{b. Liquid-Liquid Distribution Studies \\ (F. Cafasso)}

These studies have been initiated for two reasons. first, the differential partitioning of solutes between immiscible liquid metals may lead to useful separations, and, second, data obtained in such experiments can be combined with known thermodynamic data for one of the binary sys tems to predict thermodynamic functions for the other (unknown) binary system. The system uranium-cadmium-aluminum was chosen for the first study because of possible utilitarian character and because the thermody namic properties of uranium-cadmium solutions are known from galvanic cell measurements (ANL-5996) while those for uranium-aluminum solutions are unknown, but would be useful.

The partition of uranium between the liquid metals, aluminum and cadmium, was measured in the range 680 to $720 \mathrm{C}$. After bringing the charge to temperature and stirring for at least one hour, the liquid layers were individually sampled by the usual technique and analysed. The results showed that uranium concentrated strongly in the (upper) liquid aluminum layer.

The uranium poor cadmium layer, however, showed wide variations in uranium concentration $\left(6 \times 10^{-5}\right.$ per cent to 0.1 per cent) and, in fact, differences of magnitude were exhibited by duplicate samples. Sampling of the latter layer had been achieved by lowering a pressurized quartz tube, equipped with a graphite filter at its lower end, through the 
upper aluminum layer. Apparently, the cadmium layer samples so obtained were contaminated with small, variable amounts of uranium-rich aluminum as the sampling tubes passed through the upper layer.

In order to overcome the sampling difficulty, a modified technique was devised. A thin-walled $(0.05 \mathrm{~mm}), 3=\mathrm{mm} O D$ quartz tube, 36 inches long, was press-fitted with a graphite filter located about one inch from one end of the tube. Care was taken to insure that a tight fit was achieved. After coating the inside surface with magnesium oxide in the usual way, the end of the tube closest to the filter was drawn to a fine point in order to form a breakseal tip. After evacuation and flushing with argon seva eral times, the tubes were filled to a pressure of one atmosphere with argon, and then sealed at their upper ends. In order to sample the cadmium layer, the sealed tubes were lowered through the aluminum layer and the breakseal was broken against the bottom of the crucible. The tips break very easily and in no instance has a sampling tube broken elsewhere as a result of the applied force. The sample was then taken by pressurizing the furnace as sembly for a short time and withdrawing the tube rapidly. A small amount of cadmium trapped beneath the graphite filter formed a barrier to prevent contaminaition from the aluminum layer during the withdrawal through the upper layer.

A distribution experiment was conducted, using the sampling technique. Four samples were taken at $1 \frac{1}{2}$ hour intervals; the first hour was a stirring period and the remaining half hour was a settling period. The rew sults of this experiment are recorded in Table 7. The reasonable constancy of the uranium concentration in the cadmium phase and the fact that it lies well below the lowest values previously measured indicate that the contamination problem has been reduced considerably by the new sampling technique.

\section{Table 7}

\section{DISTRIBUTION OF URANIUM BETWEEN LIQUID ALUMINUM AND LIQUID CADMIUM}

Charge: $\quad 12.5$ grams of uranium to 855.8 grams of cadmium and 236.4 grams of aluminum

Temperature: $686 \mathrm{C}$

\begin{tabular}{ccccc}
$\frac{2}{\text { Aluminum Phase }}$ & & \multicolumn{2}{c}{ Cadmium Phase } \\
$\frac{U(\mathrm{w} / \mathrm{o})}{4.8}$ & $\frac{\mathrm{Cd}(\mathrm{w} / \mathrm{o})}{8.12}$ & & $\frac{\mathrm{U}(\mathrm{w} / \mathrm{o})}{3 \times 10^{-5}}$ & $\frac{\mathrm{Al}(\mathrm{w} / \mathrm{o})}{1.47}$ \\
4.8 & 7.94 & & $9 \times 10^{-5}$ & 1.51 \\
- & - & $3 \times 10^{-5}$ & 1.45 \\
4.8 & 7.86 & $3 \times 10^{-5}$ & 1.52
\end{tabular}


A provisional value of $2.3 \times 10^{-5}$ at $686 \mathrm{C}$ has been obtained for the atom fraction distribution coefficient of uranium in this system,

$$
\mathrm{K}_{\mathrm{U}}=\mathrm{N}_{\mathrm{U}} \text { in } \mathrm{Cd} / \mathrm{N}_{\mathrm{U}} \text { in } \mathrm{Al} \text {. }
$$

Since the activity of uranium is identical in both phases, there is obtained

$$
\gamma_{U}(\text { in } \mathrm{Al})=\frac{\mathrm{N}_{U}(\text { in } \mathrm{Cd})}{\mathrm{N}_{U}(\text { in } \mathrm{Al})} \gamma_{U}(\text { in } \mathrm{Cd})=\mathrm{K}_{U} \gamma_{U} \text { (in Cd) }
$$

If cadmium and aluminum were totally immiscible, the values for $\gamma_{U}$ in pure cadmium measured in galvanic cells (ANL-5996) could be used to calculate $\gamma_{U}$ in pure aluminum. Such a calculation yields a value $3.7 \times 10^{-3}$, applicable to $686 \mathrm{C}$ and a concentration of 4.8 per cent uranium in cadmium. However, this must be corrected for partial miscibility. Such a correction may be applied, to a good approximation, by making use of the equation of Alcock and Richardson 6 for ternary systems. This corrected result yields an activity coefficient for uranium in pure aluminum (at 4.8 per cent and $686 \mathrm{C}$ ) of $1.25 \times 10^{-3}$.

Work on additional systems is in progress.

\section{c. Thermodynamic Studies}

Thermodynamic functions for metallic elements of special interest in liquid alloys or in solid intermetallic phases are being measured by two methods. Galvanic cell methods have proved to be especially useful. For systems containing volatile components, so that galvanic cells are not practical, the measurement of decomposition pressures by the effusion method is being used.

\section{Thermodynamics of the Uranium-Lead System}

\section{(I. Johnson and R. M. Yonco)}

The following galvanic cell was used to determine the thermodynamic properties of the uranium-lead system:

$$
\mathrm{U} \mid \mathrm{UCl}_{3}+\cdot \mathrm{KCl}-\mathrm{LiCl} \text { (eutectic Liquid) } \mid \begin{gathered}
\mathrm{U} \text { (saturated solution in } \\
\text { liquid } \mathrm{Pb} \text { ). }
\end{gathered}
$$

The cell reaction is

$$
\mathrm{U}(\mathrm{s})+3 \mathrm{~Pb} \text { (saturated liquid solution) }-\longrightarrow \mathrm{UPb}_{3}(\mathrm{~s}) \text {. }
$$

The solubility of uranium in lead is very small (less than 0.2 atom per cent in the temperature range studied) and consequently the standard free energy of formation $\Delta F^{\circ}$ is obtained directly from the measured emf, $E$, using the equation

$$
\Delta F^{\circ}=-n F E \text { 。 }
$$

For cells of this type $\mathrm{n}=3$. 
The values of the free energy of formation computed from the emf measurements obtained from the first cell are shown in Figure 19. Below about $600 \mathrm{C}$ the data seem to fit, although there is some scatter, to a linear temperature relation. Above $600 \mathrm{C}$ the data deviate systematically

FIGURE 19

FREE ENERGY OF FORMATION OF UPb 3 FROM EMF-CELL DATA

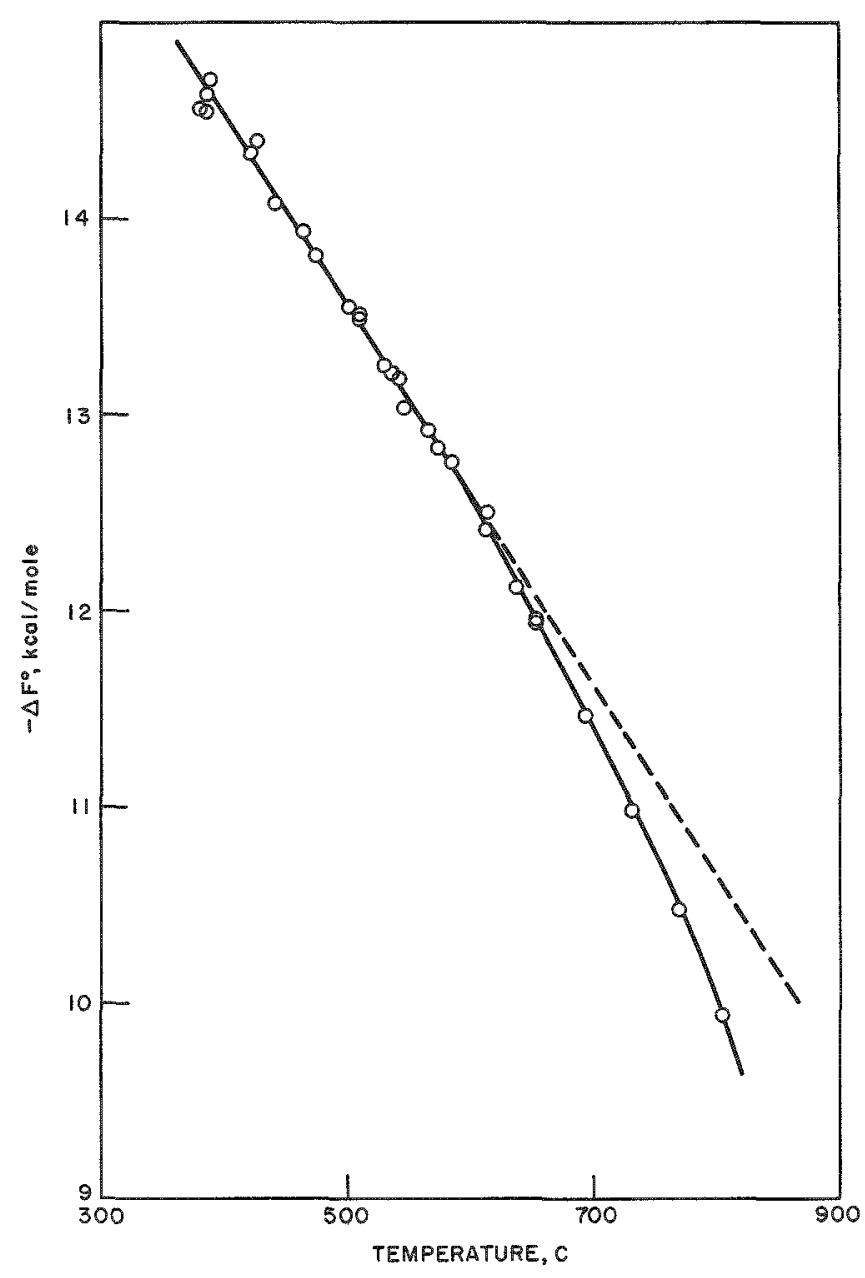
from this line. The change in the slope of the $\Delta F$ vs $T$ curve may indicate a change in the solid phase in equilibrium with the saturated liquid solution. If the slope change is discontinuous, a first-order transition is indicated; if it is continuous, an order-disorder transition is possible. It is interesting to note that, because of the approximately equal scattering powers of uranium and lead atoms, it is not known whether or not $\mathrm{UPb}_{3}\left(\mathrm{AuCu}_{3}\right.$-type structure) is ordered or disordered at room temperature. However, of the other nine known $\mathrm{UM}_{3}$ compounds of this type, six are known to be ordered at room temperature. A second cell will be used to make further measurements in the temperature region of the slope change.

An estimate of the activity coefficient of uranium dissolved in lead may be made. At $600 \mathrm{C}$ the activity of uranium in the saturated solution

is $6.95 \times 10^{-4}$, whereas the solubility is about $4.7 \times 10^{-\frac{4}{8}}$ atom fraction. The computed activity coefficient is 1.5 .

\section{Effusion Cell Studies}

(E. Veleckis)

The past quarter has been devoted mainly to modification of the electrical weighing system to improve its stability and reproducibility. A significantly improved performance has been achieved. The effective orifice areas of some effusion cells have been measured by calibration with mercury vapor effusion. 
2. Calorimetry

(W.N.Hubbard)

a. Oxygen Bomb Calorimetry

(1) Preparation and Analysis of Tungsten Disulfide

(E. Greenberg and M. Cusick)

A 50 -gram sample of tungsten disulfide has been prepared and purified for use as a calorimetric sample. Analyses for tungsten and sulfur are almost complete. Samples have also been submitted for X-ray diffraction analysis and spectrochemical analysis.

(2) Heat of Formation of Tungsten Disulfide (R.L. Nuttall and D.R. Eredrickson)

Preliminary noncalorimetric combustions of tungsten disulfide in oxygen in the trial glass bomb have been carried out. The techniques developed are now being adapted to the platinum-lined bomb for calorimetric combustions in the rotating bomb calorimeter. The trial combustions showed that practically complete combustion can be obtained with two grams of tungsten disulfide pressed into a disc, $\frac{1}{2}$ in. diameter, $\frac{3}{8}$ in. thick with a $\frac{1}{8}$ in. hole through the center, supported by the ignition wire which passes through the central hole. A small bead of sulfur is used as a kindler. The tungsten trioxide formed does not fuse or vaporize but remains as a solid disc of the same shape as the tungsten disulfide pellet. It is not soluble in water or in cold sodium hydroxide solution.

b. Fluorine Bomb Calorimetry

(1) Equipment

(E.Rudzitis, J.L. Settle, E. Greenberg)

Calorimetric measurements have been delayed during the reconstruction of the auxiliary equipment. All of this equipment has now been rebuilt and consolidated in a vacuum frame hood. This equipment in cludes a low temperature still for fluorine purification: an analytical train for purified fluorine: a system for charging bombs to 30 atmospheres pres sure of fluorine, and an analytical train for the products of combustion.

The low-temperature fractionating still for fluorine purification is an improved model, redesigned and constructed after experience was accumulated with the first still (ANL-6068, page 87). It consists of a still pot welded to a nickel helix-packed column. The pot is provided with a jacket that can be filled with liquid nitrogen for condensing fluorine. Slightly above the packing the column is provided with a liquid nitrogen filled jacket which serves as a reflux condenser. The pot. column, and condenser are enclosed in a brass can that is evacuated to reduce heat transfer from the outside. 
Aluminum head gaskets in the fluorine bomb have been a continuing source of trouble because of poor seating. work hardening, and corrosion. The substitution of a gold gasket has given good results and promises to be the solution to a rexing problem. No corrosion in service has been observed.

(2) Heat of Formation of Molybdenum Hexafluoride (J.L.Settle)

The main difficulty encountered in preliminary work on the combustion of molybdenum in fluorine was the deposition on the walls of the bomb of molybdenum-containing substances of poorly characterized mass and composition. A new series of noncalorimetric experiments has been started to try to eliminate this difficulty. The variables which are be ing investigated are the initial fluorine pressure, the shape and mass of the molybdenum sample, the method of suspending the sample, and the method of igniting the sample. Techniques have been developed which substantially reduce the deposition of molybdenum-containing compounds on the walls of the bomb. The use of fluorine at higher pressures seems to be one of the more significant modifications.

\section{(3) Heat of Formation of Boron Trifluoride (S. Wise)}

One of the available crystalline boron samples was found to contain 0.3 per cent titanium impurity. This boron had been made by the hot deposition process on titanium wire. The presence of this impurity caused spontaneous ignition of the pelleted boron in fluorine. In an effort to purify this sample it was exposed to fluorine at a pressure of four atmospheres and then heated in vacuum to $500 \mathrm{C}$. (Titanium tetrafluoride sublimes at $284 \mathrm{C}$.) Spectrographic analysis showed that the titanium content of the sample was reduced by only one-third.

A loose mound of crystalline boron with a sufficiently low titanium content shows no tendency to react spontaneously with fluorine at room temperature and at pressures up to almost seven atmospheres. Therefore, a device for protecting crystalline boron from premature reaction with fluorine will not be necessary. In this configuration, 100 mesh size boron crystals burned completely when ignited with a fuse in two atmos pheres or more of fluorine. Larger crystals of boron burst when ignited, spattered pieces to the cold walls of the bomb. these pieces cooled rapidly and were incompletely burned.

A trial combustion of crystalline boron has been carried out in the calorimeter. Two objectives were accomplished. First, the sample size, chosen on the basis of previously reported values of the heat of formation of boron trifluoride, was found to give the optimum temperature rise in the calorimeter. Second, the bomb firing technique 
proved successful. This technique employs a fuse wire suspended over the mound of boron crystals contained in a nickel dish. When ignited electrically, the burning fuse fell into the boron and ignited it.

Experiments were carried out to test the extent of reaction of boron trifluoride with nickel fluoride. Samples of nickel fluoride were exposed at various temperatures to varying pressures of boron trifluoride in a known-volume closed system whose pressure could be read on a mercury manometer. The nickel fluoride samples were prepared by (1) direct fluorination of nickel, (2) fluorination of nickel chloride, and (3) dehydration of $\mathrm{NiF}_{4} \cdot 4 \mathrm{H}_{2} \mathrm{O}$. The nickel fluoride prepared by direct fluorination of nickel was the only one of the samples that was not hygroscopic, and it showed no measurable uptake of boron trifluoride. The results indicate that there will be little danger of boron trifluoride reacting appreciably with the nickel fluoride coating formed in the bomb.

Amorphous boron reacts spontaneously with fluorine and requires isolation from it prior to intentional ignition. A nickel capsule for containing such samples has been constructed. The lid of the capsule is spring-loaded and held in place by a fuse wire. Ten-mil molybdenum has been found satisfactory for this purpose. The critical part of the device is a sealing gasket between the lid and the nickel container. Teflon makes a satisfactory seal but ignites if struck by a burning particle of the reacting material. Gold is being tried but difficulties are being encountered in obtaining a good seal with the present sealing force.

\section{(4) Heat of Formation of Zirconium Tetrafluoride (E.Greenberg)}

A nickel bomb was completely refitted with a new head gasket and valve assemblies. A series of calorimetric combustions of highpurity zirconium in pure fluorine was started. The use of these high-purity materials apparently resulted in higher burning temperatures; partial melting of the sample took place. Some additional noncalorimetric combustions were carried out in order to determine what modifications were needed to avoid this. A slightly revised technique has been developed and calorimetric experiments have been resumed.

The zirconium tetrafluoride product from one of the combustions with high-purity starting materials was examined by $\mathrm{X}-\mathrm{ray}$ diffraction. With the exception of a few very faint lines just above background level, all of the lines can be assigned to $\beta=Z_{r} F_{4}$. 


\section{FUEL CYCLE APPLICATIONS OF VOLATILITY AND FLUIDIZA TION TECHNIQUES}

Several schemes involving the volatility of uranium hexafluoride have been proposed for processing irradiated fuels. These include a direct fluorination process, the Aqueous Dissolution Fluorination (ADF) Process, and the Fused Fluoride Volatility Process. Many steps of these schemes involve the use of fluidization techniques. Fluidization techniques are also being applied to calcination of radioactive liquid wastes and preparation of uranium compounds.

The Direct Fluorination Process now under study involves direct fluorination of oxide-matrix fuels with fluorine or other fluorinating agents to produce volatile uranium hexafluoride and plutonium hexafluoride. Allied reactions of intermediate compounds are being studied. Equilibrium constants for the reaction $\mathrm{PuF}_{4}+F_{2} \leftrightharpoons \mathrm{PuF}_{6}$ have been determined in the temperature range from 150 to $400 \mathrm{C}$. The results may be represented by the equation

$$
\log K=-(1331 / \mathrm{T})-0.275
$$

The use of sulfur tetrafluoride as a fluorinating agent is being investigated in reactions with uranium tetrafluoride, uranium dioxide, $\mathrm{U}_{3} \mathrm{O}_{8}$, uranium trioxide, uranyl fluoride, plutonium dioxide, and plutonium tetrafluoride.

Additional work was performed on the ADF Process being developed for the recovery of uranium from low uranium-Zircaloy-2 fuel alloys. The process involves aqueous dissolution of the fuel, fluid abed drying of the solution to a dry powder, and fluorination of the powder to remove and recover the uranium as the volatile uranium hexafluoride. Studies of the drying step have included use of high zirconium feed solution ( $3.6 \mathrm{M}$ zirconium) and dilute zirconium feed solution (1.5 M zirconium) at feed rates up to $150 \mathrm{ml} / \mathrm{min}$ for concentrated feed and $210 \mathrm{ml} / \mathrm{min}$ for dilute feed. Some particle growth was evident at feed rates of 100 and $150 \mathrm{ml} / \mathrm{min}$ for concentrated and dilute feed respectively. An internal autoresistance-type Inconel strip heater has been introduced into the fluid bed to provide additional capacity to the dryer.

To provide feed materials with low residual water and oxygen content, investigation of the fluorination step included study of the hydrofluorination of dryer product at $300 \mathrm{C}$ with equal mixtures of hydrogen fluoride and nitrogen. Static-bed fluorination studies of the uranium-zirconium fluoride dryer products have been carried out in bench and pilot-scale fluorination reactors. Uranium removals greater than 99 per cent have been achieved in 1 to 3 -hour runs at $700 \mathrm{C}$.

Laboratory studies of uranium removal from calcined solutions of uranium-zirconium alloys have shown that vacuum sublimation may be used to remove zirconium tetrafluoride from the dried solids. The addition of 
sodium fluoride to the calcined solid does not substantially aid in uranium removal. Experimental data indicate that the ADF volatility process at moderate fluorination temperatures, could be used to recover uranium from Dresden reactor fuel, but that higher temperatures would be required for quantitative recovery from APPR fuel.

Additional studies have been made in the Fused Salt Fluoride Volatility Process for the recovery of uranium from uranium-zirconium matrix fuels. The process involves dissolution of the fuel in molten fluoride salts with a hydrogen fluoride sparge, followed by fluorination of the uranium to volatilize it as the hexafluoride. The development of process equipment has been directed toward either avoiding corrosive salt-metal contact or using corrosion resistant materials, such as graphite. A graphite pilotplant dissolver is being tested for the dissolution step. A synthetic 10-plate zirconium-uranium fuel element was dissolved in molten sodium fluoridezirconium tetrafluoride in 6 hours at $700 \mathrm{C}$ at $60 \mathrm{lb} / \mathrm{hr}$ hydrogen fluoride sparge rate. The dissolution rate was $2.2 \mathrm{mg} /(\mathrm{sq} \mathrm{cm})(\mathrm{min})$.

The use of an electrolytically heated frozen-wall fluorinator has been proposed for the fluorination step as a means of minimizing corrosion. Operation of a 17-inch diameter frozen-wall fluorinator has been successfully demonstrated in tests in which thin, uniform frozen walls were maintained. Some problems due to crust formation on the surface of the melt were encountered.

Volume reduction of radioactive liquid wastes to free-flowing granular solids may be achieved by means of calcination in a heated fluidized bed. Recent runs with radioactive wastes have demonstrated the feasibility of extending this process from aluminum nitrate-bearing wastes to Purextype wastes.

Additional studies of a one-step fluid-bed process for the conversion of uranium hexafluoride to uranium dioxide were made in the newly installed 3 -inch Monel reactor.

\section{A. Fluorine Chemistry and Fluoride Separations Processes (J. Fischer)}

Work is continuing on laboratory studies involving fluorine chemistry of uranium and plutonium applicable to fluoride separations processes. Emphasis has been placed on developmental research which is necessary to establish the feasibility of the Direct Fluorination Process as it may be applied to oxide-matrix fuels, of which the fuel for the Dresden reactor is an example.

Fluorine can be made to react directly with oxide-matrix fuels to produce volatile uranium hexafluoride and plutonium hexafluoride; this reaction serves as the basis for the Direct Fluorination Process. The process, 
however, is not limited to the reaction of fluorine with uranim and plutonium oxides, but may include the reactions of other fluorinating reagents.

The Direct Fluorination Process can be carried out by following diverse paths varying with the mode of fluorination. Uranium and plutonium can be converted completely with fluorine to their respective volatile hexafluorides; these then may be separated. By employing proper conditions of the reaction, uranium alone may be fluorinated to the hexafluoride, thereby effecting a complete or partial separation of uranium from plutonium. In another procedure, uranium may be selectively fluorinated with the use of bromine trifluoride or bromine pentafluoride in the vapor state to the hexafluoride, thereby effecting a separation from plutonium, which can be recovered by a second reaction of the residue with fluorine. A similar separation employing selective fluorination can be made with sulfur tetrafluoride. The uranium is first converted to uranium trioxide with oxygen, after which it reacts with gaseous sulfur tetrafluoride to produce uranium hexafluoride. Plutonium dioxide remains in the residue and is subsequently reacted with fluorine to produce plutonium hexafluoride.

The separated uranium hexafluoride can be used as feed in diffusion plants, can be reduced to fluorides of lower valence, or metal, or can be converted to uranium dioxide by reaction with steam and hydrogen. The plutonium hexafluoride can be similarly treated.

1. Decomposition of Plutonium Hexafluoride (L. E. Trevorrow, W. Shinn)

A detailed knowledge of the equilibrium for the reaction $\mathrm{PuF}_{4}(\mathrm{~s})+\mathrm{F}_{2}(\mathrm{~g}) \leftrightharpoons \mathrm{PuF}_{6}(\mathrm{~g})$ is needed in development of the Fluoride Volatility Process for the recovery of fissile materials from fuels containing plutonium. From the equilibrium constant it is possible to calcu= late the minimum pressure of fluorine necessary to produce a mole of plutonium hexafluoride from solid plutonium tetrafluoride. The equilibrium constant may also be used to calculate the percentage of a sample of plutonium hexafluoride which may be decomposed at thermodynamic equilibrium at a given temperature; this is important since one of the promising methods for separation of plutonium from uranium is the preferential thermal decomposition of plutonium hexafluoride.

Determinations of the equilibrium constants have been made from 150 to $400 \mathrm{C}$. Results obtained at 200,250,300, and $350 \mathrm{C}$,along with a description of the apparatus and experimental techniques, were given in ANL-6029, page 75, and ANL-6068, page 139.

Much longer periods were required for the system to reach equilibrium at the lower temperatures than at the higher temperatures. Less than $1 \frac{1}{2}$ to 2 hours were required at $300 \mathrm{C}$, a 24 to 60 -hour period was necessary at $200 \mathrm{C}$, and a 150 to 300 -hour period was necessary at $150 \mathrm{C}$. 
The results are shown in Table 8 . The equilibrium constant is defined as $K=\left(P u F_{6}\right) /\left(F_{2}\right)$, and values of $\log K$ are shown as a function of $1 / T$ in Figure 20, where the data are represented by a single straight line. A. E. Florin, et al.,$^{7}$ give a graph of $\log \mathrm{K}$ versus $1 / \mathrm{T}$ in which the data are represented by two straight lines with the break at $308 \mathrm{C}$. They suggested that a phase change occurred in the reacting material at this point. The work done in this Laboratory shows no such sharp change in the linear relation between $\log K$ and $1 / T$.

Table 8

EQUILIBRIUM CONSTANT FOR THE REACTION

$$
\mathrm{PuF}_{4}(\mathrm{~s})+\mathrm{F}_{2}(\mathrm{~g}) \rightleftharpoons \mathrm{PuF}_{6}(\mathrm{~g})
$$

Time at

Equilibrium

Temperature

(C)

$\begin{array}{lcc}395 \pm 0.5^{b} & 2 \frac{1}{2} \\ 393 \pm 0.9 & 3 & 17 \\ 336 \pm 0.3 & 18 \\ 342 \pm 0.3 & 1 \frac{1}{2} \\ 302 \pm 1 & 1 \\ 303 \pm 0.5 & 3 \\ 301 \pm 2 & 2 \\ 302 \pm 0.5 & 2 \frac{1}{2} \\ 301 \pm 0.2 & 24 \frac{1}{2} \\ 302 \pm 0.5 & 18 \frac{1}{2} \\ 300 \pm 0.5 & 66 \\ 251 \pm 0.3 & 25 \\ 251 \pm 0.5 & 24 \frac{1}{2} \\ 199 \pm 0.5 & 23 \\ 202 \pm 0.5 & 47 \frac{1}{2} \\ 200 \pm 0.5 & 136 \\ 200 \pm 0.8 & 312 \\ 152 \pm 1 & \\ 150 \pm 0.2 & \end{array}$

Equilibrium

Temperature

$(\mathrm{hr})$

bStandard deviation

$$
a_{K}=K_{P}=K_{C}=\left(P u F_{6}\right) /\left(F_{2}\right)
$$

Total Pressure at Equilibrium $(\mathrm{mm})$

\begin{tabular}{r}
$(\mathrm{mm})$ \\
\hline 924 \\
902 \\
2320 \\
3150 \\
1920 \\
1910 \\
1920 \\
1920 \\
1920 \\
1920 \\
1920 \\
5030 \\
3690 \\
6250 \\
6250 \\
6250 \\
6250 \\
5620 \\
5460
\end{tabular}

Equilibrium Constant $\left(\times 10^{-3}\right)^{2}$

5.05

5.56

3.35

3.79

2.64

2.65

2.88

2.45

2.56

2.80

2.66

1.64

1.51

0.708

0.619

0.818

0.667

0.468

0.455

${ }^{7}$ Florin, A. E., Tannenbaum, I. R., and Lemons, J. F., J. Inorg. and Nuclear Chem., 2, 368 (1956). 
FIGURE 20

RELATION BETWEEN EQULIBRIUM CONSTANT AND TEMPERATURE

FOR THE REACTION

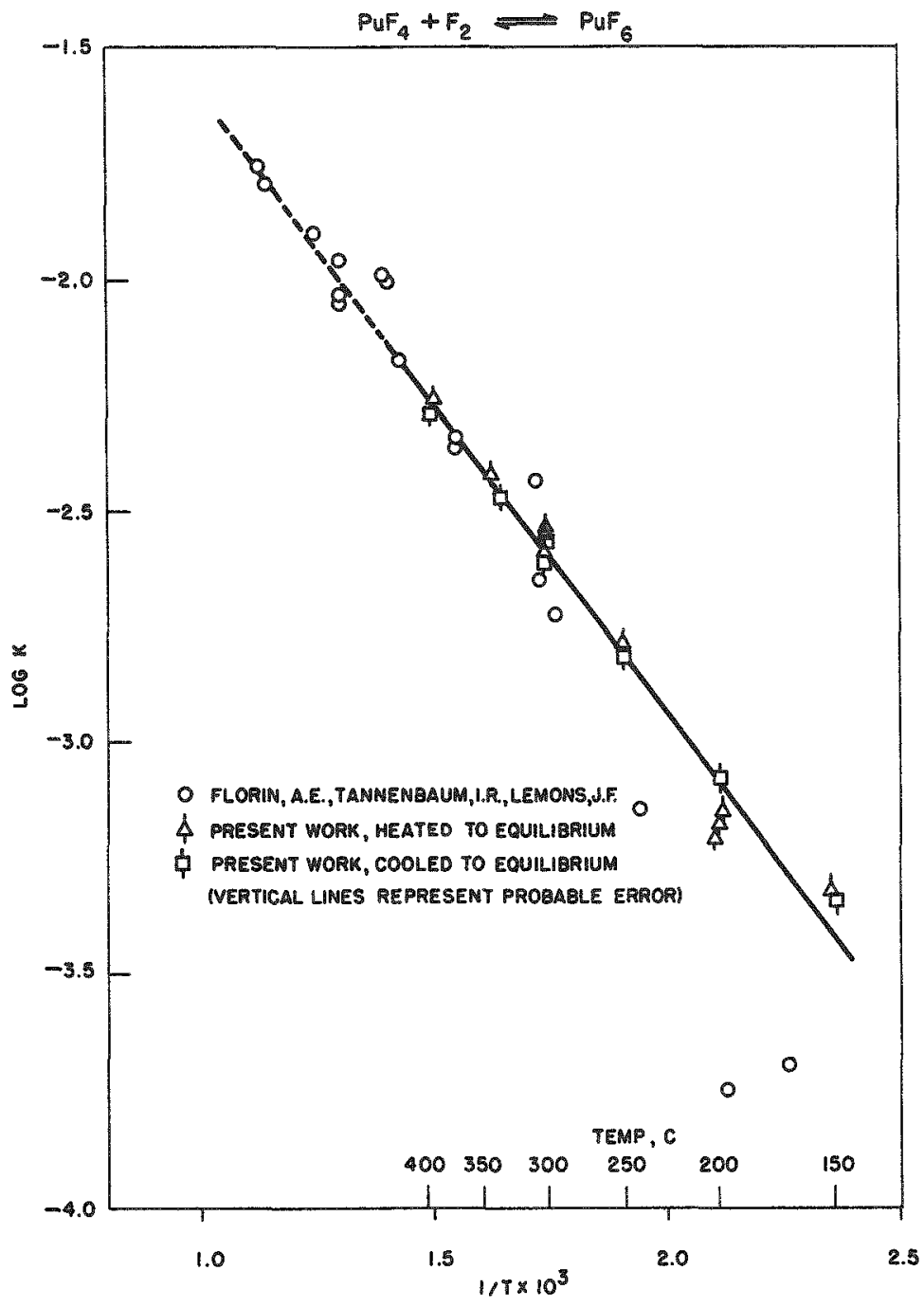

The line drawn in the figure is the result of fitting the data to an equation using the least-squares method and assuming that the error of $1 / \mathrm{T}$ is negligible compared to the error of $\log \mathrm{K}$. The equation thus determined is

$$
\log K=-(1331 / T)-0.275
$$

Values of $\Delta F^{\circ}$ for the reaction from 150 to $400 \mathrm{C}$ can be calculated from the equation

$$
\Delta F^{\circ}=-\mathrm{RT} \ln \mathrm{K}=6.09 \times 10^{3}+1.26 \mathrm{~T} \text {. }
$$

The value of $\Delta F^{\circ}$ at $275 \mathrm{C}$ is calculated to be $6.78 \pm 0.09 \mathrm{kcal} / \mathrm{mole}$. The mean $\Delta H^{\circ}$ for the reaction has been calculated from the slope of the line 
as $6.09 \pm 0.14 \mathrm{kcal} / \mathrm{mole}$. From the equation $\Delta F^{\circ}=\Delta H^{\circ}-T \Delta S^{\circ}$, the mean $\Delta S^{\circ}$ for the reaction has been calculated as $-1.3 \pm 0.2 \mathrm{cal} /(\mathrm{mole})(\mathrm{deg})$. The uncertainties listed are probably errors.

\section{Plutonium Hexafluoride Studies - Separations Chemistry (M. J. Steindler, D. V. Steidl)}

The chemistry of plutonium hexafluoride is important in fluoride separations processes for irradiated reactor fuels. Direct fluorination of oxide fuels as well as subsequent separation and decontamination steps require information on plutonium hexafluoride which is not now available. A study which will permit evaluation of variables important to plutonium hexafluoride processing has been started. Several aspects of plutonium hexafluoride handling have been investigated and a brief summary of the results is presented below.

The loss of plutonium hexafluoride due to decomposition during transfer at pressures below $120 \mathrm{~mm}$ mercury through a heated (300 C) nickel wool-packed furnace tube was investigated. An initial decrease in the per cent of plutonium hexafluoride decomposed per second with the amount of plutonium deposited on the packing is shown in Table 9.

\section{Table 9}

\section{DECOMPOSITION OF PLUTONIUM HEXAFLUORIDE AT 300 C ON NICKEL WOOL}

Surface area of nickel wool packing: $100 \mathrm{sq} \mathrm{cm}$

\begin{tabular}{|c|c|c|c|c|}
\hline $\begin{array}{l}\text { Time } \\
\text { (min) }\end{array}$ & $\begin{array}{c}\text { PuE }_{6} \\
\text { Transferred } \\
\text { (g) }\end{array}$ & $\begin{array}{c}\mathrm{PuF}_{6} \\
\text { Decomposed } \\
(\%)\end{array}$ & $\begin{array}{c}\% / \mathrm{sec} \\
\text { Decomposed }\end{array}$ & $\begin{array}{c}\text { Cumulative } \mathrm{PuF}_{4} \\
\text { on packinga } \\
(\mathrm{mg} / \mathrm{sq} \mathrm{cm})\end{array}$ \\
\hline 3 & 0.7518 & 73.2 & 0.40 & 0.4913 \\
\hline 8 & 0.8106 & 66.9 & 0.14 & 1.2425 \\
\hline 5 & 0.7187 & 61.5 & 0.20 & 1.6368 \\
\hline 6 & 0.6548 & 74.1 & 0.21 & 2.0692 \\
\hline 5 & 0.4148 & 64.7 & 0.21 & 2.3088 \\
\hline
\end{tabular}

at the end of each experiment

No further decrease in decomposition rate was observed after $1.4 \mathrm{mg} / \mathrm{sq} \mathrm{cm}$ of plutonium had been deposited on the packing. The rate of decomposition remains constant with increasing plutonium content of the packing. Experim ments using uranium hexafluoride have shown that no loss by decomposition takes place under comparable conditions. The separation of plutonium hexafluoride from uranium hexafluoride, therefore, appears feasible. Refluorination of plutonium from the packing has not been entirely satisfactory, sincelow recoveries (ca 50 per cent) were obtained. It is believed that improved equipment design will alleviate this problem. 
Transfer of plutonium hexafluoride by vacuum sublimation through long (30-foot) paths and miscellaneous laboratory equipment containing valves and flare fittings has been shown to be possible with small losses (ca 5 per cent). Improvement of these transfers to levels acceptable for process use is anticipated by both a better knowledge of prefluorination conditions and improved equipment design. The absolute loss of plutonium hexafluoride is probably related only to the interior surface of the equipment and not to the amount of hexafluoride transferred. The weight of hexafluoride remains relatively constant; with large-scale transfers the per cent lost by decomposition on the walls of the equipment decreases.

Samples of condensed plutonium hexafluoride have been held at room temperature for several days to determine the practical rates of decomposition due to alpha radiation decomposition. Rates between 2 and 3 per cent per day have been obtained; these are only slightly greater than those reported in the literature. 8

\section{Reaction of Plutonium Tetrafluoride-Uranium Tetrafluoride Mixtures and Elemental Fluorine (M. Steindler, H. Griffin)}

A knowledge of the reaction of mixtures of plutonium and uranium compounds with elemental fluorine is important in the development of the direct fluorination process for irradiated reactor fuels. As an initial study, the reaction of plutonium and uranium tetrafluoride mixtures with fluorine was investigated. Mallinckrodt uranium tetrafluoride was mixed with plutonium tetrafluoride. It was necessary to mix the powders by prolonged grinding in order to assure homogeneity of the sample. Samples of powders were analyzed for plutonium by standard counting techniques and for uranium by wet chemical methods appropriate to the range of concentration in the solutions. The analytical results for plutonium in the residue, obtained by alpha counting, were corrected for retention of the americium. Although Am ${ }^{241}$ represents a negligible weight fraction of the plutonium, the contribution to the total alpha count may be as high as 2 per cent. It was assumed, based on the chemistry of americium fluorides, that none of the americium had been volatilized during the fluorination.

Fluorination reactions were conducted in apparatus described previously (ANL-5875, page 5). A weighed sample of the mixture was contained in a hemicylindrical nickel boat and fluorinated by passing gaseous fluorine at one atmosphere pressure over the heated sample. A mixture containing 1 weight per cent plutonium tetrafluoride-99 weight per cent uranium tetrafluoride was chosen for these experiments as representing the plutonium concentration in highly irradiated uranium reactor fuels.

\footnotetext{
${ }^{8}$ Weinstock, B. and Malm, J.G., J.Inorg.Nucl.Chem.2, 380 (1956).
} 
Analysis of the residue was used to indicate the amounts of uranium and plutonium volatilized. The results of the experiments are shown in Table 10 and Figure 21. Approximately 85 per cent of the uranium is volatilized before any plutonium is lost from the sample.

Table 10

FLUORINATION OF 1 WEIGHT PER CENT PLUTONIUM TETRAFLUORIDE-URANIUM TETRAFLUORIDE MIXTURES

Initial Composition

Temperature of Fluorination

Fluorine Flow Rate

Fluorine Pressure

$$
\begin{aligned}
& 0.96 \mathrm{w} / \mathrm{OPuF}_{4}, 99.0 \mathrm{w} / \mathrm{OUF}_{4} \\
& 200 \mathrm{C} \\
& 75 \text { to } 100 \mathrm{cc} / \mathrm{min} \\
& \text { one atmosphere, } 100 \% \text { fluorine }
\end{aligned}
$$

\begin{tabular}{|c|c|c|c|c|}
\hline \multirow{2}{*}{$\begin{array}{c}\text { Sample } \\
\text { Weight } \\
\text { Initial } \\
\text { (mg) }\end{array}$} & \multirow{2}{*}{$\begin{array}{c}\text { Sample } \\
\text { Weight } \\
\text { Final } \\
\text { (mg) }\end{array}$} & & \multicolumn{2}{|c|}{ Residue Analysis } \\
\hline & & $(\min )$ & $\%$ of original $\mathrm{PuF}_{4}$ & $\%$ of original $\mathrm{UF}_{4}$ \\
\hline 428.6 & 389.0 & 10 & 102.4 & 91.3 \\
\hline 401.6 & 289.8 & 30 & 101.5 & 71.8 \\
\hline 394.1 & 171.3 & 60 & 102.1 & 42.3 \\
\hline 396.2 & 88.1 & 90 & 101.6 & 21.1 \\
\hline 401.7 & 64.1 & 120 & 102.3 & 14.6 \\
\hline 396.7 & 33.3 & 180 & 91.1 & 7.5 \\
\hline 401.8 & 5.2 & 240 & 51.8 & 0.7 \\
\hline
\end{tabular}

The rate of fluorination of uranium tetrafluoride has previously been shown to be faster than that for plutonium tetrafluoride (see ANL-5896, page 27 and ANL-5875). The rate of removal of uranium tetrafluoride is therefore greater than that for plutonium tetrafluoride. In addition, the rate of fluorination of plutonium tetrafluoride is expected to be relatively low because of its low surface concentration (1 weight per cent max). Finally, the reaction

$$
\mathrm{PuF}_{6}+\mathrm{UF}_{4} \longrightarrow \mathrm{PuF}_{4}+\mathrm{UF}_{6}
$$

has an estimated free energy at $200 \mathrm{C}$ of $-34 \mathrm{kcal}$ and could contribute to the retention of plutonium in the residue. Although the relative contributions of these three factors cannot be ascertained, it is probable that the geometry of the experimental system negates the efficient retention of plutonium by reduction of the hexafluoride. The reduction of plutonium hexafluoride can be expected to be important, however, in fluid-bed columns and other chemical reactors. The retention of plutonium may be used to 
FIGURE 21

FLUORINATION OF ONE WEIGHT PER CENT

PLUTONIUM TETRAFLUORIDE-URANIUM TETRAFLUORIDE

WITH FLUORINE AT $200 \mathrm{C}$

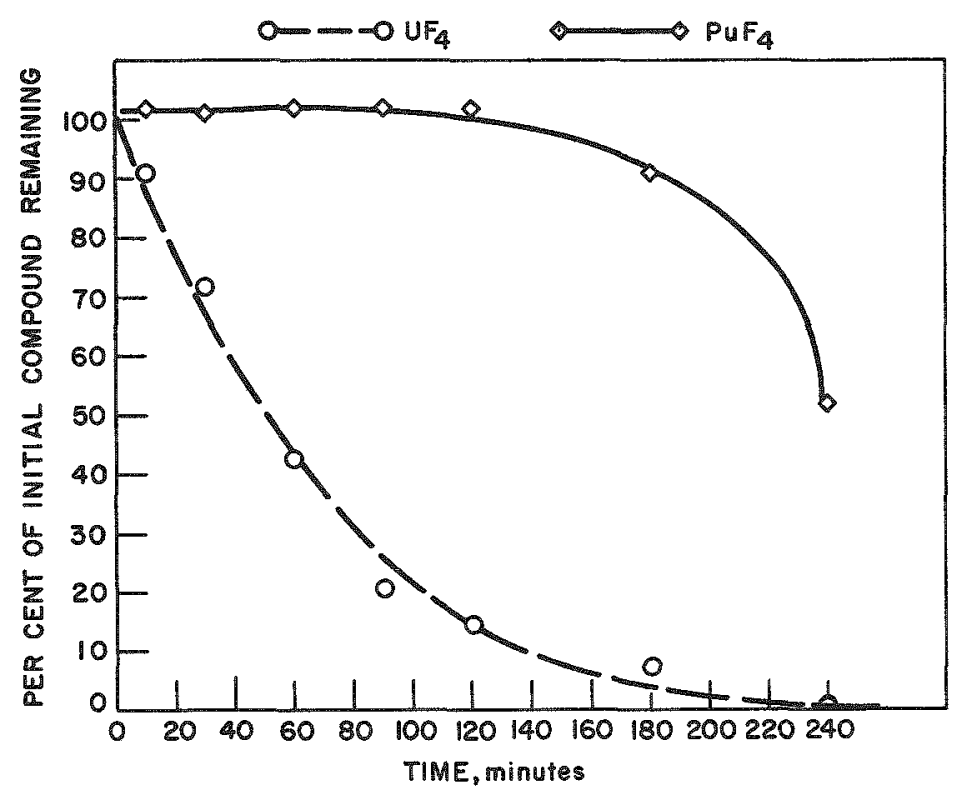

advantage in a process step in which an enrichment of the solid in plutonium is desired without excessive loss of plutonium from the system as the volatile hexafluoride. It may also be possible, using suitable equipment and fractionation procedures, to effect a separation of uranium and plutonium in the fluorination step.

Similar experiments will be tried starting with mixed uranium and plutonium oxides.

4. Complete Fluorination of Uranium Tetrafluoride-Plutonium Tetrafluoride Mixtures (M. J. Steindler, H. Griffin)

The ability to fluorinate completely samples of mixed uranium and plutonium tetrafluorides has been demonstrated. Mixtures of plutonium tetrafluoride and uranium tetrafluoride were fluorinated in equipment described previously (ANL-5875). The results, shown in Table 11, indicate that while a 50 weight per cent plutonium tetrafluoride sample required one hour at $450 \mathrm{C}$ for complete fluorination, samples containing 1 , 5, or 25 weight per cent plutonium tetrafluoride reacted at $375 \mathrm{C}$ in one hour or less. 
Table 11

\section{COMPLETE FLUORINATION OF PLUTONIUM TETRAFLUORIDE-URANIUM TETRAFLUORIDE MIXTURES}

Fluorine Pressure:

Flow Rate:

Time of Fluorination:

Temperature of Fluorination:
1 atmosphere, $100 \% \mathrm{~F}_{2}$ approximately $75 \mathrm{cc} / \mathrm{min}$ 60 minutes except where indicated $375 \mathrm{C}$ except where indicated

\begin{tabular}{|c|c|c|}
\hline $\begin{array}{l}\text { Composition } \\
\left(\mathrm{w} / \mathrm{O} \mathrm{PuF}_{4}\right)^{\mathrm{a}}\end{array}$ & $\begin{array}{c}\text { Initial } \\
\text { Sample } \\
\text { Weight } \\
\text { (mg) }\end{array}$ & $\begin{array}{c}\text { Final } \\
\text { Sample } \\
\text { Weight } \\
\text { (mg) }\end{array}$ \\
\hline 0.96 & 218.2 & -0.2 \\
\hline 0.96 & 210.7 & $\sim 1.7$ \\
\hline 4.30 & 195.7 & 0 \\
\hline 4.30 & 207.3 & 0.1 \\
\hline 24.0 & 220.1 & 0.4 \\
\hline $49.1^{b}$ & 169.6 & 0 \\
\hline $0.96^{c}$ & 398.7 & 0 \\
\hline $0.96^{d}$ & 399.0 & 0 \\
\hline $0.96^{d}$ & 208.4 & 0.3 \\
\hline \multicolumn{3}{|l|}{$w / \circ \mathrm{PuO}_{2}{ }^{\mathrm{a}}$} \\
\hline $1.00^{\mathrm{e}}$ & 108.5 & $\sim 1$ \\
\hline
\end{tabular}

\footnotetext{
${ }^{2}$ Remainder uranium hexafluoride;

$\mathrm{d}_{\text {Time }}=10$ minutes

$\mathrm{b}_{\mathrm{T}}=450 \mathrm{C}$

e 400 C. 60 minutes

$\mathrm{c}_{\text {Time }}=30$ minutes
}

\section{Fluorination of Irradiated Uranium Oxide (M. Steindler, T. Gerding, G. Redding)}

In order to evaluate the Direct Fluorination Process for oxide fuels, a qualitative knowledge of the behavior of the fission products is desirable, and so is information on the necessity of an oxidation step prior to fluorination of the fuel. Small samples ( 2 to $4 \mathrm{~g}$ ) of sintered uranium dioxide pellets were irradiated for 28 hours in CP -5 , cooled for 24 hours, and treated with oxygen and/or fluorine. The samples were reacted in a flow system while heated in a furnace tube which was connected to two product-collection traps. The product traps were cooled to $-80 \mathrm{C}$ during the experiments. The contents of the traps were scanned by a 256-channel gamma analyzer. The conditions of the reaction and results were as follows: 
1. Oxidation of irradiated uranium at $375 \mathrm{C}$ for 30 minutes using tank-grade oxygen: volatilized bromine, molybdenum, technetium, iodine, tellurium, and niobium.

2. Fluorination of irradiated uranium dioxide at $375 \mathrm{C}$ for $15 \mathrm{~min}$ utes using 100 per cent fluorine at atmospheric pressure: volatilized uranium, neptunium, arsenic, bromine, niobium, molybdenum, technetium, ruthenium, tellurium, and iodine.

3. Oxidation of irradiated uranium dioxide at $375 \mathrm{C}$ for 30 minutes, followed immediately by fluorination at $375 \mathrm{C}$ for 15 minutes: volatilized the same fission products as those obtained in the direct fluorination. No other fission products were observed.

It was not possible to determine if technetium was volatilized independently of molybdenum or if its detection was due to the molybdenumtechnetium equilibrium. Additional experiments using highly irradiated oxide are required before valid conclusions concerning fission product dis position can be reached. It appears that, other than for decladding purposes, oxidation of irradiated uranium dioxide offers no process advantage over direct fluorination. 


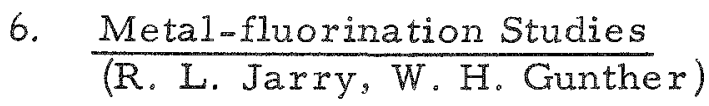

The objectives of this program are to investigate the kinetics and mechanisms of metal-fluorine reactions. Knowledge concerning such reactions are important to processes being considered or already in operation. This report covers work on the nickel-fluorine system and future work will include the reactions of fluorine systems with uranium, zirconium, and copper.

The mechanisms given for metal oxidation reactions, in which an adherent film is produced, have involved the migration of one or both of the species present. In the classical examples, nickel-oxygen and copperoxygen, the migrating species is believed to be the cation. The mechanism is considered to be diffusion controlled through cationic vacancies.

To study the mechanism of the reaction of fluorine with nickel, nickel-63 was employed as a tracer. Autoradiography and radiation counting were used to indicate the nickel-63 distribution in the sample after fluorination. The distribution of the activity in the fluorine film would indicate which species, nickel or fluorine, migrates during film growth. The position of the radioactive nickel, whether at the nickel-film or film-fluorine interface, would indicate migration of nickel or fluorine, respectively.

A-nickel specimens, $1 \mathrm{~cm}$ by $5 \mathrm{~cm}$ and $\frac{1}{16}$ in. thick, were used. The major impurities in this A-nickel ( 99.4 per cent purity) were given in ANL-6029, page 83. A plate of radionickel, approximately 2.5 microns in thickness, was electrolytically deposited on the lower $2 \mathrm{~cm}$ of one face of the coupon while the remainder of the coupon was masked with paraffin. The nickel-63 was obtained from ORNL in the form of an acidic chloride solution with total activity of 5 millicuries. The specific activity of the nickel was 12.86 millicuries per gram of nickel. Concentrated ammonium hydroxide was added to the solution, resulting in the characteristic deep blue color of the amine complex. The radionickel was plated on the nickel coupon using a current density of 7.5 milliamp per sq $\mathrm{cm}$ at 2.2 volts to produce an adherent plate having a dull luster.

The fluorination step was carried out in a tube reactor (described in ANL-6029, page 80). Prior to the admission of fluorine and the start of the heating cycle, the reactor was evacuated and kept at a pressure of about $1 \times 10^{-4} \mathrm{~mm}$ mercury for several hours. In order to obtain a sufficiently thick fluoride film, the fluorinations were carried out for 15 hours at $700 \mathrm{C}$ in a static system (initial fluorine pressure $1 \mathrm{~atm}$ ). Several samples were prepared in this manner; the thicknesses of the resulting fluoride films were in the ordex of 25 microns. The layer of radionickel fluoride comprised about one-fifth of this film. 
The autoradiographic method has been described by Gomberg and coworkers. 9 By means of this technique the sample could be mounted, sectioned and polished by standard metallurgical procedures. A piece of stripping film emulsion (Kodak Experimental Permeable Base) was placed on the polished section and sufficient exposure time, about five days, was allowed to obtain a good image. The emulsion was then developed in place on the mount and, after drying, was ready for microscopic examination. It was difficult to observe the details of the image while on the mount; therefore, the emulsion was removed and placed on a glass slide.

Radiation counting of these samples was made with a proportional counter, sensing the $K$-capture $X$ ray which results from the decay of nickel-59. The nickel-59 was present along with the nickel-63 in the sample.

The results obtained through the use of these two techniques (autoradiography and counting) were complementary. Both methods showed the radioactive portion to be concentrated in the surface of the film at the nickel fluoride-fluorine interface. Examination showed that the emulsion had replicated the surface of the specimen. This replication allowed the position of the radionickel to be located unambiguously with relation to the film and substrate. Figure 22 is a photomicrograph of an autoradiograph on a cross section of a coupon having a nickel-63 plate of about 2.5-micron thickness, the same as that for the fluorinated specimen shown in Figure 23 , which is a microphotograph of the emulsion, mounted on a microscope slide, showing the darkened area corresponding to the position of the nickel-63.

In Table 12 are listed the counting results for three samples: (1) an unfluorinated coupon having a plate of approximately 2.5 -micron thickness, (2) a detached nickel fluoride film containing radionickel, and (3) a fluorinated coupon with an adherent film. The relative counts for the unfluorinated and fluorinated nickel-63 and those for the detached film indicate that the nickel- 63 was on the surface of the fluoride film, thereby substantiating the radiographic results.

While a mechanism cannot be deduced from these results, they do allow certain possibilities to be eliminated and others favored. The consistent finding of the nickel-63 at the film-fluorine interface rules out migration of nickel through the fluoride film and, therefore, indicates that fluorine is the species migrating. However, the results do not indicate the state in which the fluorine exists during migration, whether it is ionic, molecular, or atomic.

On examining sections of A-nickel coupons fluorinated at $700 \mathrm{C}$ for 65 hours, considerable intergranular attack was noted. Figure 24 is a photomicrograph, at approximately $750 \mathrm{X}$, of a polished and etched section

${ }^{9}$ Gomber, H. J. et al., High Resolution Autoradiography for Study of Grain Boundaries in $\overrightarrow{M e t a l s}$, Project2029. Contract DA20-018-ORD-12150, Univ of Michigan, (February 1954). 
Figure 22

AUTORA DIOGRAPH OF CROSS SECTION OF NICKEL-6.3 PLA TED NICKEL COUPON

Coupon:

A-Nickel; Nickel-63 Plate Approximately 2. 5 Microns Thick.

Autoradiograph. Exposure 5 Days, Kodak Ex perimental Permeable Base Strupping Film.

Magnification: Approx $270 \mathrm{X}$.

Figure 23

AUTORADIOGRAPH OF CROSS SECTION OF NICL LL COUPON AND FLUORIDE FILM SHOWING RADIO-NICKEL L IYER

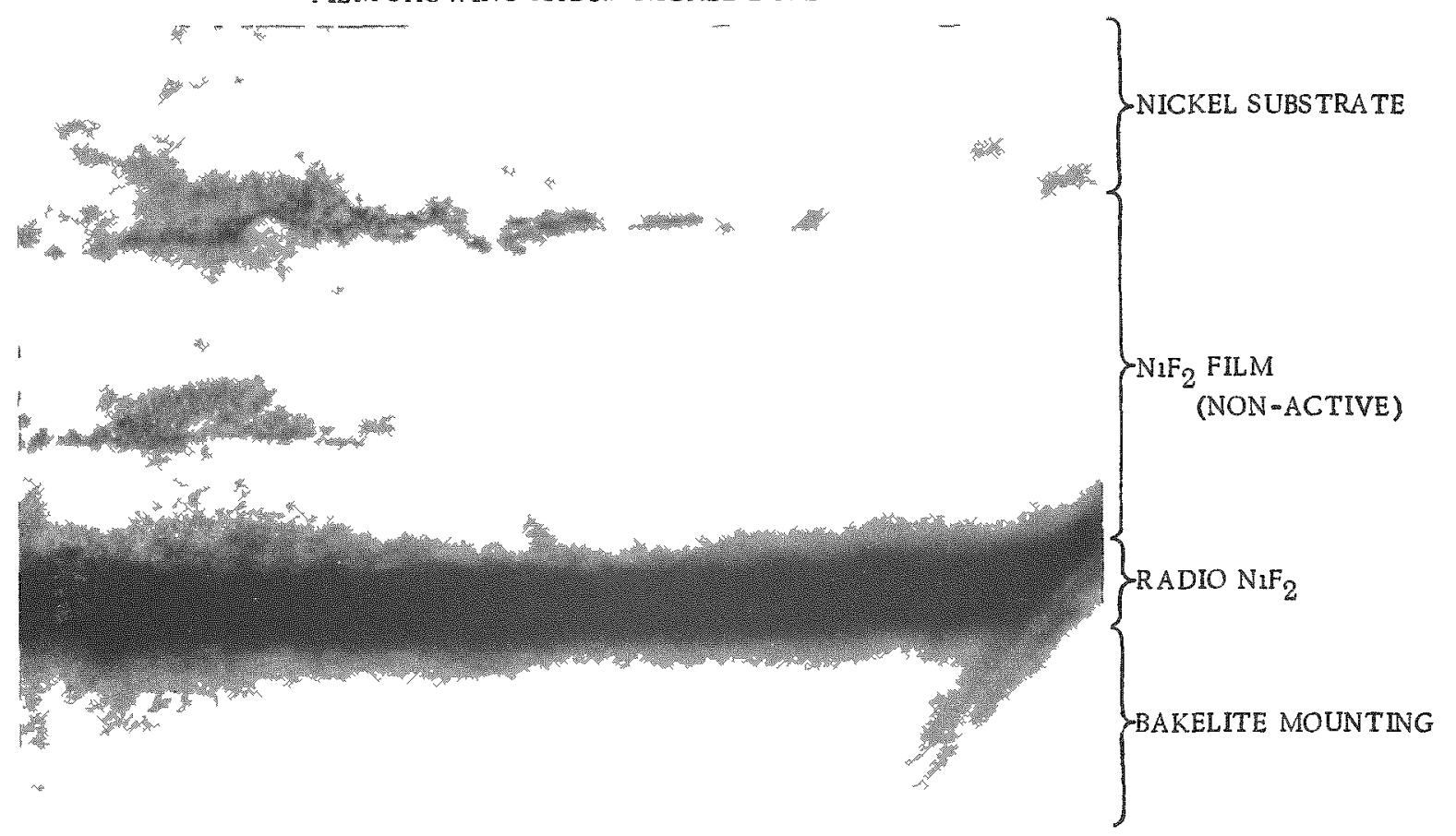

Coupon $4-$ Nickel, Hormated for 15 hr de $700 \mathrm{C}$ in Static System. Autoradiograph Exposure 5 Days, Kodak Expermental Pemeable Base Strupping Film.

Magnification Approx $270 \mathrm{X}$. 
LOCATION OF THE RADIO NICKEL PORTION OF FLUORIDE FILMS BY PROPORTIONAL COUNTING

Sample

(1) Unfluorinated Coupon

(a) Active Surface

(b) Nonactive Surface

(2) Detached $\mathrm{NiF}_{2}$ Film

(a) Film-Fluorine Surface

100

(b) Film-Nickel Surface

(3) Coupon with Adherent Film

(a) Film Surface, Active Side

(b) Film Surface, Nonactive Side

\section{Relative Counts per Minute ${ }^{a}$}

a The maximum peak height was taken as 100 .

Figure 24

MICROP HOTOGRAPH OF CROSS SECTION OF FLUORINA TED NICKEL COUPON SHOWING INTERGRANULAR ATTACK

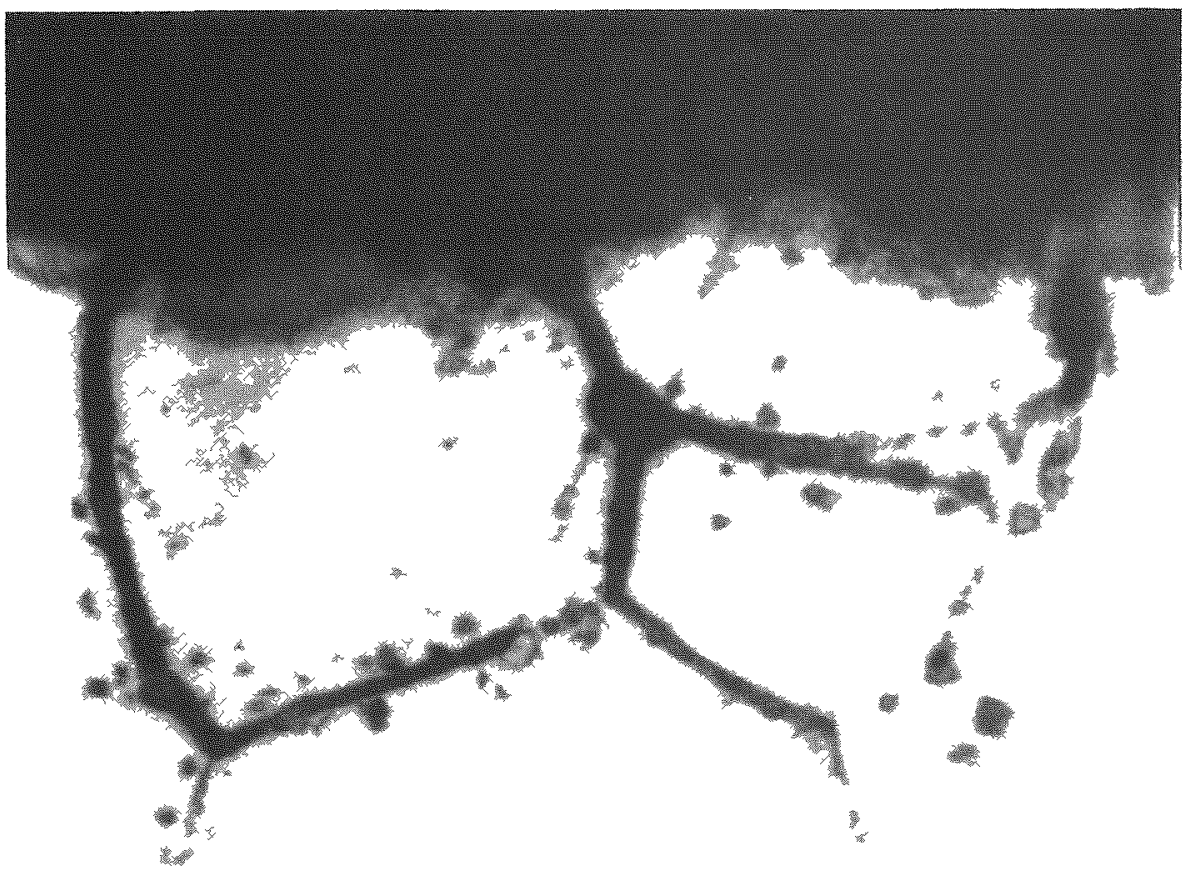

Coupon: A-Nickel, Fluormated for 65 hr at $700 \mathrm{C}$ in a Stanc System Magnification: Approx $750 x$. 
of one of these coupons. The intergranular areas shown, which penetrate up to 80 microns into the base metal and are at points 5 to 10 microns wide, appear as voids, a fact which was verified by focusing to various depths under high magnification. The production of these voids can be accounted for by the fluorination and volatilization of impurities. The impurities could be concentrated in the intergranular areas during grain growth, which would occur during the fluorination period.

The effect that a prior heat treatment would have on intergranular attack upon fluorination was investigated. An A-nickel coupon was heat treated at $850 \mathrm{C}$ under vacuum for $16 \frac{1}{2}$ hours. The heat-treated coupon and an untreated one were then fluorinated at $700 \mathrm{C}$ for 64 hours. The heattreated coupon showed no intergranular attack, whereas the untreated coupon showed the usual severe attack.

During the course of fluorination runs it was noted that at the higher temperatures $(700 \mathrm{C})$ the films were often not adherent. The specimens were heated to the selected temperature before the fluorine was added. The procedure was changed so that the fluorine was added while the specimens were at room temperature. The specimens were then heated to $700 \mathrm{C}$ and it was found that the adherence of the films was materially improved. Apparently, the slow initial buildup of the film allowed the production of a subsequent thicker film with good adherence.

\section{B. ADF Process Development for Enriched Uranium-Zirconium Fuel}

The ADF process involves the dissolution of irradiated fuels in aqueous acids, conversion of the solution to dry granular solids by evaporation or calcination, and fluorination to volatilize and separate the uranium as the hexafluoride. The process is applicable to a wide variety of fuels, but initial development is being directed toward zirconium-base fuels containing fully enriched uranium. In this case the fuel is dissolved in aqueous hydrofluoric acid containing an oxidant, such as hydrogen peroxide or nitric acid, whose purpose is to solubilize the uranium by conversion to the hexavalent state. Since development work on the dissolution step is being carried out in other laboratories in connection with solvent extraction processes, no work is being done here on this step.

Conversion of the fuel solution into dry solid salts is being carried out in a fluidized-bed dryer, because this enables the preparation of a freeflowing solid easily transferred out of the vessel. The product resulting from drying is a mixture of zirconium fluoride salts with small amounts of uranium and other fluorides. In addition to anhydrous zirconium tetrafluoride, varying amounts of the oxyfluoride and the monohydrated tetrafluoride are present, depending upon drying temperature and the ratio of hydrogen fluoride to water in the feed solution. These compounds can be converted to zirconium tetrafluoride by hydrofluorination of the dryer product. 
Experimental work previously performed on both laboratory and engineering scales indicates that separation of uranium from the zirconium fluoride salts by fluorination is incomplete at temperatures below $600 \mathrm{C}$, but is essentially quantitative above $650 \mathrm{C}$. Because of sintering, fluidization is not possible at the higher temperature. The fluorination step is therefore being studied in a static (nonfluidized) bed. This may necessitate the consideration of a disposable fluorination vessel, which can also be used as the waste container.

1. Engineering-scale Studies

(N. Levitz, A. A. Jonke)

a. Fluid-bed Drying

(J. Barghusen, D. Raue, J. Kincinas)

The fluid-bed drying step of the ADF process consists of spraying fuel solution into a heated fluidized bed where the water is flash evaporated and the metal fluoride salts are deposited on the bed particles. Satisfactory operation of the dryer has been achieved in many previous runs, but since operation of the dryer is necessary to provide material for subsequent process steps, development work to improve the operation has continued. During the past quarter, runs were made with both concentrated (3.6 $\mathrm{M}$ zirconium) and dilute ( $1.5 \mathrm{M}$ zirconium) feed solutions. Additional capacity has been provided in the dryex through the use of an efficient internal autoresistance-type strip heater. An automatic blow-back system for the filters, essentially the same as that used on the radioactive waste calciner and described in ANL-5858, page 45, was installed.

\section{(1) Internal Electric Heaters}

Although the small-scale fluid-bed dryer can be heated satisfactorily through the vessel wall, larger units will require internal heaters immersed in the fluid bed in order to provide sufficient heat trans fer area. Similar units for calcination of waste or denitration of uranyl nitrate have employed various internal heating methods: liquid metal (NaK) or molten salt inside tubes, or electric resistance heaters. For a radioactive process, a highly durable and reliable heater is desired.

Experiments were therefore conducted to determine the feasibility of employing an autoresistively-heated metal strip of sufficiently massive cross section that burnout would not be a problem. Inconel was chosen for this application, but other metals such as stainless steel could be used in other gaseous environments. The new heater was made in the form of two coils (each about 5 inches in OD) from a strip 1 inch wide by $\frac{1}{16}$ inch thick by 11 feet long. The coils were positioned one above the other and connected by a welded strap. This heater adds approximately $1.8 \mathrm{sq} f \mathrm{ft}$ of heat transfer surface to the $2.4 \mathrm{sq} f t$ of area provided by the reactor wall. 
The coils were inserted into the lower section of the fluidized bed and were connected to a power source through the two lower spray nozzle ports which were not in use. These ports are 5 inches above the gas distributor plate, while the feed point is at 11 inches. The power to the coil was supplied by a 300-amp, Vickers Controlarc welding machine. The power level was generally maintained at $4.0 \mathrm{kva}$ except for a short period at $5.7 \mathrm{kva}(22 \mathrm{v}$ and $265 \mathrm{amp})$. The heater operated efficiently and without difficulty.

\section{(2) Operating Conditions}

The feed solutions for Runs ZCP-72 and ZCP-73 were prepared by dissolution of dryer products from previous runs: for Run ZCP-74 feed solution was prepared from commercially supplied zixconium fluoride solution. The requisite amounts of nickel, tin, chromium and iron were added to simulate the dissolution of a two weight per cent uraniumZircaloy-2 alloy. Feed for Runs ZCP-72 and ZCP-74 contained about $1.4 \mathrm{M}$ zirconium, $0.012 \mathrm{M}$ uranyl fluoride, $0.8 \mathrm{M}$ free acid, and $6.5 \mathrm{M}$ fluoride. Run ZCP-73 was made with a concentrated feed solution which contained 3.6 $\mathrm{M}$ zirconium (more than twice the concentration of any previous feed), $0.03 \mathrm{M}$ uranyl fluoride, $24 \mathrm{M}$ fluoride and $10.0 \mathrm{M}$ free acid. The preparation and stability of this solution was described in ANL-6068, page 98. At a temperature of $300 \mathrm{C}$ in the dryer the highly acid, concentrated feed $x e-$ sulted in a product which was primarily zirconium tetrafluoride, whereas the low-acid, dilute feed resulted in primarily zirconyl fluoride at this temperature.

The feed rates were varied throughout Runs ZCP-72 and 73 to evaluate the capacity of the dryer with the internal strip heater. Peak operations with the dilute and concentrated feed solutions were 210 and $160 \mathrm{ml} / \mathrm{min}$, respectively. The latter represents an increase in throughput by a factor of 2.7 over previous runs.

The nozzles were the same as used previously (see Figure 24, ANL-6068, page 94). Both the feed atomizing air and the auxiliary attrition jet, an 0.047 -inch orifice, provided some attrition in the bed to counteract particle growth. The fluidizing air rate, which includes air from the attrition jet, was about $1.4 \mathrm{ft} / \mathrm{sec}$.

\section{(3) Operating Performance and Evaluation}

The operation of the fluid-bed dryer has continued to be satisfactory. Accumulated running time with the new nozzles is now about 165 hours. The internal Inconel strip heater allowed operation of the dryer at feed rates above $200 \mathrm{ml} / \mathrm{min}$. Only about one-half of the total power required was supplied by the external calrod heaters during the runs. It is estimated that heat input efficiency of the calrod heaters was about 75 per cent; the efficiency of the combined external and internal heaters was 
estimated to be 90 per cent. The automatic blow-back system was troublefree during the runs and completely eliminated any need for manually blowing-back the filters.

Operation of the dryer at the high feed rates (over $100 \mathrm{ml} / \mathrm{min}$ for concentrated feed and over $150 \mathrm{ml} / \mathrm{min}$ for dilute feed) $\mathrm{re}-$ sulted in particle growth in the bed in the form of agglomerates. Evidently at high feed rates both particle coating and agglomeration contribute to particle growth. Microscopic examination of the particles showed those from the concentrated feed to be somewhat more porous than the others. The existing supply of attrition air was apparently not great enough to overcome the growth, and it is planned to increase the supply by enlarging the attrition jet orifice and introducing a second jet through a spray nozzle port in the column wall. An increase in the atomizing air rate to effect additional attrition resulted in the formation of deposits on the wall opposite the nozzle, so this method will not be pursued further. All of the dryer products will be used in fluorination studies.

Since both water and oxygen, found in the fluid-bed. dryer products, waste fluorine and are suspected of inhibiting uranium removal during fluorination, several batches of dryer product were hydrofluorinated in the dryer in order to remove these species prior to fluorination tests.

b. Separation of Uranium from Uranium-Zirconium Fluoride Mixtures by Fluorination

Previous experimental work has shown that temperatures above $650 \mathrm{C}$ are required for complete separation of uranium as the hexafluoride from the solid fluoride mixtures obtained by fluid-bed drying of uranium-zirconium alloy fuel solutions. Fluid-bed fluorination has not been possible at these temperatures because of caking (sintering) problems encountered at temperatures near $600 \mathrm{C}$. Static-bed fluorinations have therefore been carried out in both bench-scale and pilot-scale equipment. At temperatures near $700 \mathrm{C}$ the desired uranium removal $(<0.008$ per cent residual)* has been obtained in a number of runs using reactors of 2,3 and 6-inch diameters.

(1) Bench-scale Static-bed Fluorination Studies (Tables 15 and 16)

(J. Barghusen, N. Levitz)

Laboratory experiments were performed in a vertical two-inch diameter reactor. Two methods for fluorine introduction (batch injection and continuous flow) were compared.

* Limit of X-ray analytical method 
The procedure for the experiments involving batch injection of fluorine consisted of charging the powder (250 to $600 \mathrm{~g} / \mathrm{charge}$ ) to the bomb, evacuating the bomb, heating to about $700 \mathrm{C}$, and adding fluorine to 750 or $1500-\mathrm{mm}$ mercury pressure at the prescribed temperature. Both hydrofluorinated dryer product and previously fluorinated residues were used. The fluorine was allowed to react for the specified time (5 or 15 minutes) and was then evacuated along with the reaction products through an aluminum oxide trap. The number of exposures was varied from one to six in the se studies.

For the experiments with flowing fluorine a down-leg was installed so that the fluorine was introduced at the bottom of the vessel and allowed to flow upward continuously through the charge. A helium purge was used during the heating period. Samples were obtained from both the top and bottom portions of the solid cake, which was found to be quite hard after the $700 \mathrm{C}$ exposure.

The results of the batch fluorination experiments (Table 13) indicate that uranium removal increases with the number of exposures to fluorine; however, with the amount of fluorine and number of exposures used, the desired uranium removal was not achieved. Only insignificant amounts of uranium were removed at fluorine-to-powder ratios of 0.014 or less (Runs 1,2, and 5), probably because the fluorine was reacting with unconverted zirconium oxyfluoride. Much better uranium removal was obtained at a fluorine-to-powder ratio of 0.053 (Runs $6,7,8$ ). The results of five-minute exposure (Run 8 ) were equal to those from the I5-minute exposures (Runs 6 and 7 ), indicating that the exposure time is a relatively unimportant variable. No improvement was noted when the fluorine was first introduced at room temperature (Run 7). In the cases where the same depletion of uranium occurred at the top of the cake, the uranium concentration near the bottom increased to a concentration above that in the starting material. This indicates that uranium hexafluoride can react with constituents of the bed, possibly with zirconyl fluoride, and be redeposited.

This behavior also occurred in the flowing system, that is, the uranium concentration near the fluorine inlet point (the bottom) was often much lower than that at the top of the cake. Much better uranium removal occurred in the flowing system experiments (see Table 14) where higher ratios of fluorine to powder were used. The desired removal ( $<0.008 \mathrm{w} / 0$ residue concentration) was achieved in Run 11 , in which a weight ratio of fluorine to powder of 0.25 was employed. However, the uranium removal was not as good in Run 12, even though the fluorine-to-powder ratio was higher and the fluorination time longer than in Run 11. This may indicate that the efficiency of gas-solid contact was lower in Run 12. Much better efficiency with respect to fluorine-to-solid ratio would be expected in a larger unit where gas-solid contact would be improved. 
Table 13

SUMMARY OF BENCH-SCALE STATIC-BED FLUORINATION EXPERIMENTS

(Batch Fluorine Contacts)

$\begin{array}{ll}\text { Equipment } & \text { 2-inch diametex } \times 12 \text {-inch long nickel tube } \\ \text { Temperature } & 700 \mathrm{C}\end{array}$

\begin{tabular}{|c|c|c|c|c|c|c|c|c|c|}
\hline \multirow[b]{3}{*}{$\begin{array}{l}\text { Run } \\
\text { No. }\end{array}$} & \multirow[b]{3}{*}{$\begin{array}{l}\text { Starting } \\
\text { Material }\end{array}$} & \multirow{3}{*}{$\begin{array}{l}\text { Weight } \\
\text { of } \\
\text { Charge } \\
\text { (g) }\end{array}$} & \multirow{3}{*}{$\begin{array}{l}\text { Number of } \\
\text { Fluorine } \\
\text { Exposures }\end{array}$} & \multirow{3}{*}{$\begin{array}{c}\text { Total } \\
\text { Fluorination } \\
\text { Time } \\
\text { (min) }\end{array}$} & \multirow{3}{*}{$\begin{array}{l}\text { Fluorine } \\
\text { Pressure } \\
\text { (mm Hg) }\end{array}$} & \multirow[b]{3}{*}{$\frac{\mathrm{g} F_{2}}{\mathrm{gPowder}}$} & \multicolumn{3}{|c|}{ Uranium conc $(w / o)$} \\
\hline & & & & & & & \multirow[b]{2}{*}{ Initial } & \multicolumn{2}{|c|}{ Final } \\
\hline & & & & & & & & Top & Bottom \\
\hline$B F-1$ & $\begin{array}{l}\text { Fluorinated } \\
\text { Residue } \\
(\mathrm{U}-\mathrm{Z} x-38)\end{array}$ & 600 & 1 & 15 & 760 & 0.002 & 0.44 & 0.42 & 0.40 \\
\hline$B F-2$ & $\begin{array}{l}\text { Fluorinated } \\
\text { Residue } \\
(\mathrm{U}-\mathrm{Zr}-37)\end{array}$ & 550 & 2 & 30 & 760 & 0.004 & 0.11 & 0.08 & 0.07 \\
\hline $\mathrm{BF}-5$ & $\begin{array}{l}\text { Hydrofluori- } \\
\text { nated Dryex } \\
\text { Product } \\
(\mathrm{ZCP}-71)\end{array}$ & 500 & 3 & 45 & 1500 & 0.014 & 0.21 & 0.23 & 0.20 \\
\hline BE -6 & $"$ & 250 & 6 & 90 & 1500 & 0.053 & 0.21 & 0.04 & 0.17 \\
\hline$B F-7^{b}$ & " & 250 & 6 & 90 & 1500 & 0.053 & 0.21 & 0.04 & 0.27 \\
\hline$B E-8$ & $"$ & 250 & 6 & 30 & 1500 & 0.053 & 0.21 & 0.02 & 0.64 \\
\hline
\end{tabular}

aseparate exposures of 15 minutes duration except in Run BF-8, where five minutes was used.

bFluorine was initially introduced at room temperature.

Table 14

SUMMARY OF LABORATORY FLUORINATION EXPERIMENTS

(Flowing Fluorine System)

\begin{tabular}{|c|c|c|c|c|c|c|c|c|}
\hline \multirow[b]{4}{*}{ Run No. } & \multirow{4}{*}{$\begin{array}{l}\text { Starting } \\
\text { Material }\end{array}$} & \multicolumn{2}{|c|}{ Equipment } & \multicolumn{5}{|c|}{-inch diameter $\times 12$-inch tube } \\
\hline & & \multirow{3}{*}{$\begin{array}{c}\text { Weight of } \\
\text { Charge } \\
\text { (g) }\end{array}$} & \multirow{3}{*}{$\begin{array}{c}\text { Total } \\
\text { Time } \\
(h r)\end{array}$} & \multirow{3}{*}{$\begin{array}{c}\text { Temperature } \\
\text { (C) }\end{array}$} & \multirow[b]{3}{*}{$\frac{\mathrm{g} \mathrm{F}}{\text { g Powder }}$} & \multicolumn{3}{|c|}{ Uranium Conc $(w / 0)$} \\
\hline & & & & & & & & hal \\
\hline & & & & & & Initial & Top & Bottom \\
\hline \multirow[t]{2}{*}{$\mathrm{BF}-9$} & $\begin{array}{l}\text { Hydrofluori- } \\
\text { nated Dryer } \\
\text { Product } \\
\text { (ZCP }-71)\end{array}$ & 250 & 0.75 & 700 & 0.032 & 0.21 & 0.68 & 0.11 \\
\hline & & & & & & & Entix & cake \\
\hline$B F-10$ & $"$ & 250 & 0.50 & 700 & 0.080 & 0.21 & & 16 \\
\hline$B F-11$ & $"$ & 250 & 1.0 & $300-700^{a}$ & 0.252 & 0.21 & $<0.008$ & $<0.008$ \\
\hline$B F-12$ & 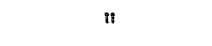 & 250 & 2.0 & 700 & 0.316 & 0.21 & 0.023 & 0.014 \\
\hline$B F-13$ & $n$ & 500 & 3.1 & 700 & 0.14 & 0.21 & 0.10 & 0.033 \\
\hline
\end{tabular}

a Fluorine introduced when temperature of charge reached $300 \mathrm{C}$ 


\section{(2) Pilot-scale Work}

(E. Carls, J. Wehrle, L. Marek)

Four static-bed fluorination runs were made during this period. The first of these was performed in the new 3-inch diameter nickel reactor which had been designed for fluid-bed experiments. Favorable results prompted the installation of a 6-inch diameter Monel reactor, Figure 25, which was more adaptable to static bed work.

FIXED-BED 6-INCH DIAMETER MONEL FLUORINATOR

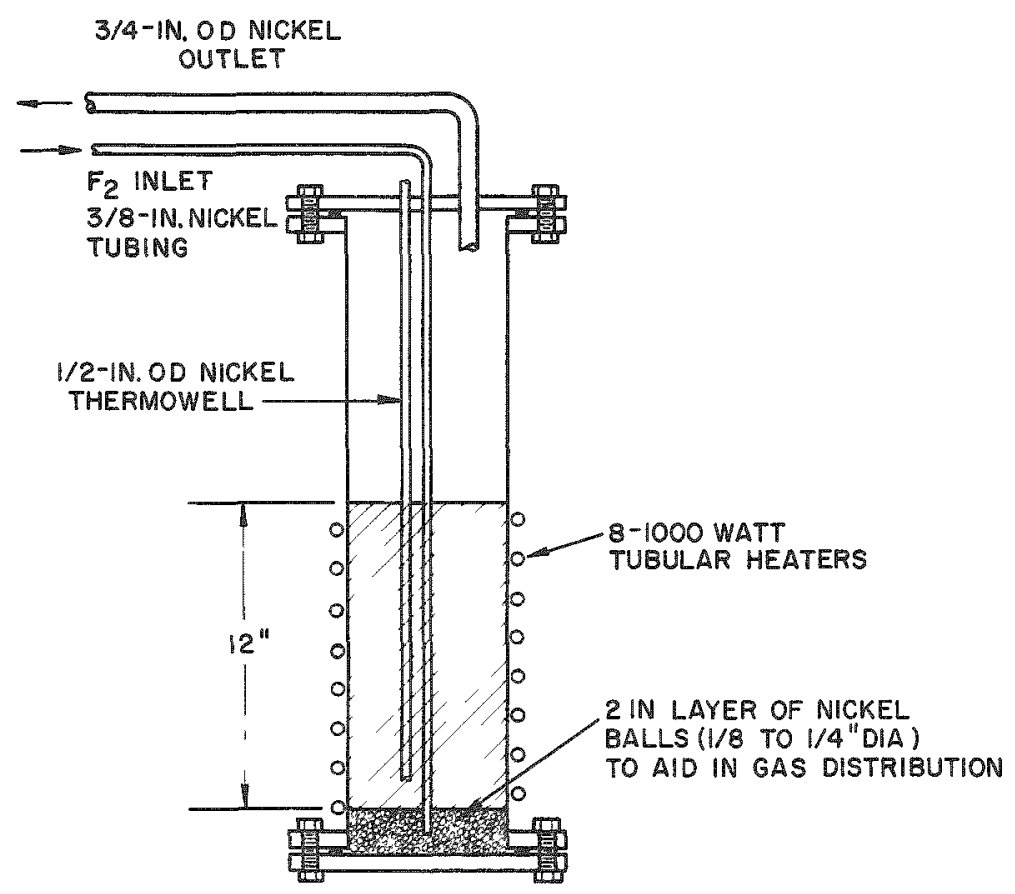

This unit is two feet long, flanged at both ends. The top flange contains a down-leg, a vent tube and a thermowell, all of nickel. Eight 1000-watt calrod-type heaters supply the necessary heat. A layer of nickel balls ( $\frac{1}{8}$ to $\frac{1}{4}$-inch diameter) is used in the bottom of the reactor for gas dispersion. The unit was filled to a height of about 12 inches with powder. Fluorine was metered through a thermal flow meter. Excess fluorine and reaction products (primarily uranium hexafluoride) passed through a condenser and then a caustic scrubber.

Table 15 is a summary of the conditions and results for the pilot-plant static-bed fluorinations. The materials used in these runs were prepared in the fluid-bed dryer and hydrofluorinated to reduce their residual oxygen and water contents since both of these constituents cause the consumption of fluorine. The fluorine was passed through the 
Table 15

PILOT-PLANT FIXED-BED FLUORINATION RESULTS

Fluorination Temp -650 to $700 \mathrm{C}$

\begin{tabular}{|c|c|c|c|c|c|c|c|c|c|c|c|c|}
\hline \multirow[b]{2}{*}{ Run No. } & \multirow{2}{*}{$\begin{array}{l}\text { Starting } \\
\text { Material }\end{array}$} & \multirow{2}{*}{$\begin{array}{c}\text { Original } \\
\text { Uranium } \\
\text { Concen - } \\
\text { tration } \\
(w / o)\end{array}$} & \multirow{2}{*}{$\begin{array}{c}\text { Wt of } \\
\text { Charge } \\
\text { (kg) }\end{array}$} & \multirow{2}{*}{$\begin{array}{c}\text { Total } F_{2} \\
\text { used } \\
(\mathrm{scf})\end{array}$} & \multirow{2}{*}{$\begin{array}{c}\text { Superficial } \\
\text { Velocity } \\
\text { Through } \\
\text { Reactor } \\
\text { (ft/sec) }\end{array}$} & \multirow{2}{*}{$\begin{array}{l}\text { Temp at } \\
\text { start of } \\
F_{2} \text { Intro- } \\
\text { duction } \\
\text { (C) }\end{array}$} & \multicolumn{3}{|c|}{ Duration of Run (hr) } & \multirow{2}{*}{$\frac{g F_{2}}{g \text { Powder }}$} & \multirow{2}{*}{$\begin{array}{l}\text { Portion } \\
\text { of Cake } \\
\text { Sampled }\end{array}$} & \multirow{2}{*}{$\begin{array}{c}\text { Residual } \\
\text { Uranium } \\
(w / 0)\end{array}$} \\
\hline & & & & & & & Total & With $F_{2}$ & Above $650 \mathrm{C}$ & & & \\
\hline$U Z x-65^{a}$ & $\begin{array}{l}\mathrm{ZCP}-71 \\
\text { Hydrofluori- } \\
\text { nated Drier } \\
\text { Product }\end{array}$ & 0.21 & 1.2 & $13^{\mathrm{d}}$ & 0.05 & Room & 3 & 3 & $1 \frac{1}{2}$ & 0.53 & $\begin{array}{l}\text { Top } \\
\text { Bottom }\end{array}$ & $\begin{array}{l}<0.008 \\
<0.008\end{array}$ \\
\hline $42 x-101^{b}$ & $\begin{array}{l}\mathrm{ZCP}-73 \\
\text { Hydrofluori- } \\
\text { nated Drier } \\
\text { Product }\end{array}$ & 0.62 & 10.0 & $75^{\mathrm{d}}$ & 0.05 & Room & 5 & 5 & $1 \frac{1}{2}$ & 0.36 & $\begin{array}{l}\text { Top } \\
\text { Middle } \\
\text { Bottom }\end{array}$ & $\begin{array}{r}0.004^{c} \\
<0.008 \\
0.002\end{array}$ \\
\hline $\mathrm{UZ} \mathrm{x}-102^{\mathrm{b}}$ & $\begin{array}{l}\text { ZCP }-73 \\
\text { Hydrofluori- } \\
\text { nated Drier } \\
\text { Product }\end{array}$ & 0.62 & 10.0 & 28 & 0.05 & 600 & 6 & 3 & 3 & 0.13 & $\begin{array}{l}\text { Top } \\
\text { Middle } \\
\text { Bottom }\end{array}$ & $\begin{array}{r}<0.008 \\
<0.008 \\
0.012\end{array}$ \\
\hline$U Z x-103^{b}$ & $\begin{array}{l}\mathrm{ZCP}-73 \\
\text { Hydrofluori- } \\
\text { nated Drier } \\
\text { Product }\end{array}$ & 0.62 & 9.6 & 11 & 0.025 & 500 & 6 & 2 & $1 \frac{1}{2}$ & 0.057 & $\begin{array}{l}\text { Top } \\
\text { Middle } \\
\text { Bottom }\end{array}$ & $\begin{array}{r}0.018 \\
<0.008 \\
-\end{array}$ \\
\hline
\end{tabular}

a Performed in 3-in. diameter nickel reactor; bed depth: 6 in.

berformed in 6-in. diameter Monel reactor; bed depth: 12 in.

cAnalysis by "wet" method. All others by X-ray with 0.008 per cent the limit of detection.

dApproximately $\frac{1}{3}$ of this fluorine added after bed temperature reached $650 \mathrm{C}$. 
reactor at average velocities of 0.025 to $0.05 \mathrm{ft} / \mathrm{sec}$. In the first two runs fluorine flow was started at room temperature. In the subsequent runs, to make conditions more severe, the materials were pre-caked in the reactor by heating the unit to $500 \mathrm{C}$ (or higher) before the fluorine was started. Heating to $650 \mathrm{C}$ (with only inert gas flow) required only about $3 \frac{1}{2}$ hours.

The bed temperature was then maintained between $650 \mathrm{C}$ and $700 \mathrm{C}$ for about one and one-half hours. During Runs 102 and 103, in which the fluorine was not introduced until the bed was already at an elevated temperature $(>500 \mathrm{C})$, temperature excursions were noted as the fluorine reacted with the oxygen-containing compounds not completely converted by the hydrofluorination step. During Run 102, in which the fluorine was introduced at $600 \mathrm{C}$, the progress of the reaction was easily followed by observing the rise in temperature recorded by the thermocouples located at several points in the bed.

The results from Run 102 are of particular importance since they indicate that the required uranium removal ( $<0.008$ per cent residual) can be achieved by passing fluorine into a bed that is already "caked." The ratio of fluorine to powder used, 0.13 , could probably be even further reduced by recycling the fluorine. This is evidenced in the results of Run 103, in which a ratio of only 0.06 was used and one of the samples showed the required ( $<0.008 \mathrm{w} / 0$ residual) uranium concentration. "Wet" analysis of the samples from Run 101 showed 0.002 and 0.004 per cent uranium for the bottom and top samples, respectively, confirming the $X-r a y$ analysis.

Future work will be directed towards the determination of minimum fluorine requirements to effect desired uranium removal and towards the design of a disposable vessel which would be adaptable to remote operation for actual process application. It is planned to study the recycling of the fluorine and the use of a higher temperature for the hydrofluorination step performed in the fluorinator prior to fluorination. The corrosion aspects at these high temperatures are also being investigated. Work is also planned to determine the effect of increased bed depths up to several feet.

\section{c. Fluorination Corrosion \\ (W. Seefeldt)}

A nickel thermowell from the laboratory-scale fixed-bed fluorinator [Section b (2) above] was recently removed because of a known perforation. The thermowell was evaluated for corrosive attack. The major constituent of the fixed beds has been zirconium fluoride in the form of fluid-bed dryer products. Total exposure involving fluorinating conditions was 13.5 hours, 12 of which were at $700 \mathrm{C}$. About 2 hours of this exposure occurred in the presence of dryer product from which water and hydrogen fluoride vapors could be evolved. 
Gross corrosion (dimensional change) was not high enough to be measured ( $<1 \mathrm{mil}$ ) but etching of the metal was visually evident. The wide, shallow pits which have been observed previously were again found. Typical depths were 1 to $1 \frac{1}{2}$ mils.

Failure of the thermowell was probably due to the fact that it was very thin at the tip and suffered sufficient intergranular attack. In the single section of sample made, metal thickness of 7 mils was observed and complete intergranular penetration had occurred. Typical subsurface attack in the sidewalls was 7 to 10 mils deep, while a maximum of $18 \mathrm{mils}$ was noted at an elevation of 2 inches (corresponds to four-inch bed depth).

Corrosion-product scale was submitted for identification by $\mathrm{X}$-ray spectrometer techniques. Early analysis of the lines reveals a predominance of nickel fluoride with other as yet unidentified lines. It would be desirable to know whether the zirconium tetrafluoride contributes to the mechanism of attack, either in general surface corrosion or the for mation of the pits.

2. Laboratory Studies

a. Fluorination of Calcined, High Zirconium-content Fuel Solutions (C. Johnson, J. Stockbar, T. Gerding)

In a large number of experiments to determine uranium removal from calcined solutions of uranium-zirconium alloys, the major fraction of the uranium is removed quickly at low temperatures, e.g., $500 \mathrm{C}$. Higher temperatures $(<650 \mathrm{C})$ are needed to remove the last 5 to 10 per cent. To facilitate a change in the structure, and supposedly to lessen the forces holding the uranium, the fluorinated material was subjected to pyrohydrolysis. The material used for these experiments was ZCP-50, a $300 \mathrm{C}$ drier product. The initial uranium concentration of this material was 2.2 weight per cent. Initially, ZCP-50 had been fluorinated for two 2 -hour periods, giving a final uranium concentration in the fluorinated residue of 0.11 to 0.14 weight per cent. This fluorinated residue was then reacted with vaporized $1 \mathrm{M}$ aqueous hydrogen fluoride in a fluidized bed at $300 \mathrm{C}$ for 13.3 hours. The fluoride/zirconium ratio was initially 3.88. After reaction with aqueous hydrogen fluoride the fluoride/zirconium ratio dropped to 2.41 . These materials, the fluorinated residue and the pyrohydrolyzed residue, were then fluorinated for two hours in a nickel tube furnace. As may be seen from Table 16, pyrohydrolysis has aided markedly in uranium removal. It must be emphasized that never before has uranium removal been so great at the lower temperatures. 
Table 16

EFFECT OF PYROHYDROLYSIS ON URANIUM REMOVAL

Time for Experiment: 2 hours

Fluorine Flow Rate: $\quad 12 \mathrm{~g} / \mathrm{hr}$

\begin{tabular}{ccccc} 
Material & $\begin{array}{c}\text { Temperature } \\
\text { (C) }\end{array}$ & $\frac{c}{\begin{array}{c}\text { Uranium } \\
\text { Concentration } \\
\text { (w/o) }\end{array}}$ \\
\cline { 1 - 2 } Fluorinated Residue & 600 & & 0.11 & 0.09 \\
Pyrolyzed Residue & 450 & & 0.14 & 0.13 \\
& 525 & & 0.14 & 0.034 \\
& 600 & & 0.14 & 0.008
\end{tabular}

b. Fluorination of Calcined Solutions of Aque ous Dissolved Power-reactor Fuels (C. Johnson, J. Stockbar, T. Gerding)

In the past, the laboratory group has applied the ADF process scheme solely to high-zirconium fuels. It appeared profitable to include fuels typical of those in present use in power reactors. The Dresden fuel and the APPR fuel were chosen.

The Dresden fuel is composed of high-density uranium dioxide in Zircaloy cladding; the APPR fuel is made up of uranium dioxide in a stainless steel compact. A simulated Dresden-type feed solution was prepared with the following composition: $0.44 \mathrm{MUO}_{2}\left(\mathrm{NO}_{3}\right)_{2} \cdot 6 \mathrm{H}_{2} \mathrm{O}$, $0.13 \mathrm{M} \mathrm{ZrF} 2\left(\mathrm{NO}_{3}\right)_{2}, 3.55 \mathrm{MHNO}_{3}$. A synthetic APPR fuel solution was prepared based on the data of Cunningham and Beaver. 10 Its composition was as follows: $0.51 \mathrm{MCr}\left(\mathrm{NO}_{3}\right)_{3} \cdot 9 \mathrm{H}_{2} \mathrm{O}, 1.75 \mathrm{MFe}\left(\mathrm{NO}_{3}\right)_{3} \cdot 9 \mathrm{H}_{2} \mathrm{O}, 0.086 \mathrm{M}$ $\mathrm{UO}_{2}\left(\mathrm{NO}_{3}\right)_{2} \cdot 6 \mathrm{H}_{2} \mathrm{O}, 2 \mathrm{MHCl}$ and $6 \mathrm{MHNO}_{3}$. The boron carbide was deleted.

The aqueous feed salutions were dried at $350 \mathrm{C}$ in a laboratory calciner by adding the dissolver solution dropwise to a preheated drying tube, which has an internal stainless steel drying cup serving as a collecting surface. The system was operated under partial vacuum.

Data from experiments on the effect of fluorination temperature on uranium removal from Dresden and APPR fuels are given in Table 17. Application of the ADF process scheme to Dresden-type fuels

10 Cunningham J. E., and Beaver, R. J., Second United Nations International Conference on Peaceful Uses of Atomic Energy, Geneva, (1958), Vol. 6, p. 521 . 
appears promising. Data typical of those obtained from work on highzirconium fuels indicate a general similarity to the APPR fuels in that temperatures above $650 \mathrm{C}$ would be necessary to get satisfactory uranium removal upon fluorination.

\section{Table 17}

\section{EFFECT OF TEMPERATURE ON URANIUM REMOVAL FROM CALCINED DRESDEN AND APPR - TYPE FUELS}

\begin{tabular}{|c|c|c|c|c|}
\hline \multirow[b]{2}{*}{$\begin{array}{l}\text { Calcined Fuel } \\
\text { Solution }\end{array}$} & \multicolumn{2}{|c|}{ Fluorine Flow Rate: } & $2 \mathrm{~g} / \mathrm{hr}$ & \multirow[b]{2}{*}{$\begin{array}{c}\text { Uranium } \\
\text { Removed } \\
(\%)\end{array}$} \\
\hline & $\begin{array}{c}\text { Calcined Solid, } \\
\text { Initial Uranium } \\
\text { Concentration } \\
(\mathrm{w} / \mathrm{o})\end{array}$ & $\begin{array}{l}\text { Fluorine } \\
\text { Flow } \\
\text { Time } \\
\text { (hr) }\end{array}$ & $\begin{array}{l}\text { Fluorination } \\
\text { Temperature } \\
\text { (C) }\end{array}$ & \\
\hline Dresden & 73.5 & 1 & 350 & 20 \\
\hline Dresden & 73.5 & 1 & 450 & 87 \\
\hline Dresden & 73.5 & 1 & 550 & 98 \\
\hline Dresden & 73.5 & 1 & 600 & 99 \\
\hline APPR & 10.9 & 2 & 450 & 65 \\
\hline APPR & 10.9 & 2 & 525 & 67 \\
\hline APPR & 10.9 & 2 & 600 & 95 \\
\hline APPR & 10.9 & 2 & 650 & 93 \\
\hline
\end{tabular}

In the fused salt process for the recovery of uranium from zirconiummatrix fuels, the alloy is dissolved in the fused salt at $600 \mathrm{C}$ with a hydrogen fluoride sparge; the uranium is then volatilized as the hexafluoride in a fluorine sparge. Because the materials used in the fused salt process are corrosive to metals, equipment is being developed to avoid salt-metal contact. Results are reported on the dissolution of a synthetic zirconiumuranium fuel element in the graphite pilot-plant dissolver and on frozenwall control studies in the electrolytically heated frozen-wall fluorinator.

1. Graphite Dissolver Tests

(R. W. Kessie, J. Gates, W. Murphy, A. Rashinskas)

In the present period a dissolution of a synthetic zirconiumuranium fuel element was made at a higher temperature and a higher hydrogen fluoride sparge rate than previously reported. The graphite internal heaters were removed and examined after about 900 hours of exposure to fused salt. 
The synthetic fuel element was made by welding together ten individually fabricated fuel plates consisting of a low uranium-zirconium alloy clad in zirconium. The overall uranium content was about 1 weight per cent. The plate thickness and the channel spacing were both approximately 0.09 inch. The surfaces of the metal were black, resulting from previous autoclaving. Plate widths were $2 \frac{1}{2}$ inches and the assembly length was three feet. The edge welds were continuous.

The fuel element was charged through the air lock and during processing rested vertically over the gas distributor at the bottom of the dissolver. The fuel element was covered by the salt, which was at a depth such as to allow a 36 -inch freeboard in the dissolver.

\section{a. Dissolution Rates}

The progress of the dissolution was followed in this run by determining hydrogen fluoride consumption from the time record of boiler and receiver weights. A summary of the hydrogen fluoride consumed during the run is given in Table 18. Data in the table indicate that the dissolution was complete in less than $7 \mathrm{hr}$ and that the average hydrogen fluoride sparge rate over this period was $57 \mathrm{lb} / \mathrm{hr}$. The average hydrogen fluoride consumption rate was $4.7 \mathrm{lb} / \mathrm{hr}$.

Table 18

\section{CONSUMPTION OF HYDROGEN FLUORIDE DURING DISSOLUTION RUN A5}
Conditions: (a) Zirconium-Uranium Element Dissolved in Fused $\mathrm{NaF}-\mathrm{Zr}_{\mathrm{r}} \mathrm{F}_{4}$
(b) $700 \mathrm{C}$ and $57 \mathrm{lb} \mathrm{HF} / \mathrm{hr}$.

\begin{tabular}{|c|c|c|c|c|c|}
\hline \multirow[b]{2}{*}{ Period } & \multirow{2}{*}{$\begin{array}{l}\text { Run Time } \\
\text { at End of } \\
\text { Period } \\
\text { (hr) }\end{array}$} & \multirow{2}{*}{$\begin{array}{c}\text { HF Added } \\
\text { in Period } \\
\text { (1b) }\end{array}$} & \multirow{2}{*}{$\begin{array}{c}\text { HF } \\
\text { Consumed } \\
\text { (1b) }\end{array}$} & \multicolumn{2}{|c|}{ HF Rate $(1 \mathrm{~b} / \mathrm{hr})$} \\
\hline & & & & Addn & Consumption ${ }^{a}$ \\
\hline 1 & 1.68 & 87.2 & 7.0 & 51.8 & 4.17 \\
\hline 2 & 3.52 & 106 & 9.0 & 58.4 & 4.89 \\
\hline 3 & 5.26 & 100 & 10.0 & 57.5 & 5.74 \\
\hline 4 & 6.71 & 90.7 & 5.6 & 62.5 & $3.86^{\mathrm{b}}$ \\
\hline 5 & 9.3 & 79 & 0.4 & -30 & 0.15 \\
\hline \multicolumn{4}{|c|}{ overall average to end of 4 th period } & 57 & 4.71 \\
\hline
\end{tabular}


Other information on the variation of dissolution rate during the run is shown in Table 19. These data show the absence of significant variations of dissolution rate during the run. This confirms previous indications that channel areas of the fuel elements are available for reaction.

Table 19

VARIATION OF DISSOLUTION RATE DURING RUN A5

Conditions: (a) Uranium-zirconium assembly dissolved in $\mathrm{NaF}-\mathrm{ZxF}_{4}$

(b) $700 \mathrm{C}$ and $57 \mathrm{lb} \mathrm{HF} / \mathrm{hr}$

(Based on Data in Table 18)

$\begin{array}{cccc}\text { Period } & \begin{array}{c}\text { Run Time at } \\ \text { End of Period } \\ \text { (hr) }\end{array} & \begin{array}{c}\text { \% of Total Metal } \\ \text { Dissolved at } \\ \text { End of Period }\end{array} & \begin{array}{c}\text { Average dissolution } \\ \text { Rate During Period } \\ \text { (\% of overall } \\ \text { average rate) }\end{array} \\ 2 & 1.68 & 22 & 89 \\ 3 & 3.52 & 51 & 107 \\ 4 & 5.26 & 82 & 121 \\ 1 & 6.71 & 100 & 82\end{array}$

Calculated on the as sumption that zirconium dissolution was proportional to HF consumption and that dissolution was complete at the end of the fourth period.

The average specific dissolution rate may be calculated from data in Table 19. which showed 82 per cent dissolved in $5.2 \mathrm{hr}$. The equivalent specific reaction rate for the $21.7-1 \mathrm{~b}$ element is $2.2 \mathrm{mg} /(\mathrm{min})$ (sq $\mathrm{cm}$ ) based on total initial surface area. A comparison with previous runs is given in Table 20. The higher rate is due to the higher temperature and sparge rate. It appears that four dissolutions could be carried out in a 24-hr period at the se conditions.

Table 20

COMPARISON OF DISSOLUTION RATES

\begin{tabular}{|c|c|c|c|c|}
\hline \multirow[t]{2}{*}{ Conditions: } & \multicolumn{4}{|c|}{$\begin{array}{l}\text { Salt composition: } 38 \text { to } 46 \mathrm{~m} / 0 \mathrm{ZrF}_{4} \text {, balance NaF } \\
\text { Subassemblies completely submerged. } \\
\text { Subassemblies consist of } 10 \text { plates with } 0.09 \text {-inch } \\
\text { channels. }\end{array}$} \\
\hline & Run & $A I^{2}$ & $\mathrm{~A} 2^{\mathrm{a}}$ & $A 5^{b}$ \\
\hline \multicolumn{2}{|c|}{ Salt temperature, $\mathrm{C}$} & 600 & 600 & 700 \\
\hline \multicolumn{2}{|c|}{$\mathrm{HF}$ sparge rate, $\mathrm{lb} \mathrm{HF} / \mathrm{hr}$} & 19 & 32 & 57 \\
\hline \multicolumn{2}{|c|}{ Length of subassembly, inches } & 48 & 48 & 36 \\
\hline \multicolumn{5}{|c|}{ Overall average } \\
\hline \multicolumn{2}{|c|}{ dissolution rate, $\mathrm{mil} / \mathrm{hr}$} & 3.4 & 4.1 & 8.2 \\
\hline \multicolumn{2}{|c|}{ dissolution rate, $\mathrm{mg} /(\mathrm{sq} \mathrm{cm})(\mathrm{min})$} & 0.9 & 1.1 & 2.2 \\
\hline \multirow{3}{*}{\multicolumn{2}{|c|}{$\begin{array}{l}\text { Overall HF efficiency, } \\
\text { Calculated time for } 90 \% \text { dis solution } \\
\text { of } 0.09 \text { in thick plates, hr } \mathrm{c}^{\mathrm{c}}\end{array}$}} & 8.4 & 6.1 & 6.7 \\
\hline & & & & \\
\hline & & 10.5 & 8.8 & 5.4 \\
\hline \multicolumn{5}{|c|}{ aplates of pure zirconium } \\
\hline \multicolumn{5}{|c|}{ bplates of zixconium-uranium, clad in zirconium } \\
\hline \multicolumn{5}{|c|}{ CBased on given specific dissolution rate. } \\
\hline
\end{tabular}




\section{b. Graphite Heater Operation}

The graphite heaters operated without difficulty in all fused salt process operations to date. After the present tests the salt was drained from the dissolver as usual and the system cooled down. When preparations were made for another run, it was found that an open circuit had developed in one heater. Both heaters were removed for examination. It was found that the damaged heater had cracked in a region about 24 inches from the bottom. The breakage was apparently due to expansion of salt which had entered the heater annulus (a diagram of the heater construction was shown in ANL-5858, Figure 4, page 25), but had not drained with the dissolver salt. Because the trapped salt showed plastic distortion and yet did not drain through the cracked sections, it appeared that the damage was done during cooling. Improved heaters to allow better purging and positive drainage are under construction.

The heaters had functioned normally during the run. Heater resistance (including leads) of 0.0385 ( $\pm 1 \%$ ) ohm was noted during Run A5. This was only slightly lower than the value of $0.042 \mathrm{ohm}$ observed during the previous runs. There was no sign of attack upon either the rod or shell portion of the graphite heaters in contact with either salt or gas phases. No appreciable surface or dimensional change (see Table 21) had occurred, which indicated the absence of air or moisture in the dissolver. No evidence of electrical arcing was apparent. The shell of the south heater, which was completely intact, was virtually indistinguishable from an unused shell on hand.

Table 21

\section{VARIATION OF DIAMETER OF ONE-INCH SECTION GRAPHITE HEATER ROD AFTER RUN 5}

\begin{tabular}{cc}
$\begin{array}{l}\text { Operating Time: } \\
\text { Dissolution Time: }\end{array}$ & $\begin{array}{c}\text { approx } 900 \text { hours } \\
\text { approx } 200 \text { hours }\end{array}$ \\
$\begin{array}{cc}\text { Probable temperature: } \\
\text { up to } 1200 \mathrm{C}\end{array}$ \\
$\begin{array}{cc}\text { Distance from Top of Rod } \\
\text { (in.) }\end{array}$ & $\begin{array}{c}\text { Diameter } \\
\text { (in.) }\end{array}$ \\
\hline 1 & 1.008 \\
8 & 1.012 \\
14 & $1.013-1.015$ \\
$20^{\mathrm{a}}$ & $1.010-1.013$ \\
26 & $1.014-1.015$ \\
32 & $1.012-1.013$ \\
38 (bottom) & 1.025
\end{tabular}

approximate observed level of salt in contact with rod; the rod was exposed to salt below this level. 


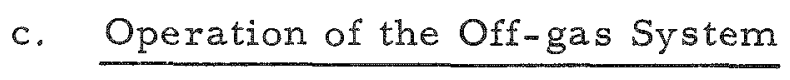

The chief modifications made in the system since the previously reported runs were the following:

1) A boost in the available electrical power to the heaters was made so that power up to $26 \mathrm{kw}$ could be delivered. For the conditions of Run A-5 (700 C, $57 \mathrm{lb} \mathrm{HF} / \mathrm{hr})$, the power requirement was $21 \mathrm{kw}$.

2) A caustic scrubber was added to remove residual hydrogen fluoride from the waste noncondensible gas leaving the hydrogen fluoride recovery condenser.

Previous difficulties with plugging of the six-inch off-gas connection at the head of the dissolver were not encountered in the present period of operation, which (for both check-out and completion of Run A-5) entailed 168 hours of operating time with about 36 hours at a high sparge rate of 50 to $60 \mathrm{lb}$ hydrogen fluoride per hour. A small rim of solid salt at the very bottom of the six-inch pipe was noted, but its size was below that required to cause difficulty either in gas flow or fuel element charging. The elimination of plugging was believed due to the 36 -inch salt freeboard.

Other major components in the off-gas system included a) a desublimator packed with sodium fluoride pellets for removal of zir.conium tetrafluoride vapor, b) a blow-back filter assembly using porous carbon filters, c) a hydrogen fluoride condenser system and, d) a caustic scrubber for the condenser off-gas. During the present operation a partial plug in the desublimator resulted in appreciable pressure drop. It was found that the rather restricted entrance of the packed bed had plugged with dust (probably zirconium tetrafluoride). The pellet-bed support was modified to give greater cross-sectional area to the gas distribution point and to provide a dust baffle ahead of the bed proper. Considerable improvement is expected by these changes. No pressure buildup on the filters has been noted in any operation to date.

Hydrogen fluoride used in the Fused Salt Process dissolverhydrofluorinator is recycled by means of a boiler-condenser system. Electrically heated boilers on remote-reading scales are used to vaporize the hydrogen fluoride, which is then conducted in steam-traced piping through the process equipment and thence to a dry ice-cooled condenser. Condensate is returned to a weigh tank receiver. Because quantities of noncondensibles are also present in the off-gas, a caustic scrubber is used to remove hydrogen fluoride from the gas passing through the condenser. The scrubber was of a simple bubbler type. A gas distributor of fairly large diameter was selected after an initial trial and was found not to plug. Determination of the efficiency of the condenser and bubbler system was made to establish the accuracy of material balances of the hydrogen fluoride and to ensure that the waste off-gas is substantially free of corrosive hydrogen fluoride vapor. 
In these efficiency measurements the dissolver itself was bypassed, although the major part of the process piping was utilized. The flow rate of hydrogen fluoride was determined by weight changes in the boiler. The hydrogen fluoride was piped through approximately $100 \mathrm{ft}$ of $\frac{1}{2}$ to 1 -inch pipe traced with $\frac{1}{4}$-inch tubing containing 60 -psig steam.

A schematic diagram of the condensing and scrubbing system for hydrogen fluoride is shown in Figure 26. The hydrogen fluoride containing off-gas passes through the tube section of two helical tube-andshell condensers in series. Most of the condensation occurs in the first exchanger and the condensate drains from the vapor-liquid separator between the condensers. The Heliflow condensers were obtained from the Graham Manufacturing Co., Inc. The total heat transfer area is approximately $4.4 \mathrm{sq} \mathrm{ft}$ in each unit.

FIGURE 26

HYDROGEN FLUORIDE CONDENSER AND SCRUBBER SYSTEM

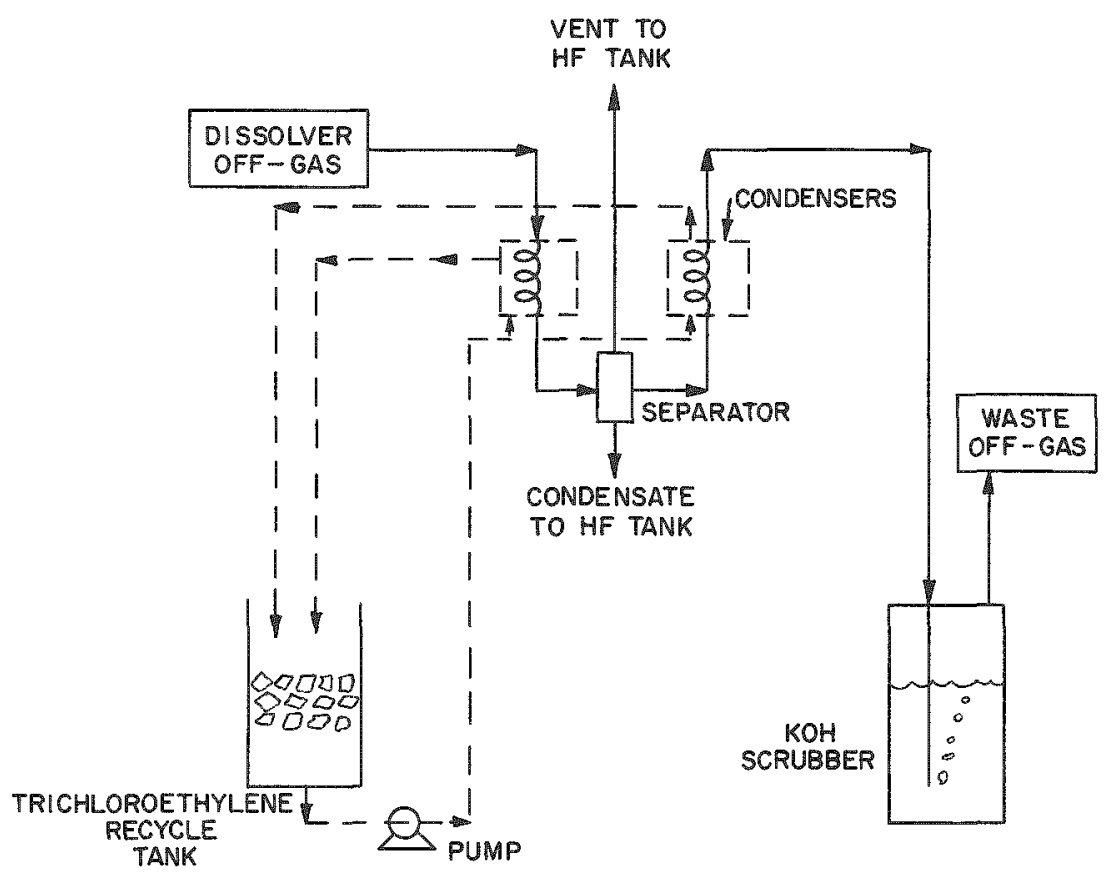

Trichloroethylene cooled by dry ice is circulated from a 55-gal recycle tank through a 30 -gpm centrifugal pump $\left(\frac{1}{2}-\mathrm{hp}\right)$ to the shell side of each condenser. Separately throttled return lines are used; the total trichloroethylene flow was about $10 \mathrm{gpm}$. The piping is 1 -inch ID copper tubing with asbestos insulation 2 inches thick. The condensers and separator are located in a vapor-sealed steel box $24 \times 24 \times 30$ inches, filled with vermiculite insulation to a thickness of 4 or more inches. 
Blocks of dry ice were charged to the recycle tank for cooling. At the temperature involved, approximately $-75 \mathrm{C}$, the dry ice has a slightly lower density than the tricholoroethylene. The return trichloroethylene enters above the liquid level. The exit liquid line is provided with a screen to prevent carry-through of solid dry ice. In order to simulate process conditions, argon was passed through the condenser with the hydrogen fluoride. A measured portion of gas leaving the process bubblex was then passed through a small bubbler used for the test. The hydrogen fluoride pick-up in both the process scrubber and the test bubbler was determined from the change in hydroxide concentration as determined by titration.

The conditions of the test and the results are summarized in Table 22. The operating efficiency of the condenser at the conditions was 99.8 per cent of entering hydrogen fluoride. The amount of hydrogen fluoride in the condenser off-gas was 126 per cent of the theoretical minimum, based on available data of the vapor pressure of hydrogen fluoride at $-78.6 \mathrm{C}$ (dry ice temperature). This shows a high degree of freedom from entrainment as well as a good the rmal performance of the condensers. A high efficiency, in excess of 99.95 per cent, was obtained for the scrubber.

Table 22

EFFICIENCY OF CONDENSER AND BUBBLER

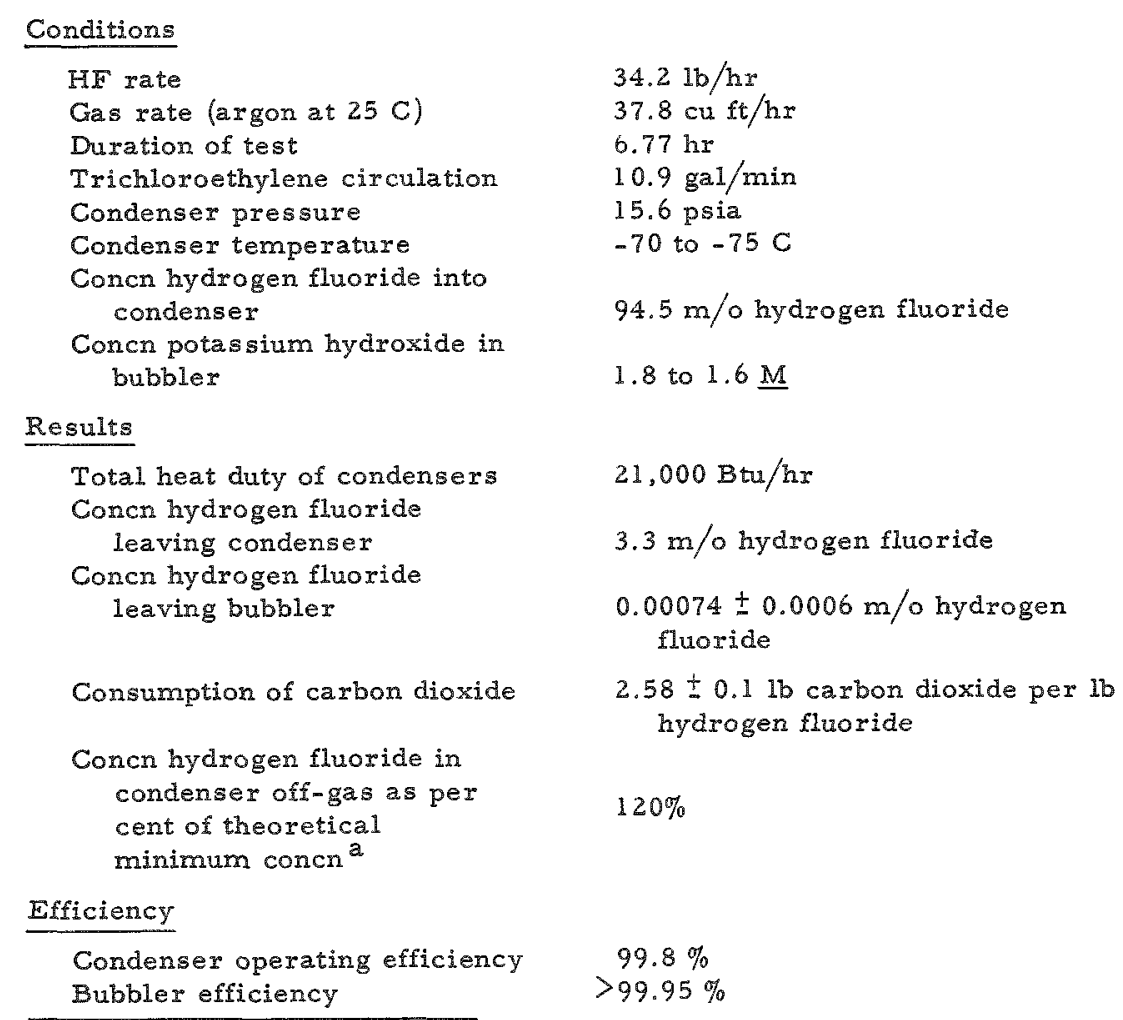

aBased on literature value for partial pressure of hydrogen fluoride at dry ice temperature, $-78.6 \mathrm{C}$. 
Heat duty and losses for the condenser system were also determined. From weight measurements of dry ice and hydrogen fluoride, the net dry ice consumption was determinedas $2.58 \pm 0.1 \mathrm{lb}$ carbon dioxide/ $1 \mathrm{~b}$ hydrogen fluoride. For total dry ice consumption, the amount due to heat in-leakage and heat from the circulating pump must be added. The heat pick-up from the pump was found to be about 60 per cent of the total heat leak, which was $8.75 \mathrm{lb}$ carbon dioxide per hour. This value has remained essentially constant for all tests to date.

\section{Electrolytically Heated Frozen-wall Fluorinator Tests}

(R. W. Kessie, J. Gates)

Operational tests of the electrolytically heated frozen-wall fluorinator were continued in order to demonstrate the control of thin, uniform frozen walls. Wall measurements were made for various conditions of power input, sparge gas rate, and salt depth.

A description of the vessel and its components has been given previously (e.g., ANL-6068, page 117). The electrodes were the same as employed in the last tests reported, but in the current experiments the electrodes were lowered from 4 inches to 1.5 inches from the bottom. Electrical circuit modifications were also made to allow higher power inputs and a wider range of electrical resistance measurements.

\section{a. Operating Procedure}

Solid salt was charged to the vessel cold and the internal resistance heaters in the electrodes used for initial melting. Complete melting was carried out by electrolytic power. A large caliper was used to measure the thickness of the salt wall. Cooling water and sparge gas flows were measured with rotameters. Temperatures of the electrodes and of the water coolant of the vessel wall were recorded during operations.

Two salt depths, three power levels and three sparge rates were used. The unit was left overnight on a medium power level and low sparge rate. During the day the conditions of the test were set and maintained. Wall measurements were made after about 7 hours at given conditions. During this time any salt crust formed was broken back into the molten zone to insure uniformity.

During these operations, a progressively heavier crust of solid salt at the interface was noted. Because the top of the vessel was open, hydrolysis of the salt could occur and contribute to the crust formation. The salt was hydrofluorinated between Runs 4 and 5 to reconvert the oxide to fluoride. 
After the wall measurements were made, the water cooling zones were blown out (one after the other, starting at the top) to determine the effect on the frozen wall and on the crust at the surface. Finally, the electrodes were removed with the salt molten.

\section{b. Results of Wall Measurements}

As can be seen from the frozen-wall profiles in Figure 27, the thickness of the frozen wall was maintained quite uniformly in the range of $1 / 2$ to 1 inch on the wall and 1 to $1 \frac{1}{2}$ inches on the bottom with a power level of approximately $1.5 \mathrm{kw} / \mathrm{sq} \mathrm{ft}$ of frozen wall. The dependence of wall thickness on power level can be seen in Figure 28. Lower power densities resulted in thicker walls, particularly at the bottom. The overall mean wall thickness is defined by heat transfer equations in which total heat flow is obtained by summarizing the flow in separate zones of differing thickness $\Delta \mathrm{x}_{\mathrm{i}}$. The following equation was derived for the total heat flux:

$$
\begin{aligned}
q & =k(\Delta T)\left(A_{i} n\right)\left[\frac{\sum_{i=1}^{n}\left(\frac{1}{\Delta x_{i}}\right)}{n}\right], \\
& =k A\left[\frac{\Delta T}{\text { overall mean wall thickness }}\right],
\end{aligned}
$$

where $\mathrm{k}$ is the thermal conductivity, $\Delta \mathrm{T}$ is the temperature difference between the molten salt and the cooling water, $A_{i}$ is the area of one zone, $\mathrm{n}$ is the number of zones, and $\mathrm{A}$ is the total zone area assuming all zones are of equal area.

A summary of heat balance and sparge conditions for the eightruns is given in Table 23. Maximum heat pick-up was found in the middle cooling zones. The salt input values are the difference between the kva supplied and losses in the bus conductors. In Run 1 the bus losses were high because of a poor connection, and are not reported. The heat losses unaccounted for in the cooling water varied from very low values to about 10 per cent of input power.

Power density appeared to be the controlling variable with respect to wall thickness. The variation in salt levels and sparge rate did not appear to have any definite effect. The salt levels used were 26 and 36 inches, and the sparge rates ranged from 0.01 to $0.5 \mathrm{ft} / \mathrm{min}$, based on the total cross-sectional area of the vessel. The sparge was divided between two $\frac{1}{4}$-inch open tube sparge lines, one in the bottom of each electrode. 
FIGURE 27

FROZEN-WALL CROSS SECTIONS

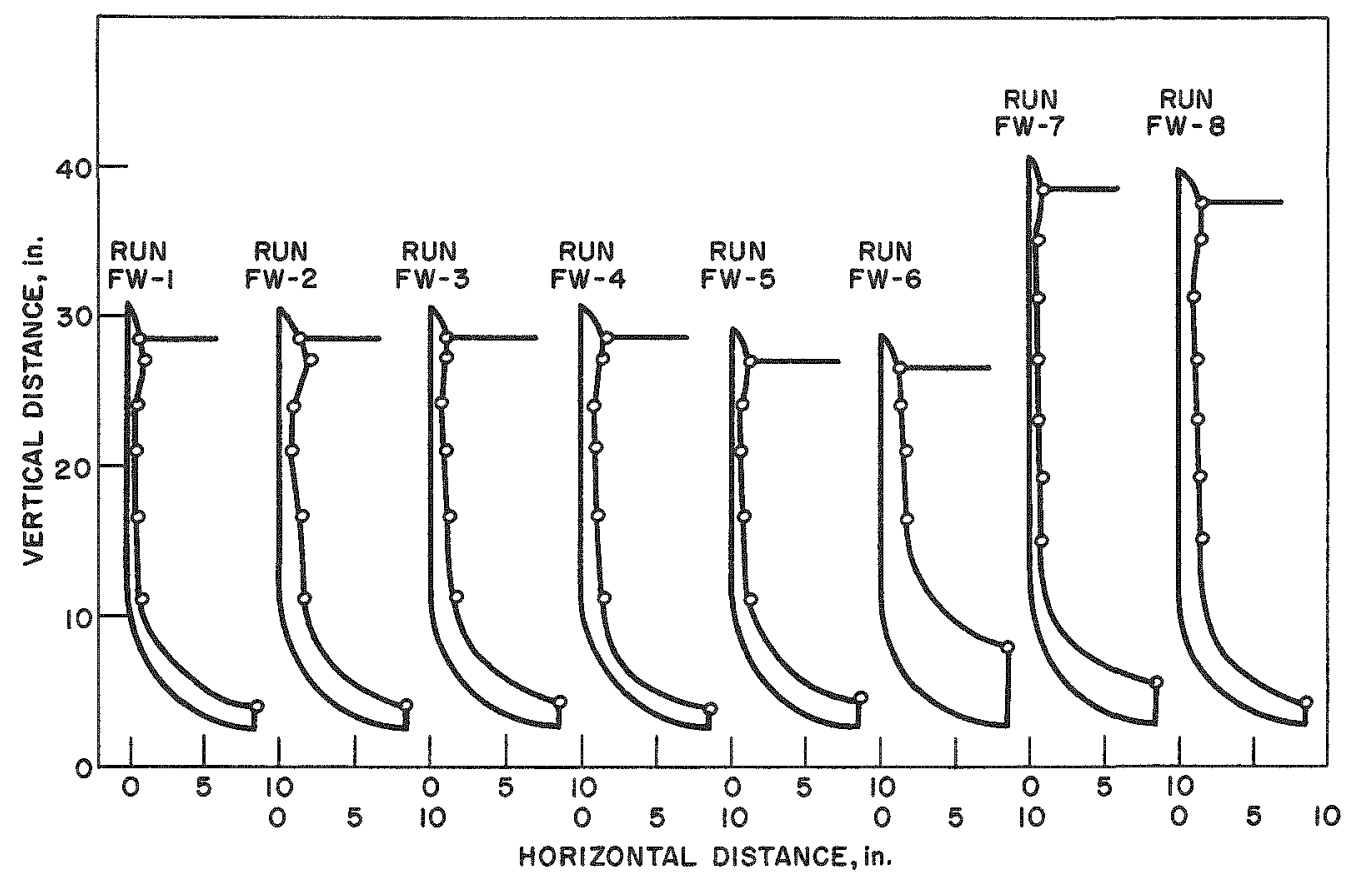

FIGURE 28

OVERALL MEAN WALL THICKNESS AT VARIOUS WALL HEAT FLUXES

* (See text for explanation)

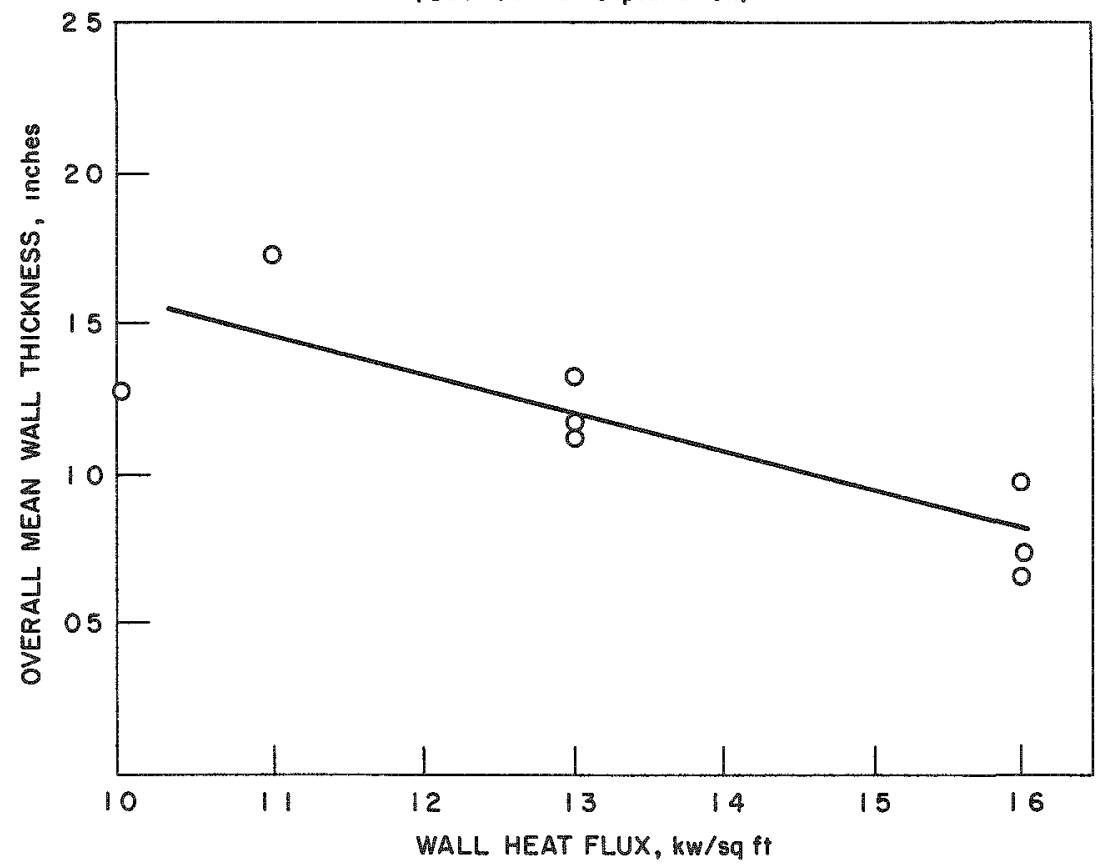


Table 23

HEAT BALANCE AND SPARGE RATES FOR FUSED SALT RUNS

\begin{tabular}{|c|c|c|c|c|c|c|c|c|c|c|c|c|}
\hline \multirow[b]{3}{*}{ Run } & \multirow{3}{*}{$\begin{array}{l}\text { Total } \\
\text { Power } \\
\text { Input } \\
\text { (kva) }\end{array}$} & \multirow{3}{*}{$\begin{array}{l}\text { Bus } \\
\text { Power } \\
\text { Loss } \\
\text { (kva) }\end{array}$} & \multirow{3}{*}{$\begin{array}{l}\text { Power } \\
\text { Input } \\
\text { to Salt } \\
\text { (kva) }\end{array}$} & \multicolumn{5}{|c|}{$\begin{array}{c}\text { Zone Cooling Load } \\
(\mathrm{kw})\end{array}$} & \multirow{3}{*}{$\begin{array}{l}\text { Total } \\
\text { Cooling } \\
\text { Load } \\
\text { (kw) }\end{array}$} & \multirow{3}{*}{$\begin{array}{l}\text { Heat } \\
\text { Loss } \\
\text { (kva) }\end{array}$} & \multirow{3}{*}{$\begin{array}{c}\text { Sparge } \\
\text { Rate } \\
\text { (cfm) }\end{array}$} & \multirow{3}{*}{$\begin{array}{c}\text { Thickness } \\
\text { of Frozen } \\
\text { Wall } \\
\text { (in.) }\end{array}$} \\
\hline & & & & \multicolumn{4}{|l|}{ Bottom } & \multirow{2}{*}{$\frac{\text { Top }}{5}$} & & & & \\
\hline & & & & 1 & 2 & 3 & 4 & & & & & \\
\hline 1 & 25.2 & - & - & 0.30 & 3.4 & 8.7 & 3.5 & 0.42 & 16.32 & - & 0.18 & 0.5 to 1.4 \\
\hline 2 & 15.6 & 1.9 & 13.7 & 0.26 & 3.8 & 6.0 & 2.8 & 0.38 & 13.24 & 0.5 & 0.18 & 1.0 to 2.1 \\
\hline 3 & 16.0 & 1.8 & 14.2 & 0.27 & 3.7 & 5.7 & 2.9 & 0.40 & 12.97 & 1.2 & 0.88 & 0.8 to 1.7 \\
\hline 4 & 15.6 & 2.0 & 13.6 & 0.27 & 3.7 & 5.7 & 2.9 & 0.40 & 12.97 & 0.6 & 0.02 & 0.9 to 1.6 \\
\hline 5 & 18.0 & 2.0 & 16.0 & 0.29 & 5.4 & 6.2 & 2.9 & 0.53 & 15.32 & 0.7 & 0.17 & 0.7 to 2.1 \\
\hline 6 & 10.1 & .9 & 9.2 & 0.21 & 3.4 & 4.2 & 2.1 & 0.33 & 10.24 & -1.0 & 0.17 & 1.2 to 5.5 \\
\hline 7 & 26.4 & 4.5 & 21.9 & 0.24 & 4.7 & 6.9 & 7.5 & 1.2 & 20.54 & 1.4 & 0.24 & 0.4 to 2.7 \\
\hline 8 & 18.2 & 2.7 & 15.5 & 0.21 & 2.5 & 4.0 & 5.0 & 1.1 & 12.81 & 2.7 & 0.26 & 1.2 to 1.5 \\
\hline
\end{tabular}

a The wall is cooled by 5 separate coils, each cooling a zone of approximately equal area.

\section{c. Electrical Resistance Measurement of Salt Wall}

Measured values of overall wall resistance varied from 1600 to 78,000 ohms for the operating conditions noted. These were obtained with a dc bridge circuit using a 30 -volt positive potential across the vessel wall. (The control circuit was outlined in the previous quarterly, ANL-6068, page 118.) The opposite polarity was tried initially, but it resulted in false low readings, probably because of deposition of zirconium metal needles in the salt wall. A summary of measured electrical resistance and calculated values of electrical and thermal conductivity of the salt wall is given in Table 24.

Table 24

PROPERTIES OF SALT WALL

\begin{tabular}{|c|c|c|c|c|c|c|c|c|c|}
\hline \multirow[b]{2}{*}{ Run } & \multicolumn{4}{|c|}{$\begin{array}{c}\text { Frozen-wall Thickness } \\
\text { (in.) }\end{array}$} & \multirow{2}{*}{$\begin{array}{l}\text { Wall } \\
\text { Area } \\
(\mathrm{sqft})\end{array}$} & \multirow{2}{*}{$\begin{array}{c}\text { Avg } \\
\text { Wall Heat } \\
\text { Flux } \\
(\mathrm{kw} / \mathrm{sq} \mathrm{ft})\end{array}$} & \multirow{2}{*}{$\begin{array}{l}\text { Wall Thermal } \\
\text { Conductivity, } \\
\frac{\text { BTU }}{(\mathrm{hr})(\mathrm{sq} \mathrm{ft})(\mathrm{F} / \mathrm{ft})}\end{array}$} & \multirow{2}{*}{$\begin{array}{c}\text { Wall } \\
\text { Resistance } \\
\text { (ohms) }\end{array}$} & \multirow{2}{*}{$\begin{array}{c}\text { Wall } \\
\text { Resistivity } \\
(\text { ohm })(\mathrm{cm})\end{array}$} \\
\hline & $\operatorname{Min}$ & $\operatorname{Max}$ & $\begin{array}{c}\text { Arithmetic } \\
\text { Average }\end{array}$ & $\begin{array}{l}\text { Overall } \\
\text { Mean }\end{array}$ & & & & & \\
\hline$F W-1$ & 0.5 & 1.4 & 0.80 & 0.72 & 9.9 & 1.6 & 0.40 & 8,600 & $43 \times 10^{6}$ \\
\hline FW-2 & 1.0 & 2.1 & 1.41 & 1.32 & 9.9 & 1.3 & 0.59 & 47,000 & $120 \times 10^{6}$ \\
\hline$F W-3$ & 1.0 & 1.7 & 1.21 & 1.14 & 9.9 & 1.3 & 0.51 & 53,000 & $120 \times 10^{6}$ \\
\hline$F W-4$ & 1.0 & 1.7 & 1.24 & 1.18 & 9.9 & 1.3 & 0.52 & 78,000 & $210 \times 10^{6} \mathrm{~b}$ \\
\hline FW -5 & 0.7 & 2.1 & 1.13 & 0.98 & 9.3 & 1.6 & 0.54 & 1,600 & $5.6 \times 10^{6^{6}}$ \\
\hline FW-6 & 1.2 & 5.5 & 2.30 & 1.72 & 9.1 & 1.1 & 0.65 & 8,900 & $17 \times 10^{6}$ \\
\hline$F W-7$ & 0.4 & 2.7 & 0.88 & 0.64 & 13.6 & 1.6 & 0.35 & 2,900 & $23 \times 10^{6}$ \\
\hline$F W-8$ & 1.0 & 1.5 & 1.30 & 1.28 & 13.3 & 1.0 & 0.44 & 12,000 & $46 \times 10^{6}$ \\
\hline
\end{tabular}

a Reciprocal of the reciprocal average wall thickness, inches.

bA minimum value of $2 \times 10^{6}$ was observed during HF additions. 
The variation of electrical resistivity of the frozen wall with time was pronounced. Pure salt at low temperature has a resistivity of $10^{7}$ to $10^{8} \mathrm{ohm}-\mathrm{cm}$. In Runs 1 to 4 the calculated resistivity increased from $4 \times 10^{7}$ to $2 \times 10^{8} \mathrm{ohm}-\mathrm{cm}$, the increase being due apparently to an increasing oxide content of the salt. Following hydrofluorination of the molten salt in Run 5, the resistivity dropped to $6 \times 10^{6} \mathrm{ohm}-\mathrm{cm}$, then increased slowly in subsequent runs.

In Table 24 the thermal conductivity of the wall was calculated from the heat transfer equation using the overall mean wall thickness as previously defined.

D. Direct Fluorination of Uranium Dioxide Fuel

(W. Mecham, A. A. Jonke)

Since many power reactors will use uranium dioxide fuels, a process based on direct fluorination of uranium dioxide to the hexafluoride is of interest. Laboratory work has shown (ANL-6029, page 73) that fused or sintered uranium dioxide can be fluorinated at practical rates. Work on the separation of plutonium from such fuels by fluorination is being studied on a laboratory scale.

When uranium dioxide is converted directly to the hexafluoride in an atmosphere of fluorine, the heat released is about $1100 \mathrm{kcal} / \mathrm{kg}$ of uranium. A means for controlling the reaction and removing the large amount of heat is required. A technique in which the pelleted uranium dioxide fuel is surrounded by a fluidized bed of some inert solid is being studied.

\section{Engineexing-scale Experiments (J. D. Gabor, J.Wehrle)}

Because the uranium dioxide pellets frequently used as nuclear fuel are too large to be fluidized directly, the use of an inert fluidized medium to fill the void spaces in a packed bed of pellets has been considered. Such an inert bed would have several advantages: 1) aid in the removal of heat, 2) dilute the solid reagent, 3) distribute the gaseous reagent, 4) retain the reagent fines, and 5) dilute and ultimately transport the radioactive residues. This technique could be used to carry out the reaction of solid. fuel material of various forms, such as rods, plates, or pellets within a fluid bed of smaller particles. A similar technique has been studied at Brookhaven National Laboratory for the hydrochlorination of zirconiumbase fuel.

In order to observe conditions in such systems, initial mock-up tests were carried out. A three-inch diameter glass column was used to observe fluidized copper powder in annuli and in beds of coarsely packed solids. Visual observation, bed-expansion ratios, and pressure-drop measurements were used as indices to compare case of "hindered" fluidization with fluidization in the usual open tubes. The results of these measurements are given in Figures 29, 30, and 31. 
FIGURE 29

COMPARISON OF FLUIDIZED-BED EXPANSION IN ANNULI ANO IN AN OPEN TUBE

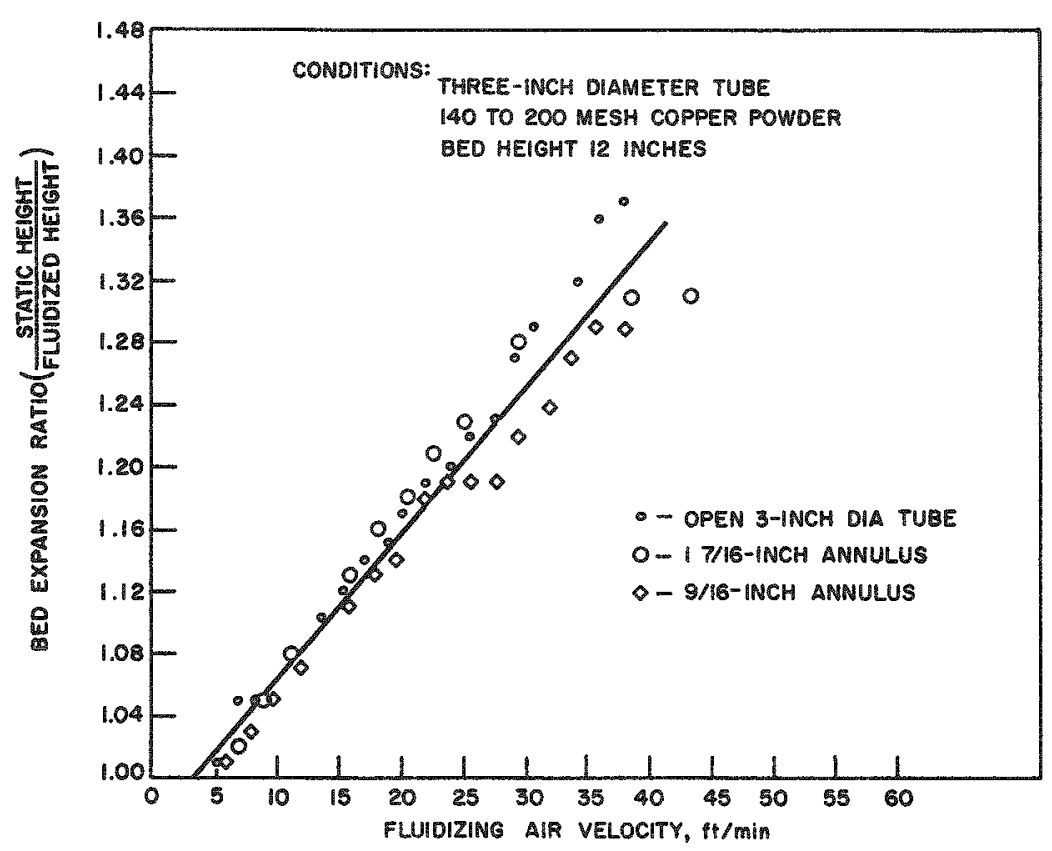

FIGURE 30

COMPARISON OF FLUIDIZED-BED EXPANSIŌN IN AN OPEN TUBE WITH PACKED BED

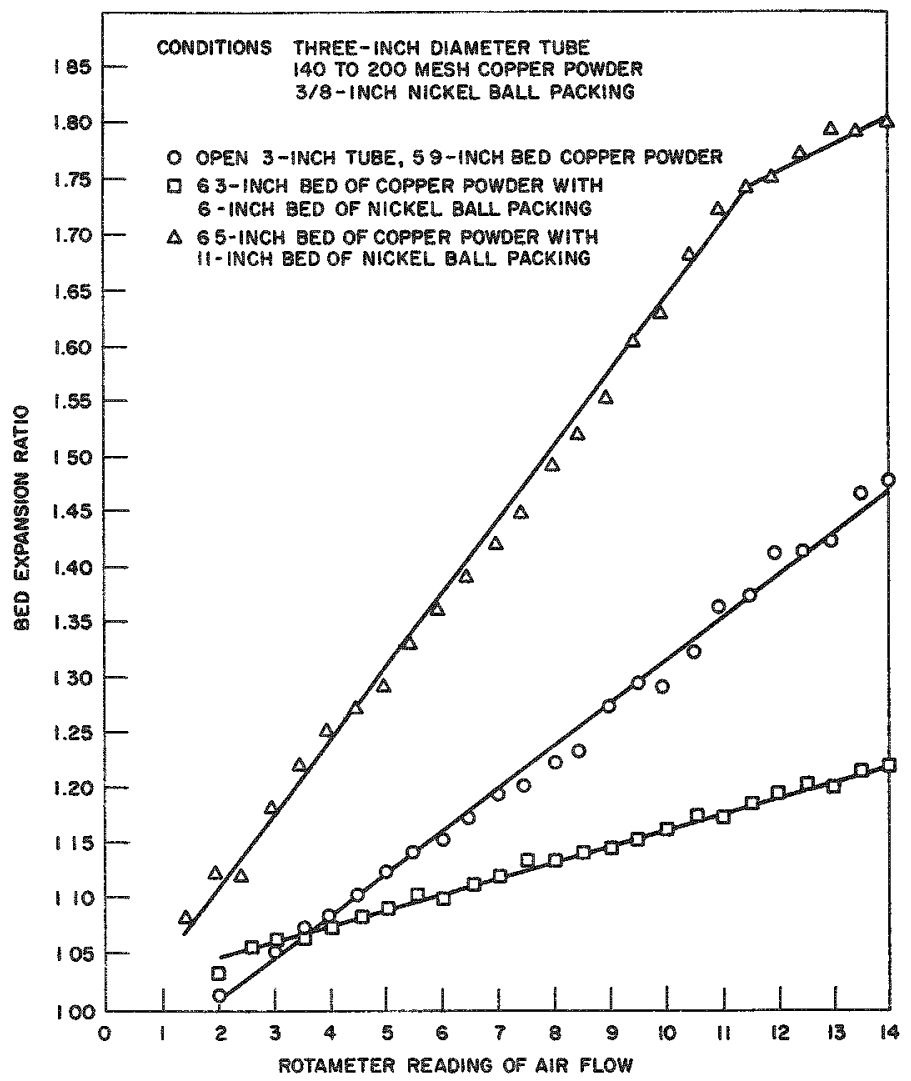


FIGURE 3 !

COMPARISON OF BED PRESSURE DROP FOR FLUIDIZATION IN OPEN TUBE AND IN PACKED BED

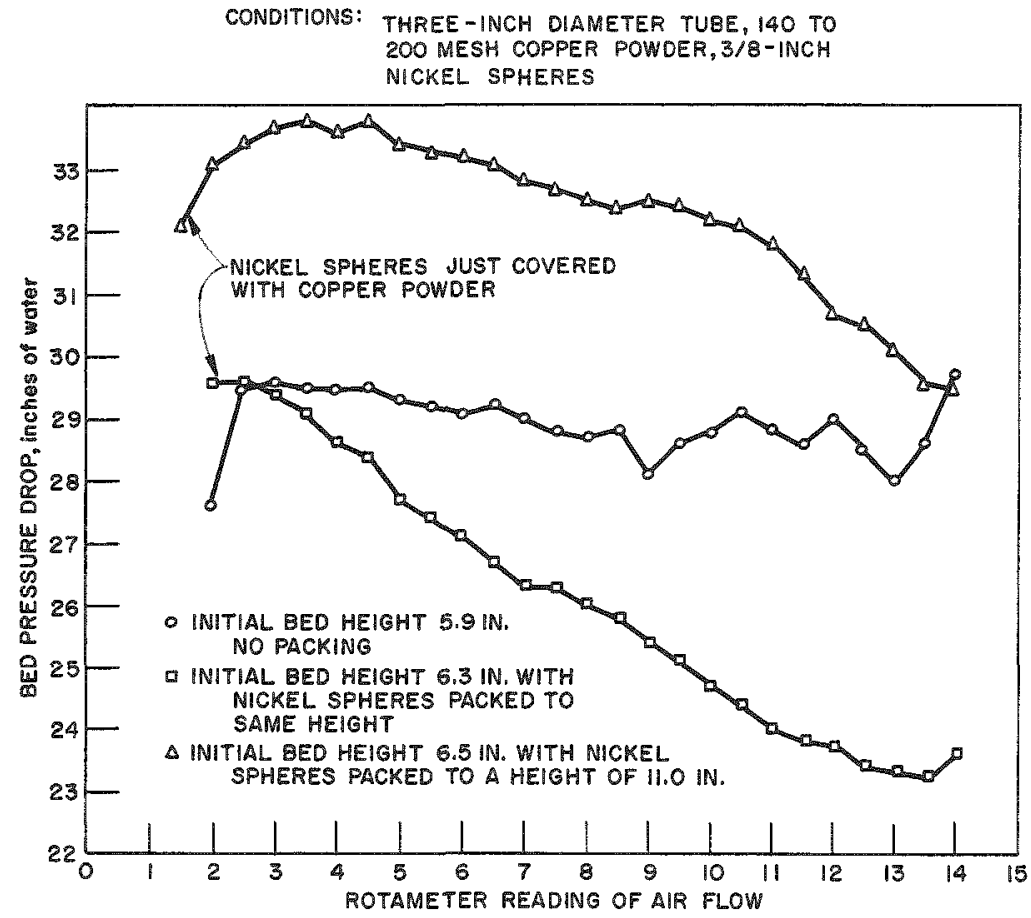

From Figure 29 it appears that the bed-expansion ratios show the same behavior for both an open circular tube and for annuli of $\frac{9}{16}$ to $1 \frac{9}{16}$-inch width. A comparison of fluidized bed expansion for the packed bed and for the open tube may be made for various gas rates from the data in Figures 30 and 31 . The case in which the line shows a sharp change of slope is explained by the fact that the fluid bed expanded into the open tube above the packing and thereby occupied a zone of higher cross-sectional area with correspondingly lower gas velocities. The case in which the fluid bed remained in the packed zone showed behavior similar to the opentube case.

Magnesium fluoride was chosen as an inert, low-cost material for the fluorination runs. The material used was a sintered slag and liner material obtained as a by-product of commercial uranium-reduction processes. Before use, the material was crushed and screened to 60 to $80 \mathrm{mesh}$, and prefluorinated in the reactor.

The uranium dioxide pellets were cylinders, approximately one $\mathrm{cm}$ in height and one $\mathrm{cm}$ in diameter, manufactured by the Davison Chemical Company. The material was made by the ammonium diuranate process, calcined at $1400 \mathrm{~F}$ and inert fired at $3100 \mathrm{~F}$. The 3 -inch fluid-bed reactor system used was the same as used previously for fluorination of ADF process residues. 
The initial runs were made primarily to check control of the reaction temperature and to obtain preliminary information on the reation rate and fluorine efficiency. A summary of the conditions and general behavior of the runs is given in Table 25. The results are best described in chronological sequence.

Table 25

\section{SUMMARY OF RESULTS OF URANIUM DIOXIDE PELLET FLUORINATION RUNS}

$\left(\mathrm{UO}_{2}\right.$ pellet charge: $\left.1757 \mathrm{~g}\right)$

\begin{tabular}{|c|c|c|c|c|c|}
\hline Run & $\begin{array}{l}\text { Fluidizing Gas } \\
\qquad(\%)\end{array}$ & $\begin{array}{c}\text { Gas } \\
\text { Flow Rate } \\
(\mathrm{ft} / \mathrm{sec})\end{array}$ & $\begin{array}{l}\text { Time } \\
\text { of Run } \\
(\mathrm{hr})\end{array}$ & $\begin{array}{l}\text { Bed } \\
\text { Temp } \\
(\mathrm{C})\end{array}$ & Results \\
\hline UOF-1 & $10 F_{2}-90$ Air & $\sim 0.7$ & 3 & 400 & $\begin{array}{l}\text { Pellets disintegrated to } \\
\text { fines. } 232 \mathrm{~g} \text { collected } \\
\text { on filter. }\end{array}$ \\
\hline UOF - 2 & $10 F_{2}-90 N_{2}$ & $\sim 0.7$ & $2 \frac{1}{2}$ & 400 & $\begin{array}{l}\text { Pellets disintegrated to } \\
\text { fines. } 417 \mathrm{~g} \text { collected } \\
\text { on filters. }\end{array}$ \\
\hline UOF -3 & $100 \mathrm{~N}_{2}$ & $\sim 0.7$ & $2 \frac{1}{2}$ & 400 & $\begin{array}{l}\text { Pellets had not dis- } \\
\text { integrated. Surface } \\
\text { crumbling and pitting } \\
\text { observed. Fines in } \\
\mathrm{MgF}_{2} \text { bed. }\end{array}$ \\
\hline UOF -4 & $10 F_{2}-90 N_{2}$ & $\sim 0.35$ & 3 & 500 & $\begin{array}{l}\text { Pellets had not dis- } \\
\text { integrated. Fines } \\
\text { were produced, but } \\
\text { were substantially less } \\
\text { than in UOF-1 and } 2 \text {. }\end{array}$ \\
\hline
\end{tabular}

a. Run UOF - 1

This initial 3-hour run was made with a fluidizing gas of 10 per cent fluorine and 90 per cent air. Air was used for two reasons: (1) to determine the effect of oxygen on the uranium dioxide pellets in a fluid-bed reaction and (2) to test the effect of its use as the least expensive diluent possible. Although it was known that sintered uranium dioxide bodies react with oxygen to form higher uranium oxides, with a resulting pulverization to very small fines, it was hoped that the oxidation would not occur in preference to fluorination, or if it did occur that the resulting fines would react with the fluorine before being carried out of the bed. The presence of oxygen cannot be avoided completely since it is a reaction 
product, and, in the case of gas recycle, the oxygen content would be substantial. In the above case the oxygen concentration was 18 per cent.

The bed was maintained at $400 \mathrm{C}$, and the gas flow rate was approximately $0.7 \mathrm{ft} / \mathrm{sec}$. The heat from the reaction was small under these conditions and temperature control presented no problem.

The pellets pulverized during the run and 232 grams of uranium oxide fines were found in the off-gas filter chamber. The initial charge of uranium dioxide pellets weighed 1757 grams. The magnesium fluoride in the column weighed 528 grams more than prior to the run. By this crude material balance it was deduced that 1000 grams of original charge had reacted with the fluorine to form uranium hexafluoride. The magnesium fluoride proved to be a good bed material for these conditions. There was no evidence of sintering or caking.

\section{b. Run UOF-2}

This run of $2 \frac{1}{2}$-hour duration was carried out under the same conditions as UOF-1 except that nitrogen was used instead of air to dilute the fluorine. This was done to determine if air was the cause of the uranium dioxide pulverization. If the pulverization of the pellets could be prevented, an accurate determination of reaction rate could be made from examination of the bed residues.

Examination of the bed showed that the pellets had again pulverized. There were about 420 grams of fines, about one fourth of the weight of the original pellet charge $(1766 \mathrm{~g})$, on the filters. After both runs, the bed residue contained a number of various-sized uranium dioxide lumps remaining from the original pellet charge, indicating that pulverization had proceeded inward from the pellet surface.

$$
\text { c. Run UOF -3 }
$$

The extensive pulverization of pellets in Runs UOF-1 and UOF - 2 prompted speculation that the disintegration might be due to simple thermal stresses. Run UOF-3 was then performed to test further the stability of the pellets during operating conditions by exposing the pellets to nitrogen only (no fluorine or oxygen) in the reactor. The nitrogen flow rate was about $0.7 \mathrm{ft} / \mathrm{sec}$ with a bed temperature of $400 \mathrm{C}$. The run proceeded at these conditions for $2 \frac{1}{2}$ hours.

The pellets were found to be whole after the run. The surfaces were roughened and pitted. Only about 7 grams of pellet weight were lost. Even though the pellets had not disintegrated, there was evidence (a darkening of the bed of magnesium fluoride) of crumbling at the surface and of formation of fines. It is possible that the effect of thermal stresses would be increased by local high temperatures in the reaction with fluorine. 


\section{d. Run UOF -4}

In this three-hour run three conditions were changed with the objective of reducing the carry-over of fines: a) the bed temperature was increased to $500 \mathrm{C}$; b) the magnesium fluoride bed height was increased from 6 to 12 inches, so that the pellet charge was well-covered; and c) the rate of flow of nitrogen-fluorine gas was cut in half, to approximately $0.35 \mathrm{ft} / \mathrm{sec}$. The inlet fluorine concentration (10 per cent) and the pellet charge $(1750 \mathrm{~g})$ remained the same.

A considerable reduction in fines as compared with previous runs was observed. The bed was lighter in color, indicating less uranium dioxide in the magnesium fluoride phase. Only a small amount of fines $(17.5 \mathrm{~g})$ was found in the filter chamber. The pellets remaining were largely intact, rather than breaking up as in previous runs. The reason for the different pellet behavior is not clear. A material balance for Run UOF -4 is given in Table 26.

Table 26

\section{MATERIAL BALANCE IN RUN UOF- 4}

Conditions: $10 \% \mathrm{~F}_{2}$ in $\mathrm{N}_{2}$

Gas Velocity: $0.35 \mathrm{ft} / \mathrm{sec}$

Bed Height: 12 in.

Bed Temp: $500 \mathrm{C}$

$$
\begin{aligned}
& \text { Charge } \\
& \mathrm{MgF}_{2} \\
& \mathrm{UO}_{2} \text { pellets }
\end{aligned}
$$

End of Run

$\mathrm{MgF}_{2}+\mathrm{UO}_{2}$ fines in bed

$\mathrm{UO}_{2}$ pellets

$\mathrm{UO}_{2}$ pieces in bed

fines in filter $\left(\mathrm{UO}_{2}\right)$

Material Leaving System

$\mathrm{UO}_{2}$ equivalent of $\mathrm{UF}_{6}$ product $(680 \mathrm{~g}$ in condenser)

\begin{tabular}{l}
$\begin{array}{c}\text { Weight } \\
(\mathrm{g})\end{array}$ \\
\hline 1318 \\
$\frac{1736}{3054}$
\end{tabular}

1394

1067

11.5

17.5

2490.0

564

520

The runs thus far have indicated that the reaction temperature can be controlled by fluorine dilution and that magnesium fluoride is a satisfactory fluidizing medium, at least at these temperatures. A filter 
directly above the bed in the disengaging section may be necessary. The collected fines could then be blown back into the column to complete the reaction.

A three-inch reactor with a disengaging and filter section directly over the primary reaction zone is being fabricated in the shops. This reactor also has provision for additional cooling, which may be required at higher temperatures and fluorine concentrations. Future runs with the present equipment will be directed toward finding means of carrying out the fluorination without production or carry-over of fines. Two promising approaches are indicated by the runs thus far: (1) use of lower gas velocities and a deeper bed to retain the fines, and (2) use of higher temperatures and higher fluorine concentrations to promote more rapid reaction of the fines.

E. Calcination of Reactor Fuel-processing Wastes

(A. Jonke, J. W. Loeding, L. J. Anastasia, C. Schoffstoll, L. Marek)

Radioactive aqueous wastes resulting from certain solvent extraction processes can be calcined by means of direct spray injection into a heated fluidized bed. The resultant physicochemical change produces a free-flowing granular solid and considerably reduces the volume of waste. Initial work was applied to aluminum nitrate-bearing waste. Recent work has extended this application to Purex-type wastes. With the completion of two active runs to determine the fission product distribution throughout the equipment, feasibility and demonstrational studies of the Purex waste were concluded.

\section{Operating Conditions}

The first of the active runs ( $\mathrm{HWC}-141$ ) utilized a synthetic Purex low-acid waste (simulating formaldehyde-treated waste) with the concentration given in ANL-5996. Table 25; the second run was made with the same waste diluted by the addition of one pound of sugar to each gallon of waste. The sugar was added to produce a more friable product with less particle growth and to supply part of the heat required in the process. ICPP radioactive aluminum nitrate waste ( 5 years old) was used to spike the liquid feed for both runs. In each case the dilution factor was 100:1.

Both runs were made with the projecting tip, JJB nozzle (ANL-6068, Figure 24), and a calcination temperature of $500 \mathrm{C}$. The runs were characterized by the smoothness of operation expected from the extended tip nozzle. Nominal operating conditions for these runs are presented in Table 27. Run HWC-141 was made at a total fluidizing gas velocity of $1.50 \mathrm{ft} / \mathrm{sec}$, attrition air at $1.56 \mathrm{scfm}$, and a power input of $13.2 \mathrm{kva}$. The run with sugar added to the feed. HWC-142, was made at a total fluidizing 
Table 27

NOMINAL OPERATING CONDITIONS FOR ACTIVE RUNS FOR CALCINATION OF HANFORD LOW-ACID PUREX WASTES

\begin{tabular}{|c|c|c|c|c|c|c|c|c|c|c|}
\hline & & & Temp: & & $500 \mathrm{C}$ & & & & & \\
\hline & & & Dilution: & & 1 part acti & to 100 & rts inact & e solu & & \\
\hline & & & Feed: & & $\begin{array}{l}\text { Gross } \gamma 6.3 \\
\operatorname{Ru} \gamma 1.2 \times\end{array}$ & $\begin{array}{c}10^{6} \mathrm{cpm} \\
\mathrm{cpm} / \mathrm{ml}\end{array}$ & & & & \\
\hline & & & Starting Be & & Screened -2 & $+200 \mathrm{me}$ & & & & \\
\hline & & & Atomizing $N$ & zle: & Projecting & $\mathrm{p}(\mathrm{JJ} \mathbf{J B})$ & & & & \\
\hline $\begin{array}{l}\text { Run } \\
\text { No. } \\
\text { HWC- }\end{array}$ & $\begin{array}{c}\text { Avg Feed } \\
\text { Rate } \\
(\mathrm{ml} / \mathrm{min})\end{array}$ & $\begin{array}{l}\text { Fluid- } \\
\text { izing } \\
\text { Air } \\
(\operatorname{scfm})\end{array}$ & $\begin{array}{c}\text { Attrition } \\
\text { Air } \\
(\operatorname{scfm})\end{array}$ & $\begin{array}{c}\text { Total } \\
\text { Fluid- } \\
\text { izing } \\
\text { Gas } \\
\text { Velocity } \\
\text { (ft/sec) }\end{array}$ & $\begin{array}{l}\text { Volume } \\
\text { Initial } \\
\text { Bed } \\
\text { (1iters) }\end{array}$ & $\begin{array}{c}\text { Bed } \\
\text { Bulk } \\
\text { Density } \\
(\mathrm{g} / \mathrm{cc})\end{array}$ & $\begin{array}{l}\text { Duration } \\
\quad(\mathrm{hr})\end{array}$ & $\begin{array}{l}\text { Power } \\
\text { Input } \\
\text { (kva) }\end{array}$ & $\begin{array}{c}\text { Sugar } \\
\text { Content } \\
\text { (lb/gal) }\end{array}$ & Comments \\
\hline 14.1 & 79.4 & .3 .22 & 1.56 & 1.50 & 6 & 1.43 & 5.6 & 13.2 & - & $\begin{array}{l}\text { Venturi scrubber } \\
\text { and silica-gel } \\
\text { adsorber by- } \\
\text { passed }\end{array}$ \\
\hline 142 & 76.4 & 3.78 & - & 1.24 & 6 & 0.87 & 6.4 & 9.8 & 1.04 & $\begin{array}{l}\text { Silica-gel } \\
\text { adsorber by- } \\
\text { passed. Venturi } \\
\text { scrub cycle rate } \\
\sim 390 \mathrm{ml} / \mathrm{min} \text {. }\end{array}$ \\
\hline
\end{tabular}


gas velocity of $1.24 \mathrm{ft} / \mathrm{sec}$ and a power input of $9.8 \mathrm{kva}$. In order to minimize production of fines, and thereby to simplify equipment clean-up, attrition air was not used during the second active run.

To avoid any reaction of the sugar with the feed, the addition of sugar was made immediately prior to the use of the feed; the feed was not permitted to stand for extended periods. On a plant scale this problem could be resolved by introducing the sugar in correct proportion to the feed line immediately prior to the atomizing nozzle.

2. Results

a. Particle Growth

No particle growth was visually observed during the run with attrition air. Visual observations were made because of the difficulty involved in screening active samples. Because of the short duration of the experiment, only a slight amount of particle growth was observed during the run using feed with added sugar. As shown in ANL-6068, Figure 34, particle growth with a Purex low-acid waste containing sugar can be controlled by use of an attrition air jet.

\section{b. Fission Product Distribution}

Qualitative indications obtained during the runs by means of a portable $\beta-\gamma$ counter showed the presence of appreciable acitivity in the off-gas and condensate streams from the feed containing no sugar and considerably less activity in the same streams from the feed which did contain sugar. Gamma-scintillation spectrometer scans indicated that the activity was predominantly ruthenium. These indications were confirmed by the analytical results obtained following the runs. Results are summarized in Table 28. The ruthenium distribution for the low-acid feed showed 47.4 per cent in the condensate, 6.5 per cent in the off-gas, and 24.9 per cent in the calcine, giving an overall ruthenium balance of 78.8 per cent. Ruthenium distribution in the effluent streams for the run with added sugar were $0.5,0.03$, and 81.2 per cent, respectively, for the condensate, off-gas, and calcine, the overall ruthenium balance for this run being 81.8 per cent.

Table 28

RUTHENIUM DISTRIBUTION AND CONDENSATE ANALYSIS FOR ACTIVE PUREX LOW-ACID CALCINATION RUNS AT $500 \mathrm{C}$

Percentage of Feed

Run

No.

HWC- Added

141

142
No

Yes
Ruthenium Recovered

$\frac{\text { Product }}{24.9}$

81.2

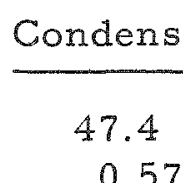

0.57
Off-gas Total

6.5

0.03

78.8

81.8

Condensate

Nitrate Sulfate

(M) $(\mathrm{mg} / \mathrm{ml})$

1.16

0.17

0.11

0.20 
The nonvolatile decontamination factor across the calciner was of the order of $2 \times 10^{5}$, which was essentially determined by the limit of detection.

Several anomalies with respect to previous experience were evidenced during these runs. The efficiency of the condenser in removing ruthenium activity was 89 per cent for $\mathrm{HWC}-141$ and 95 per cent for HWC-142. In all previous "spike" runs made with aluminum nitrate feeds, the condenser efficiency has been approximately 99 per cent. Also, the work with aluminum nitrate repeatedly showed about 1 per cent of feed ruthenium volatilized at a $500 \mathrm{C}$ bed temperature. In experiments with the Purex low-acid waste, however, there was as much as 54 per cent ruthenium volatilization at this same bed temperature. The feed containing sugar, when calcined at $500 \mathrm{C}$, yielded ruthenium distribution results comparable to the earlier work with aluminum nitrate waste in which carbon monoxide was injected into the calciner to reduce the nitrates and ruthenium chemically. An additional advantage to the sugar addition is indicated by the power input reduction of 25 per cent as a result of the heat generated by reaction of the sugar with nitrates contained in the feed solution.

A further incongruity with previous work is indicated by the behavior of the venturi scrubber. Previous mention (ANL-5959, page 57) has been made of the ability of the venturi scrubber in removing volatilized ruthenium from the off-gas, although its primary function is the removal of particulates. Efficiencies for ruthenium removal of from 20 to 40 per cent have been recorded. In Run $\mathrm{HWC}-142$, however, the efficiency of the venturi scrubber in removing ruthenium for the off-gas was zero. This abnormal behavior of ruthenium in these active runs may be explained by the possibility that different ruthenium species were present in the dissimilar feeds. It should be mentioned that the primary porous metal bayonet filters performed so well that insufficient nonvolatile activity was found in the scrub stream to permit an evaluation of the scrubber efficiency in removing particulate from the off-gas.

Nitrate concentration in the condensate for $\mathrm{HWC}-141$ was $1.16 \mathrm{M}$; for the run with added sugar. the concentration of nitrate in the condensate was $0.11 \mathrm{M}$, indicating the destruction of about 90 per cent of the acidity. Sulfate concentration was approximately $0.2 \mathrm{mg} / \mathrm{ml}$ for both runs.

With the determination of fission product distributions for the two synthetic low-acid Purex wastes, calcination of these wastes have been successfully demonstrated. Although feasibility and demonstration studies have been concluded with the 6 -inch waste calciner at Argonne, future work will be continued at Hanford, where an 8-inch fluidized-bed calciner of larger capacity has been designed and installed. 
F. Conversion of Uranium Hexafluoride to Uranium Dioxide in Fluidized Beds (I. Knudsen, N. Levitz, R. Finley, M. Jones)

Additional studies of a fluid-bed process for the conversion of uranium hexafluoride to uranium dioxide were made in the newly installed 3-inch diameter Monel reactor. Previous work, carried out in a $1 \frac{1}{2}$-inch diameter unit, was summarized in topical report ANL-6023. Steam and hydrogen, used both as the reactants and fluidizing medium, were contacted with a uranium hexafluoride stream in a fluidized bed or uranium dioxide, permitting the occurrence of "simultaneous" fluoride-pyrohydrolysis reduction reactions. The newly formed dioxide was deposited as a dense coating on the original bed material or formed new seed particles. Final evaluation of the product for use in ceramic-grade fuel will be determined in subsequent sintering studies. An alternate use of the process is the recovery of the fluoride as hydrofluoric acid from the stores of depleted uranium hexafluoride.

\section{Equipment Description}

The 3-inch diameter Monel Column is 5 feet high overall. The upper two-foot section is an expanded eight-inch diameter disengaging section containing three porous Monel bayonet filters, which are periodically cleaned by an automatic blow-back system. The fluidizing gases enter at the apex of the sixty-degree cone bottom. The uranium hexafluoride feed stream is regulated by an automatic control valve and enters the column through $\frac{1}{4}$-inch $O D$ tubing extending about 1 inch into the bed. Some minor difficulties were encountered with lump formation on this inlet tube and on thermowells in too close proximity to it. The fluidized bed level is continuously recorded and maintained constant by periodic (manual) withdrawal of product from an outlet on the cone bottom. An electrically operated valve to permit automatic product withdrawal is on order. The off agases (excess steam and hydrogen and hydrofluoric acid from the reaction) are condensed, scrubbed, and then diluted with air before being discharged to the stack.

Operating Conditions

All of the runs to date in the new unit were made at $600 \mathrm{C}$. Uranium hexafluoride rates ranged from 23 to $40 \mathrm{~g} / \mathrm{min}$ [ 40 to $70 \mathrm{lb}$ uranium/(hour) (square foot of reactor cross section)]. Superficial gas velocities of 0.75 and $1.12 \mathrm{ft} / \mathrm{sec}$ were used with bed heights of 12 and 18 inches. Reactant excesses ranged from 280 to 520 per cent for steam and from 300 to 740 per cent for hydrogen. Run durations ranged from 2.8 to 11.0 hours. 
Results and Discussion

The residual fluoride content and changes in particle size distribution were the criteria for noting trends or the effect of the particular variable under study. Final evaluation of the product will be made on the basis of subsequent sintering tests. It was felt that data from runs which allowed 1 to 2 bed displacements would be meaningful, although an interdependence of variables in some cases does not permit and exact interpretation of the results.

The starting bed in each case was the final bed from the previous run; this bed was contacted with additional steam and hydrogen to complete the conversion to dioxide and give more uniform starting materials. The necessity for the clean-up step has led to the suggestion that the overall process consist of 2 steps or stages which could give added throughput as well as make more efficient use of the reactant gases. The second stage would also give desirable flexibility in adjusting conditions for control of particle sizes.

Some typical product analyses are summarized in Table 29. Calculations based on these data indicate the product contains uranium dioxide, uranyl fluoride and $\mathrm{U}_{3} \mathrm{O}_{8}$, as well as small amounts of uranium tetrafluoride in some cases.

Table 29

SUMMARY OF RUNS ON FLUID-BED CONVERSION OF URANIUM HEXAFLUORIDE TO URANIUM DIOXIDE

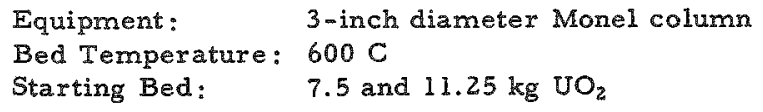

\begin{tabular}{|c|c|c|c|c|c|c|c|c|c|c|c|}
\hline \multirow[b]{3}{*}{$\begin{array}{l}\text { Run } \\
\text { No. }\end{array}$} & \multirow{3}{*}{$\begin{array}{c}\text { Super - } \\
\text { ficial } \\
\text { Gas } \\
\text { Velocity } \\
\text { (ft/sec) }\end{array}$} & \multirow{3}{*}{$\begin{array}{c}\text { Static } \\
\text { Bed } \\
\text { Height } \\
\text { (in.) }\end{array}$} & \multirow{3}{*}{$\begin{array}{c}\text { Average } \\
\text { UF }_{6} \\
\text { Rate } \\
\text { (g/min) }\end{array}$} & & & \multirow{3}{*}{$\begin{array}{l}\text { Run } \\
\text { Dura- } \\
\text { tion } \\
\text { (hr) }\end{array}$} & \multirow{3}{*}{$\begin{array}{l}\text { Average } \\
\text { Solids } \\
\text { Resi- } \\
\text { dence } \\
\text { Time } \\
\text { (hr) }\end{array}$} & \multicolumn{4}{|c|}{ Analytical Results } \\
\hline & & & & \multicolumn{2}{|c|}{ Reactant Excess } & & & \multirow{2}{*}{$\begin{array}{c}\text { Time } \\
\text { Sample } \\
\text { Taken } \\
\text { (hr) }\end{array}$} & \multirow{2}{*}{$\begin{array}{c}\text { Residual } \\
\text { Fluoride } \\
(w / o)\end{array}$} & \multirow[b]{2}{*}{$\begin{array}{c}U^{+4} \\
(w / o)\end{array}$} & \multirow{2}{*}{$\begin{array}{c}\text { Total } \\
U \\
(w / o)\end{array}$} \\
\hline & & & & $\begin{array}{c}\text { Steam } \\
(\%)\end{array}$ & $\begin{array}{l}\text { Hydrogen } \\
\qquad \%)\end{array}$ & & & & & & \\
\hline 25 & 0.75 & 12 & 30 & 330 & 340 & 2.8 & 5.4 & 2.3 & 1.41 & 71.5 & 86.2 \\
\hline 26 & 0.75 & 12 & 26 & 400 & 400 & 4.0 & 6.3 & 3.9 & 0.46 & 84.9 & 86.2 \\
\hline 27 & 0.75 & 12 & 23 & 330 & 740 & 9.8 & 7.1 & 7.5 & 0.66 & 76.7 & 86.4 \\
\hline 28 & 0.75 & 18 & 33 & 280 & 300 & 9.2 & 7.4 & 8.0 & 3.52 & 71.6 & - \\
\hline 29 & 1.12 & 18 & 40 & 370 & 400 & 11.0 & 6.1 & 10.0 & 2.93 & 35.6 & - \\
\hline 30 & 1.12 & 18 & 31 & 520 & 540 & 7.1 & 7.9 & 7.0 & 1.26 & 72.2 & 85.6 \\
\hline 31 & 1.12 & 12 & 38 & 400 & 410 & 6.0 & 4.3 & 6.0 & 2.80 & 38.3 & - \\
\hline
\end{tabular}

Improved (lower) residual fluoride content was noted for increased solids residence times at constant reactant excesses (compare Runs 31 and 26) and also for higher steam and hydrogen excesses (compare Runs 28 and 30) 
and higher hydrogen excess alone (Runs 27 and 25). Unexpectedly, little effect (on residual fluoride) was noted when the solids residence time was increased 50 per cent by increasing the bed height (from 12 to 18 inches, Runs 31 and 29) at constant gas velocity.

Fines formation, apparently a function of gas residence time in the bed, increased with the increase in gas velocity and decreased with increased bed height. In some cases there was an increase in both the coarse-sized fractions and the fines. The bulk density of the solid product has ranged from about 4 to $5.4 \mathrm{~g} / \mathrm{cc}$ (measured for the 60 to 100 mesh fraction in each case) and appears to vary inversely as the fluoride content. To date, negligible amounts of uranium have been found in the off-gas condensate, about $1 \mathrm{mg}$ per $\mathrm{kg}$ of uranium fed.

Future work will attempt to evaluate the effect of bed temperature on conversion to dioxide and determine the maximum capacity of the system. Some consideration is being given to the design of a 2 -stage unit. 


\section{REACTOR SAEETY}

A. Metal Oxidation-Ignition Studies

(J.G.Schnizlein)

The program to clarify the factors governing the pyrophoric characteristics of the metals uranium, zirconium, thorium, and plutonium has continued with studies of ignition phenomena and the combustion process. Techniques reported in ANL-5974 have been used to extend the study to determine the effects of specific area and contaminants on the ignition of uranium metal in the form of wires and powders. The linear relationship between specific area and the reciprocal of the ignition temperature is obeyed by the wires as well as cubes and foils, and covers the range of specific areas of uranium fuel assemblies in use in enriched reactors (from $\frac{3}{8}$-inch rod through 1 -mil foil). However, experimental ignitiontemperatures of metal powders appear to be lower than the extrapolated relationship would indicate. The lack of agreement is attributed to the uncertainty of estimation of the specific areas.

Measurements of particle size distribution and surface areas are under way in the continuing study of powder ignitions. Burning-curve experiments have demonstrated that the presence of 10 per cent ferric oxide or zirconium dioxide does not decrease the ignition temperature of uranium powder but does increase the burning temperature, as might be expected from a thermite-type reaction.

The effects of aluminum and copper additives on the ignition temperature of uranium in oxygen are masked in burning-curve experiments in air by the complexity of the thermocycling behavior. Weight gain and sample temperature measurements have been used to demonstrate that, when the alloys are heated in helium to $700 \mathrm{C}$ and exposed to air, the oxidation rates are in accord with the order of ignition temperatures in oxygen.

One of the most common pyrophoricity hazards involves the ignition and burning of chips from machining operations. Because chips usually have irregular cross sections and are not uniform along their length, a more careful study of the burning process can be performed on foil strips or wires. Studies of the propagation of burning along foil strips have provided a method for appraising the effects of many variables on the combustion process. Previous studies with uranium (ANL-5959, page 71; ANL-5996, pages 196 and 204; and ANL-6068, page 129-131) have included the effects of (1) varied thickness, width, and shape in oxygen and in air and (2) surface and gas contaminants and etchants; with zirconium there has been investigated (ANL-6029, page 120; and ANL-6068, pages 137-142) (1) varied thickness, width, and shape in oxygen and in air, (2) alloy additives, and (3) varied oxygen content of the gas. Some measurements of the 
burning-temperature profiles along the strip have been made for both uranium and zirconium (ANL-6068, pages 135 and 140). The completeness of combustion of zirconium, the width of the sample, alloying agent present, and burning temperature were shown to be interdependent (ANL-6029, page 119).

Studies with uranium during this period have shown (1) that the extent of combustion is strongly dependent on the thickness of the foil, and. (2) that the product oxide is a mixture of $\mathrm{UO}_{2}$ and $\mathrm{U}_{3} \mathrm{O}_{8-\mathrm{X}}$. Studies with zirconium and several gas contaminants (ozone, carbon dioxide, and water vapor) have shown a limited effect of these gases on the burning propagation rates of foils in air.

Microscopic observation of the surfaces of uranium samples during oxidation at 150 and $200 \mathrm{C}$ have indicated by time-lapse photography that change in the rate of onset and growth of nucleation on the oxide surface occurs at the same time as the transition of the kinetics to the second-stage oxidation rate. Other studies with several alloys demonstrated negligible effects on the oxidation kinetics at $125 \mathrm{C}$, as was observed at $200 \mathrm{C}$ (ANL-5974, page 62).

1. Uranium-ignition Studies

(L. Leibowitz, J. D. Bingle)

a. Effect of Specific Area on Ignition Temperature

In the continuing study of the ignition characteristics of uranium, the most important variable leading to lower ignition temperatures has been the specific area (surface area per gram) of the sample. Linear relationships have been found between the reciprocal absolute temperature of ignition and the logarithm of the specific area of the sample. This is true of burning-curve ignition temperatures in both air and oxygen; these temperatures have been determined using samples of varying size and shape. It was felt expedient, however, to test this specific area dependence further by determining the ignition temperatures of uranium wires of several different diameters. * These are the same wires used in the uranium burningpropagation experiments reported in ANL-6068, page 128. The compositions of these wires and $1-\mathrm{mm}$ thick foil not previously presented are compared in Table 30 with that of the BMI-Base Metal uranium.

* Obtained from L. Baker, Chemical Engineering Division, ANL. 
Table 30

COMPOSITIONS OF URANIUM WIRES AND FOIL SAMPLES

(in parts per million)

\begin{tabular}{|c|c|c|c|c|c|c|}
\hline \multirow[b]{2}{*}{ Element ${ }^{\mathrm{a}}$} & \multirow{2}{*}{$\begin{array}{l}\text { BMI - } \\
\text { Base } \\
\text { Metal }\end{array}$} & \multicolumn{4}{|c|}{$\begin{array}{c}\text { Uranium Wires } \\
\text { (Diameter in } \mathrm{mm} \text { ) }\end{array}$} & \multirow{2}{*}{$\begin{array}{c}\text { Uranium } \\
\text { Foil } \\
(\mathrm{SMF}-40) \\
1 \mathrm{~mm} \text { thick }\end{array}$} \\
\hline & & 0.47 & 0.83 & 1.56 & 2.59 & \\
\hline $\mathrm{Al}$ & $10 \mathrm{~b}$ & 5 & 5 & 15 & 5 & $<5$ \\
\hline $\mathrm{Fe}$ & 50 & 10 & 10 & 30 & 20 & 10 \\
\hline $\mathrm{Mg}$ & 2 & 10 & 10 & 10 & 5 & 2 \\
\hline $\mathrm{Mn}$ & 4 & $<1$ & 1 & 2 & 1 & 1 \\
\hline $\mathrm{Pb}$ & $<1$ & $<1$ & $<1$ & $<1$ & $<1$ & 8 \\
\hline $\mathrm{Cu}$ & 3 & $<1$ & 1 & 1 & 1 & $<1$ \\
\hline $\mathrm{Si}$ & 20 & 150 & 75 & 150 & 100 & 50 \\
\hline $\mathrm{Ni}$ & 30 & $<5$ & 5 & 6 & 5 & $<5$ \\
\hline $\mathrm{Cr}_{r}$ & 30 & $<1$ & $<1$ & $<1$ & $<1$ & $<1$ \\
\hline
\end{tabular}

a The analyses for those constituents not indicated were below the limits of spectrographic detection. Limits of detection are (in ppm): Ag 1, As 10, B 0.1, Be 0.5, Bi l, Ca 20, Co 5, K 50, Li 1, Mn 1, Mo 20, Na 10, P 50, Sb 1, Sn 5, Ti 50, Zn 50.

${ }^{\mathrm{b}}$ Special wet chemical analysis indicated $34 \mathrm{ppm}$ aluminum.

Table 31 lists all the various uranium samples and the ignition temperatures that have been determined for them. Figure 32 illustrates the relationships described. It should be noted again that the deviation from linearity in the area of approximately 2 to $10 \mathrm{sq} \mathrm{cm}$ per gram is attributed to metallurgical variables and is more completely discussed in ANL-5974, page 28. It should also be mentioned that in the region from 0.5 to $2 \mathrm{sq} \mathrm{cm}$ per gram it is extremely difficult to interpret the burning curves in air. The samples seem to be largely consumed before the ignition temperature is attained.

\section{b. Ignition of Uranium Powder}

In order to extend and investigate further the effect of specific area on ignition, some work has been carried out using uranium powders obtained from the Sylvania-Corning Nuclear Corporation. The material was prepared by the hydriding-dehydriding method, and as received was -100 mesh. This metal was subdivided by sieving in a dry box into five fractions: $-100+140,-140+200,-200+230,-200+325$, and -325. Ignition temperatures were measured in oxygen by the burningcurve method for all these samples and, except for the -325 fraction, were found to be $150 \mathrm{C}$. This finest fraction gave an ignition temperature of $140 \mathrm{C}$. The ignition temperature of the original unsieved powder was 
Table 31

EFFECT OF URANIUM SAMPLE SIZE ON IGNITION TEMPERATURE IN OXYGEN AND AIR

\begin{tabular}{|c|c|c|c|c|c|}
\hline \multirow{2}{*}{$\begin{array}{c}\text { Dimensions } \\
(\mathrm{mm})\end{array}$} & \multirow[b]{2}{*}{ Sample $e^{a}$} & \multirow{2}{*}{$\begin{array}{l}\text { Weight } \\
\text { (g) }\end{array}$} & \multirow{2}{*}{$\begin{array}{c}\text { Specific } \\
\text { Area } \\
(\mathrm{sq} \mathrm{cm} / \mathrm{g})\end{array}$} & \multicolumn{2}{|c|}{$\begin{array}{l}\text { Ignition } \\
\text { Temp }\end{array}$} \\
\hline & & & & In $\mathrm{O}_{2}$ & In Air \\
\hline $18 \times 12.4 \times 8.2$ & $\mathrm{BMI}$ & 34.2 & 0.280 & 640 & \\
\hline $10 \times 10 \times 10$ & ANL & 17.6 & 0.334 & 615 & \\
\hline $8.5 \times 8.5 \times 8.5$ & ANL & 11.1 & 0.396 & 595 & 650 \\
\hline $8.5 \times 8.5 \times 8.5$ & High Purity & 11.1 & 0.396 & 595 & \\
\hline $8.5 \times 8.5 \times 8.5$ & $\mathrm{BMI}$ & 11.1 & 0.396 & 575 & \\
\hline $2.9 \times 3.5 \times 18$ & $\mathrm{BMI}$ & 3.23 & 0.790 & 540 & \\
\hline $3.2 \times 3.3 \times 4.0$ & $\mathrm{BMI}$ & 0.690 & 1.06 & 530 & \\
\hline $0.97 \times 15.5 \times 18.4$ & $\mathrm{SMF}-40$ & 5.22 & 1.22 & 570 & \\
\hline 1.56 dia $\times 23.6$ & Wire & 0.847 & 1.41 & 510 & \\
\hline $0.60 \times 11 \times 12$ & ANL (as cast) & 1.45 & 2.02 & 385 & \\
\hline 0.83 dia $x 23.3$ & Wire & 0.238 & 2.59 & 460 & 525 \\
\hline $0.45 \times 7.9 \times 6.7$ & ANL & 0.456 & 2.63 & 470 & \\
\hline $0.43 \times 8.2 \times 9.2$ & ANL (as rolled) & 0.535 & 3.10 & 390 & \\
\hline 0.47 dia $x 24.2$ & Wire & 0.0773 & 4.67 & 435 & 475 \\
\hline $0.24 \times 13 \times 14$ & BMI (as rolled) & 0.807 & 4.68 & 385 & 385 \\
\hline $0.24 \times 9.5 \times 10$ & ANL (as rolled) & 0.388 & 5.18 & 410 & \\
\hline $0.22 \times 10 \times 10$ & - & 0.412 & 5.30 & 385 & \\
\hline $0.13 \times 15.5 \times 22.5$ & $S M F-5$ & 0.856 & 8.26 & & 410 \\
\hline $0.13 \times 13 \times 13$ & BMI (as rolled) & 0.408 & 8.50 & 380 & 390 \\
\hline $0.03 \times 13.5 \times 14$ & - & 0.0772 & 49.0 & 335 & 350 \\
\hline $0.03 \times 17 \times 25^{c}$ & - & 0.172 & 49.6 & 315 & \\
\hline $0.01 \times 15.5 \times 17.5$ & $S M F-5$ & 0.0448 & 121 & 315 & 315 \\
\hline
\end{tabular}

${ }^{a}$ For typical analyses of mentioned samples, see Table 30 and ANL-5996, page 202. Those samples not designated have not yet been analyzed.

${ }^{b}$ Determined by intercept method on burning curves in flowing oxygen or air with programmed temperature increase of 10 degrees per minute.

C Sample was subsequently shredded. 


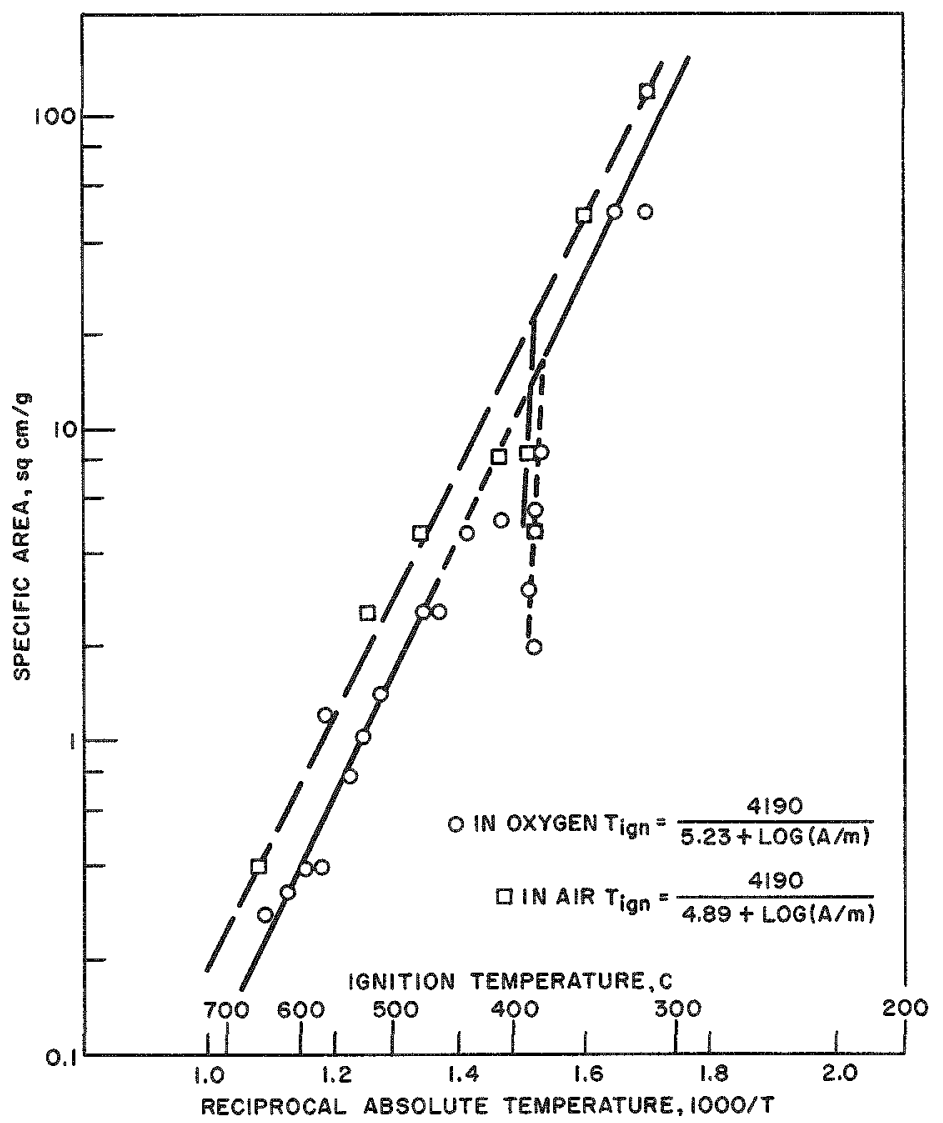

also measured in oxygen by the burning-curve technique and was found to be $140 \mathrm{C}$, which is the same as was found for the finest fraction. The notion that the smallest particle present in sufficient quantities is responsible for ignition thus receives support. Burning-curve experiments in air gave ignition temperatures in the region of $150 \mathrm{C}$, also. These values should be compared with the ignition temperature of $125 \mathrm{C}$ found previously using a more heterogeneous powder prepared at this Laboratory (ANL-5974, page 29).

If the metal powder is considered to consist of uniform spheres, then these ignition temperatures are considerably lower than extrapolation of the above specific area-ignition temperature curve would indicate. This may be due to the broad range of specific areas represented in a given sample of powder. As was stated above, the smallest particle present in sufficient quantity determines the ignition temperature. Particle size distribution and surface area will be determined for the uranium powder used in these experiments in order to appraise the lack of agreement with the extrapolation of curves on the specific area dependence. 
c. Ignitions Involving Thermite-type Reactions

It has been suggested that a possible cause of enhanced pyrophoricity of uranium lies in reactions of the metal with reducible metal oxides. For example, the reaction $3 \mathrm{U}+2 \mathrm{Fe}_{2} \mathrm{O}_{3}=4 \mathrm{Fe}+3 \mathrm{UO}_{2}$ is highly exothermic. This additional energy, it was proposed, could cause a lowered ignition temperature of the mixture compared to that of uranium alone. Several experiments have been carried out to test this possibility.

Burning-curve experiments were conducted with uranium powder ( -325 mesh) containing 10 per cent by weight of ferric oxide or zirconium dioxide. In neither air nor oxygen was the ignition temperature of the mixture lower than that found for the metal alone. It did appear, not unexpectedly, in both media that, once the ignition had occurred, a much brighter burning resulted because of either the added energy release or the greater availability of oxygen.

An additional experiment was carried out in an attempt to ignite a mixture of uranium and ferric oxide in a helium atmosphere. In an experiment of the burning-curve type, a temperature of $650 \mathrm{C}$ was reached without the occurrence of ignition. Moreover, no change in appearance could be detected on examination of the sample after cooling.

\section{d. High-temperature Oxidations in Air}

On most of the occasions in which bulk uranium has burned accidentally, the metal has been heated before the ignition occurred, such as during rolling, biscuit discharging, or reactor operations when fission product heating can raise the temperature of a specimen considerably.

It has been observed that copper and aluminum have the greatest effect on the ignition temperature of uranium cubes in oxygen. Listed below are the values for $8.5 \mathrm{~mm}$ cubes of the one atom per cent alloys.

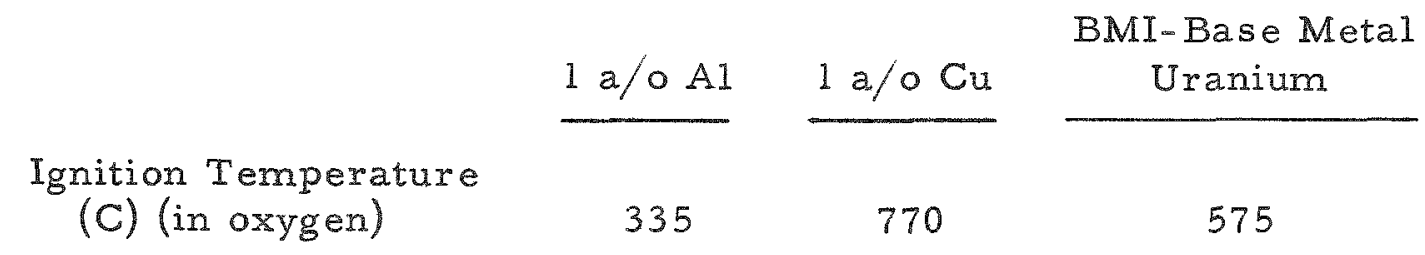

Because of the complexities introduced by thermocycling (ANL-5974, page 31), no similar alloy effect has been clearly observed in air. In order to obtain some information on the possibility of a related alloy effect in air, a number of shielded-type experiments of the type described in ANL-5959, page 65, in which the sample temperature is 
FIGURE 33

TEMPERATURE TRACE OF 620 O OXIDATION IN AIR OF URANIUM AND ALLOY (8.5-mm CUBES IN $6000 \mathrm{cc} / \mathrm{mm}$ AIR)

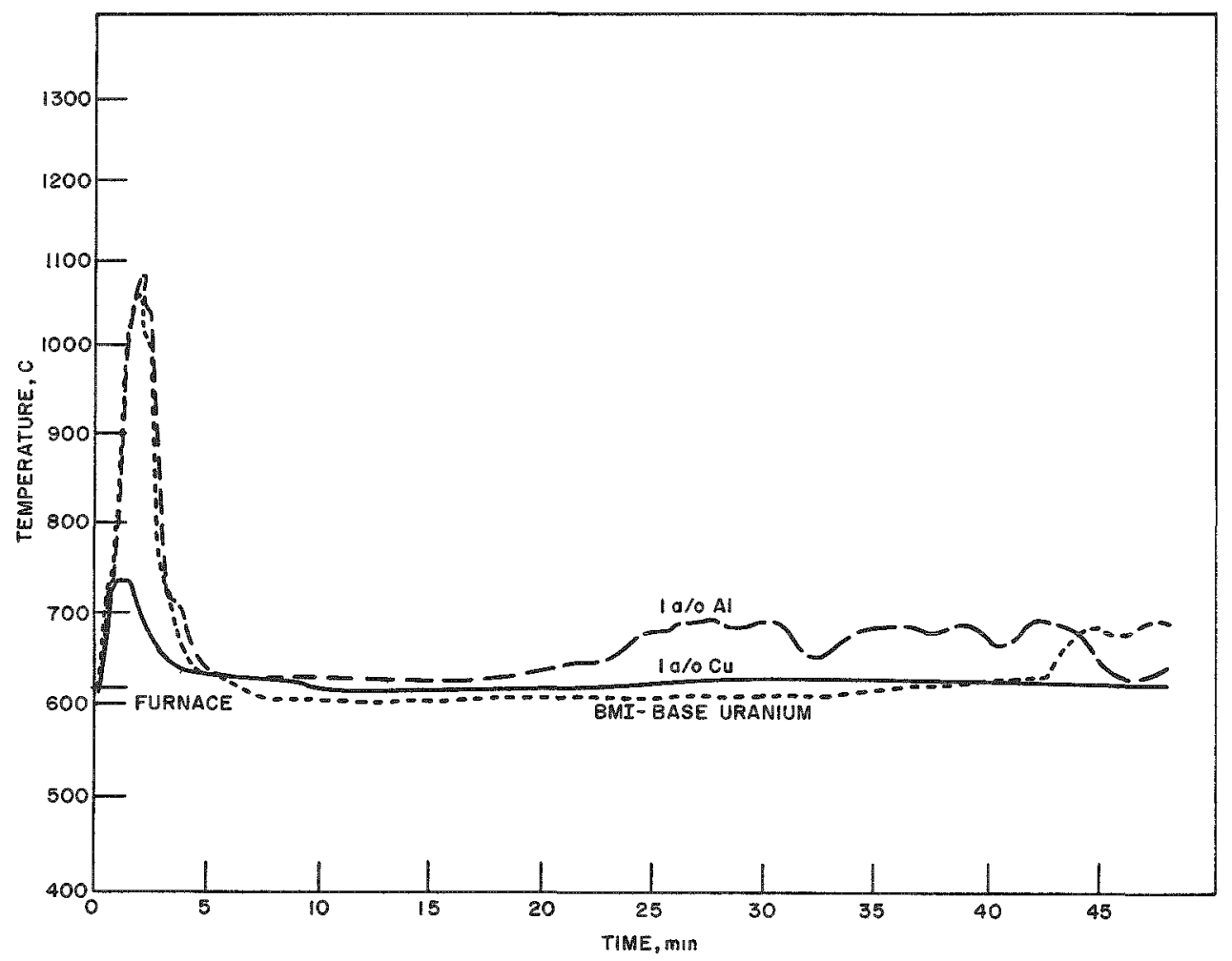

FIGURE 34

TEMPERATURE TRACE OF $500 \mathrm{C}$ OXIDATION IN AIR OF URANIUM AND ALLOY $(8.5-\mathrm{mm}$ CUBE IN $6000 \mathrm{cc} / \mathrm{min}$ AIR)

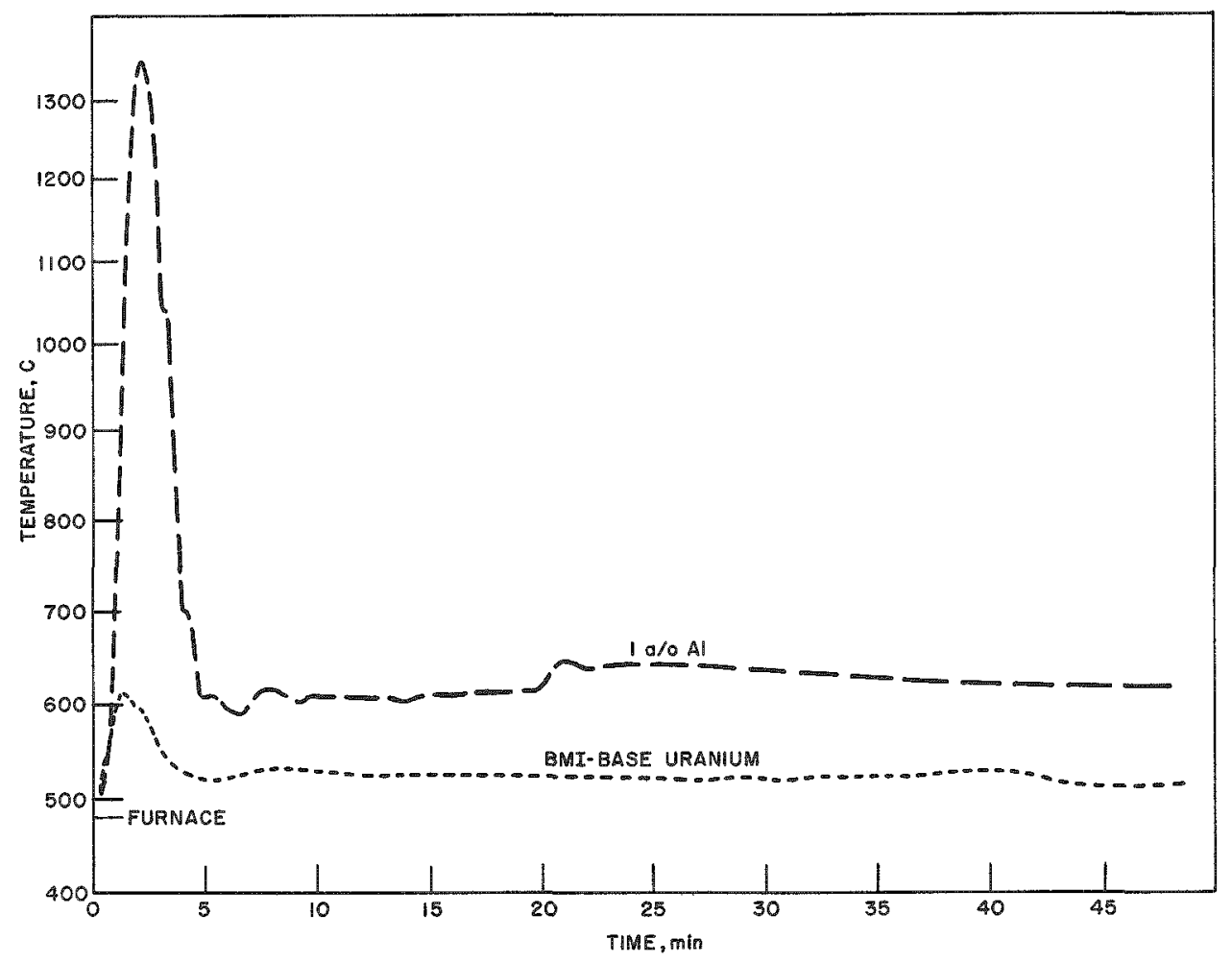


measured and the furnace maintained at constant temperature, have been carried out. Figures 33 and 34 show the temperature-time record when a sample was exposed to air after being heated in helium to 620 and $500 \mathrm{C}$, respectively. It is obvious from Figure 33 that the copper alloy behaved very differently from both the base metal and the aluminum alloy and, moreover, that the self-heating is in accord with the expectations from the ignition temperatures in oxygen. At $620 \mathrm{C}$ both the aluminum alloy and the base metal were above their ignition temperatures, whereas the copper alloy was below its ignition temperature. At $500 \mathrm{C}$ the base metal was below, whereas the aluminum alloy was still above, its ignition temperature. Figure 34, in which there is shown a marked distinction between the base metal and the aluminum alloy, is similarly in accord with this concept.

An attempt was made to obtain a more quantitative relationship by measuring the weight increase of samples of these metals during the course of an oxidation in a constant-temperature furnace. The sample, with a thermocouple inserted into a hole in the metal cube, was suspended in a tube furnace from the beam of a Sartorius balance. By disconnecting the thermocouple leads, periodic weight measurements could be made. With the metal initially at $700 \mathrm{C}$, results, which seemed similar to those found earlier, were obtained. The copper alloy and the base metal behaved almost identically, with a slightly higher rate of oxidation measured for the base metal. The aluminum alloy, by contrast, oxidized markedly faster. For example, after twenty-five minutes of oxidation the copper alloy had gained about $35 \mathrm{mg} / \mathrm{sq} \mathrm{cm}$ and the base metal $40 \mathrm{mg} / \mathrm{sq} \mathrm{cm}$, whereas the aluminum alloy had gained about $63 \mathrm{mg} / \mathrm{sq} \mathrm{cm}$. This is roughly in accord with the previous results relating reactivity and ignition temperature.

\section{e. Identification of Oxides after Burning Foil Strips in Air}

Because it had been observed (ANL-5959, page 75) that metal remained when uranium was burned in air, foil strips, 0.01, 0.13, and $0.99 \mathrm{~mm}$ thick, were burned in air in such a manner that weight gains would provide an indication of the extent of reaction. The oxide products were examined by $\mathrm{X}$-ray diffraction* to provide identification of relative quantities of $\mathrm{UO}_{2}$ and $\mathrm{U}_{3} \mathrm{O}_{8}-\mathrm{x}$. The results presented in Table 32 show that (1) thickness has a marked effect on the extent of reaction, and (2) the product oxide is a mixture of $\mathrm{UO}_{2}$ and $\mathrm{U}_{3} \mathrm{O}_{8}-\mathrm{x}$. The presence of $\mathrm{UO}_{2}$, even for the thinnest foil, is interesting in view of the high temperatures observed during the burning (ANL-6068, page 135).

*Performed and interpreted by B. Tani and D. S. Flikkema, Chemical Engineering Division, Argonne National Laboratory. 
Table 32

MEASUREMENTS OF THE EXTENT OF REACTION AND IDENTIFICATION OF OXIDE PRODUCED BY BURNING URANIUM FOIL STRIPS IN AIR

(foils approximately $3 \times 65 \mathrm{~mm}$ )

\begin{tabular}{|c|c|c|c|c|c|c|}
\hline \multirow{2}{*}{$\begin{array}{l}\text { Sample } \\
\text { Thickness } \\
\text { (mm) }\end{array}$} & \multirow{2}{*}{$\begin{array}{c}\text { Weight } \\
\text { (mg) }\end{array}$} & \multirow{2}{*}{$\begin{array}{l}\text { Weight } \\
\text { Gain } \\
\text { (mg) }\end{array}$} & \multicolumn{2}{|c|}{$\begin{array}{l}\text { Per Cent } \\
\text { Reaction } \\
\text { Based on } \\
\text { Calculated } \\
\text { Product }\end{array}$} & \multicolumn{2}{|c|}{$\begin{array}{l}\text { Relative Amounts } \\
\text { of Oxide by } \\
\text { X-ray Diffraction }\end{array}$} \\
\hline & & & $\mathrm{UO}_{2}$ & $\mathrm{U}_{3} \mathrm{O}_{8}$ & $\mathrm{UO}_{2}$ & $\mathrm{U}_{3} \mathrm{O}_{8-\mathrm{x}}$ \\
\hline 0.99 & 3468.6 & 107.3 & 23 & 17 & major $b$ & minor $\mathrm{b}$ \\
\hline 0.13 & 426.4 & 28.1 & 49 & 37 & medium $c$ & medium $^{c}$ \\
\hline 0.01 & $\mathrm{~d}$ & $\mathrm{~d}$ & $d$ & d & minor $\mathrm{c}$ & $\operatorname{major}^{c}$ \\
\hline
\end{tabular}

${ }^{a}$ Performed and interpreted by B. Tani and D. S. Flikkema.

b

Metallic core removed before $\mathrm{X}$-ray analysis.

No $\alpha$-uranium detected.

d

No weight data taken because of lack of precision with an analytical balance. Sample was converted to a powder, indicating essentially complete reaction.

2. Zirconium-ignition Studies

(L. Leibowitz, J. D. Bingle)

A variety of incidents involving combustion of zirconium powders, chips, and lathe turnings have prompted this extended study of the burning properties of zirconium. Measurements of the rate of burning propagation have proven to be valuable in comparing the effects of various factors on the combustion process.

The Effect of Some Gas Contaminants on the Burningpropagation Rates of Foils in Air

The effects of various gas contaminants, such as ozone, carbon dioxide, and water vapor, on the rates of burning propagation of zirconium in air are being investigated. The results of these experiments along with data from control runs are listed in Table 33. Also included in this table are some values previously reported in ANL-5996, page 225 for the 2.12 atom per cent titanium-zirconium alloy foil. It is clear from these data that these 
Table 33

\title{
EFFECT OF GAS CONTAMINANTS ON BURNING-PROPAGATION RATE OF ZIRCONIUM IN AIR
}

\author{
(foil samples: $0.13 \times 0.60 \times 70 \mathrm{~mm}$ )
}

\begin{tabular}{|c|c|c|}
\hline Gas Contaminant & $\begin{array}{l}\text { Length of } \\
\text { Burning Zone } \\
\text { (cm) }\end{array}$ & $\begin{array}{c}\text { Rate of } \\
\text { Burning Propagat } \\
(\mathrm{cm} / \mathrm{sec})\end{array}$ \\
\hline Pure Zirconium Foils & & \\
\hline None & $1.3 \pm 0.1^{\mathrm{a}}$ & $0.463 \pm 0.027^{a}$ \\
\hline $1 \% \mathrm{O}_{3}$ & 1.7 & 0.569 \\
\hline $5 \% \mathrm{CO}_{2}$ & 1.1 & 0.432 \\
\hline $\mathrm{H}_{2} \mathrm{O}$ saturated $(25 \mathrm{C})$ & 1.4 & 0.542 \\
\hline
\end{tabular}

2.12 a/o Titanium-Zirconium Alloy Foils

$\begin{array}{cll}\text { None } & 2.6 \pm 0.0^{\mathrm{b}} & 0.835 \pm 0.014^{\mathrm{b}} \\ \mathrm{H}_{2} \mathrm{O} \text { saturated }(25 \mathrm{C}) & 2.6 \pm 0.0^{\mathrm{b}} & 0.805 \pm 0.005^{\mathrm{b}}\end{array}$

\footnotetext{
average deviation from the mean of seven runs.

$\mathrm{b}$

Average deviation from the mean of two runs.
}

contaminants have only a slight effect on the burning propagation rates. The effects of several halogenated hydrocarbons as gas contaminants on the burning propagation rates of both uranium and zirconium are currently being investigated; they appear to have a great effect.

3. Plutonium-ignition Studies

(D. F. Fischer, J. G. Schnizlein)

The objectives of the current exploratory ignition experiments are: (1) to gain experience in handing metallic plutonium and in glove-box manipulations; (2) to develop suitable apparatus and techniques for carrying out the measurements within the limitations imposed by glove-box operation; (3) to determine whether useful ignition data for plutonium and its alloys can be obtained by burning-curve or shielded ignition experiments; and (4) to obtain information for establishing specifications for the pure metal and alloy specimens.

Preliminary studies indicate that burning-curve experiments provide reproducible ignition data consistent with that from shielded ignition experiments. Studies with plutonium metal with varied impurity levels are under way to aid in establishing specifications for the metal to be used in preparing alloys. 
4. Isothermal Studies of Uranium

(L. Leibowitz, L. W. Mishler)

a. Low-temperature Oxidations of Uranium Alloys

In reviewing the studies of uranium oxidation (ANL-5974, page 39), it was deduced that the lack of a marked influence of additives on the oxidation rate of uranium indicated that the rate-controlling step occurs at the gas-oxide interface. It has been suggested by Cubicciottill that a change in mechanism of the uranium oxidation occurs in the neighborhood of $165 \mathrm{C}$; inasmuch as the effect of additives had been mainly studied at $200 \mathrm{C}$, some information was obtained on the oxidation rates of a few uranium alloys at $125 \mathrm{C}$. The alloys that showed the greatest rate change over that for the base metal at $200 \mathrm{C}$ were chosen for oxidation at $125 \mathrm{C}$ and $200 \mathrm{~mm}$ oxygen pressure in the usual way. These alloys contained the following additives: 0.5 and 2 atom per cent aluminum, and 2 atom per cent molybdenum and niobium. No significant differences were observed between the oxidation of these alloys and that of the base metal. It is interesting that these samples, as well as the Battelle-base metal, initially showed approximately parabolic oxidations.

\section{b. Time-lapse Photomicrography}

It has been proposed that there may be a connection between the abrupt increase in oxidation rate invariably observed with uranium and the onset of heavy nucleation on the oxide surface. In order to explore this notion more thoroughly, it seemed necessary to obtain a number of photomicrographs during the course of an oxidation. Studies of this kind have already been carried out (see ANL-5959, page 95) using induction heating, which, however, was later shown to change the oxidation kinetics (ANL-5996, page 214). Induction heating had the effect of so shortening the first stage that the nucleation and growth process began extremely early in the oxidation. Therefore, a resistance-heated hot stage (see ANL-6068, page 140) connected to the conventional volumetric isothermal oxidation apparatus was used in the current study.

With a sample of ANL-base uranium at $200 \mathrm{C}$ in $200 \mathrm{~mm}$ of oxygen, photographs were taken at frequent intervals while the metal was oxidizing. In Figure 35 is shown the measured oxygen consumption as a function of time. In Figure 36 are shown photographs of the surface of the sample at the following times during the course of the oxidation:
a) 20 minutes
d) 140 minutes
b) 70 minutes
e) 180 minutes
c) 90 minutes
f) 260 minutes.

11 Cubicciotti,

D. J.,Am. Chem. Soc., 74, 1079 (1952). 
FIGURE 35

OXIOATION OF ANL-BASE METAL URANIUM AT $200 \mathrm{C}$ IN $200 \mathrm{~mm}$ OXYGEN (ARROWS INDICATE EXTENTS OF OXIDATION FOR EACH PHOTOGRAPH SHOWN IN FIGURE 36)

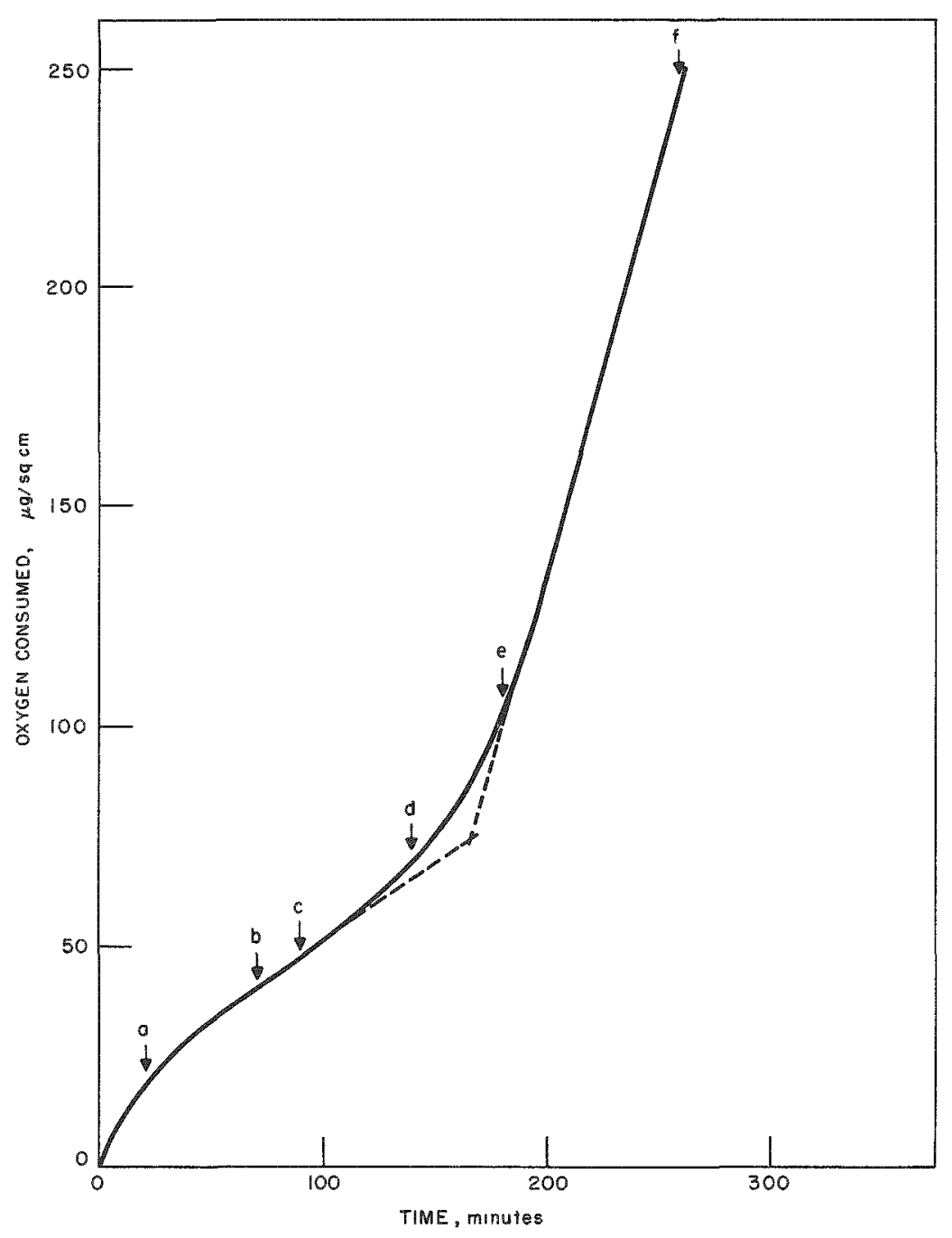

In contrast to the observation when using induction heating (ANL-5959, page 95), it now seems clear that the surface appearance changes abruptly at a time between 70 and 90 minutes, corresponding to the time at which the oxidation rate begins to increase. This rate change is much earlier than what has been defined as the break time, which occurs between 140 and 180 minutes. Observations made at $150 \mathrm{C}$ using timelapse photomicrography also show the correspondence between oxide nodule growth and the beginning of the increase of the oxidation rate.

\section{B. Metal-Water Reactions}

(L. Baker, R. C. Liimatainen, M. Kilpatrick*)

The experimental program to determine rates of reaction of molten reactor fuel and cladding metals with water is continuing. The principal laboratory-scale method involves the rapid melting and dispersion of metal

* Consultant from Illinois Institute of Technology. 
FIGURE 36

MICROGRAPHS OF SURFACE OXIDATION OF URANIUM AT $200 \mathrm{C} \mathrm{IN} 200 \mathrm{~mm}$ OXYGEN FOR DESIGNATED TIMES
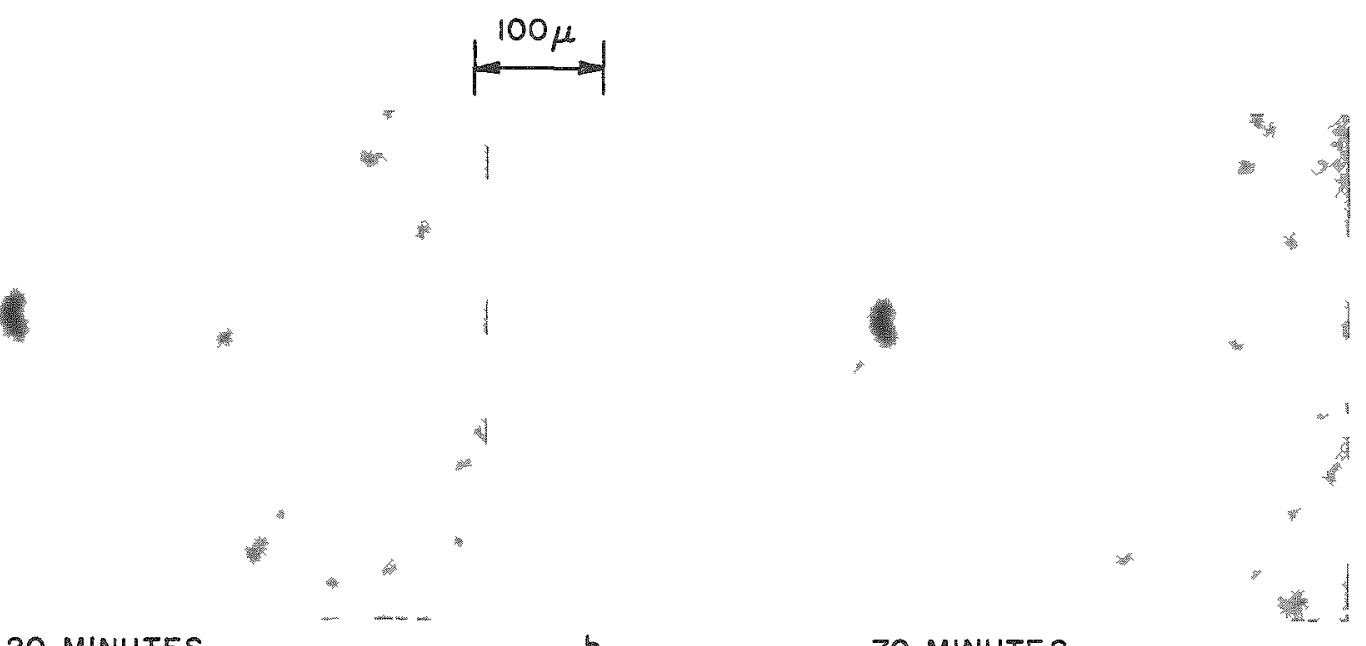

a

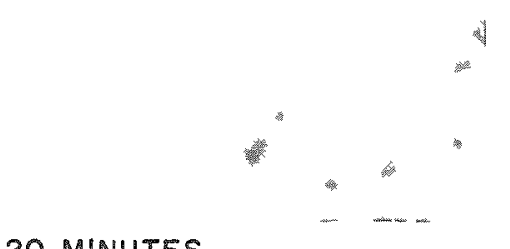

20 MINUTES

b

70 MINUTES

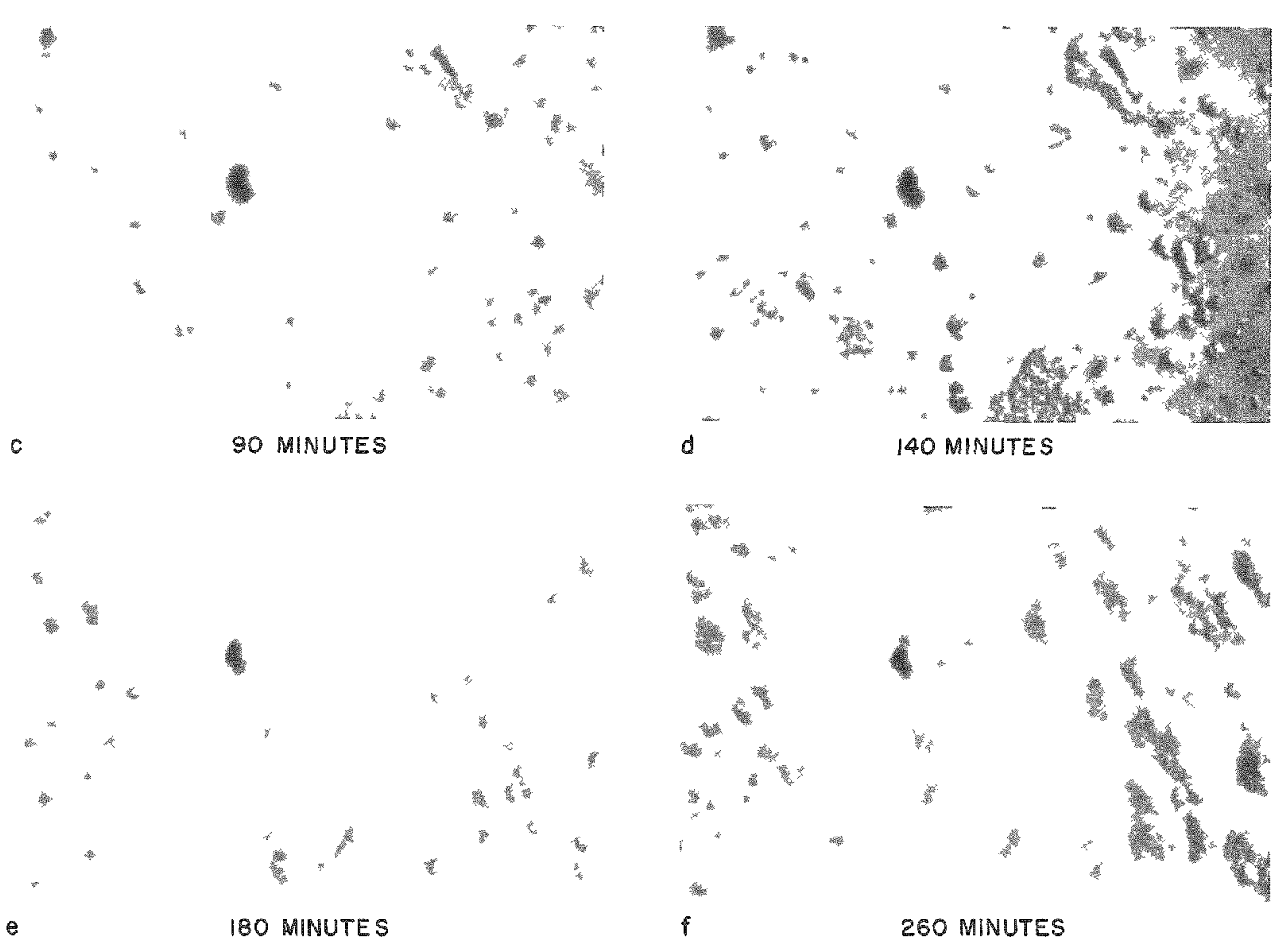


wires in a water or steam environment by a surge current from a bank of condensers. An analysis of the data from runs with zirconium was reported in previous quarterly reports. Further runs with 30-mil zirconium wires showed that the apparently critical "ignition temperature" of $2600 \mathrm{C}$ is independent of initial wire diameter. The ignition is possibly due to melting of the oxide and the resulting loss of protectiveness.

A series of runs with aluminum showed that very irregular heating occurred. The bulk of the specimen wire was heated only slightly by the discharge, although at several points along the wire vaporization occurred. The energy of the discharge was thus dissipated as arcs.

A second laboratory-scale method involves the rapid contact of steam with molten metal. In this method the molten metal receives a "pressure pulse" of water vapor. A series of preliminary runs with molten zirconium and water vapor at $20 \mathrm{~mm}$ was completed. A two-color photoelectric pyrometer was developed in order to improve the accuracy of temperature measurements.

A series of eight experiments has been conducted in the TREAT reactor. In each experiment, a stainless steel autoclave containing a fuel pin, gold foils, helium, and water was subjected to a short burst of neutrons. In these experiments, 20 per cent enriched uranium pins were heated to a maximum of $1560 \mathrm{C}$ and completely melted. A maximum of 3.2 per cent of the uranium reacted with water in the most energetic run to date. The uranium was not effectively dispersed throughout the water.

\section{Laboratory Studies: Condenser Discharge Method (L. Baker, R. Warchal)}

The condenser-discharge experiment is an attempt to obtain fundamental rate data under experimental conditions similar to those during a serious accident in a nuclear reactor. Either a nuclear runaway or a sudden loss of coolant during operation of a water-cooled reactor could result in contact between very hot fuel and cladding metals with water or steam and might involve fine particles. The condenser-discharge experiment simulates the limiting case of a nuclear incident in that the heating time is very short and very fine metal particles are produced.

In the condenser-discharge experiment, metal wires are rapidly melted and dispersed in a water-filled cell by a surge current from a bank of condensers. The energy input to the wire indicates reaction temperature; the transient pressure measures reaction rate, the amount of hydrogen generated gives the extent of reaction, and the particle size of the residue indicates the surface area exposed to reaction. 
Analysis of the results of runs is based on one of the usual laws of metal oxidation and a simple model of heat transfer. In this way, it has been possible to obtain rate constants which in turn may be applied toward a detailed analysis of particular reactor conditions.

\section{a. Runs with Zirconium}

Additional runs were made with 30-mil zirconium specimens in the region of an initial temperature of $2600 \mathrm{C}$. This temperature was found to be critical with 60-mil specimens. Runs with higher initial

FIGURE 37

SUMMARY OF EXPERMGERTAL RESULTS FOR ZIRCONUUM-WATER REACTICN BY COADENSER DISCHARGE METHOO

O 60-MIL WIRES

- 60-ML WIRES - EXPLOSIVE PRESSURE RISE

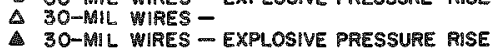

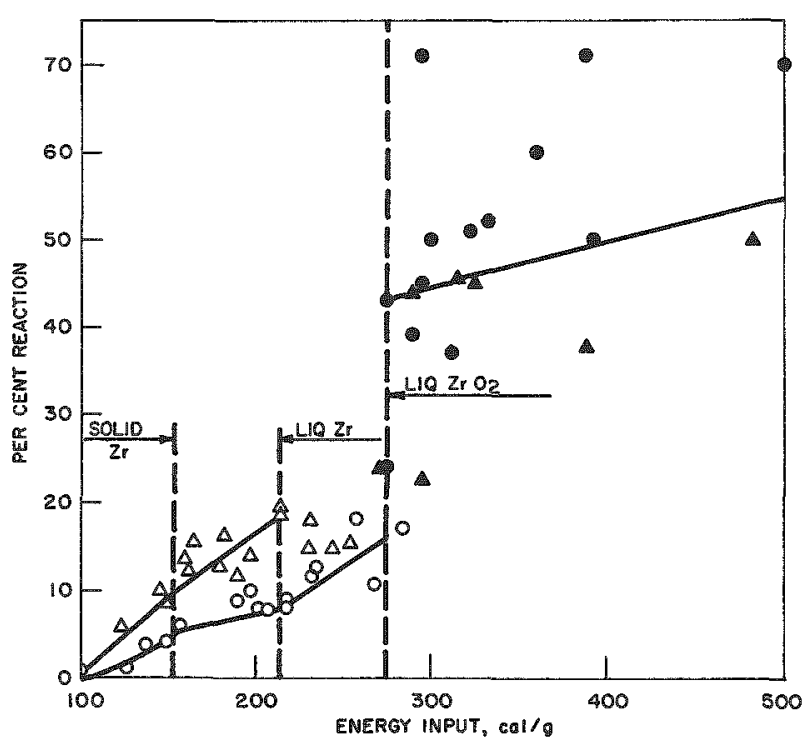

SOLI0 $\rightarrow$ SOL + LI0 $F-L 10+$ VAPOR INITIAL TEMPERATURE, $C$ temperatures had explosive pressure rises and produced up to 70 per cent of the theoretical quantity of hydrogen. The data for all of the runs with zirconium are shown in Figure 37. The results show that the apparent critical temperature of $2600 \mathrm{C}$ is independent of the original wire size. This temperature corresponds approximately to the melting point of the oxide. Catastrophic oxidations corresponding to melting of the oxide have been observed with several other metals, notably with alloys containing molybdenum and vanadium. 12 Measurements of particle size and the detailed analysis of the more recent runs are under way.

\section{b. Runs with Aluminum}

A series of runs was made with $30-$ mil aluminum wires. Energies imparted to the wires ranged from 150 to $850 \mathrm{cal} / \mathrm{g}$, sufficient to raise the wire temperature to $600 \mathrm{C}$ in the former case and to the boiling point of $2060 \mathrm{C}$ and vaporize about 10 per cent of the metal in the latter case. The extent of reaction as determined from the quantity of hydrogen liberated ranged from 0.0 to 2.0 per cent. Two per cent reaction appeared to be an unreasonably low value for metal which was partially vaporized. Residue from a very

12 Kubaschewski, O. and Hopkins, B. E., Oxidation of Metals and Alloys, Butterworths Scientific Publications, London, 1953, p. 213 ff. 
energetic run was found to contain pieces of original wire, which indicated that nonuniform heating had occurred. Finally, high-speed motion pictures showed clearly that parts of the specimen were melted and vaporized preferentially, forming arcs while the bulk of the metal remained relatively cool. A high-speed motion picture sequence is shown in Figure 38 along with typical sequences obtained with 30-mil zirconium specimens. Film speed and exposure were identical for the sequences shown. The extremely shortduration of light emission from the aluminum runs corresponded to the duration of the heating current $\left(400 \mu \mathrm{sec}\right.$ or ca. $1 \frac{1}{2}$ frames). The absence of luminous metal in succeeding frames indicates that light was due solely to arcing. Luminous emission persisted for zirconium runs up to 1.1 seconds. The uniformity of heating for zirconium specimens is apparent in the figure. Much of the disturbance apparent in later frames is due to bubbles of steam and hydrogen.

FIGURE 38

FILM SEQUENCES OF CONDENSER DISCHARGE RUNS WITH 30-MIL SPECIMENS (4000 FRAMES / SEC)

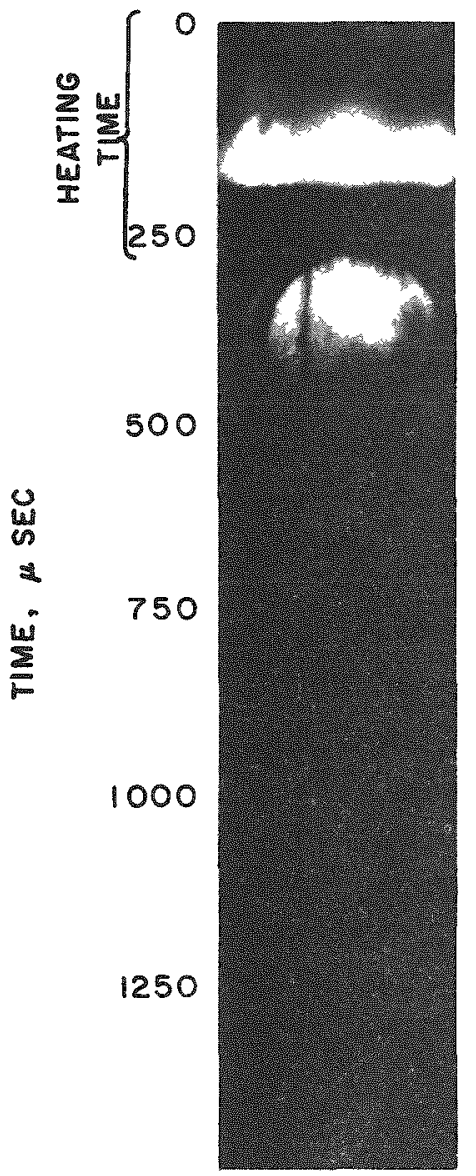

A

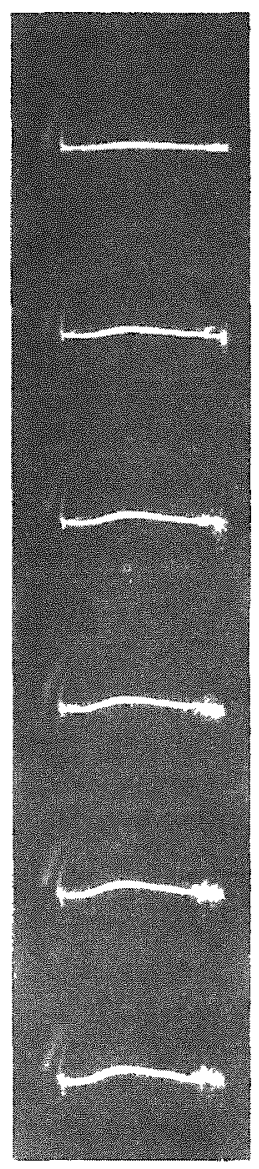

B

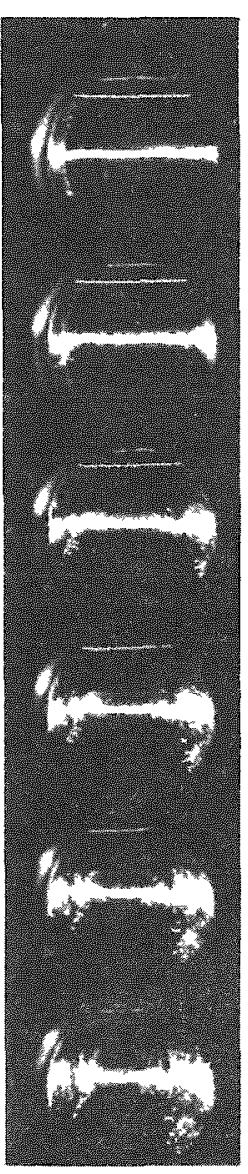

C

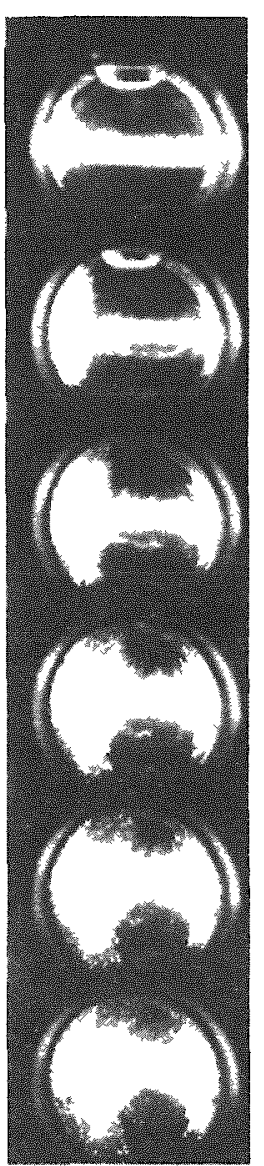

D

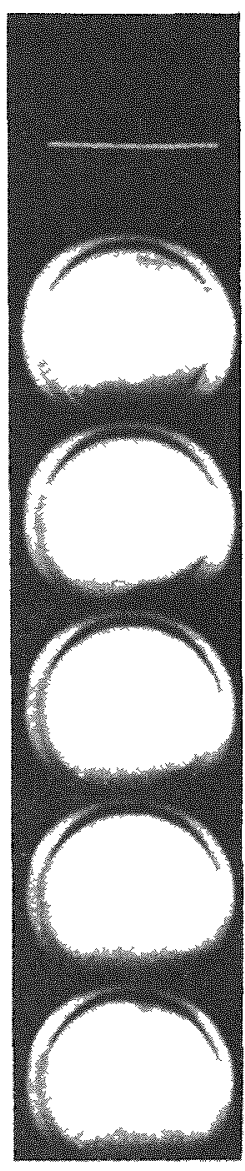

E
A ALUMINUM - $850 \mathrm{cal} / \mathrm{g}$
B ZIRCONIUM - $1840 \mathrm{C}-10 \%$ MELTED
C. ZIRCONIUM- $1840 \mathrm{C}-100 \%$ MELTED
D. ZIRCONIUM- $2350 \mathrm{C}$ - LIQUID
E. ZIRCONIUM- $3100 \mathrm{C}-$ LIQUID (EXPLOSIVE PRESSURE RISE) 
Attempts to determine the cause of the nonuniform heating are under way. It appears that some property of aluminum causes a tendency to magnify irregularities in heating. Design of a reaction cell to facilitate runs at high pressure is under way. Runs with 30-mil uranium wires will be made.

\section{Laboratory Studies: Pressure-pulse Method (D. Mason, P. Martin)}

The pressure-pulse method is an attempt to study the reaction of molten metals with water vapor under nearly isothermal conditions at very high temperatures. The method involves the momentary contact of water vapor with molten metal contained in a crucible, followed by an analysis of the hydrogen generated by reaction. Momentary contact is accomplished by a system of electronically controlled solenoid valves. The apparatus and run procedure were described in the previous quarterly report (ANL-6068, pages 153 and 154).

Isothermal rate data obtained by this method should provide a check on the results of both the condenser-discharge method and the in-pile studies. The method should give the best determination of the form of the rate law to be used to interpret results of the other methods.

A series of preliminary runs with zirconium and water vapor at $20 \mathrm{~mm} \mathrm{Hg}$ has been completed. A two-color photoelectric pyrometer has been developed to measure the temperature of liquid zirconium.

\section{a. Temperature Measurement}

Preliminary runs with molten zirconium ( $\mathrm{mp}, 1840 \mathrm{C}$ ) showed that accurate temperature measurements with an optical pyrometer were not possible because of the uncertainty of the emissivity. Accurate measurements could be made up to the melting point by introducing a black body cavity into the solid sample. Melting not only destroyed the cavity, but also changed the shape of the specimen in the induction field, brought the metal into more intimate contact with the thoria crucible, and caused the release of traces of dissolved gas. It was therefore not possible to assume that the metal remained at the melting point following collapse of the cavity.

A two-color photoelectric pyrometer was constructed and calibrated. A disc containing two interference filters (600 $\mathrm{m} \mu$ and $800 \mathrm{~m} \mu$ ) was mounted on a shaft rotating up to $3600 \mathrm{rpm}$. The disc was arranged to interrupt light radiating from the melt and impinging on a vacuum phototube. It was then possible to determine the relative ratio of light intensity emitted at the two wavelengths by measurements made on an oscillogram of the signal from the phototube. 
The two-color pyrometer was calibrated against an optical pyrometer by use of a cavity drilled into an inductively heated graphite rod. The slope of the plot of $\log \left(E_{800} / E_{600}\right)$ vs $1 / T(K)$ was found to be a straight line, although the slope deviated somewhat from the Planck's Law value. The calibration curve is shown in Figure 39. An error of 5 per cent in the measured ratio would result in an error of $30 \mathrm{C}$ at $1400 \mathrm{C}$ and an error of $65 \mathrm{C}$ at $2200 \mathrm{C}$. The melting point of platinum $(1773 \mathrm{C}$ ) was checked to within $20 \mathrm{C}$. The melting point of zirconium (1840 C) was also checked to within $20 \mathrm{C}$. Temperatures measured on a tungsten ribbon filament lamp were about $60 \mathrm{C}$ higher than those measured with an optical pyrometer using handbook values of emissivity.

FIGURE 39

CALIBRATION OF TWO-COLOR PHOTOELECTRIC PYROMETER

ILINE OETAINED BY ALEAST SOUAAES METHOD ASSUMING

LOG RATIO VS WT (K) TO BE A STRAIGHT LINE)

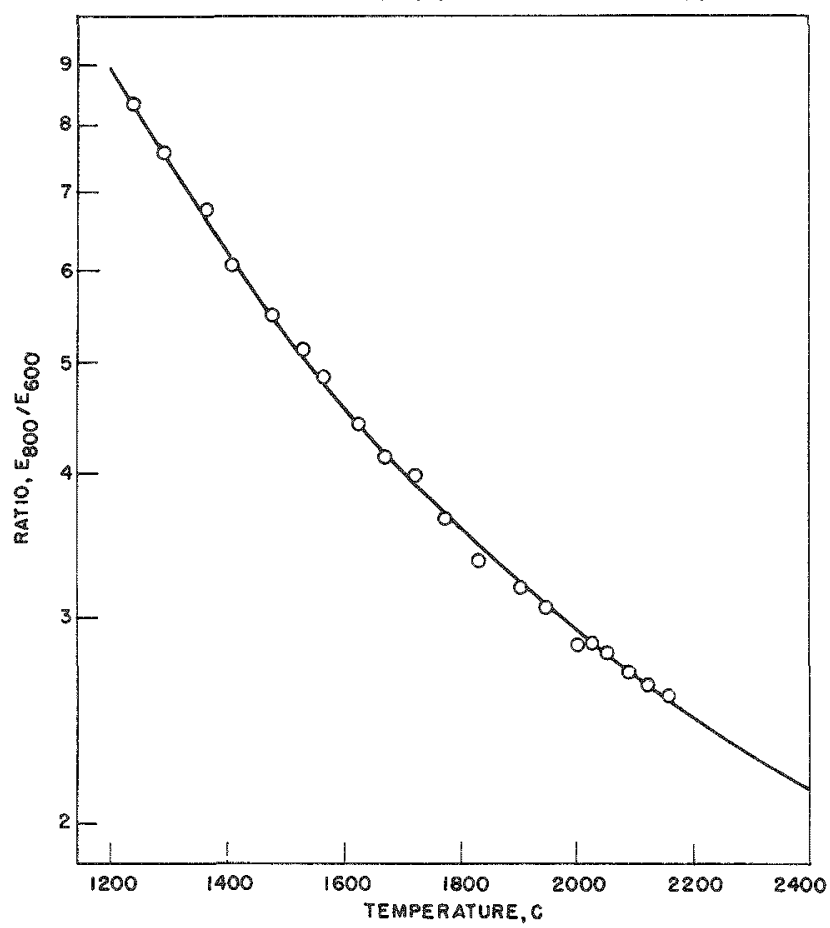

b. Runs with Zirconium

Table 34 shows the results of preliminary runs with

zirconium. Only temperatures obtained with the two-color pyrometer are reported. Temperatures for the other runs could not have differed greatly from the melting point of $1840 \mathrm{C}$. The exposed surfaces of the metal in the crucible were not uniform and flat for many of the runs. The surface areas reported in the table were obtained by geometrical measurements of the frozen sample, where only minor surface irregularities appeared. Data from runs resulting in extremely irregular surfaces were discarded. The correction factor applied to the minimum cross-sectional area of the crucible did not exceed 1.5. The thoria crucibles were generally found to be 
Table 34

PRELIMINARY RESULTS FOR ZIRCONIUM-WATER REACTION AT $20 \mathrm{~mm}$ Hg BY THE PRESSURE-PULSE METHOD

\begin{tabular}{|c|c|c|c|c|c|}
\hline Run & $\begin{array}{l}\text { Contact } \\
\text { Time } \\
(\mathrm{sec})\end{array}$ & $\begin{array}{c}\text { Temp } \\
\text { (C) }\end{array}$ & $\begin{array}{l}\text { Surface } \\
\text { Area } \\
(\mathrm{sq} \mathrm{cm})\end{array}$ & $\begin{array}{c}\text { Volume } \\
\mathrm{H}_{2} \text { Evolved } \\
\text { (cc STP) }\end{array}$ & $\begin{array}{c}\text { Volume } \mathrm{H}_{2} \\
\text { per Unit Area } \\
(\mathrm{ccSTP} / \mathrm{sq} \mathrm{cm})\end{array}$ \\
\hline Blank & 0.11 & 1850 & - & 0.02 & - \\
\hline Blank ${ }^{a}$ & 0.11 & 1990 & - & 0.03 & - \\
\hline 7 & 0.11 & $-b$ & 1.0 & 0.35 & 0.4 \\
\hline 15 & 0.11 & 1870 & 1.3 & 0.53 & 0.4 \\
\hline 5 & 0.11 & - & 0.9 & 0.53 & 0.6 \\
\hline 9 & 0.11 & - & 0.9 & 0.54 & 0.6 \\
\hline 18 & 0.11 & 1950 & 1.2 & 0.71 & 0.6 \\
\hline 17 & 0.11 & 2050 & 1.0 & 0.77 & 0.7 \\
\hline 10 & 0.50 & - & 0.9 & 1.18 & 1.3 \\
\hline 13 & 1.02 & - & 1.0 & 1.97 & 2.1 \\
\hline 14 & 1.02 & - & 0.9 & 2.25 & 2.4 \\
\hline
\end{tabular}

${ }^{a}$ Runs were made with platinum contained in thoria crucibles instead of zirconium.

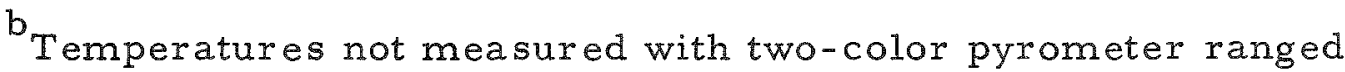
from 1800 to $1950 \mathrm{C}$.

cracked after a run. Additional metal exposed to the vapor through cracks was negligible. Very gradual heating minimized the cracking and only a few runs had to be terminated because of a complete collapse of the crucible.

No correction has been applied to the measured volumes of hydrogen reported in Table 34. The outlet valve in the apparatus was open long enough for about 83 per cent of the gas in the cell to be expanded into the collection bulb. At least one-third of the cell volume is located up-stream of the outlet valve, however, so that the concentration of hydrogen in the residual gas is almost certainly lower than that in the sample. An experiment to evaluate the error is being designed.

Runs with a longer contact time are required before an accurate determination of the order of reaction can be made. The operating pressure of $20 \mathrm{~mm} \mathrm{Hg}$, however, precludes longer runs, at least with liquid zirconium, because of the possibility that the reaction rate will become limited by the quantity of water available for reaction. A 10-sec run would require approximately half of all of the vapor in the cell. Most future work with zirconium will therefore be carried out at higher pressure in a heated apparatus. Plans are under way for runs with aluminum. 
3. In-pile Testing in TREAT Reactor

(R. C. Limatainen, R. O. Ivins, W. A. Rodger, M. Deerwester, F. Testa)

The purpose of this program is to obtain data on metal-water reactions initiated by nuclear reactor transients. This is accomplished by exposing a small reactor fuel pin to conditions simulating either a power excursion or loss of coolant incident.

A series of eight experiments has been conducted in the TREAT reactor.* For the test transients a stainless steel autoclave containing a fuel pin, ** gold foils, helium and water was subjected to a short burst of neutrons; the flux varied in roughly a Gaussian manner with time. The autoclave was located in the center of the reactor; this capsule was in turn contained in a. TREAT fuel can which was also made of stainless steel. Graphite reflector blocks were used on either end of the autoclave to fill in the space inside the dummy element and to fix the position of the autoclave. Figure 40 is a photograph of an assembled autoclave. Signals from the strain gage pressure transducer and from the thermocouples were first amplified ( 20 gain or 40 gain) in the reactor building and then again amplified in the control building to drive the galvanometers of an oscillograph.

FIGURE 40

AUTOCLAVE FOR METAL-WATER REACTION TESTS

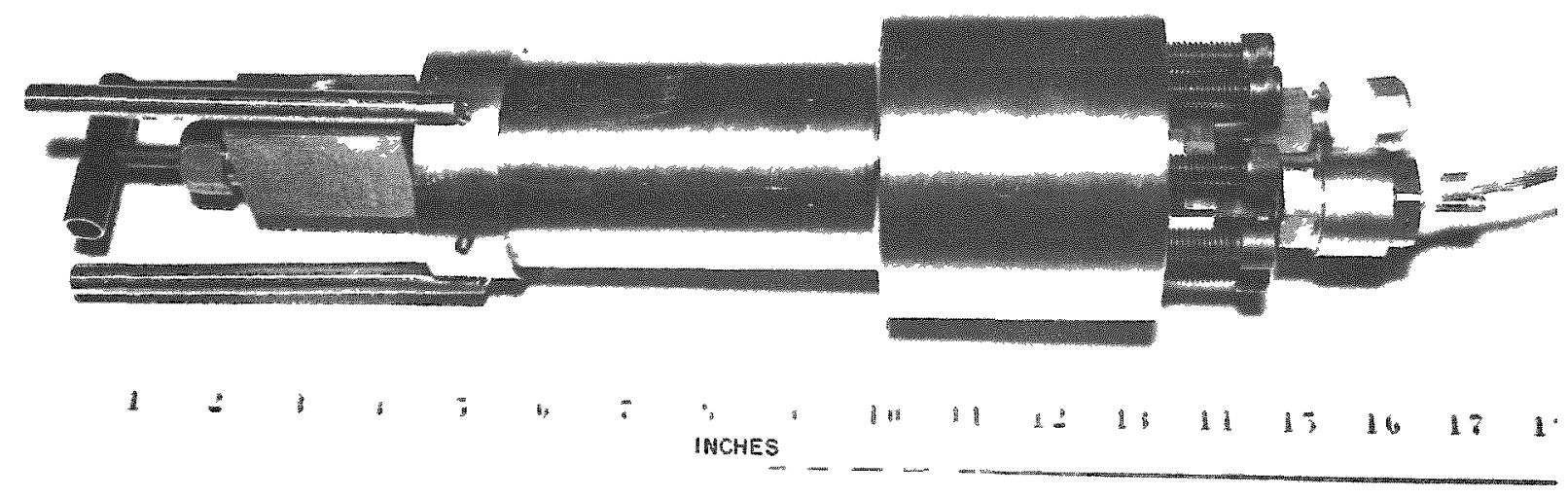

*The operation of TREAT is under the direction of J. Boland of the Idaho Division; the transient tests were made in cooperation with TREAT personnel.

**Specimens were fabricated by the Metallurgy Division. 
(The control building is located about one-half mile from the reactor.) Shielded cable was used for connection between the signal sources and the amplifiers. Before each test calibration signals in 5 or 10 -millivolt steps were recorded on the oscillograph. Each transient test was monitored by gold foils; also the fission-energy input was obtained by an analysis of the pin for $\mathrm{Ba}^{140}$. The extent of the reaction was determined by an analysis of a gas sample from each experiment for hydrogen.

The pins in these experiments were twenty per cent enriched, cylindrical in shape ( 0.5 inch long by 0.2 inch in diameter), and composed of either pure uranium or an alloy containing 93.5 per cent uranium, 5 per cent zirconium, and 1.5 per cent niobium, the alloy being available since this material was used for the EBWR core. For the metal-water transients, the pins were immersed in up to $35 \mathrm{cc}$ of distilled water and the autoclave charged with 20 psia of helium.

A typical oscillograph record from an experiment is shown in Figure 4l. The reactor characteristics and experimental results from

FIGURE 41 OSCILLOGRAPH RECORD OF TRANSIENT CEN-3

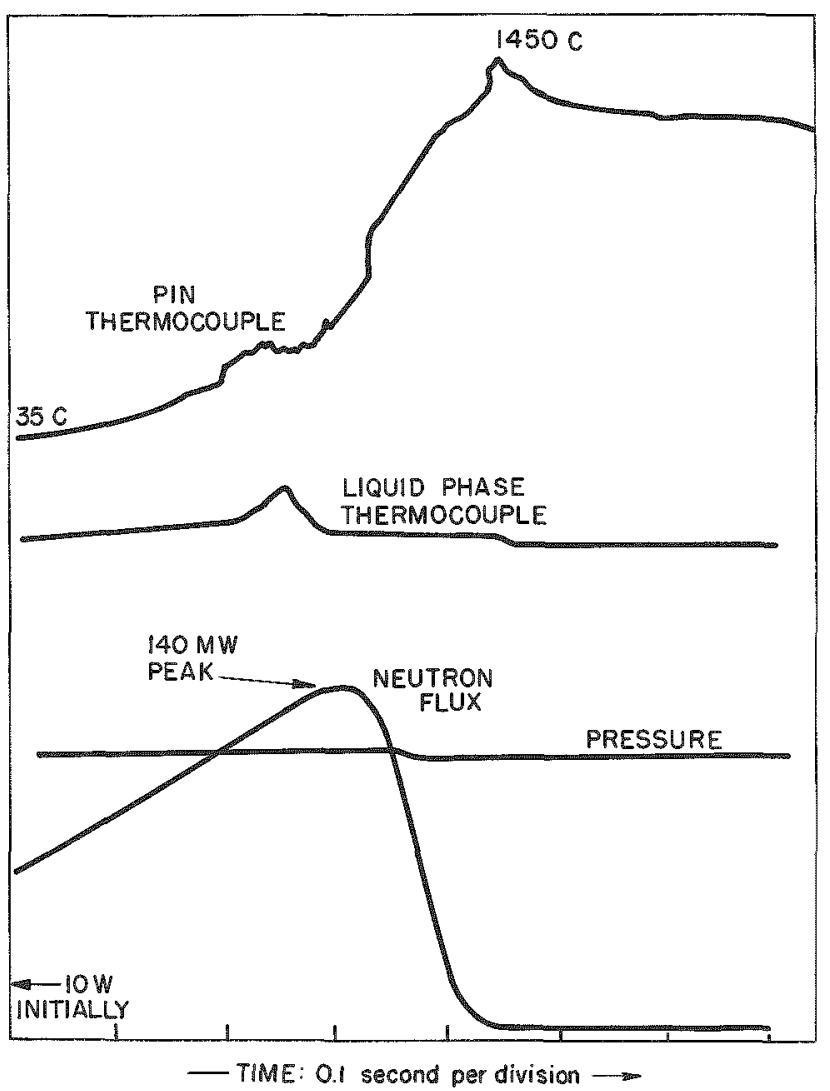
five metal-water transients are summarized in Table 35 . In interpreting the data on the extent of reaction of the metal, it is appropriate to bear in mind that, in the runs carried out to date, no efficient mechanism for dispersion of the uranium has been used. Therefore, the per cent reactions observed may be less than in an actual reactor incident where some mechanism might be operative to produce small particles having a high surface to volume ratio. Experiments are under way to achieve dispersion of the uranium.

Transients CEN-1, 4, and 7 , which do not appear in the table, were essentially base-line runs. The purpose of CEN-I was to establish the temperature rise of a pin in a helium atmosphere with no water present. In Run CEN-7 no pin was included; the purpose of this test was to determine whether the decomposition of water by radiation was a problem. The results showed an amount of hydrogen present that would correspond to less than 0.05 per cent reaction for a pin weighing 4.5 grams. This amount 
Table 35

SUMMARY OF DATA ON METAL-WATER TRANSIENTS IN TREAT

CEN Transient Number

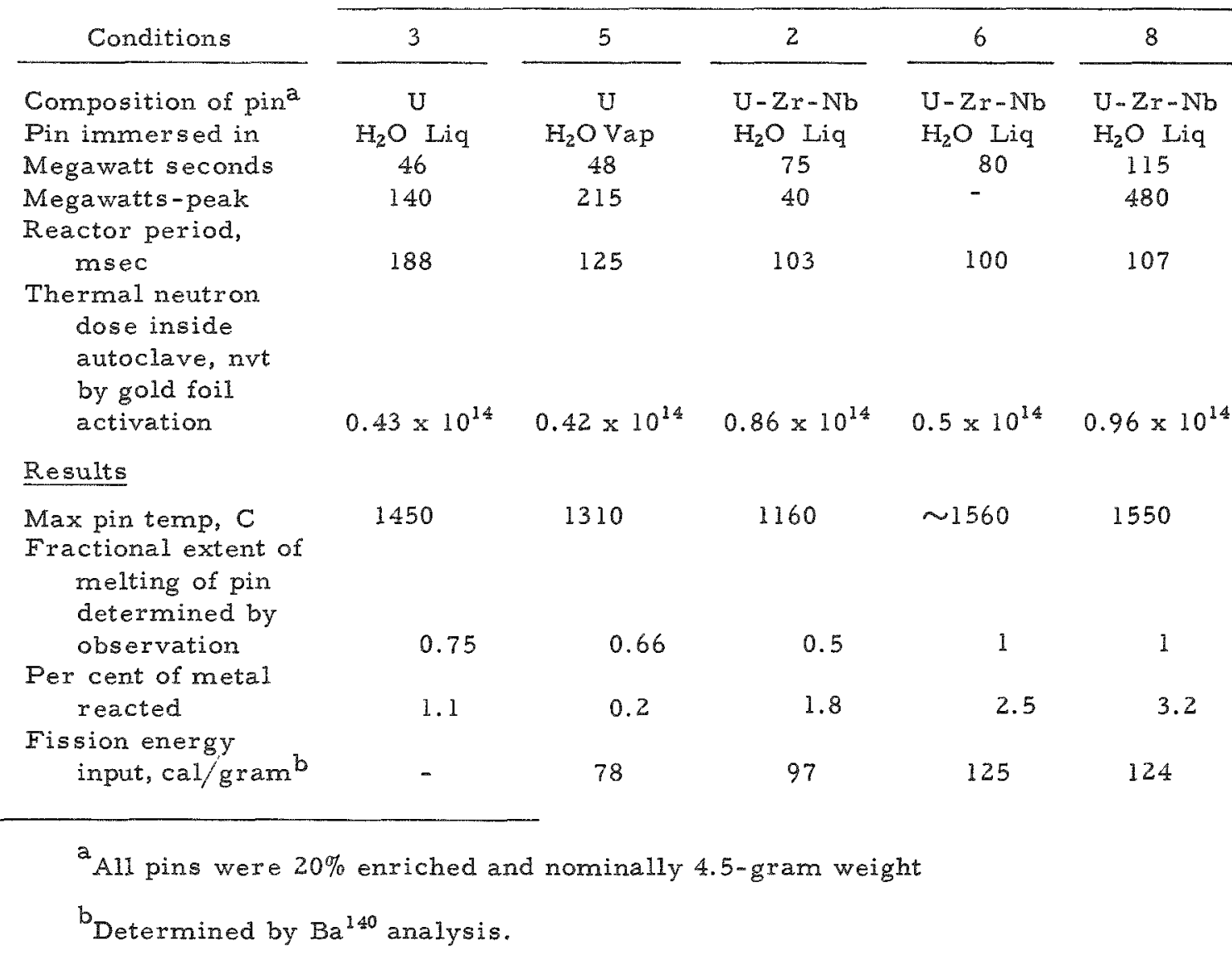

is negligible. CEN-4 was made to determine the influence of the reactor radiation on the unbonded strain gage pressure transducer. An interesting effect, wherein the output of the transducer followed the reactor power level, was observed. This is shown in Figure 42. A 7.2 per cent change of full-scale output was recorded. In a transducer with a 1000-psi range, this corresponds to an apparent pressure of 72 psi. To date no transducer with its associated cable has been found to be completely insensitive to the transient neutron-gamma radiation. Thus, pressure traces from actual metal-water runs cannot be interpreted as caused purely by hydrogen or steam production.

In CEN-2 and -3 the pins were partially melted. In Run CEN-5 only enough water was added to saturate the helium atmosphere and provided a comparison of the vapor metal reaction vs. the liquid metal reaction. Only 0.2 per cent of the metal was reacted. Figures 43 and 44 are photographs of the pins used in experiments 5, 6, and 8 and show the results of the increase in power for each successive test. The highest integrated power was obtained in CEN-8. In this test 3.2 per cent of the metal was reacted. 
FIGURE 42

TRANSIENT OSCILLOGRAPH RECORD

RUN CEN-4

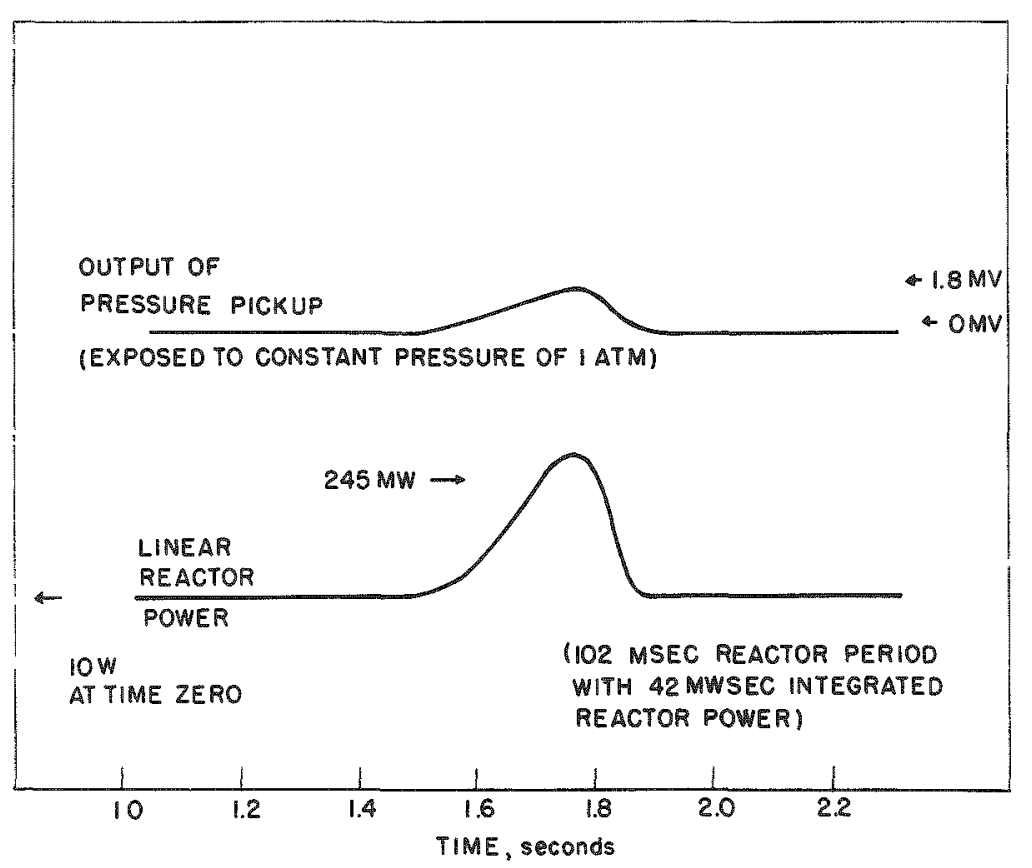

In all the in-pile runs performed to date, there has been a fairly smooth variation of pressure with time; thus far there is no evidence for explosive pressure peaks. Since the frequency response of the pressuremeasuring system (strain gage, amplifier, and oscillograph) is 5,000 cycles/ sec, pressure pulses having rise times of the order of 0.2 millisecond could be picked up if they existed. The maximum pressure indicated in experiments thus far is 500 psi.

It is of interest to compare the value obtained

for the extent of reaction of a pin heated by a nuclear transient to results obtained by condenser-discharge heating of uranium wires. Condenserdischarge data showed 1.6 per cent reaction for uranium wire which just reached the melting point and 2.2 per cent reaction for a 50 per cent melted specimen (ANL-6029, page 125). The value of 1.8 per cent observed in CEN-2 is thus in good agreement with the laboratory data. It is also interesting to note, from the temperature and flux records, the evidence of chemical heating following the reactor transient. This is apparent on the oscillograph traces.

The next phase of the TREAT metal-water experimental program will be to obtain data on pins canned in Zircaloy. The can will have a hole drilled in one end to simulate a ruptured fuel pin. It is hoped that this technique will allow the molten uranium $(1130 \mathrm{C})$ to spray out of the confining solid can, which melts at about $1830 \mathrm{C}$.

When two more series of runs in TREAT are completed, sufficient data should be available to begin an analysis and correlation of the data by means of an analog computer. The actual time dependence of the neutron flux can be inserted into the computer and the integrated energy input adjusted to match with normalized values from the gold foil and barium-140 fission product analyses. The kinetic rate and heat transfer coefficients would be varied until the calculated temperatures and extent of reaction match those observed in the experiments. 
FIGURE 43

PHOTOGRAPHS OF PINS BEFORE AND AFTER TREAT METAL-WATER TRANSIENTS IFROM LEFT TO RIGHT UNUSEO URANIUM PIN, PARTIALLY MELTED PIN FROM CEN-5, MELTED PIN FROM CEN-6)
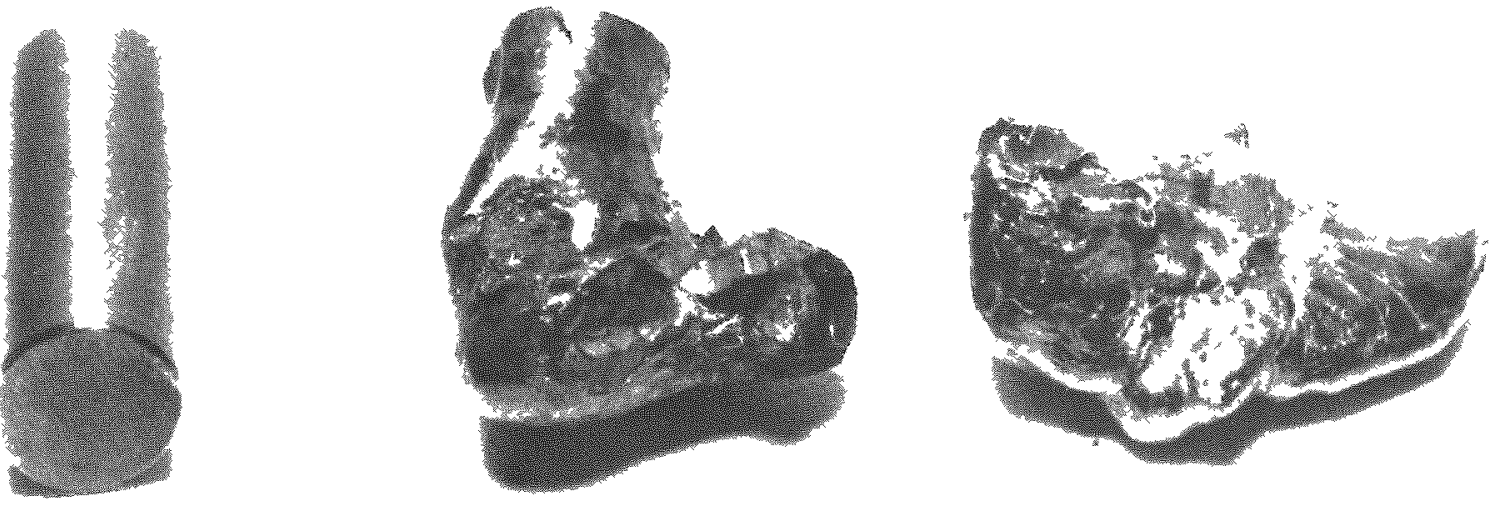

FIGURE 44

UNUSED PIN AND MELTED PIN FROM TRANSIENT CEN-8
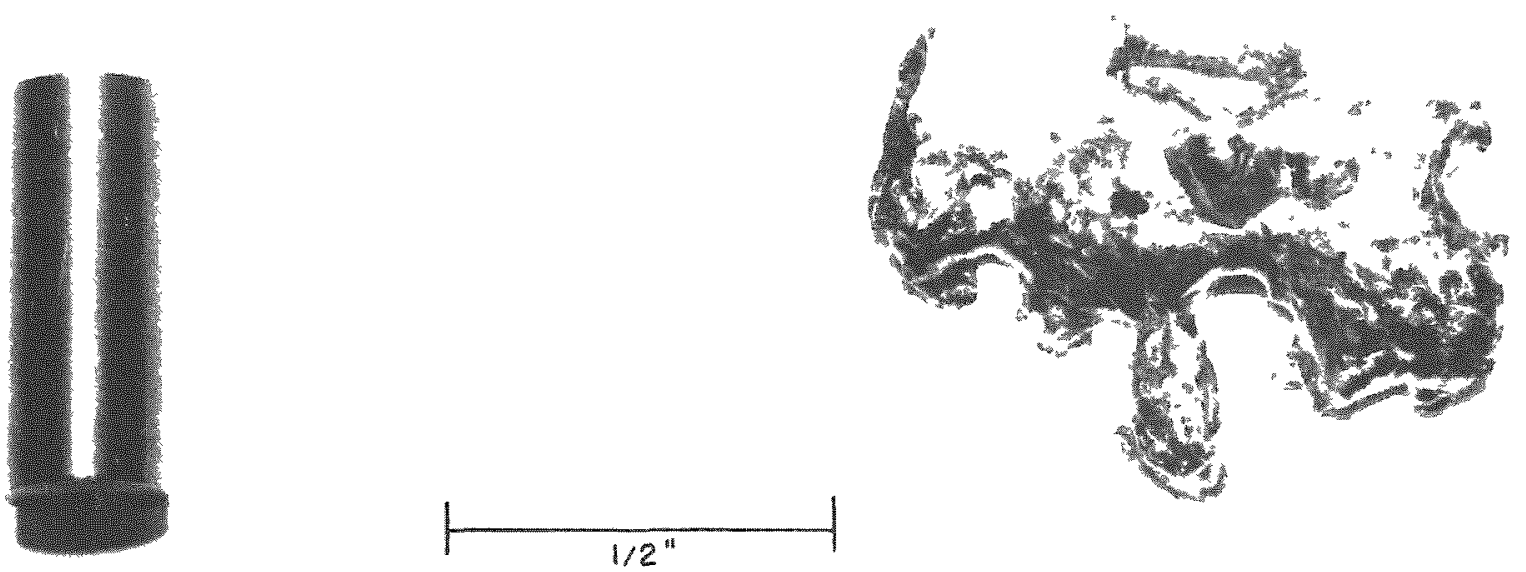


\section{REACTOR CHEMISTRY}

A. Determination of Nuclear Constants

(C. E. Crouthamel)

1. Van de Graaff Neutron Cross-Sections

(D. Stupegia and R. Heinrich)

Two Van de Graaff irradiations have been carried out on a sintered disc of uranium dioxide containing about 95 per cent $\mathrm{U}^{236}$. The irradiated disc was subsequently gamma-analyzed for the activation product $\mathrm{U}^{237}$, and several gamma-ray peaks, which could be attributed to $\mathrm{U}^{237}$ on the basis of half-1ife and energy, were found. The neutron energy was about $0.6 \mathrm{Mev}$ and the neutron capture cross section is of the order of 5 barns.

Calibration of the gamma-count of $U^{237}$ will be made on the basis of its $4 \pi$ beta count. A known amount of $U^{237}$ will be introduced into uranium dioxide discs which closely duplicate the irradiation targets. The gamma-analyzer response of the known $U^{237}$ under these conditions can then be found. Work on this calibration has begun.

B. Reactor Decontamination

(W.B. Seefeldt)

The Reactor Decontamination Program was initiated because of uncertainties over the consequences of a fuel rupture in a boiling water reactor system. It will endeavor to determine the magnitude and distribution of fission products in the vapor phase of the system and methods for removing such deposited activities.

Laboratory studies of contaminated stainless steel type 304 surfaces have confirmed that the second step of the alkaline-permanganate procedure works with nearly equal effectiveness with either ammonium citrate or citric acid. Reducing the temperature of this step reduces the decontamination factor to about 20 .

Transportation of decontamination reagents using foaming techniques is being investigated. Ethylene oxide-base and alkyl aryl sulfonate-base foaming agents have been selected for initial studies. A decontamination factor of 15 was obtained using the alkaline-permanganate procedure at room temperature in conjunction with Makon 10 (ethylene oxide-base) foaming agent: a factor of 50 was obtained with ammonium persulfatehydrofluoric acid.

Qualitative studies of foam characteristics revealed that both types of foaming agents (in 0.2 per cent solution) had no foaming ability above moderate ability at $75 \mathrm{C}$, and considerable ability at room temperature. Measured foam ratios (foam volume generated to the original volume of liquid) of 20 to 30 were obtained at the latter temperature. 
Chemical stability tests with 0.1 per cent potassium permanganate indicated incompatibility with ethylene oxide-base foaming agents, and reasonable stability with alkyl aryl sulfonate-base agents.

Several additional runs with yttrium 90 tracer activity were made at 600 psi and a steam rate of 0.36 feet per second in a loop simulating the action of a boiling water reactor. Deposition of yttrium-90 in the steam phase in all runs reached a minimum value 25 to 35 inches above the steam water interface. Disengaging factors were obtained up to a maximum of $8.1 \times 10^{3}$, depending on activity level.

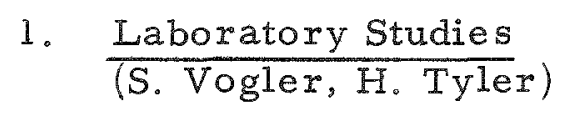

Laboratory studies are being made to evaluate decontamination methods that have potential usefulness in boiling water reactor systems. Efforts to date have been focused on the decontamination of stainless steel type 304 with liquid reagents. In one successful procedure, the contaminated metal specimen is treated with a solution of potassium permanganate in sodium hydroxide followed, after rinsing, by treatment with a solution of ammonium citrate or citric acid.

Exploratory experiments on the use of foams as vehicles for bringing the decontaminating solution in contact with the contaminated metal have been initiated.

The contaminated metal used in the experiments was produced by heating $2 \mathrm{~g}$ of irradiated natural uranium in $100 \mathrm{ml}$ of saturated deionized water at $498 \mathrm{~F}(600 \mathrm{psi})$ in a stainless steel liner placed inside an autoclave. At the completion of the experiment, the contents were removed, and the liner was rinsed with distilled water and cut into one inch squares for use in decontamination experiments. Each liner was preoxidized with 600 psi steam for one week prior to contamination.

\section{a. Liquid-phase Decontamination}

\section{(1) "Alkaline-Permanganate"}

Additional tests have confirmed indications that both ammonium citrate and citric acid are equally effective as the second rem agent in the alkaline-permanganate decontamination procedure. Lowering the temperature of the second reagent to room temperature (from $85 \mathrm{C}$ ) results in a decrease of the gamma decontamination by a factor of 2 , giving decontamination factors of approximately 20 .

Examination of the decontamination for individual fission elements reveals that zirconium-niobium activity is most readily removed, whereas cerium and ruthenium are more difficult to remove. 
(2) Continuous Decontamination Results

The small glass loop described previously (ANL-6068, page 164) has been used for two additional two-step experiments. The loop was constructed as a laboratory tool to provide a means for circulating solutions past specimens of interest at a slow but definite rate: stagnant solutions and the problems associated with them are thus avoided. The first reagent in each case was 0.5 per cent potassium permanganate in one per cent sodium hydroxide, followed by 10 per cent ammonium citrate at room temperature for the first experiment, and 10 per cent citric acid at room temperature for the second experiment. In both experiments the potassium permanganate was circulated for four hours and the second reagent for 45 minutes. The latter was replaced at 15 -minute intervals to avoid buildup of activity in the solution.

The results indicated a gamma decontamination of 24 for the ammonium citrate and 13 for the citric acid. This is in reasonable agreement with the coupon tests reported previously.

Periodic scans with a single-channel gamma spectrometer were made on the test specimens during the course of the experiments. No change in gamma activity was observed during the permanganate treatment, which confirms previously reported results (ANL-6068, page 164). The scans obtained during the second step indicated that zirconium-niobium contamination was most easily removed.

\section{b. Deposition of Activity on Metal Surfaces}

In determining the decontamination of individual fission elements as measured by coupon tests, it was necessary to assay for these with the 256-channel gamma-scintillation spectrometer before the experiment. The data were compiled to determine if there was a pattern in the adsorption of fission elements on the liner as a function of vertical height. The areas under the various peaks were determined with a planimeter and from these the number of counts and the percentage of total counts were calculated. The data are given in Table 36. The activity deposits fairly uniformly on the metal, as determined by measurements of ratios of the various activities to the total activity. In addition, there appears to be little or no preferential leaching of activity from the solid uranium dioxide. 
Table 36

DEPOSITION OF ACTIVITY ON STAINLESS STEEL TYPE 304

Activity Source: Natural uranium irradiated 3 days and cooled 3 months

Method of Deposition: $2 \mathrm{~g}$ uranium heated with $100 \mathrm{ml}$ deionized water at 600 psi for 6 days

Activity level: $\quad$ Approximately $2 \times 10^{5} \mathrm{cpm}$ per plate

Per Cent Activity under Indicated Peak Sample Number ${ }^{a}$

Peak

\begin{tabular}{|c|c|c|c|c|c|c|c|}
\hline Energy (kev) & 1 & 2 & 3 & 4 & 5 & 6 & $7^{b}$ \\
\hline 145 & 12 & 13 & 10 & 11 & 13 & 12 & 9 \\
\hline 365 & 2.4 & 2.1 & 4.6 & 1.4 & 1.4 & 0.8 & - \\
\hline 500 & 11 & 11 & 11 & 12 & 12 & 12 & 7 \\
\hline 650 & - & - & 3.5 & 3.4 & - & 3.0 & - \\
\hline 740 & 32 & 32 & 29 & 32 & 33 & 31 & 42 \\
\hline
\end{tabular}

aSamples 1 through 6 are the stainless steel samples numbered from the top of the liner to the surface of the liquid. Sample 7 is an assay of the $\mathrm{UO}_{2}$ precipitate after the test. Sample 8 is an as say of the supernatant liquid in the autoclave.

bSamples 7 and 8 were assayed one month later than samples 1 through 6.

c. The Use of Foam as a Carrier for Decontaminating

(1) Decontamination Experiments

Most of the decontamination studies to date have involved liquid-phase decontamination in which various chemical reagents have been used in an aqueous medium. It has been recognized that the use of such aqueous solutions to decontaminate boiling water reactors would produce large volumes of waste solution.

In order to minimize waste processing and heating problems, the alkaline-permanganate procedure was modified by reducing concentrations and temperature; to minimize waste volumes, several studies were made of vapor-phase decontamination. Results with the latter indicated a modest decontamination for the several reagents tried. In these tests, reagents of high volatility were sought; these included nitric and acetic acids. 
Another technique, somewhat analogous to the use of vapors condensing on the contaminated metal, is the use of foam to carry the decontaminating reagent to the metal requiring treatment. In exploratory experiments previously studied, decontamination reagents were used with the addition of a suitable foaming agent.

There are several types of foaming agents which might be considered:

a) Soaps: sodium salts of fatty acids

b) Synthetic detergents

1) sodium alkyl sulfates ( $\mathrm{NaOSO}_{2} \mathrm{O}$ alkyl)

2) sodium salts of aliphatic sulfonic acids (alkyl $\mathrm{SO}_{2}-\mathrm{ONa}$ )

3) ethylene oxide condensation products.

In the initial selection of a foaming agent, the object was to select a material which did not produce an excessively stable foam, thus permitting it to break easily at the end of the decontamination cycle and permitting easy washing or rinsing. It was suggested by a commercial supplier that a material of the ethylene oxide condensation class would be most effective, and such were selected for investigation.

Other detergents had limitations which might make them less useful. The soaps, for example, are apt to precipitate with metal cations; the sulfates and sulfonates are known as heavy foamers and. difficulty might be encountered in breaking the foam.

Experiments were carried out in a small glass decontamination loop. The foaming agent used was Makon 10, which is a condensation product of nine moles of ethylene oxide per mole of nonyl phenol. The first reagent investigated was 0.5 per cent potas sium permanganate in one per cent sodium hydroxide in conjunction with 0.2 per cent of the foaming agent. The solution was placed in the glass loop and the foam generated by passing air through a porous disc placed in the liquid. The foam rose in the tube and passed over a contaminated stainless steel coupon. The condensing foam was returned by the other leg of the loop. After the exposure to the permanganate solution for four hours at room temperature, the loop and contaminated coupon were rinsed with water. Then 10 per cent ammonium citrate with 0.2 per cent Makon 10 was foamed in the loop for four hours at room temperature to complete the decontamination procedure. Under these conditions a gamma decontamination of 15 was achieved, as measured by the single-channel scintillation spectrometer using a 4 in. $x 4$ in. thallium-activated sodium iodide crystal. A second experiment with a $3 / 4$-hour ammonium citrate foaming time gave a decontamination factor of nine.

* Supplied by courtesy of the Stepan Chemical Company. 
In several additional experiments the temperature of the solutions was varied. Visual observation indicated an increased rate of reaction of the permanganate with the foaming agent at elevated temperatures. It also became apparent that at higher temperatures foaming becomes more difficult with the Makon 10 foaming agent. Despite these difficulties, two runs, which gave gamma decontamination factors of 10 and 4, were completed. Distilled water was also foamed at $75 \mathrm{C}$ for four hours with 0.2 per cent Makon 10 to give a decontamination factor of 3 .

Other reagents were tried. One reagent was 5 per cent ammonium persulfate and 2 per cent hydrofluoric acid; another was 2 per cent potassium periodate in 5 per cent potassium hydroxide. The ammonium persulfate reagent when foamed for four hours at room temperature gave a decontamination factor of 50 with a contaminated stainless steel coupon. In a parallel test, mild steel was severely attacked. The alkaline periodate solution was rather ineffective as a decontaminating reagent at room temperature.

\section{(2) Foam Characteristics}

(a) Stability to Reagents

When 0.2 per cent Makon 10 was added to a solution of 0.5 per cent potassium permanganate in one per cent sodium hydroxide and allowed to stand at room temperature for several days, the permanganate color was completely discharged and a precipitate was observed. The same solution prepared with an alkyl aryl sulfonate did not show the same permanganate instability, al though some reaction took place, as indicated by small changes of the permanganate color. However, even after several weeks of standing, the color of potassium permanganate was very strong.

\section{(b) Foam Stability}

A 0.2 per cent solution of Makon 10 foamed very well at room temperature. As the temperature was raised to $50 \mathrm{C}$, little change was noticed in the foam characteristics. Further temperature increases caused the bubble sizes to increase and finally at 70 to $75 \mathrm{C}$ foaming stopped completely. As the temperature of the solution was lowered, foaming recommenced below $70 \mathrm{C}$. The same general behavior was observed with an aryl alkyl sulfonate foaming agent.

A useful value in determining the decrease in liquid volume required for decontamination is the foam ratio. Several of these measurements were made by passing air slowly through approximately $200 \mathrm{cc}$ of liquid contained in a $2-1$ iter graduated cylinder. This 
was continued until the foam level reached the upper marking on the cylinder. The volume of foam and liquid were determined immediately after turning off the air. Values of the foam ratio were then calculated and found to be between 20 and 30 . Upon standing, drainage of the foam occurred, thus increasing the foam ratio and producing a drier foam.

\section{Loop Operations \\ (W. Seefeldt, D. Grosvenor, C. Bally)}

A loop which simulates the action of a boiling water reactor (see ANL-5858, page 66) has been installed in a shielded cell. The unit is intended primarily to determine the deposition characteristics of mixed fission products in the steam phase as a result of introduction of such activities in the form of irradiated uranium metal in the liquid phase. This deposition is monitored on metal sample strips inserted into the dis engaging section of the equipment. A secondary objective is the procurement of deentrainment data between the liquid and vapor phases.

The initial runs in the loop are being made with yttrium -90 tracer activity. The results of the first run were reported in ANL -6068 , page 164. Three additional $r$ uns have been made, the results of two of which ( $Y 2$ and $Y 3$ ) are reported below; Run Y4 produced spurious data.

Runs $Y 2$ and $Y 3$ differed from the first run ( $Y 1)$ in two respects: 1) the metal sample strips were not thoroughly preoxidized as was the first, and 2) 5 milligrams of yttrium carrier were added as compared to 1000 milligrams in the first run. The latter change was made because of the yttrium deposition that occurred in the heated section in Run $Y 1$. Reducing the carrier content did not prevent some depletion of yttrium with time: however, the rate was considerably reduced.

Operationally, Run $Y 2$ was inferior to $Y 1$. The leakage rate of 130 grams per hour caused excessive change of liquid level. In Run Y3 the leakage rate was a more nearly acceptable 19 grams per hour. However, after 17 hours of operation the loop was shut off by a safety interlock.

Tabulated results from the first three runs are shown in Table 37: activities vs, elevation on the stainless steel 304 sample strips are shown in Figure 45. The activity deposited in the vapor phase in all three runs made to date showed a minimum value at elevations of 25 to 35 inches. The activities at higher elevations increased above the minimum values by factors of four to six; the reasons for these increases have not been determined. The concentrations of activity on the metal samples have been reasonably proportional to the amount of yttrium -90 introduced into the loop. 
Table 37

\section{OPERATING CONDITIONS AND RESULTS OF LOOP RUNS WITH} YTTRIUM-90 TRACER

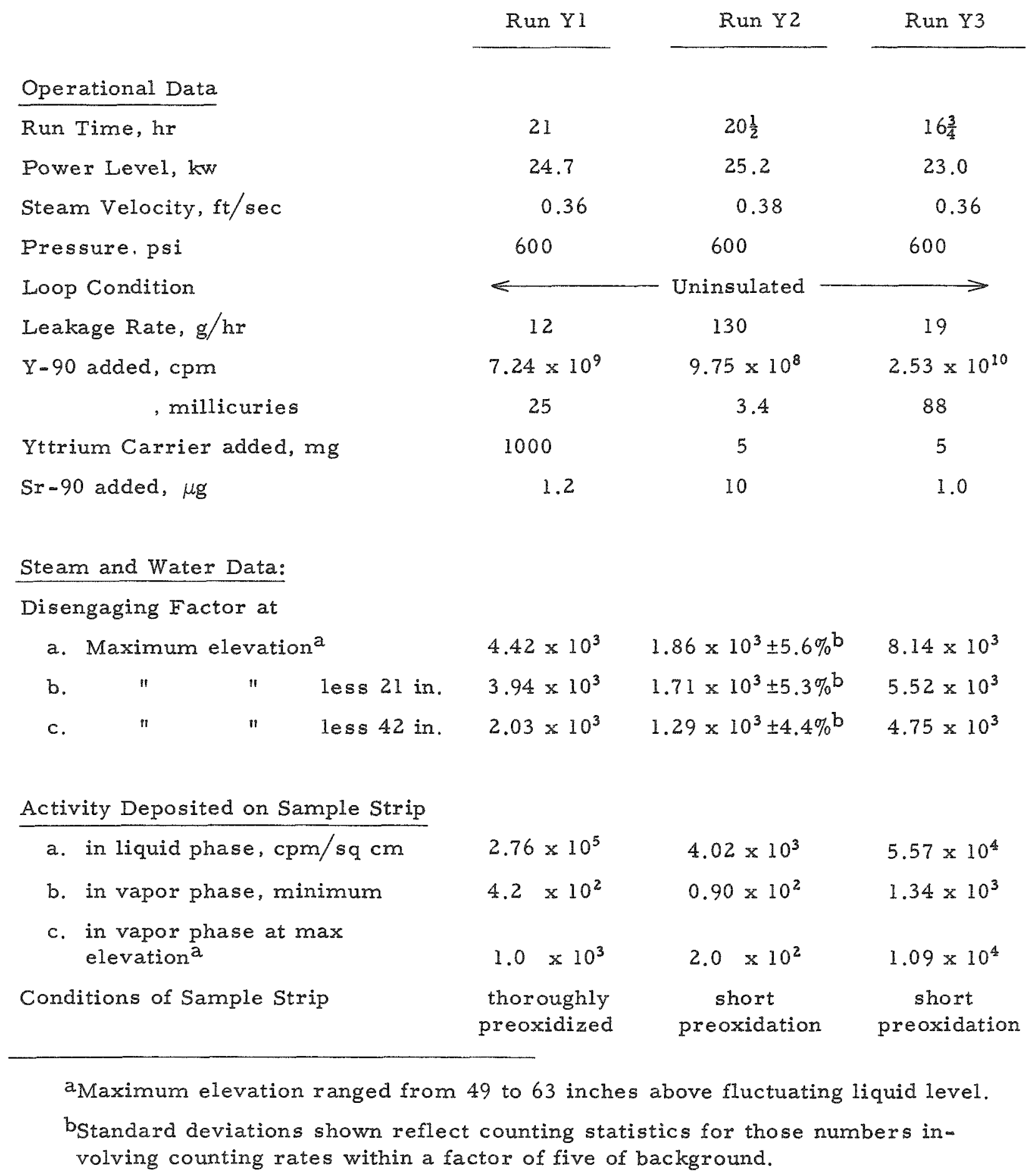


FIGURE 45

BETA ACTIVITIES DEPOSITED ON STAINLESS STEEL 304 SAMPLE STRIP AT VARIOUS ELEVATIONS

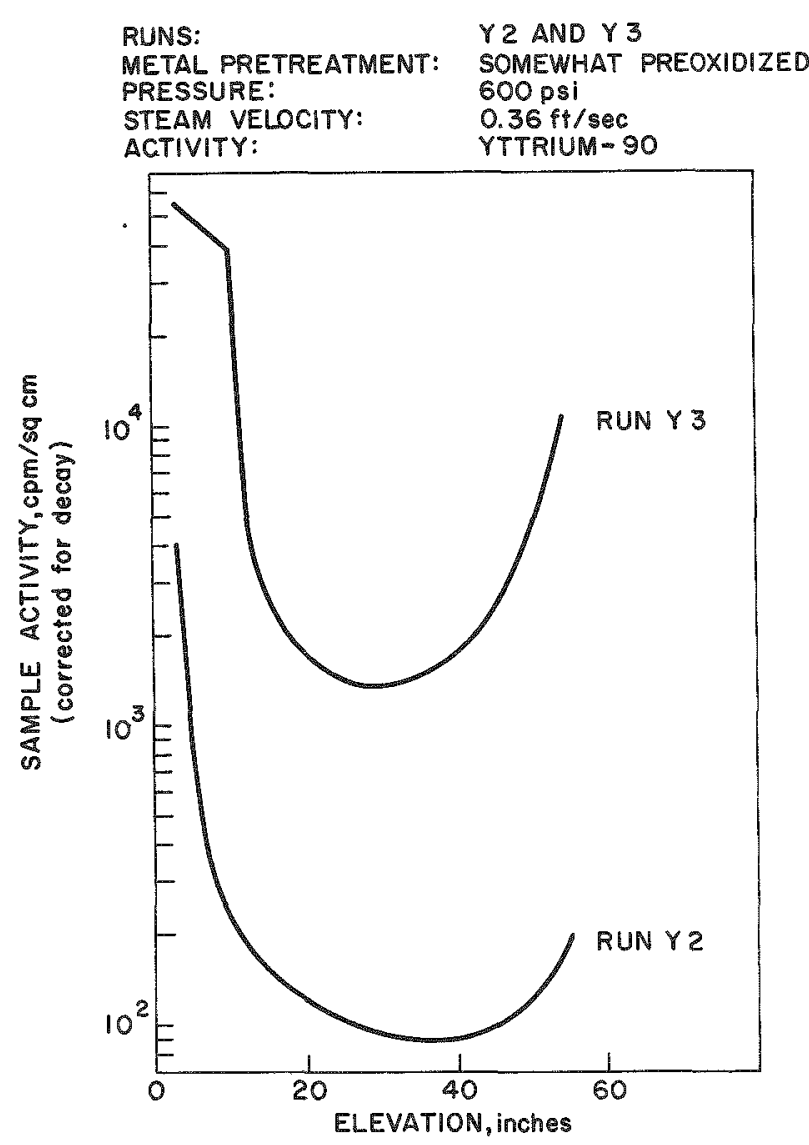

The disengaging factors* shown in Table 37 also show dependence on activity level; in theory there should be no such dependence. The values of $1.9 \times 10^{3}$ and $8.1 \times 10^{3}$ are associated with 3.4 and 88 millicuries of yttrium-90, respectively. This effect cannot be explained by poor counting statistics as the lowest counts were well above background; standard deviations are included in Table 36 where low counting rates were obtained.

C. Slurrex Chemical Supporting Program

(C. E. Crouthamel)

Work has begun on development of a Boiling Slurry Reactor (Slurrex) Concept, which consists basically of a vessel in which the boiling slurry circulates by natural convection. Steam is withdrawn directly

* "Disengaging factor" is defined as the ratio of activity in the liquid phase to that in the steam phase. This factor is often called a "decontamination factor" in the literature, but is not so called herein to avoid confusion with the "decontamination factors" reported, which are the ratios of activities on solid surfaces before and after various chemical treatments. 
from the vessel into the primary heat exchanger, making this an indirectcycle boiling reactor. This concept retains many of the advantages of both the pressurized homogeneous and the boiling heterogeneous reactors. These advantages include promise of high power density, a potentially attractive fuel cycle, excellent safety characteristics, simplicity of reactor control and operation, and significant reduction in the external system, simplifying the problem of remote maintenance.

Several chemical problems relating to development of the Slurrex reactor are being examined. They include determination of physical properties of uranium trioxide-thorium dioxide slurries and slurry ingredients, methods for determination of particle sizes and surface areas of thorium and uranium oxide powders, and the effect of in-pile radiation up to 10 per cent burnup.

A program has been initiated on the preparation of slurry from spherical colloid gel particles.

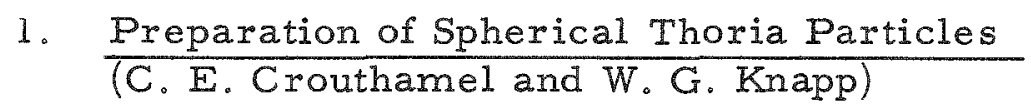

This work is concerned with the preparation of micron-sized thoria and thoria-urania particles for use as slurry reactor fuels. A thoria-urania particle is taken here to be a particle of thorium dioxide in which about 8 or 10 per cent urania is distributed more or less uniformly. The object is to prepare particles which are spherical rather than cubic or otherwise sharp-cornered, since a flowing slurry of spherical particles is known to be less erosive to its container than are those of the other shapes. Furthermore, spherical particles are expected to exhibit less tendency to break down into smaller particles, and to have better flowing characteristics (lower apparent viscosity).

Powdered thorium dioxide supplied to us by ORNL was pre pared by heating the oxalate at $650 \mathrm{C}$. To prepare a thoria-urania powder, the thorium dioxide is suspended in water and treated in a autoclave with the desired amount of uranium trioxide. This method, however, produced the cubic and platelet shapes.

Another procedure, the alcholic dehydration of a nitratestabilized thorium hydroxide sol, where the sol is jetted into liquid isopropyl alcohol, has been used at ORNL. ${ }^{13}$ This method has given small quantities of spherical particles.

${ }^{13}$ Culler, F. L., et al, Chemical Technology Division Monthly Report for September 1959, CF-59-9-108. 
A procedure has now been developed by this group, by which spherical thoria particles have been prepared by jetting the nitratestabilized thorium hydroxide sol into gaseous ammonia. The particles have been examined under a microscope and were found to be quite spherical, having diameters in the range of several microns. Densities and particle-size distributions are being determined and will be related to the firing temperature of the products, and possibly to the conditions of their preparation.

\section{Particle-size Distribution (Donald C. Stupegia)}

A neutron-activation sedimentation method 14,15 for the determination of particle-size distribution of thorium and uranium oxide powders has been set up. The powder is neutron-activated and then uniformly dispersed in a suitable liquid medium in a sedimentation tube and allowed to settle freely. At a fixed level of the tube is a collimating slit in a heavy lead wall, allowing one to count gamma rays from the activated particles as they settle past the slit. From the sedimentation law of Stokes, one can calculate the time, $t_{i}$, for a spherical particle of diametex, $d_{i}$, to settle from the surface of the liquid down to the slit level. The ratio of the gamma activity at time $t_{i}$ to the activity at time $t_{0}$, the time at which the particles were uniformly dispersed, is equal to the weight fraction of particles hav ing diameter less than $d_{i}$. If the particles are not spherical, then the dim ameter $d_{i}$ is considered to be the effective Stokesian diameter.

This apparatus has been used to determine the particle-size distribution of a powdered oxide containing 92 per cent thorium and 8 per cent natural uranium. This material is one of several batches of powdered thorium and uranium oxides supplied by ORNL. Oak Ridge had measured the particle-size distribution of these oxides by the same method, and a comparison of our data with theirs gave satisfactory agreement.

This method is now being used to determine particle sizes of various thorium and uranium oxides which are being prepared by this group, as described elsewhere in this report.

3. Evaporation and Spallation of Thorium and Uranium by Fission Fragments

(Robert R. Heinrich)

The use of an oxide slurry with particles 5 to 30 microns in diameter will involve the loss of the majority of the fission fragments from the originating particle. It is of some interest to know how many

\footnotetext{
14Abraham, B. M. Flotow, H. E. and Carlson, R。 D., Anal Chem. 29, 1059 (1957).

15 Bate, L. G. and Leddicotte, G.W., An Evaluation of the Particle-size Distribution in Multicomponent Systems, TID -7568 (Part 3), page 43.
} 
heavy element atoms (thorium and uranium) are removed (by spallation and evaporation) on the average by each fission fragment. Even though these atoms may be redeposited on the slurry particle surface the rate of this phenomenon may play an important part in the useful life of slurrytype fuel.

A method for determining the number of atoms evaporated or spallated per fission from thoria-urania particles is being developed. The following experimental approach is being used. Thoria-urania particles were intermixed with carbon and this system was irradiated until a sufficient number of fissions had occurred. Thorium and uranium atoms evaporated from the particles have been presumed to be caught by the carbon. The carbon was then separated from the thoria-urania powder by floating the carbon in a liquid denser than the carbon and less dense than the powder. The number of metal atoms entrapped by the carbon can then be determined by counting the activation products.

The feasibility of this separation method was examined by conducting a number of experiments on a 90 weight per cent carbon- 10 weight per cent thoria-urania mixture (unirradiated) using bromoform (sp.gr.2.89) as the liquid for separating the carbon from the thoriamurania. The separated carbon was then irradiated in $C P-5$ and the amount of thoria-urania carried along with the carbon was calculated from the activity due to the 306-kev gamma peak of the capture product $\mathrm{Pa}-233$. The amount of thoria carried over was approximately 1 ppm of the initial weight.

Assuming the lowest extreme, that ten metal atoms ${ }^{16}$ are evaporated or spallated per fission fragment, and assuming that $10^{17}$ fis sions occurred in the enriched sample embedded in the carbon matrix, the activity due to the activated spallated metal atoms would be higher than the observed blank activity by a factor of one thousand. However, if the amount of spallated metal atoms is assumed to be 50 per fission fragment and again $10^{17}$ fissions were achieved, the activity due to the activated spal. lated metal atoms would be higher than the blank activity by a factor of ten thousand. From this it may be concluded that the experiment is feas m ible.

\section{Small-scale Glass Slurrex Mock-up}

A scaled-down model of the Slurrex mock-up has been built and is being used to observe the behavior of slurried thoria (See Figure 46). The model, holding about 4 liters of fluid, has a 4 -in. diam core, a $9-$ in. diam steam separator, a $1 \frac{1}{2}-i n$. downcomer, and a 2 -in. riser. In this apparatus the following properties are being studied: (1) the foaming of the slurry during boiling: (2) occurrence of particles in the foam: (3) difficulty of re-suspending the slurry after long settling: and (4) the carry-over of particles from the steam separator into the condensing system above it.

$$
16 \text { Ershler, B. V., and Lapteva, F. S, J.Nucl。Enrg, 2(4), 471, (1957). }
$$




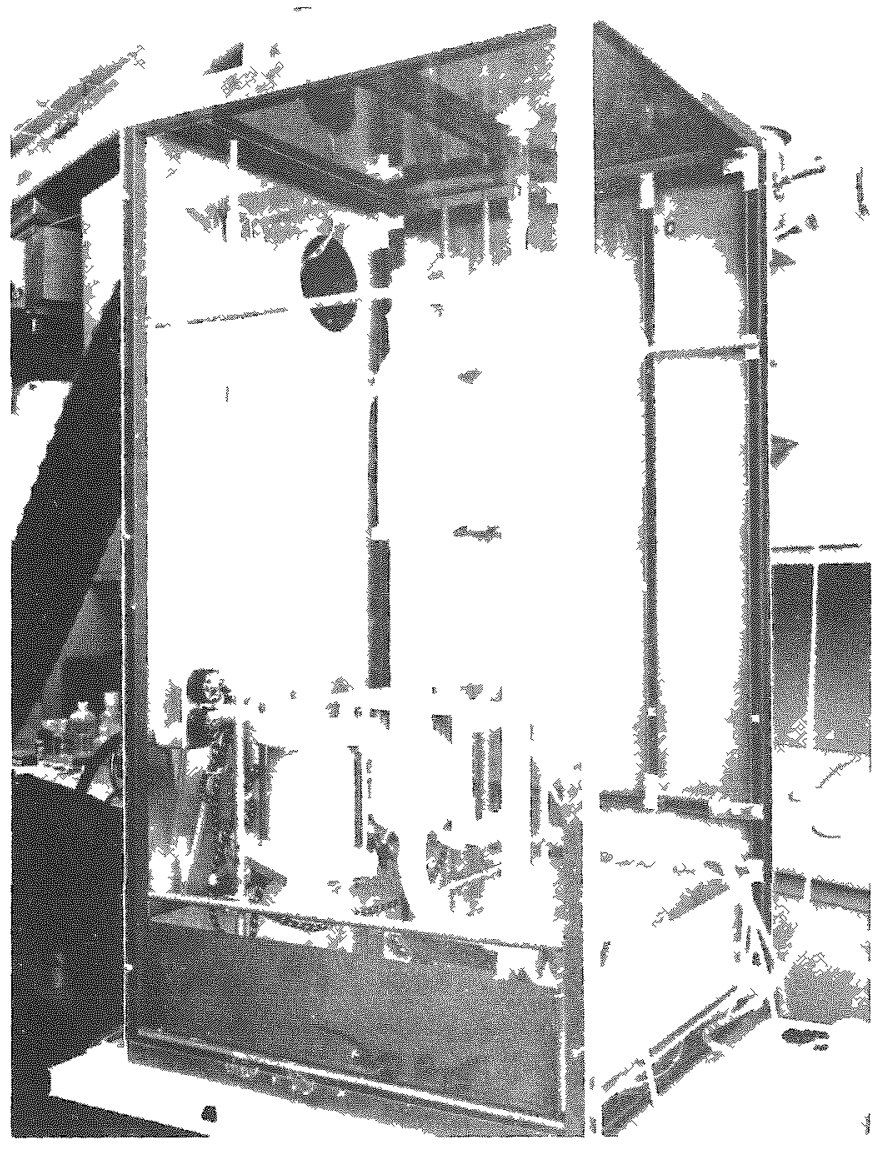

This apparatus was loaded with $1600 \mathrm{C}$-11red thorium dioxide (Oak Ridge batch DT-16) to test its operation and the methods of sampling. The slurry concentration was $500 \mathrm{~g} /$ iltex of thorium dioxide in $0.001 \mathrm{M}$ $\mathrm{Na}_{2} \mathrm{P}_{4} \mathrm{O}_{7}$. A temperature of $100 \mathrm{C}$ was reached using a heating element surrounding the core, but the boiling was not sufficient to give the desired crrculation. Superheating, which allows the slurry to crrculate only 5 seconds out of every 15, was observed. It was necessary, therefore, to introduce forced a1r through the inlet at the bottom of the apparatus in order to keep the slurry suspended and circulating properly. When the air flow and the boiling was stopped, and the slurry allowed to settle for 18 hours, it then required 6 hours to refluidize the system.

A baffle was installed between the steam separator and the condenser to prevent the splashing of particles anto the latter. Nevertheless, after a few days, visible amounts of oxlde were found in the condensex. This material, however, appeared in well-defined pattern, and was not due to splashing. In this case the partucles were carried by the air. 


\section{ANALYTICAL RESEARCH AND DEVELOPMENT}

Gamma and X-Ray Spectrometry: Proportional Counter Spectrometry (C. Gatrousis and C. E. Crouthamel)

The proportional gas spectrometer can be utilized with the same multichannel analyzing equipment as employed with the scintillation detectors. However, this detector is applied more easily in the low-energy region ( 50 to $1.0 \mathrm{kev}$ ) than is the scintillation detector, and with 3 to 4 times bettex resolution. The applications of such a detector are many and varied in the programs of this Division. Here we have attempted to make very cheap detectors from low-Z (atomic number) materials. This has eliminated the secondary wall effects in the low-energy portion of the spectra and yielded a detector of excellent resolving power.

Two high-resolution gas flow proportional counters have been constructed and tested. The counters consist essentially of a stainless steel wire, $1 \mathrm{mil}$ in diameter, which is accurately aligned along the axis of a cylinder. The cylinders consist of graphite-impregnated resin-bonded tubes whose inner surfaces have been coated with an alcoholic suspension of colloidal graphite. This type of construction features a uniform low $-Z$ cylinder wall capable of transmitting extremely low-energy photons along the entire length of the counter. In the use of brass or aluminum-walled counters, the spectra are highly distorted due to excitation of the characteristic $X$ rays of the wall materials and their various impurities. These adverse effects are eliminated completely by utilizing the above-mentioned materials. Figures 47 and 48 show typical examples of undistorted lowenergy $\mathrm{X}$-ray spectra observed with the new type of counters.

Of somewhat greater importance to proportional counter spectrometry is the ability to separate the $K$ emission lines of neighboring elements. In order to analyze adjacent elements $(Z$ and $Z+1)$ a counter of extremely high resolving powder is required. The two instruments which have been constructed are presently capable of resolving elements separated by two atomic number very effectively. The pulse-height distribution shown in Figure 49 has been obtained for vanadium $(Z=23)$ and manganese $(Z=25)$ $X$ rays counted simultaneously. Based on the resolution that has been achieved with the present counters, only a slight further improvement is required in order to separate the spectra of adjacent elements effectively. The highest resolution that has been reported for low-energy X-ray counters is that attained by Bisi and Zappa. 17 Figure 50 shows the favorable agreement of our resolution data with the highest that has been achieved.

A paper summarizing the results of this investigation is being prepared and will be submitted for publication.

17 Bisi, A. and Zappa, L., Nuovo Cimento, 2, 988 (1955). 
FIGURE 47

LOW-ENERGY CHARACTERISTIC X-RAYS OF

THORIUM IN THE DECAY OF URANIUM-233

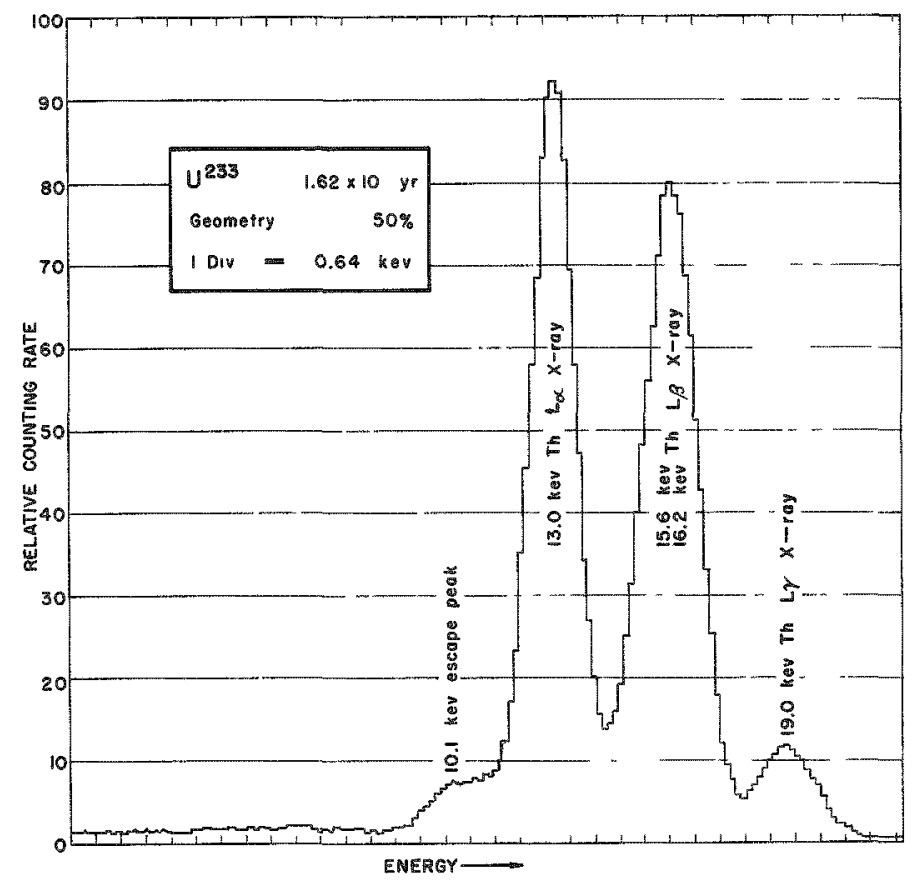

FIGURE 48

LOW-ENERGY CHARACTERISTIC X-RAYS OF SILVER IN THE DECAY OF CADMIUM-109

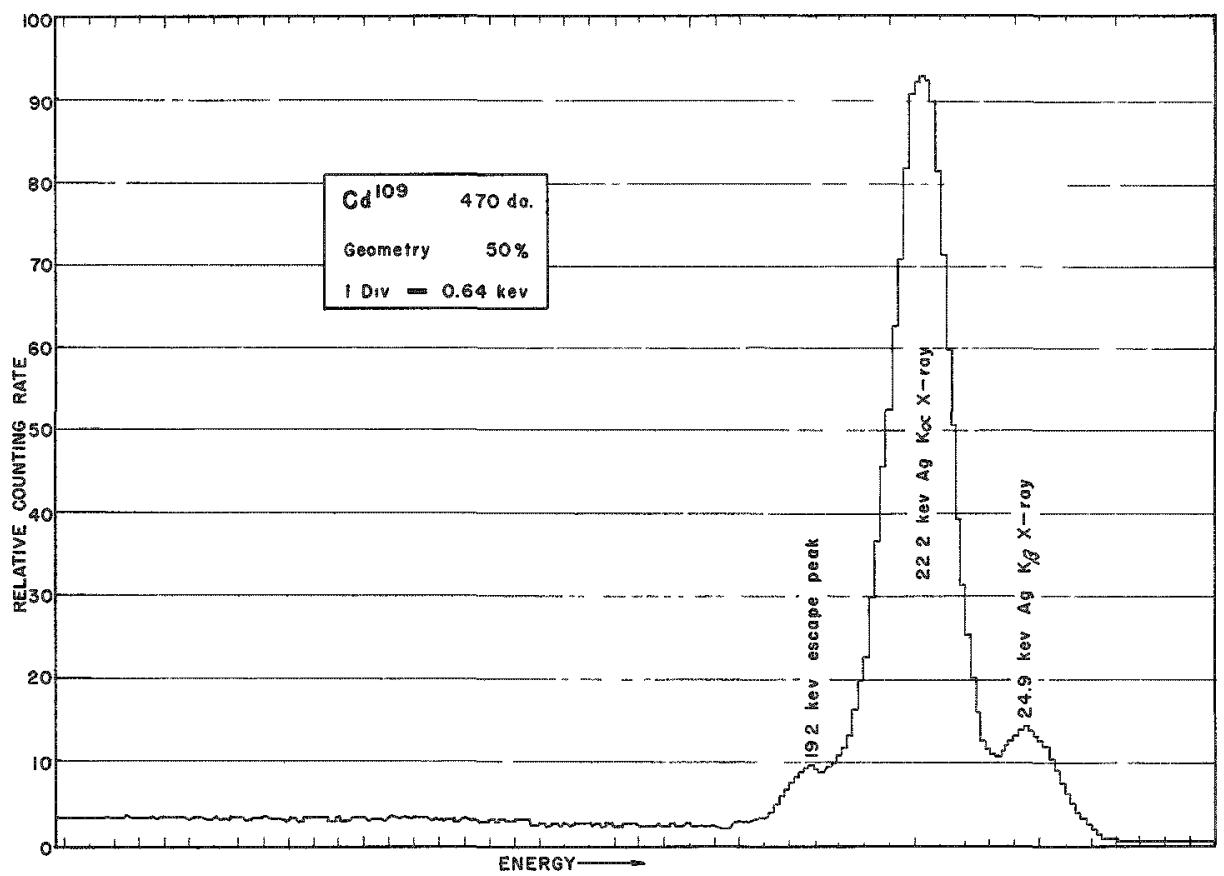


VI. ROUTINE OPERATIONS

(H. G. Swope)

A. Waste Processing

1. Operations

(H.G.Swope, J. Harast, G. Teats, R. Juvinall, C.Ryberg)

The total volume of liquid wastes processed from October through December, 1959, was 39,865 gallons. Of this amount, 28,430 gallons were evaporated, 9,680 gallons were filtered, 1,450 gallons were flocculated, 85 gallons were absorbed into vermiculite, and 220 gallons were neutralized.

A summary of the amount of wastes processed by the various methods in 1959 is shown in Table 38.

B. High-level Gamma-irradiation Facility

(H. G. Swope, J. Harast, B. Kullen, N. Ondracek, R. Jarrett and M. Bowden)

The year 1959 was the fourth full year of operation of the Argonne High-level Gamma-irradiation Facility. Table 39 summarizes 1959 work in Rack $\mathrm{M}-1$.

A total of 8,109 samples were irradiated in 1959 as compared to 8,525 in 1958; day units were 13,787 and 13,420 and total night units were 29,351 and 23,529 in 1959 and 1958, respectively. In addition 3,083 special dosimetry samples were run during the year.

In addition to the work done in Rack $\mathrm{M}-1$ a second Rack, $\mathrm{M}-2$ was occasionally used. In this rack samples as large as 20 in. in diameter and 29 in. high may be accommodated. 
FIGURE 49

RESOLUTION OF K-CHARACTERISTIC X-RAYS OF LOW $z, z+1$ ELEMENTS WITH THE PROPORTIONAL GAS SPECTROMETER

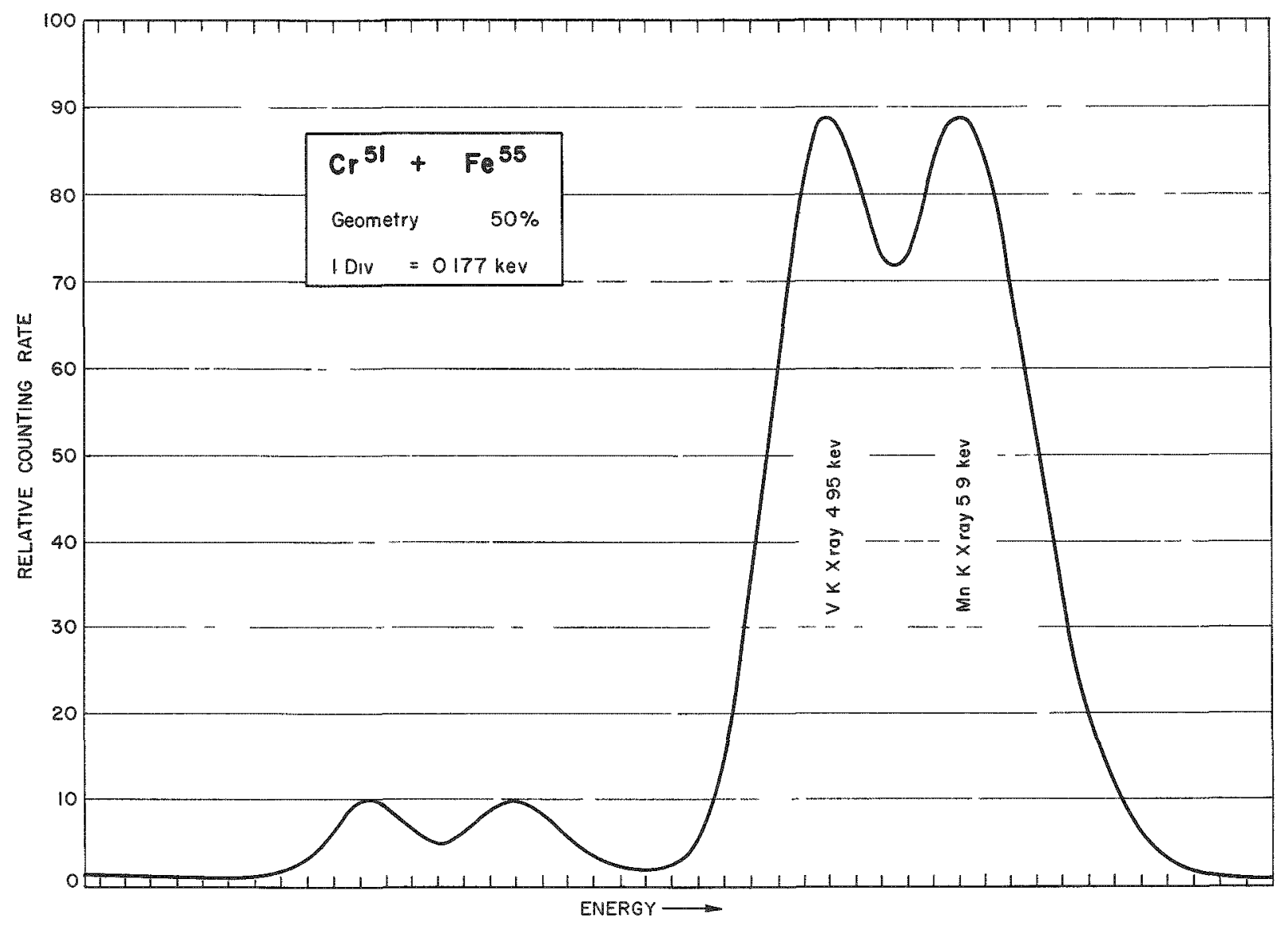

FIGURE 50

RESOLUTION OF X-RAY PROPORTIONAL COUNTER

AS A FUNCTION OF ENERGY

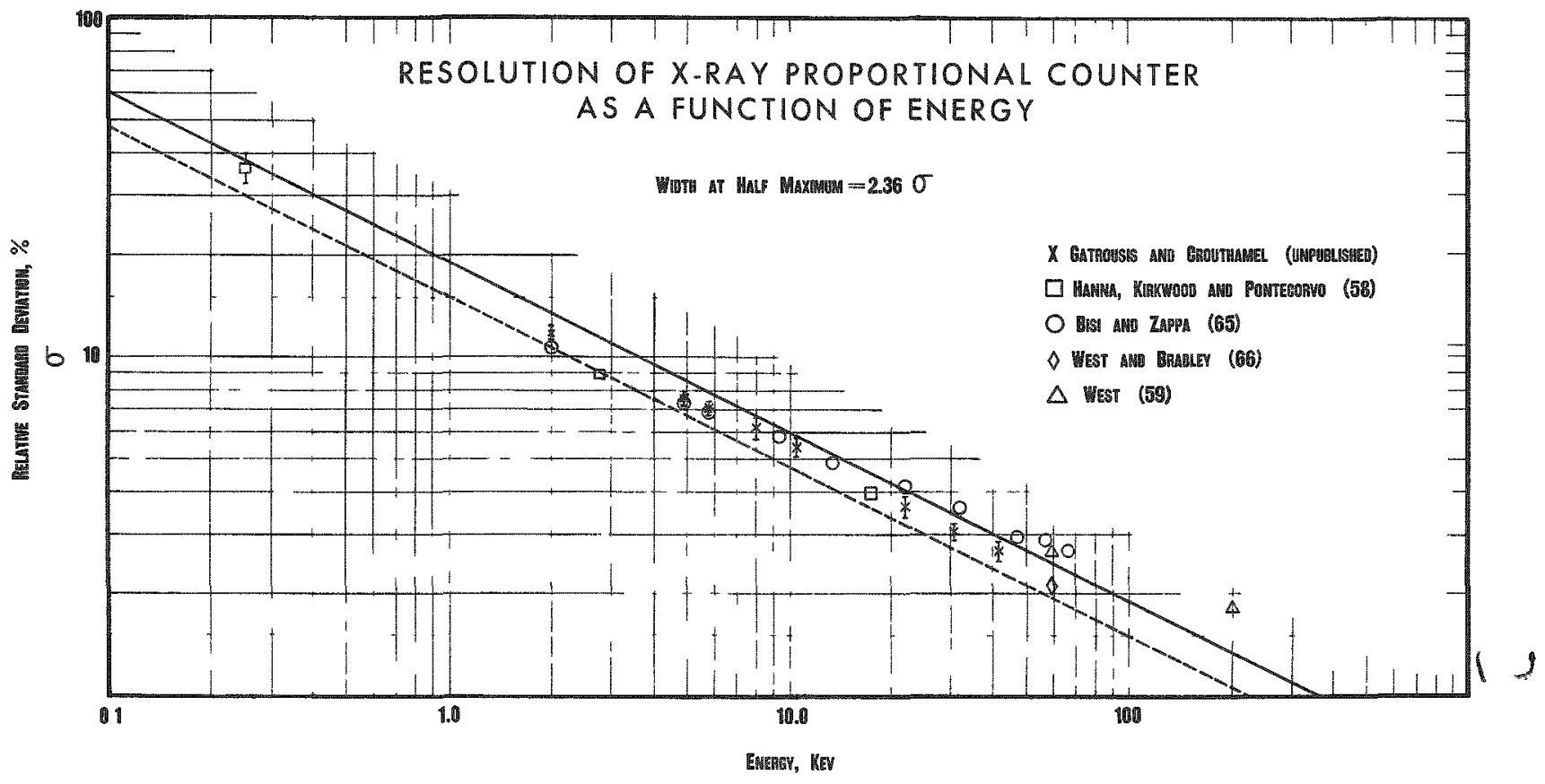


Table 38

SUMMARY OF IIQUID RADIOACTIVE WASTES PROCESSED DURING THE YEAR 1959

Gallons of Wastes Treated as Shown

\begin{tabular}{|c|c|c|c|c|c|c|c|c|c|c|c|c|c|c|c|c|c|c|c|c|}
\hline \multirow{3}{*}{$\begin{array}{c}1959 \\
\text { Quarterlv } \\
\text { Period }\end{array}$} & \multirow{3}{*}{$\begin{array}{l}\text { Reten- } \\
\text { tron } \\
\text { Tanks }\end{array}$} & \multicolumn{7}{|c|}{ Seruthers-Wells Evaporator } & \multirow{3}{*}{$\begin{array}{l}\text { Adams } \\
\text { Filter } \\
\text { Cake }\end{array}$} & \multicolumn{3}{|c|}{$\begin{array}{l}\text { 30-Gallon } \\
\text { Concentrator }\end{array}$} & \multirow{2}{*}{\multicolumn{2}{|c|}{$\begin{array}{l}\text { Ion-Exchange } \\
\text { Catson(ICR-IIt) }\end{array}$}} & \multirow{3}{*}{$\begin{array}{l}\text { Fil- } \\
\text { tra- } \\
\text { tron }\end{array}$} & \multirow{3}{*}{$\begin{array}{l}\text { Floce- } \\
\text { cula- } \\
\text { tion }\end{array}$} & \multirow{3}{*}{$\begin{array}{l}\text { Absorp } \\
\text { tion } \\
\text { Into } \\
\text { Vermi- } \\
\text { culite }\end{array}$} & \multirow{3}{*}{$\begin{array}{c}\text { HF } \\
\text { Wastes } \\
\text { Neu- } \\
\text { tral- } \\
\text { zzed }\end{array}$} & \multirow[b]{3}{*}{ Decay } & \multirow[b]{3}{*}{ Totals } \\
\hline & & \multirow{2}{*}{$\begin{array}{r}\text { Decon } \\
\text { Soln }\end{array}$} & \multirow{2}{*}{$\begin{array}{l}\text { Masc. } \\
\text { Aque- } \\
\text { ous }\end{array}$} & \multirow{2}{*}{$\begin{array}{l}\text { GIF } \\
\text { Hatera }\end{array}$} & \multirow{2}{*}{$\begin{array}{l}\text { Cim- } \\
\text { Cool }\end{array}$} & \multirow[b]{2}{*}{ Floc } & \multirow{2}{*}{$\begin{array}{l}\text { D-34 } \\
\text { Sludge }\end{array}$} & \multirow{2}{*}{$\begin{array}{r}\text { Regen } \\
\text { Soln }\end{array}$} & & \multirow{2}{*}{$\begin{array}{l}\text { Evap } \\
\text { Bottoms }\end{array}$} & \multicolumn{2}{|c|}{ Misc } & & & & & & & & \\
\hline & & & & & & & & & & & $\mathrm{Aq}$ & Org & $\mathrm{RT}$ & EBWR & & & & & & \\
\hline Jan, -Mar. & 1,580 & 17,400 & 2,965 & 360 & 385 & 760 & - & 280 & 50 & 1,280 & - & - & 4,200 & 8,670 & 14,800 & 960 & 10 & 165 & 4,220 & 58,085 \\
\hline Apr. -June & 2,170 & 10,630 & 1,280 & $\mathrm{I}, 080$ & 3,400 & - & - & 2,000 & - & 853 & 46 & 78 & - & 2,680 & 2,680 & - & 450 & 200 & - & 27,550 \\
\hline July-Sept. & 2,020 & 7,600 & 1,340 & 311 & 780 & - & 1,600 & - & 275 & 960 & 18 & - & 1,360 & - & 1,360 & - & 410 & 100 & - & 18,140 \\
\hline Oct.-Dec. & 2,666 & 13,400 & 3,860 & 750 & 1,720 & 260 & 680 & 2,330 & 1,370 & 1,400 & - & - & - & - & 9,680 & 1,450 & 85 & 220 & - & 39,865 \\
\hline Totals & 8,430 & 49,030 & $9,4.45$ & 2,500 & 6,285 & 1,020 & 2,280 & 4,610 & 1,695 & 4,500 & 64 & 78 & 5,560 & 11,350 & 28,520 & 2,410 & 955 & 685 & 4,220 & 143,640 \\
\hline$\%$ & 5.87 & 34.13 & 6.58 & 1.74 & 4.38 & 0.71 & 1.59 & 3.21 & 1.18 & 3.13 & 0.04 & 0.05 & $3.6 \%$ & 7.90 & 19.86 & 1.68 & 0.66 & 0.48 & 2.94 & 100.00 \\
\hline
\end{tabular}

ancludes water from the fuel rod carrier.

Abbreviations

GIF - High-Level Gamma Irradiation Facılaty

Retention Tanks

IIF - Hydrofluoric ac1d

EBWR - Experumental Borling Water Reactor 
Table 39

SUMMARY OF IRRADIATIONS PERFORMED IN RACK M-1 OF THE ARGONNE HIGH-LEVEL GAMMA-IRRADIATION FACILITY DURING 1959

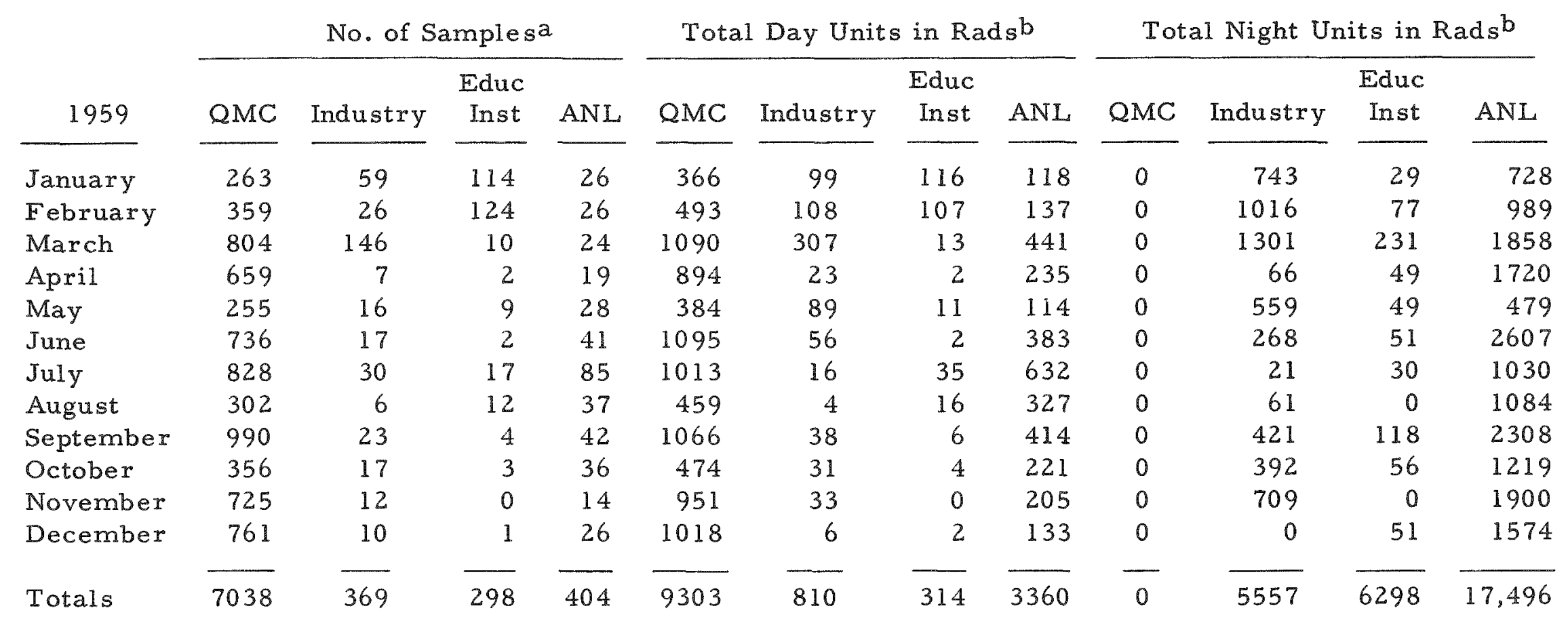

a Equivalent to a No. 2 sized can ( $3 \frac{7}{16}$ in. diameter $x 4 \frac{9}{16}$ in. high)

bone urn unit $=2 \times 10^{6} \mathrm{r}$. 